\title{
Introducción a la toxicología
}
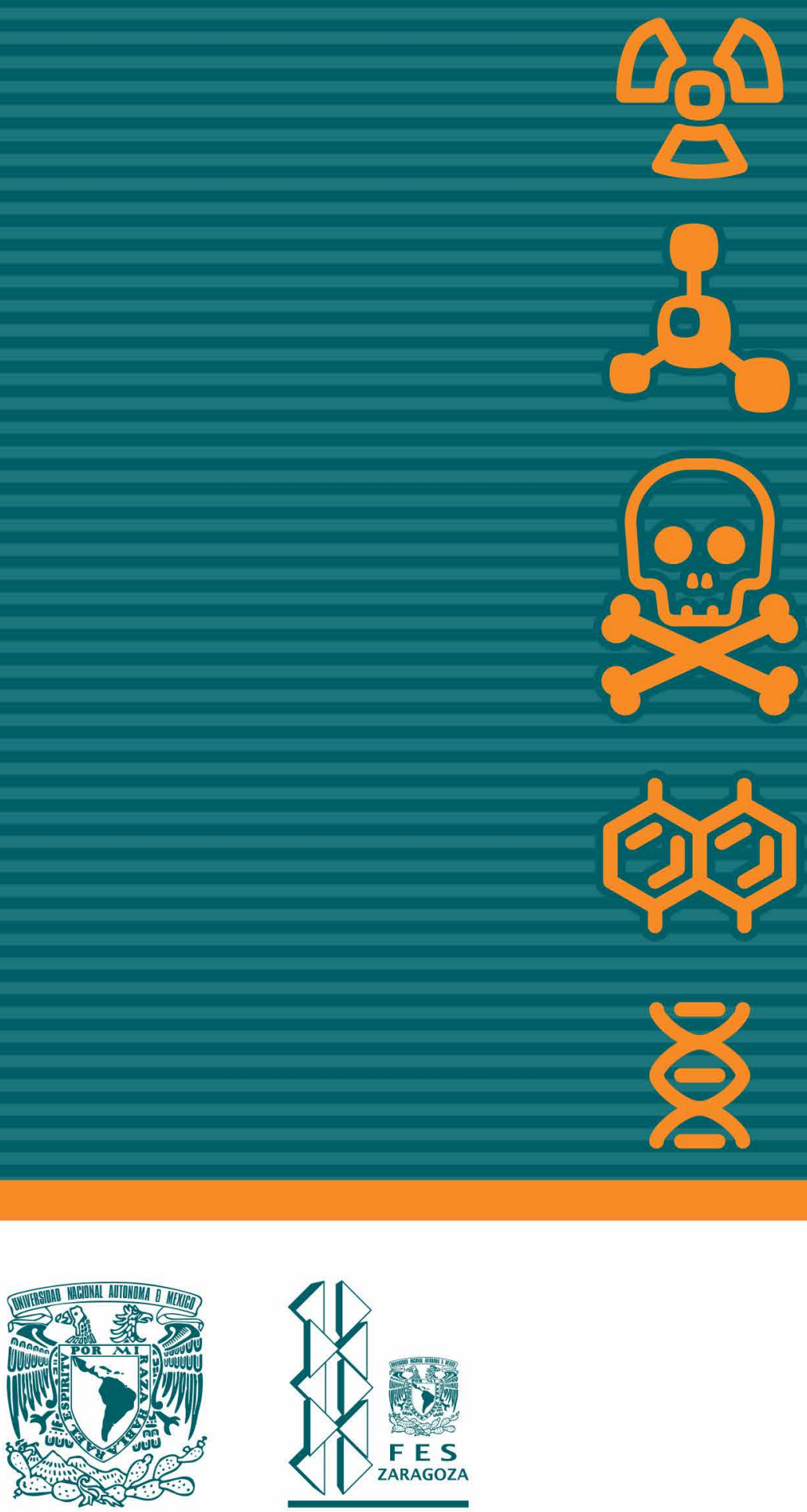

Elia Roldán Reyes 


\section{Introducción a la toxicología}

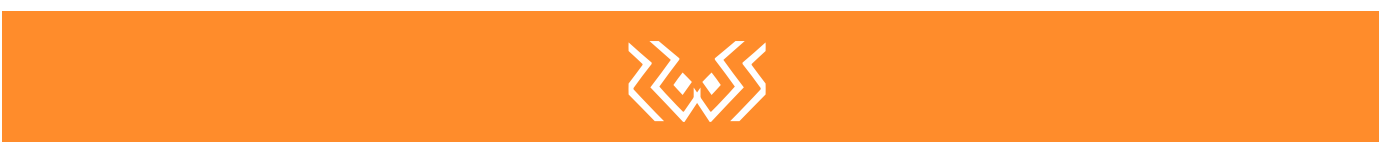

Elia Roldán Reyes

Agradezco el apoyo brindado para la edición de este libro al equipo del Depto. de Publicaciones: Lic. Carlos Raziel Leaños, Claudia Ahumada Ballesteros y Gabriel Ivan Romero Nuñez

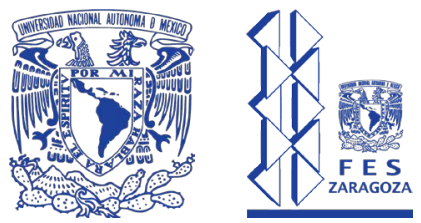




\section{Universidad Nacional Autónoma de México \\ Facultad de Estudios Superiores Zaragoza}

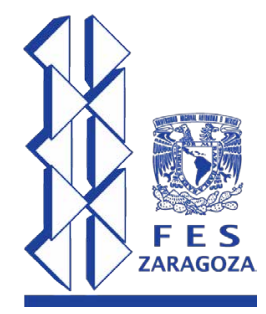

\section{Datos para catalogación bibliográfica}

Autora: Elia Roldán Reyes

Introducción a la toxicología

UNAM, FES Zaragoza, agosto de 2016

Peso: 8,009 kB

ISBN: 978-607-02-8172-3

Diseño de portada: Carlos Raziel Leaños

Diseño y formación de interiores: Claudia Ahumada Ballesteros

\section{DERECHOS RESERVADOS}

Queda prohibida la reproducción o transmisión total o parcial del texto o las ilustraciones de la presente obra bajo cualesquiera formas, electrónicas o mecánicas, incluyendo fotocopiado, almacenamiento en algún sistema de recuperación de información, dispositivo de memoria digital o grabado sin el consentimiento previo y por escrito del editor.

\section{Introducción a la toxicología}

\section{D.R. (C) Universidad Nacional Autónoma de México} Av. Universidad \# 3000, Col. Universidad Nacional Autónoma de México, C.U., Delegación Coyoacán, C.P. 04510, México, D.F.

Facultad de Estudios Superiores Zaragoza Av. Guelatao \# 66, Col. Ejército de Oriente, Delegación Iztapalapa, C.P. 09230, México, D.F. 
A Marycarmen Cruz Hurtado y Mayra Pamela Tello Mora, Biólogas. Por sus aportaciones, participación y entusiasmo durante el desarrollo del manuscrito.

A los Biólogos Patricia Uribe León y Gael Güitrón Castillo por su colaboración en la preparación de las imágenes.

A todos los alumnos de la Carrera de Biólogo de la FES-Zaragoza, que llevaron la materia optativa de Toxicología Genética, por los comentarios y críticas, que inspiraron la elaboración del presente material.

A los Programas UNAM: PAPIIT IN-213013-3 y PASPA-2011. 



\section{Contenido}

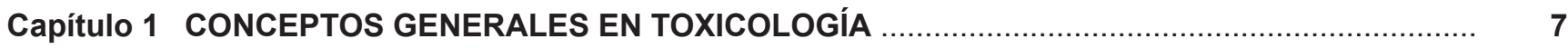

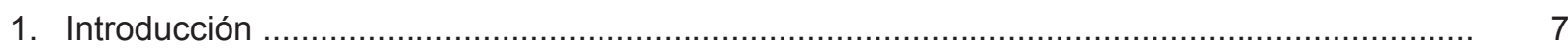

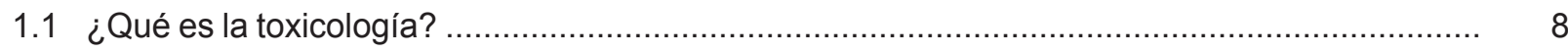

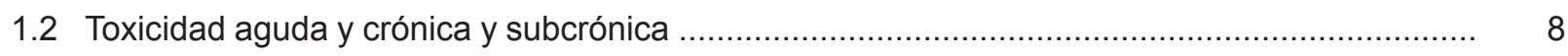

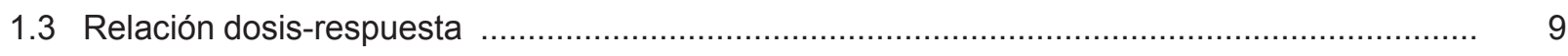

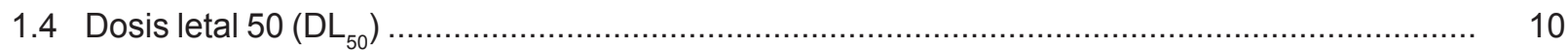

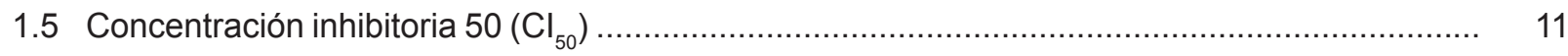

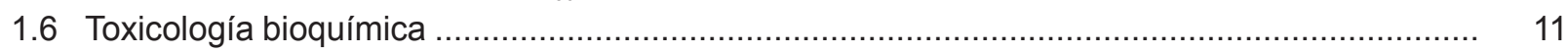

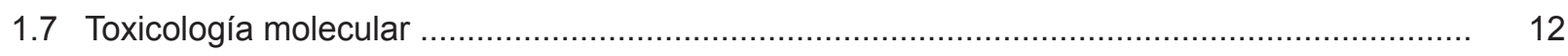

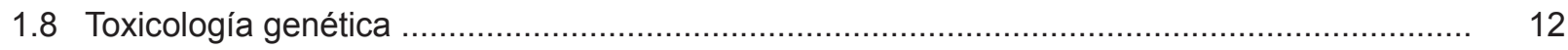

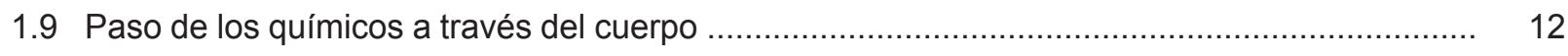

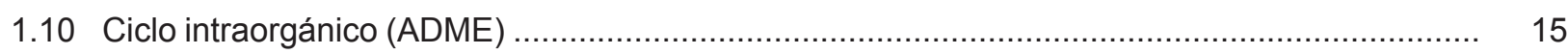

Capítulo 2 PAPEL DEL METABOLISMO FASE I EN TOXICOLOGÍA …......................................... 23

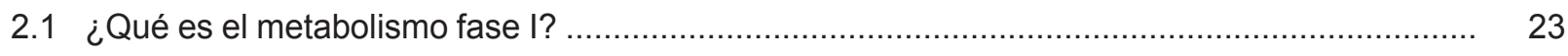

2.2 Citocromo p450 como mediador de la fase I del metabolismo .............................................. 24

2.3 Fase I del metabolismo mediada por Monooxigenasas de Flavín ........................................... 32

2.4 Toxicidad mediada por otras enzimas Fase I ........................................................... 40

Capítulo 3 EL PAPEL DEL METABOLISMO FASE II EN TOXICOLOGÍA .......................................... 49

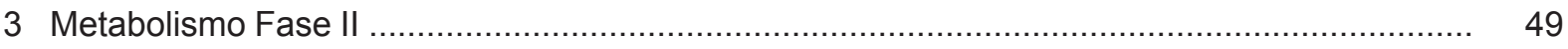

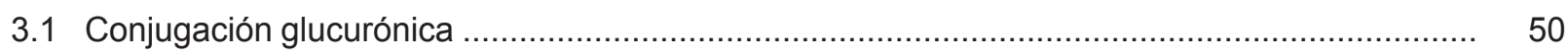

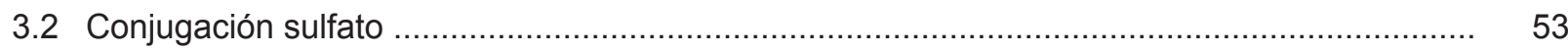

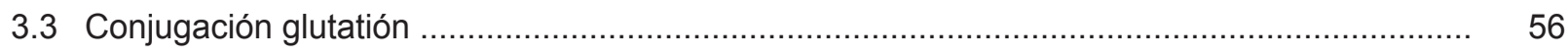

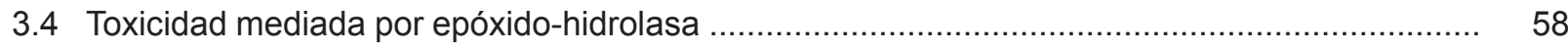

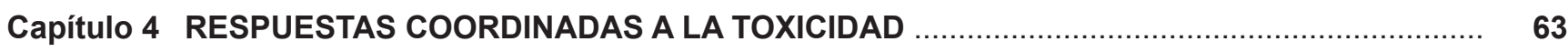

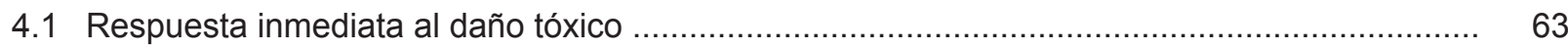

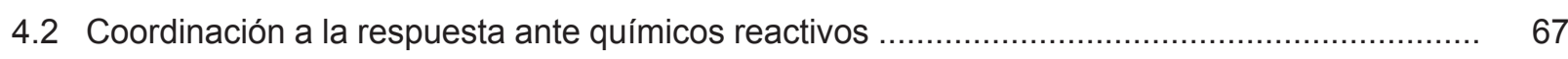




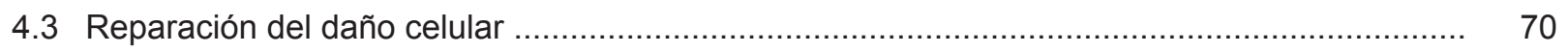

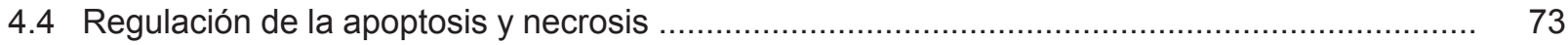

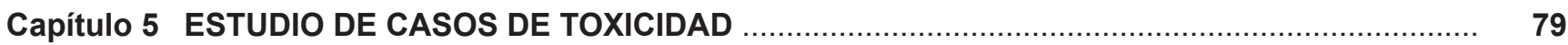

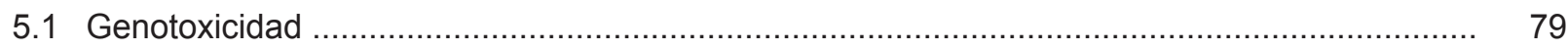

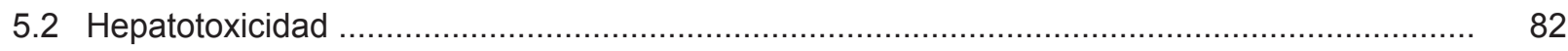

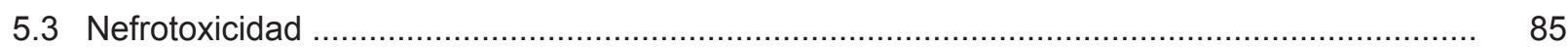

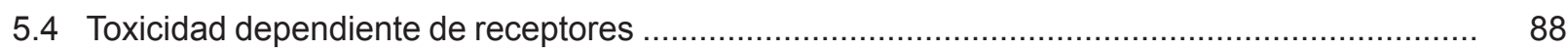

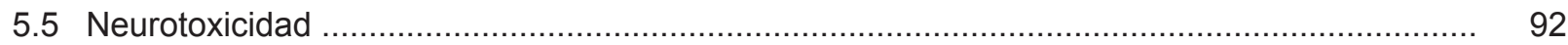

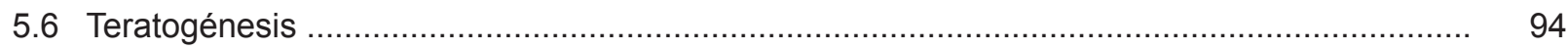

Capítulo 6 TECNOLOGÍAS PARA LA EVALUACIÓN DE LA TOXICIDAD ....................................... 101

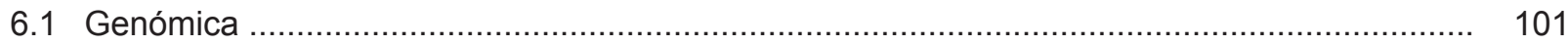

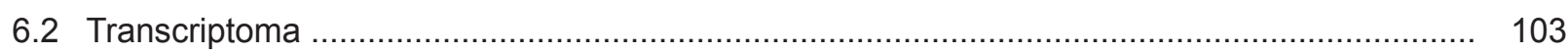

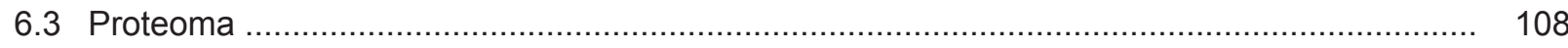

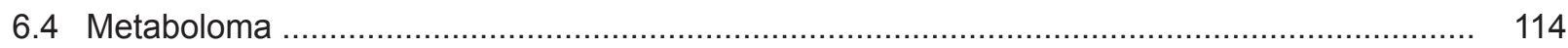

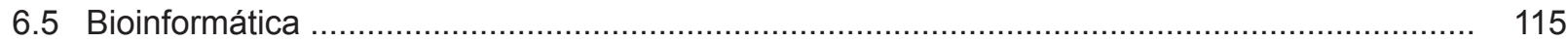

Capítulo 7 PAPEL DE LA GENÉTICA EN LA RESPUESTA TÓXICA …......................................... 121

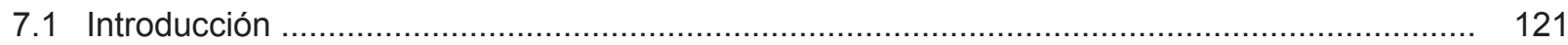

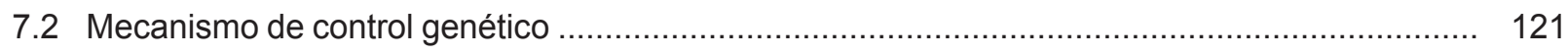

7.3 Herramientas para el estudio de la respuesta genética a la exposición química ...................... 130

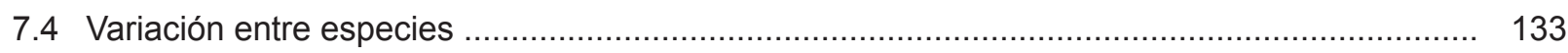

7.5 Variación dentro de una especie ........................................................................... 137 


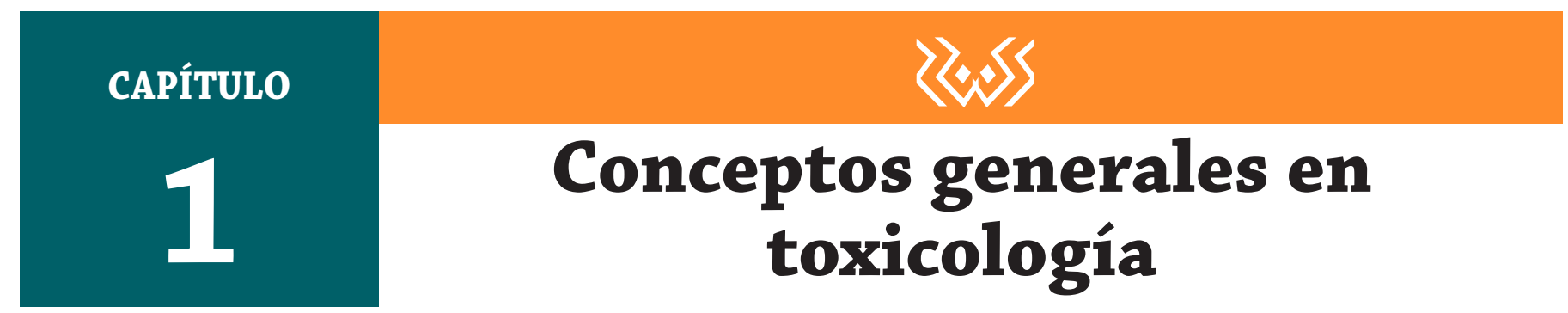

\section{INTRODUCCIÓN}

Antes de empezar a examinar como el cuerpo responde a las exposiciones tóxicas debemos primero preguntarnos ¿Qué es una exposición tóxica? Y ¿Que es la toxicología? La toxicología se define como "La ciencia que se encarga del estudio de los venenos (tóxicos) y sus efectos". Un veneno es "cualquier substancia tóxica que causa efectos nocivos y/o letales en dosis muy pequeñas, ya sea por accidente o de forma planeada cuando se administra a un organismo vivo" (Hodgson y Smart, 2008; Penningroth, 2010). A partir de esto se define a la Toxicología como el estudio de los agentes químicos que dañan al organismo. Dicha definición sugiere que la toxicología es una ciencia aplicada, por tanto su estudio tiene un impacto directo sobre la sociedad. De tal forma que el papel del toxicólogo es importante en la vida diaria.

Debido a la participación del toxicólogo en diferentes áreas de trabajo, que va desde la protección del medio ambiente hasta la producción de medicamentos seguros con efectos secundarios mínimos, esto muestra un amplio campo de acción en general. Entonces se puede desempeñar como toxicólogo: Industrial (Desarrollo de medicamentos "seguros", agroquímicos, etc.), Universitario (educación e investigación de la toxicidad), Clínico (especialista en los efectos tóxicos de los agentes químicos sobre el hombre), Forense (investigación del papel de los químicos tóxicos en casos legales), Ecotoxicólogo (efectos tóxicos de los compuestos químicos en los ecosistemas), Legislador o Regulador (asesoría y regulación de los químicos que son tóxicos), y al Ocupacional (Efectos potenciales de los agentes químicos tóxicos en el "uso diario") (Hodgson et al., 1998).

La Toxicología esta directamente relacionada con la medicina y la agricultura, las cuales son dos disciplinas de la biología aplicada. En medicina, el diagnostico clínico y el tratamiento del envenenamiento, así como los efectos tóxicos aumentados de los fármacos, son de gran importancia. En agricultura es primordial, el desarrollo de biócidas selectivos tales como insecticidas, herbicidas y fungicidas, y sus efectos secundarios son de gran significancia en la salud pública. La Toxicología es considerada un área fundamental de las ciencias, porque la adaptación del organismo al ambiente tóxico tiene implicaciones muy importantes para la ecología y la evolución.

Las herramientas de la química, la bioquímica, y la biología molecular son fundamentales para la toxicología, tanto que el progreso de la toxicología esta directamente relacionado con el desarrollo de los nuevos métodos en estas ciencias. 
De tal forma que la química provee métodos analíticos para el estudio de los tóxicos y sus metabolitos, en particular para la toxicología forense, el análisis de residuos, y el metabolismo de tóxicos; así la bioquímica proporciona los métodos para la investigación del metabolismo y el mecanismo de acción de los tóxicos; así mismo la biología molecular contribuye con los métodos para la investigación del papel que juega los genes y la expresión génica en la toxicidad (Hodgson y Smart, 2008).

\section{1 ¿QUÉ ES LA TOXICOLOGÍA?}

La toxicología puede ser definida como la rama de la ciencia que se ocupa de los venenos. Una vez dicho esto, los intentos para definir los diversos parámetros conducen a algunas dificultades. Un tóxico es toda radiación física o agente químico que, tras generarse internamente o entrar en contacto, penetrar o ser absorbido por un organismo vivo, en dosis suficientemente alta, puede producir un efecto adverso directo o indirecto en el mismo (Guitart, 2008).

Evidentemente, la medida de este efecto es dosis-dependiente para algunas sustancia, en una dosis lo suficientemente baja, no tienen efecto, mientras que muchos sino es que en la mayoría, la sustancias tienen efectos deletéreos en algunas dosis más altas. Mucho de la toxicología trata de compuestos exógenos al metabolismo normal de los organismos, estos compuestos se denominan xenobióticos. Sin embargo, muchos compuestos endógenos incluyendo intermediarios metabólicos como el glutamato, u hormonas como la tiroxina, son tóxicos cuando son administrados en dosis más altas a las naturales. Similarmente, los micronutrientes como el selenio, es esencial en una dieta en bajas concentraciones, pero es frecuentemente tóxico en niveles elevados. Estos efectos están debidamente incluidos en toxicología, mientras que la generación endógena de altos niveles de sustancias metabólicas intermedias debidas a enfermedades o defectos metabólicos no lo están, y los efectos sobre el organismo pueden ser similares (Smarth y Hodgson, 2008).

\section{Dosis}

La palabra "dosis" es la más comúnmente usada para referir la cantidad de un químico aplicado o introducido en un sistema biológico en periodo o unidad de tiempo, puede mencionarse de diversas formas, la más común es el peso del agente químico por unidad de peso del animal experimental dado en una sola ocasión $(\mathrm{g} / \mathrm{kg})$ o repetida diariamente $(\mathrm{g} / \mathrm{kg} / \mathrm{día})$. Un total de dosis diaria puede ser dividida en varias dosis administradas en intervalos específicos (g/Kg/6 hr). También puede expresarse como el peso por unidad de área de superficie corporal, ejem., gramos por metro cuadrado del área de superficie corporal por día (Loomis y Wallace, 1996).

\subsection{TOXICIDAD AGUDA Y CRÓNICA Y SUBCRÓNICA}

La evaluación de los efectos tóxicos, es otro parámetro de complejidad considerable. La toxicidad aguda se investiga frecuentemente en ratas. Donde el efecto tóxico cuantificable o parámetro, es la muerte. Típicamente una prueba de toxicidad aguda consiste en la exposición en una sola ocasión a grupos de 10 a 20 animales cada uno, más un grupo control, a aproximadamente cinco dosis diferentes del xenobiótico a probar, el cual se administra al inicio del estudio. Los animales se examinan diariamente, se registran los signos clínicos y los síntomas de toxicidad. Después de un intervalo de 14 días, se cuenta el número de animales muertos en cada grupo de dosis y en el 
grupo control, los resultados son analizados estadísticamente con respecto a la frecuencia de animales expuestos muertos como función de la dosis.

En el contexto de estos estudios de toxicidad aguda, la dosis media se refiere como la dosis letal media o LD $_{50}$ (por sus siglas en inglés) es importante mencionar que la dosis letal media es una dosis estadística no es una dosis real. Y se deriva de los estudios de toxicidad aguda mencionados anteriormente, donde la mitad de los animales de prueba mueren y la otra mitad sobrevive. Cuando se reporta la LD50, se deben señalar tanto la especie de los animales de prueba como la ruta de exposición, porque ambos son factores determinantes en la determinación de la $L D_{50}$. Por ejemplo, la $L D_{50}$ para el arsénico en ratas expuestas por la vía de la ingestión oral se reporta como sigue: $L_{50 \text { oral,rata }}=48 \mathrm{mg} / \mathrm{Kg}$. Es muy importante mencionar que se deben realizar por separado pruebas de toxicidad para cada una de las tres rutas de exposición, para las que se prevé la exposición humana a agentes químicos: ingestión, inhalación, y/o absorción dérmica (Penningroth, 2010). Una prueba de toxicidad crónica en pequeños mamíferos puede cubrir la vida útil entera del adulto de la especie de prueba, dos años en ratón y dos y medio en rata. Las pruebas de carcinogenicidad de un agente químico (potecial-carcinógeno), son pruebas de toxicidad crónica, diseñadas para la vida adulta completa de los animales de prueba.

Las exposiciones arriba mencionadas se manifiestan en una gran variedad de formas, incluyendo cáncer, cataratas, ulceras pépticas y efectos reproductivos, por nombrar solo algunas. Además, los xenobióticos pueden tener diversos efectos a diferentes dosis (Smarth y Hodgson, 2008).

\section{La toxicidad subcrónica}

A diferencia del tiempo de exposición en las pruebas de toxicidad aguda, las de toxicidad subcrónica implica dosis repetidas del compuesto químico a probar, normalmente se administra por un periodo de aproximadamente 90 días. El objetivo de este tipo de pruebas es investigar la toxicidad en órganos, obtenida de los datos de dosis efecto con los cuales se diseñan las pruebas de toxicidad crónica, incluida la estimación de un "nivel de efectos adversos no observados", o NOAEL (por sus siglas en inglés). Se prueban al menos tres dosis: la dosis alta seleccionada que causa mortalidad en un $10 \%$ o menos; la dosis baja seleccionada no produce efectos tóxicos; una o más dosis intermedias; y un grupo control que no se expone al químico a probar. Se deben utilizar dos especies, por ejemplo, ratas y perros (grupos pequeños de 10 a 20 ratas y de 2 a 4 perros). Además, generalmente se aplican pruebas por separado en machos y hembras, porque el género puede afectar la vía de respuesta del cuerpo al químico tóxico.

Se observa cuidadosamente a los animales expuestos y se registran los signos y síntomas de toxicidad. Se colectan muestras de sangre y se analizan durante intervalos regulares. Al final de los 90 días, todos los animales sobrevivientes se sacrifican y autopsian, incluye examinación al microscopio de órganos y tejidos para caracterizar las patologías asociadas con la exposición al químico de prueba (Penningroth, 2010).

\subsection{RELACIÓN DOSIS-RESPUESTA}

El objetivo fundamental de una evaluación dosis-respuesta es el obtener una relación matemática entre la cantidad de sustancia tóxica a la cual un organismo está expuesto y el riesgo de desarrollar una respuesta negativa a esa dosis. Los compuestos tóxicos pueden inducir efectos a través de mecanismos fisiológicos y metabólicos distintos, lo cual se ve reflejado en la forma que adquiere la relación dosis-respuesta (INE, 2010). 
Tomando como base la forma de la curva dosis-respuesta, se pueden dividir a los compuestos tóxicos en dos categorías generales (Figura 1.1):

a) Compuestos tóxicos sin umbral o punto a partir del cual se observa un efecto.

b) Compuestos tóxicos con umbral o sin un punto claro donde inicie un efecto.

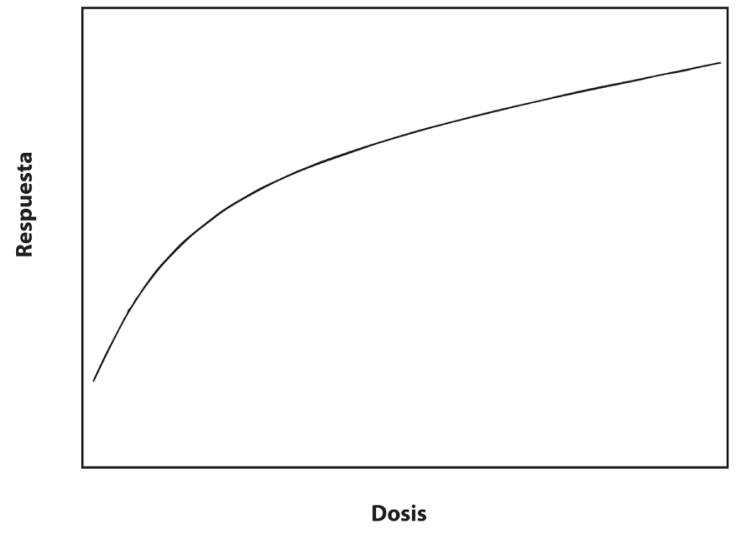

A)

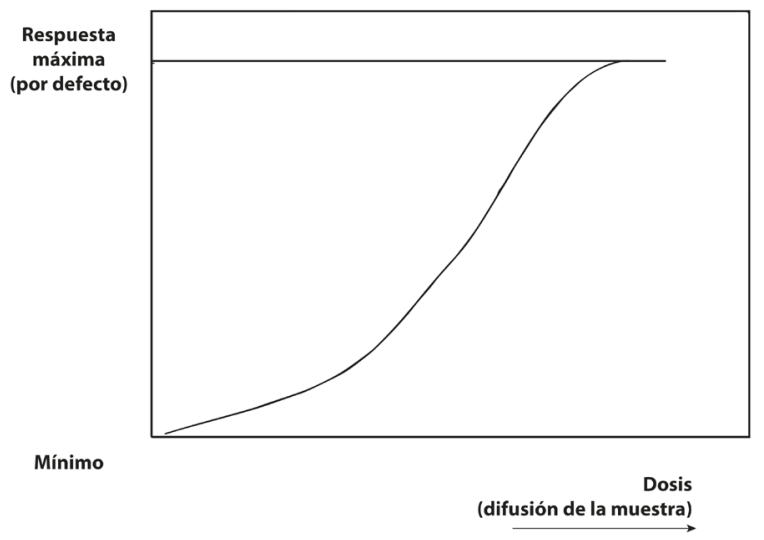

B)

Figura 1.1. Gráficas de relación dosis-respuesta. a) Sin umbral; b) Con umbral (Repetto, 2009).

Si el agente químico es capaz de producir un efecto observable, tal como la muerte del organismo o un efecto del cual las células o animales se recuperan completamente en un periodo de tiempo. Se puede seleccionar la dosis o concentración de la sustancia química de manera que dicho efecto se produzca. Además si este efecto se puede cuantificar, la experiencia mostrara que no todos los miembros del grupo responden a la misma dosis o concentración de la sustancia de una manera cuantitativamente idéntica. Algunos de los animales experimentan una respuesta intensa mientras que otros muestran una respuesta mínima para la misma dosis del agente. Además, si la dosis se escoge convenientemente, algunos animales o células podrían morir y otros sobrevivir. Es decir, lo que se ha considerado como una respuesta de todo o nada solo se aplica a un único miembro del grupo de ensayo, y con respecto al conjunto de todos los miembros del mismo se trata en realidad de una respuesta gradual. Estas desviaciones en las respuestas aparentemente uniforme de células animales a una concentración dada de una respuesta única pueden ser consideradas generalmente como una consecuencia de la variación biológica (Loomis y Hayes, 1996).

\subsection{DOSIS LETAL $50\left(\mathrm{DL}_{50}\right)$}

La Dosis Letal 50 hace referencia a aquella dosis de xenobiótico que causa la muerte del $50 \%$ de los animales de prueba. La DL50 es un valor virtual obtenido estadísticamente. Se trata de un valor calculado que representa la 
mejor estimación de la dosis requerida para producir la muerte en el $50 \%$ de los animales y, por lo tanto, siempre va acompañada de algunos tipos de estimación del error del valor hallado, tal como su intervalo de confianza (Repetto, 2009).

Los límites del intervalo de confianza se escogen arbitrariamente para indicar que se obtendrían resultados similares en el 90 o 95 por cien de los ensayos llevados a cabo de una forma idéntica a la descrita. Se disponen de varios métodos para efectuar los cálculos. Los más empleados son el método gráfico de Litchfield y Wilcoxon (1949), el procedimiento de hallazgo del intervalo (o nivel) de Weil (1952), y el método del papel cuadriculado logarítmico de Probit de Miller y Tainter (1994), (Loomis y Hayes, 1996).

\subsection{CONCENTRACIÓN INHIBITORIA 50 ( CI $\left._{50}\right)$}

Es la medida de eficacia de un xenobiótico para inhibir biológica o bioquímicamente un proceso. Esta medida cuantitativa indica que cantidad del compuesto particular o de la sustancia (inhibidor) es necesaria para inhibir un proceso biológico dado (o el componente de un proceso, es decir, enzima, célula, receptor celular o microorganismo), por la mitad (NCGC, 2008). La concentración de un compuesto necesaria para reducir el crecimiento celular en general, incluyendo células eucarióticas, en un $50 \%$ in vitro. Aunque a menudo se usa para denotar actividad antibacteriana en un cultivo (Bertrudis et al., 2005). Según la FDA, la $\mathrm{Cl}_{50}$ representa la concentración de un xenobiótico que se requiere para lograr el $50 \%$ de la inhibición del proceso in vitro. $\mathrm{La} \mathrm{Cl}_{50}$ puede ser determinada construyendo la curva de la dosis-respuesta y examinando el efecto de diversas concentraciones del antagonista en invertir actividad del agonista (NCGC, 2008).

\section{Biomarcadores}

La relación dosis respuesta antes mencionada, es necesario ser considerada en la dosificación de un compuesto químico, la naturaleza de la respuesta a éste, y los factores que afecta dicha respuesta. Estas consideraciones también son importantes en el proceso de evaluación del riesgo a cualquier agente químico. La determinación de la exposición real a cualquier substancia química, la respuesta del organismo al químico y la susceptibilidad a los efectos tóxicos; son parámetros cruciales en toxicología. Los biomarcadores son herramientas útiles para medir dichos parámetros. Hay tres tipos: biomarcadores de exposición del organismo a la substancia tóxica, biomarcadores de respuesta del organismo a la exposición, y biomarcadores de susceptibilidad del organismo al químico. Para profundizar en el tema referirse a la cita bibliográfica (Timbrell, 2009).

\subsection{TOXICOLOGÍA BIOQUÍMICA}

La toxicología bioquímica se ocupa de los procesos que ocurren a nivel celular y molecular cuando un químico tóxico interactúa con un organismo viviente. Definir estas interacciones es fundamental para nuestro entendimiento de los efectos tóxicos, tanto agudos como crónicos, y es esencial para el desarrollo de nuevas terapias, para determinar los riesgos tóxicos, y para el desarrollo de nuevos compuestos de uso clínico para medicina y biócidas para agricultura (Smarth y Hodgson, 2008). 
El proceso de envenenamiento puede ser pensado como una cascada de eventos más o menos distintos. Mientras que la bioquímica y toxicología molecular son involucradas en todo esto, su desarrollo en el análisis de la exposición es restringido al descubrimiento y uso de biomarcadores de exposición (Smarth y Hodgson, 2008).

\subsection{TOXICOLOGÍA MOLECULAR}

El campo de la biología molecular inicio con la descripción de la estructura de la doble hélice del ADN por Watson y Crick en 1953, seguido por la elucidación del código genético en 1960s. En el medio siglo siguiente las técnicas de biología molecular fueron extendidas exponencialmente así como su importancia en muchos, sino es que en todos, los campos de la biología. El suceso del proyecto del genoma humano ah dado lugar a grupos dedicados a la descripción de genomas completos de los organismos de todos los niveles en el árbol evolutivo. En la Unidad 7 se presenta una visión general de las técnicas moleculares aplicadas a la Toxicología, en el cual se incluyen la reacción en cadena de la polimerasa (PCR por sus siglas en inglés), la producción de ratones genéticamente modificados (transgénicos). Los microarreglos, utilizados para evaluar la expresión génica bajo ciertas condiciones, incluyendo exposición a tóxicos (xenobióticos), son de las más importantes y en concordancias con otras técnicas moleculares, se consideran potencialmente útiles para ser aplicadas en áreas de evaluación y análisis de riesgo (Smarth y Hodgson, 2008).

\subsection{TOXICOLOGÍA GENÉTICA}

La toxicología genética es la disciplina científica que identifica y analiza la acción de un grupo de agentes tóxicos que son capaces de interactuar con el material genético de los organismos (compuestos genotóxicos). Su objetivo primordial es detectar y entender las propiedades de los agentes físicos y químicos, que producen efectos hereditarios mínimos hasta letales. Es, por lo tanto, una ciencia esencialmente multidisciplinaria que pretende establecer la correlación que existe entre la exposición a agentes xenobióticos y la inducción de alteraciones genéticas tanto en las células germinales como en las células somáticas de los organismos, y definir a partir de ello los efectos que los tóxicos ambientales producen sobre la integridad genética de los seres vivos (Smarth y Hodgson, 2008).

\subsection{PASO DE LOS QUÍMICOS A TRAVÉS DEL CUERPO}

\subsubsection{Xenobióticos}

Los xenobióticos son considerados como todas aquellas sustancias que no forman parte de la composición del organismo, pero que son capaces incorporarse a las rutas metabólicas para su procesamiento. Se trata de compuestos de naturaleza química (fármacos, cosméticos, aditivos alimenticios, pesticidas, contaminantes, etc.); algunos otros son de origen natural (micotoxinas o alcaloides). Por lo general son compuestos de naturaleza lipofílica por lo que pueden atravesar con relativa facilidad las membranas biológicas, acceder al interior de las células y unirse a estructuras celulares de carácter lipofílico (Josephy, 2006). 


\subsubsection{Transportadores de xenobióticos}

La absorción de un xenobiótico no se hace de forma homogénea a todos los tejidos, estando condicionada a los siguientes factores:

- Características físicoquímicas: pH, grado de ionización. Los fármacos pequeños y liposolubles se distribuyen mejor porque pueden atravesar fácilmente las barreras.

- Unión a proteínas plasmáticas o de membrana: los fármacos en la sangre viajan unidos sobre todo a proteínas como la albúmina. A mayor unión menor absorción.

- Flujo sanguíneo de los tejidos: tejidos muy vascularizados facilitan la llegada del fármaco.

- Existencia de tropismo (igualdad, afinidad). Liposolubles.

- Existencia de barreras especiales: hematoencefálica, placentaria y hematotesticular.

\subsubsection{Unión a Proteínas Plasmáticas}

Los xenobióticos fundamentalmente suelen unirse a las proteínas albúmina, glicoproteína ácida y lipoproteínas. Cuando las sustancias químicas se unen a proteínas plasmáticas en proporciones elevadas, puede conducir a la liberación de la sustancia elevando su fracción libre apareciendo síntomas de sobredosificación, esto porque la capacidad de las proteínas es limitada, la presencia de otros fármacos: que tengan afinidad por la misma proteína, desplazara al otro y la fracción libre del fármaco desplazado se verá incrementada. Un ejemplo de las más importantes es la albúmina, una molécula de 69000 daltones que se fija a muchos fármacos ácidos (p.eje. warfarina) y aun pequeño número de fármacos básicos (p.eje. clorpromazina); aunque la carga de la albúmina a pH de 7.4 es negativa, fija tanto fármacos ácidos como básicos mediante enlaces iónicos y, ocasionalmente, enlaces covalentes. Hay tres grupos de fármacos cuya unión a la albúmina es muy importante: anticoagulantes, AINES, benzodiacepinas (ansiolíticos). La unión xenobiótico-albúmina suele ser de gran afinidad, uniéndose en regiones especificas de la albúmina, no son necesarias altas concentraciones para unirse (Velázquez, 2005; Armijo, 2010).

\subsubsection{Unión a Proteínas de Membrana}

Las proteínas de membrana son transportadores presentes en varios tejidos como intestino, hígado, riñón, testículos, placenta y el sistema nervioso central. Estos transportadores juegan un papel significativo en la absorción de sustancias y en la distribución a los sistemas del organismo, especialmente si los órganos están protegidos por barreras. Son proteínas que actúan como una bomba de expulsión, pertenecientes a la superfamilia de proteínas unidas a ATP, ya que requiere de energía para cumplir su función. Estas proteínas transportan metabolitos y algunos tóxicos cuya expulsión beneficia y protege las funciones celulares (Ronis y Cunny, 2008). 
Las proteínas transportadoras de xenobióticos han sido clasificadas dentro de múltiples subfamilias por su secuencia homóloga. En mamíferos, la mayoría de transportadores de xenobióticos entran en la superfamilia de transportadores $A B C$ o facilitadores principales (SLC), cada una de las subfamilias de transportadores poseen una secuencia de aminoácidos y especificidad similar (Tabla 1.1).

Tabla 1.1. Principales Familias de Transportadores

\section{Superfamilia de Facilitadores Principales (SLC)}

Transportadores de Aniones Orgánicos (OATs; SLC22A)

Polipéptidos transportadores de aniones orgánicos (OATPs; SLC21)

Transportadores de Cationes orgánicos (OCTs; SLC22A)

Transportadores de Péptidos (PEPT1-2; SLC15A)

Transportadores de Nucleósidos ( ENT1-2, SLC28A; CNT-1-3, SLC29A)

Transportadores ABC: multiespecíficos, impulsados por ATP

p-Glicoproteína (MDR, P-GP; ABCB1)

Proteínas Asociadas a resistencia a multidrogas (MRP1-9; subfamilia ABCC)

BCRO (ABCG2)

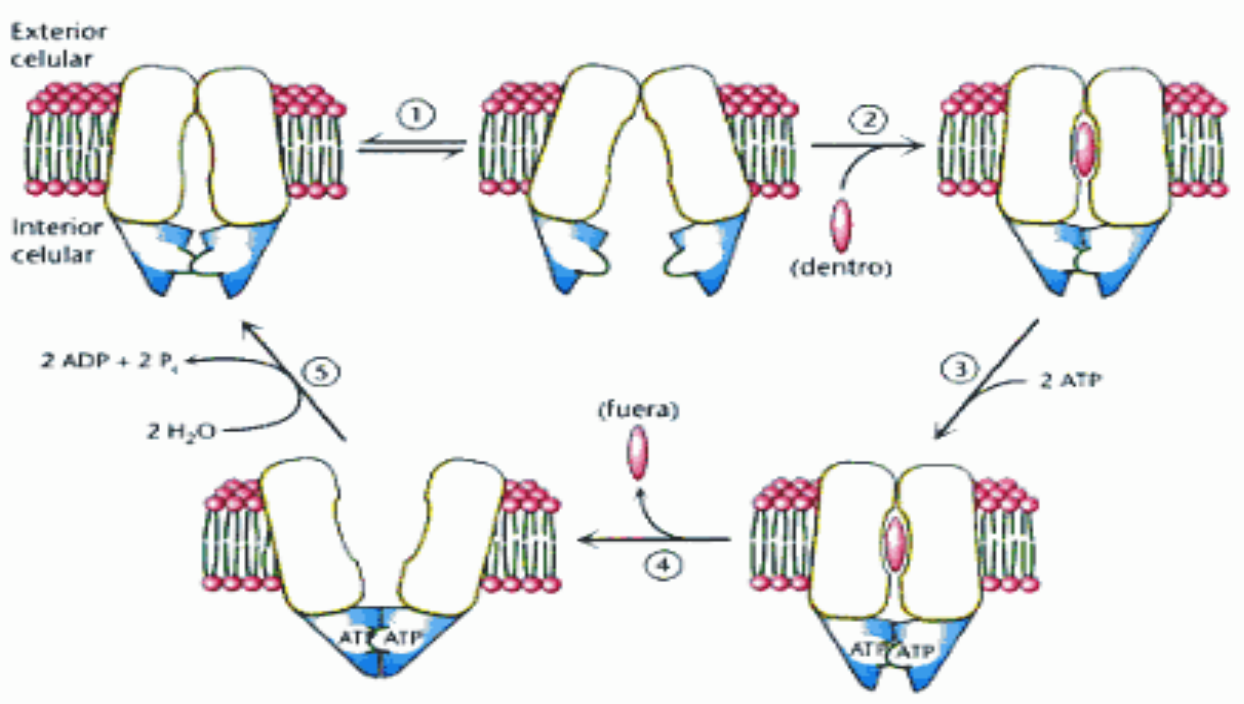

Figura 1.2. Mecanismo de un trasportador ABC. 1. Apertura del conducto hacia el interior de la célula; 2. Fijación del sustrato y cambio conformacional; 3. Unión del ATP y cambios conformacionales consiguientes; 4. Separación de los dominios que separan la membrana y liberación del sustrato al otro lado de la membrana; 5. Hidrólisis del ATP y restauración del transportador en su estado inicial (Mendoza, 2008). 
Las proteínas $A B C$ funcionalmente activas contienen doce dominios transmembranales distribuidos en dos mitades homólogas, dos zonas de unión al ATP ubicadas en la parte citoplasmática y un sitio de glicosilación. Esta estructura básica puede estar presente en una única proteína de una cadena polipéptidica ("full-transporters"), o en dos proteínas separadas ("half-transporters"), en este último caso los transportadores ABC necesitan una dimerización específica para su función (Figura 1.2) (Álvarez et al., 2008; Mendoza, 2008; Smarth y Hodgson, 2008). Dentro de las $A B C$ una de las más importantes es la glicoproteína-P ( $P$-gp), una molécula de pequeñas dimensiones (170kD), formada por un carbohidrato y una molécula de proteína, constituida por 1200 aminoácidos (Repetto, 2009).

\subsection{CICLO INTRAORGÁNICO (ADME)}

Se conoce como ciclo Intraorgánico a todos los procesos que sufren los xenobióticos desde que ingresan en el organismo hasta que se eliminan: absorción, distribución, metabolismo y excreción y se denominan con el acrónimo ADME.

\subsubsection{Absorción}

Es el mecanismo por el cual los xenobióticos atraviesan las barreras corporales para entrar, antes de poder penetrar el flujo sanguíneo, la llegada del xenobiótico a la sangre puede ocurrir a través de la piel, aparato digestivo, respiratorio, etc.; una vez en la sangre puede metabolizarse, pero la mayor parte es distribuida, pudiendo quedar muy restringido a algunos tejidos o que sea una distribución muy homogénea (Repetto, 2009).

La absorción de los xenobióticos está condicionada a algunos factores como: Características fisicoquímicas como el pH y el grado de ionización, las sustancias pequeñas y liposolubles se distribuyen mejor por qué pueden atravesar fácilmente las barreras. Unión a proteínas plasmáticas, las sustancias en la sangre viajan unidas sobre todo a proteínas como la albumina. A mayor unión menor absorción. Flujo sanguíneo de los tejidos: tejidos muy vascularizados facilitan la llegada de la sustancia. Existencia de barreras especiales: hematoencefálica, placentaria, hematotesticular, etc.

Cuando se administra un xenobiótico por una vía diferente a la intravenosa, la concentración plasmática es igual a cero, posteriormente sube al máximo, y finalmente disminuirá de manera gradual, debido al metabolismo, hasta que llega a desaparecer del plasma (Armijo, 2010). La absorción de los xenobióticos dependerá de la vía de ingreso al organismo; las rutas más obvias de exposición del cuerpo a los químicos son: la vía oral (ingestión), a continuación la respiratoria (inhalación) y/o por la piel (dérmica) (Plant, 2003).

Parenteral, intravenosa: No hay absorción, ya que se introduce el xenobiótico directamente a la sangre, por tanto se tiene al xenobiótico en un $100 \%$ en el torrente sanguíneo (distribución).

Parenteral, extravascular, Endotelios capilares: los capilares del músculo a la piel son vasos pequeños que tienen pocas capas, la absorción es bastante rápida y buena. 
Oral, epitelio gástrico, intestinal y cólico: es una capa de células mucho más gruesas, encontrando muchos xenobióticos que son inestables en medio ácido, degradándose con facilidad. Los factores que influyen por la vía oral son el pH que se va modificando a lo largo del tubo digestivo, encontrando los valores más bajos en el estómago, aumentando a lo largo del intestino; el pH condiciona el grado de ionización, de manera que los xenobióticos que sean ácidos débiles se absorben mejor en el estómago, caso contrario a los xenobióticos que sean bases débiles que se absorberán mejor en el intestino.

Sublingual y bucal: Es una absorción rápida para sustancias liposolubles.

Transpulmonar: junto con la oral es la más importante sobre todo para contaminantes, se da a través del tracto respiratorio y de los alvéolos.

Dérmica o cutánea: Los xenobióticos liposolubles son mejor absorbidos por este medio. Existen otras vías como la ocular y rectal siendo esta última la que se encuentra más en desuso. La absorción a través del tracto gastrointestinal puede ser altamente dependiente de la afinidad a proteínas de transporte lipofílicas. Las proteínas de transporte pueden estar incluidas en la absorción activa (Ayrton y Morgan, 2001).

\subsubsection{Mecanismos de absorción}

De los mecanismo de absorción (Figura 1.3) el más simple es la difusión pasiva, todo lo que se necesita es un compuesto no polar lipofílico (aumentando su habilidad para atravesar una membrana lipídica) y un gradiente de concentración; siempre que la membrana sea permeable a la sustancia, esta tiende a moverse de áreas de mayor a menor concentración. Por lo tanto, la mayoría de xenobióticos se someten a la absorción por esta vía.

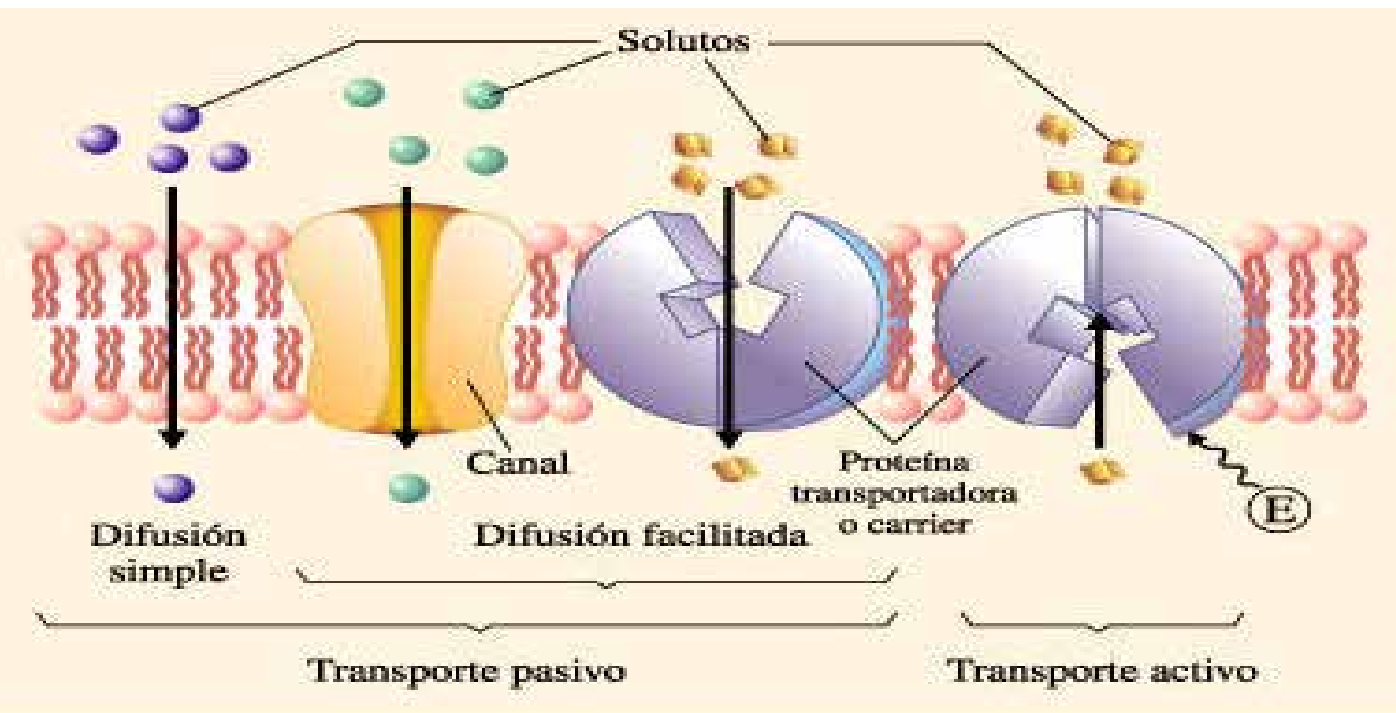

Figura 1.3. Mecanismo de absorción (Curtis y Barnes, 2000). 
La difusión facilitada y el transporte activo permiten la absorción a través de la membrana, de agentes químicos que no son buenos candidatos para la absorción por difusión pasiva. Esto puede deberse a que son polares o no presentan la suficiente concentración para formar un buen gradiente. En la difusión facilitada, los "poros proteicos" permiten la transferencia de moléculas polares a través de la membrana, aunque también es requerido un gradiente de concentración.

En el transporte activo, sin embrago, el movimiento de químicos polares puede ocurrir contra un gradiente de concentración, pero a costa de energía (ATP $\rightarrow$ ADP). Ya que ambos, la difusión facilitada y el transporte activo utilizan proteínas de membrana, la abundancia de estas proteínas puede ser un factor limitante en la velocidad de absorción (Plant, 2003; Flanagan et al. 2007).

\subsubsection{Distribución}

La distribución se define como la llegada y disposición de un xenobiótico en los diferentes tejidos de un organismo. Es un proceso importante pues según su naturaleza, cada tejido puede recibir cantidades diferentes del xenobiótico, el cual se mantendrá en este sitio por tiempos variables. En síntesis es el paso del xenobiótico a los diferentes compartimentos celulares (intracelular, extracelular e intersticial). La tasa de distribución a un tejido depende principalmente de dos factores: El flujo sanguíneo en el tejido y la facilidad con la que el xenobiótico atraviesa la membrana capilar y penetra las células del tejido (Plant, 2003; Armijo, 2010; Wallace, 2010).

La distribución de xenobióticos en el cuerpo es controlada por la permeabilidad a través de las membranas tisulares, el acceso a áreas especiales, como el SNC y el ojo, el paso a la circulación fetal y el acceso a secreciones exocrinas como lágrimas, saliva, leche o líquido prostático, presentan características peculiares, ya que la filtración a través de hendiduras intercelulares en estas áreas está muy limitada. Por ello, el transporte de xenobióticos en estas áreas se realiza por difusión pasiva o por transporte activo. Además, en algunas de estas áreas hay diferencias de $\mathrm{pH}$ que pueden generar un efecto de atrapamiento (Ayrton y Morgan, 2001).

\section{La barrera hematoencéfalica}

La barrera hematoencéfalica (BHE) está localizada entre la sangre y el tejido cerebral y consiste principalmente de células capilares del endotelio cerebral. Es la menos permeable que hay en el organismo, solo pasaran moléculas muy pequeñas y liposolubles o aquellas que tengan un transportador especifico (Velázquez et al., 2005). Está formada por un conjunto de estructuras que dificultan notablemente el paso de las sustancias hidrófilas desde los capilares hacia el SNC (Figura 1.4): 1) las células endoteliales de los capilares sanguíneos del SNC están íntimamente adosadas sin dejar espacios intercelulares; 2) entre una y otra célula existen bandas o zónulas ocludens que cierran herméticamente el espacio intercelular; 3) una membrana basal que forma un revestimiento continuo alrededor del endotelio; 4) los pericitos forman una capa discontinua de prolongaciones citoplasmáticas que rodean el capilar y 5) las prolongaciones de los astrocitos de la glía perivascular forman un mosaico que cubre el $85 \%$ de la superficie capilar. Como consecuencia, no hay ni filtración ni pinocitosis, por lo que los xenobióticos sólo pueden pasar por difusión pasiva (Ayrton y Morgan 2001; Flanagan et al., 2007; Armijo, 2010). 


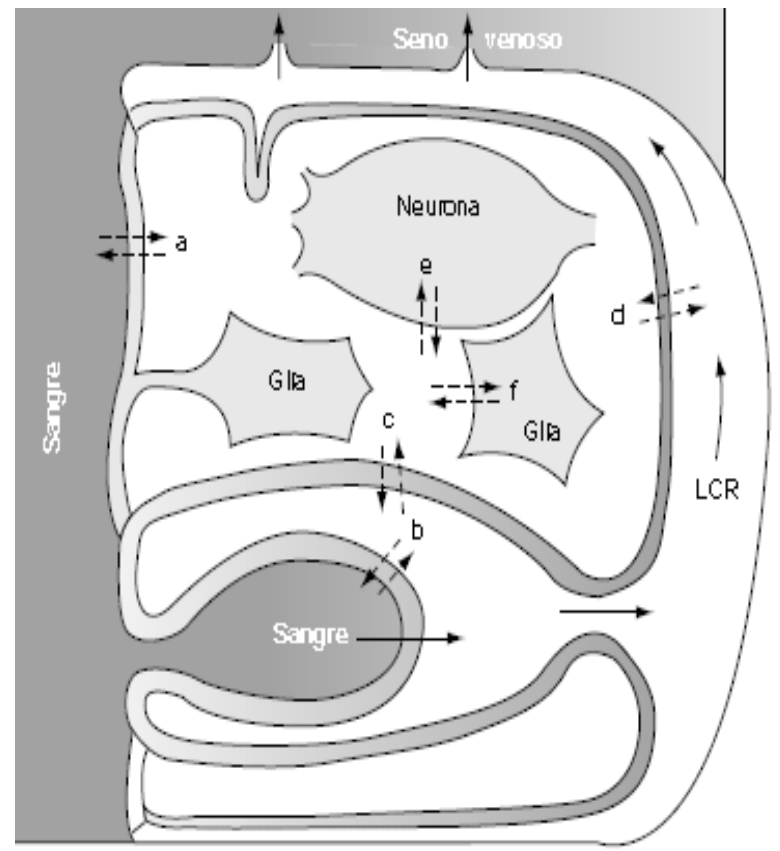

Figura 1.4. Esquema de los compartimientos intracraneales. Las flechas continuas indican la dirección del flujo del líquido cefalorraquídeo.

Las flechas discontinuas indican los sitios donde existe difusión de agua y solutos: a) De la BHE (de capilar a espacio intersticial); b) Del epitelio de los plexos coroideos; c) La membrana ependimaria entre el espacio ventricular y el espacio intersticial; d) De la piamadre entre el espacio intersticial y el espacio subaracnoideo; e) De la membrana neuronal, y f) a través de la membrana de células gliales (Armijo, 2010).

\section{La barrera placentaria}

\section{La placenta}

La placenta separa y une a la madre con el feto. Para atravesarla, los xenobióticos y sus metabólitos tienen que salir de los capilares maternos, atravesar una capa de células trofoblásticas y mesenquimáticas, y entrar en los capilares fetales. Los xenobióticos pasan principalmente por difusión pasiva y su velocidad de paso depende del gradiente de concentración, de la liposolubilidad, del grado de ionización y del pH de la sangre materna y fetal. La fijación a proteínas limita el paso cuando el xenobiótico difunde con dificultad. Cuando es muy lipofílico y no polar no depende de la unión a proteínas sino del flujo sanguíneo placentario. La unión a proteínas y el pH fetales son menores que en la madre. La placenta tiene enzimas que pueden metabolizar los xenobióticos y los metabólitos que pasan de la madre al feto, y viceversa. La barrera placentaria es particularmente acentuada en el primer trimestre del embarazo y disminuye en el tercer trimestre debido al progresivo aumento en la superficie y la reducción de su grosor (Velázquez et al., 2005; Flanagan et al., 2007; Armijo, 2010). 
La placenta posee sistemas enzimáticos como la monoaminooxidasas y colinesterasas. Se considera la posibilidad de que en ella se metabolicen xenobióticos tóxicos dando lugar a metabolitos reactivos. En realidad el hígado fetal y la placenta tienen capacidad metabolizadora y por eso los efectos en la madre como en el feto pueden ser diferentes (Velázquez et al., 2005).

\subsubsection{Metabolismo}

El término biotransformación ha sido definido como cualquier transformación química de un xenobiótico, producida por organismos vivos o por preparaciones obtenidas de estos (Repetto, 2009). Mientras que el metabolismo es definido como la suma de todos los procesos físicos y químicos que sufren los constituyentes del cuerpo en organismos vivos. Incluye la incorporación y distribución en el organismo de los componentes químicos, los cambios (biotransformaciónes sufridas) y la eliminación de los compuestos y sus metabolitos normales (Plant, 2003; Repetto, 2009).

Por su parte, catabolismo es el proceso de biotransformación de moléculas complejas a otras más simples, lo que proporciona a menudo energía biológicamente disponible. Lo contrario o antagónico, es decir, biotransformar para eliminar, es anabolismo. Cuando una sustancia extraña ingresa en el organismo, la biotransformación desempeña un importante papel en la reducción o en el incremento de posibles efectos tóxicos, de tal forma que, al igual que sustancias nocivas son desactivadas, o desprovistas de su capacidad lesiva, compuestos poco tóxicos pueden ser transformados en perniciosos, quizás estos sean luego eliminados después de un proceso desintoxicante (Repetto, 2009).

La actividad de las diferentes vías metabólicas determina la concentración efectiva del metabolismo activo en los lugares de acción. Múltiples factores endógenos (genéticos y fisiológicos) pueden modificar el metabolismo de sustancias extrañas y de este modo la intensidad de la respuesta, a la exposición (Figura 1.5) (Wallace, 2001).

Las biotransformación de los xenobióticos se realiza por vías puramente química o bioquímica, con participación de enzimas, cuantitativamente importantes (Repetto, 2009).

\subsubsection{Excreción}

Las vías urinaria y biliar son las principales vías de excreción de las sustancias extrañas. Ciertas sustancias se eliminan también parcialmente por el aire espirado, el sudor, la saliva, la leche y las secreciones gastrointestinales. La importancia relativa de las dos vías principales de eliminación (riñón y bilis) está íntimamente ligada a las transformaciones metabólicas que los xenobióticos experimentan. En general, estos procesos metabólicos liberan derivados cuyas propiedades fisicoquímicas favorecen una eliminación más rápida. Son varios los factores endógenos que modifican la velocidad de excreción y, por tanto, la concentración del xenobiótico en su lugar de acción (Wallace, 2001). 


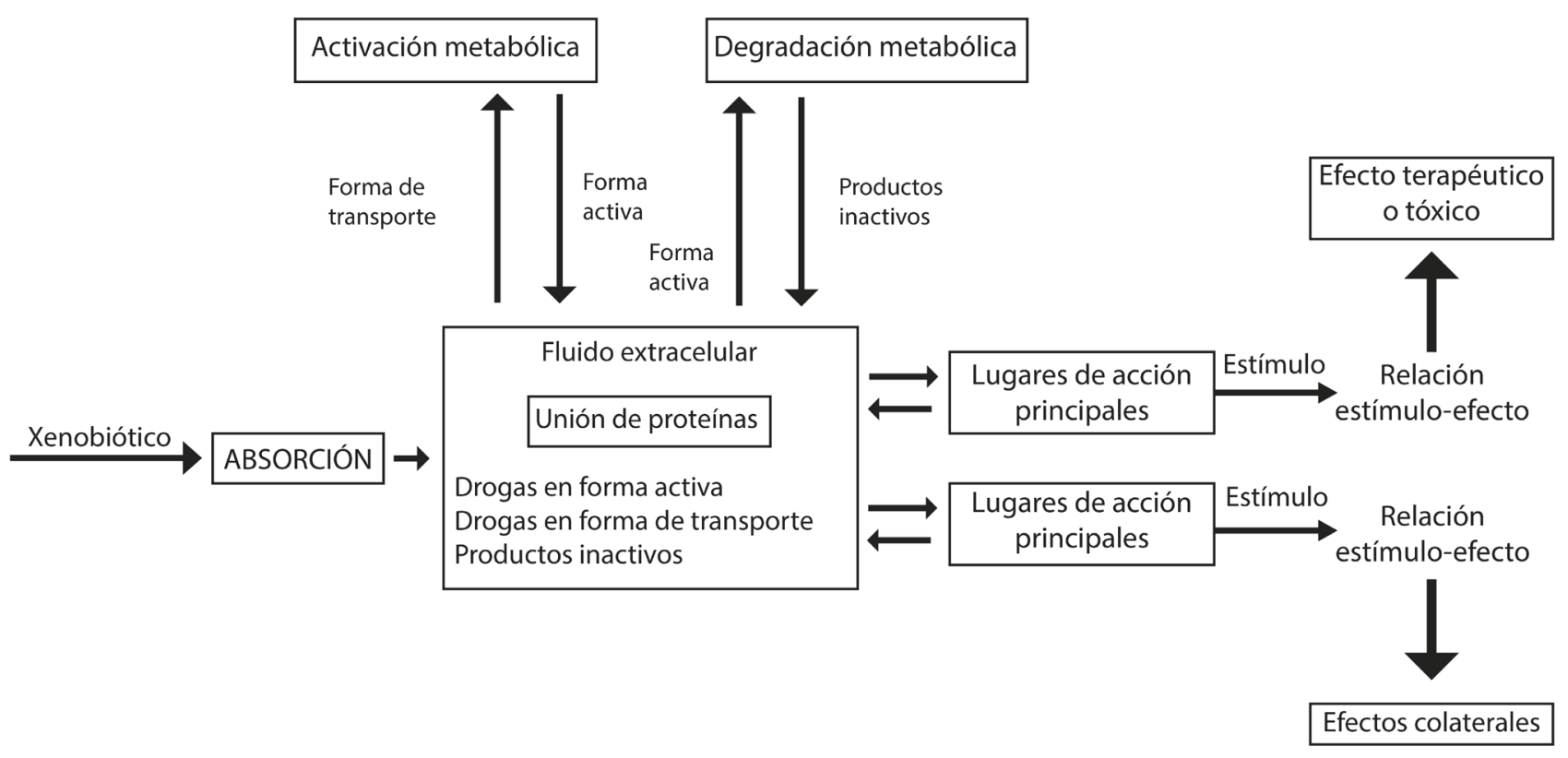

Figura 1.5. Vías Metabólicas (Lauwerys, 1994).

\subsubsection{Vías de Excreción}

Excreción Renal: Es la vía más importante de excreción de los xenobióticos, siendo particularmente relevante cuando se eliminan de forma exclusiva o preferente por esta vía, en forma inalterada o como metabolitos activos. Por el contrario, es poco importante en los fármacos que se eliminan principalmente por metabolismo, aun cuando una parte sustancial de sus metabólitos inactivos se eliminen por el riñón. La cantidad final de un xenobiótico que se excreta por la orina es la resultante de la filtración glomerular y de la secreción tubular, menos la reabsorción tubular. La filtración se produce en los capilares del glomérulo renal, que poseen abundantes poros intercelulares por donde pasan todas las moléculas (PM < 300), excepto las de gran tamaño y las unidas a las proteínas plasmáticas. Como consecuencia, la filtración aumenta cuando disminuye la unión de los fármacos a las proteínas plasmáticas (Flanagan et al., 2007; Armijo, 2010).

Excreción Biliar: Sigue en importancia a la excreción urinaria y está muy relacionada con los procesos de biotransformación. Se produce principalmente por secreción activa con sistemas de transporte diferentes para sustancias ácidas, básicas y neutras. Se eliminan principalmente por la bilis (Tabla 1.2) (Flanagan et al., 2007; Armijo, 2010):

a) Sustancias con elevado peso molecular (PM > 300). La conjugación hepática, al añadir radicales, eleva el peso molecular, facilitando la excreción biliar.

b) Sustancias con grupos polares, tanto aniones como cationes, que pueden ser del fármaco principalmente amonio cuaternario) o de los radicales suministrados por el metabolismo (glucurónidos o sulfatos). 
c) Compuestos no ionizables con una simetría de grupos lipófilos e hidrófilos que favorece la secreción biliar (p. ej., digitoxina, digoxina y algunas hormonas).

d) Algunos compuestos organometálicos.

Tabla 1.2. Ejemplos de fármacos con excreción biliar significativa.

\begin{tabular}{cc} 
Acebutolol & 5-Fluorouracilo \\
Ampicilina & Hidrocortisona \\
Carbenoxolona & Indometacina \\
Cefamandol & Metronidazol \\
Cefoperazona & Nafcilina \\
Cloranfenicol & Pivampicilina \\
Clortetraciclina & Practolol \\
Desmetilclortetraciclina & Rifampicina \\
Digitoxina & Terbutalina \\
Digoxina & Testosterona \\
Doxiciclina & Vincristina \\
Estradiol & \\
\hline
\end{tabular}

Excreción intestinal: Los fármacos pueden pasar directamente de la sangre a la luz intestinal, por difusión pasiva, en partes distales en que el gradiente de concentración y la diferencia de pH lo favorezcan (Flanagan et al., 2007).

La excreción a la leche: puede hacer que los xenobióticos lleguen al lactante y origine reacciones características y tóxicas. Los xenobióticos pasan a la leche sobre todo por difusión pasiva, por lo cual el cociente leche/ plasma será tanto mayor cuanto mayor sea su liposolubilidad y menor sea su grado de ionización y unión a proteínas plasmáticas. La concentración en la leche depende también de la unión del xenobiótico a las proteínas y lípidos de la leche, y algunos xenobióticos pasan a la leche mediante transporte activo (Flanagan et al., 2007; Armijo, 2010).

La excreción salival: es poco importante desde el punto de vista cuantitativo y, además, la mayor parte del xenobiótico excretado por la saliva pasa al tubo digestivo, desde donde puede reabsorberse de nuevo. Pasan a la saliva principalmente por difusión pasiva, por lo que la concentración salival es similar a la concentración libre del xenobiótico en el plasma (Flanagan et al., 2007).

\section{REFERENCIAS BIBLIOGRÁFICAS}

Álvarez F., Ana I., Pulido D., Mivis M. (2008) Transportadores de tipo ABC: Consecuencias de su interacción con flavonoides. Boletín Latinoamericano y del Caribe de Plantas Medicinales y Aromáticas 7: 296-311. 
Armijo J. Absorción, Distribución y Eliminación de los Fármacos. Farmacología humana en línea http://www.phar.kftox. com/file03.pdf Consulta: 19/08/2010.

Ayrton A., Morgan P. (2001). Role of transport proteins in drug absorption, distribution and excretion. Xenobiotica 31:8/9, 469-497.

Bertrudis H., Silva D., Taboada V., Tamariz O. (2005) Concentración mínima inhibitoria y concentración mínima bactericida de ciprofloxacina en bacterias uropatógenas aisladas en el Instituto Nacional de Enfermedades Neoplásicas. Rev Med Hered 16:1, 39-45.

Curtis H. y Barnes S. (2000) Biología. 6ª ed. Editorial Médica Panamericana, Madrid pp. 1496.

Flanagan R., Taylor A., Watson I., Whelpton R. (2007) Fundamentals of analytical toxicology; Editorial Wiley, Great Britain pp. 505.

Instituto Nacional de Ecología (INE) http://www2.ine.gob.mx Consulta: 7/12/2010.

Josephy P. (2006) Molecular Toxicology, 2a ed. Editorial Oxford, New York pp. 589.

Lauwerys R. (1994) Toxicología industrial e intoxicaciones profesionales; Editorial Masson, Barcelona pp. 631.

Loomis A. y Hayes W. (1996) Loomis's Essentials of toxicology; 4ª ed. Editorial Academic Press, ～USA pp. 282.

Mendoza P. (2008) Farmacología Médica; Editorial Médica Panamericana, México pp. 1000.

NCGC, Lilly E. (2008) Determination of EC50/IC ${ }_{50}$; Site official Nih Chemical Genomics Center (publicación en línea), http://www.ncgc.nih.gov/guidance/section3.html Consulta 08/12/2010.

Plant N. (2003) Molecular Toxicology; Editorial BIOS Scientific Publisher, USA pp. 149.

Repetto M. y Repetto G. (2009) Toxicología fundamental. $4^{a}$ editorial Díaz de Santos pp. 587.

Ronis M. y Cunny H. (2008) Developmental Effects on Xenobiotic Metabolism. En: Molecular and Biochemical Toxicology. Smart R. y Hodgson E. (Eds). 4ª ed. Editorial Wiley, New Jersey 257-286.

Smart C. y Hodgson E. (2008) Molecular and biochemical toxicology. $4^{\mathrm{a}}$ ed. editorial Willey, New Jersey pp. 901.

Velázquez P. Morena A., Leza J., Lozasoain., Moro M. (2005) Farmacología básica y clínica, $1^{a}$ reimpresión. Editorial Médica Panamericana S.A, Madrid pp. 321.

Wallace A. (2001) Principles and methods of toxicology. $4^{\text {a }}$ ed. Editorial Taylor y Francis, Boston pp. 1887. 


\section{CAPÍTULO}

\section{2 \\ Papel del metabolismo fase I en toxicología}

\section{1 ¿QUÉ ES EL METABOLISMO FASE I?}

Como se describió en la unidad uno, muchos compuestos endogénos (endobióticos) o exógenos (xenobióticos) requieren de ciertas transformaciones químicas antes de poder ser excretados por cualquiera de las vías disponibles. Los animales superiores han desarrollado diversas rutas metabólicas que convierten a los agentes xenobióticos liposolubles en metabolitos hidrosolubles capaces de ser excretados por las vías de eliminación. A esta actividad bioquímica se le ha denominado proceso de biotransformación, el cual se ha dividido a su vez en dos grupos de actividad enzimática: Reacciones de Fase I y Fase II.

Los xenobióticos, una vez que se introducen en el organismo, son biotransformados o metabolizados; la función principal del proceso de biotransformación es la conversión de los xenobióticos en compuestos más polares y menos tóxicos para facilitar su remoción por las diferentes vías de excreción; sin embargo, cuando se modifica la estructura química del agente xenobiótico, se pueden presentar algunos casos en los que se modifique la actividad original, así como que aumente la toxicidad, lo que se conoce como bioactivación (Repetto, 2009; Castell, 2010).

La Fase I comprende aquellas biotransformaciones que aumentan la hidrosolubilidad del compuestos mediante la introducción de grupos funcionales de carácter polar, como $-\mathrm{OH}^{-},-\mathrm{NH}_{2},-\mathrm{COH},-\mathrm{COOH}$, $-\mathrm{SH}$, etc., que además, por ser más reactivos, capacitan al compuesto para experimentar las reacciones de la fase II; generalmente, de un mismo compuesto se derivan varios metabolitos (Repetto, 2009; Hodgson y Rose, 2010).

En general, las enzimas de fase I son capaces de transformar múltiples substratos y catalizar reacciones diferentes. Se trata de proteínas catalíticas de naturaleza muy diversa entre los que se incluyen enzimas con actividad monooxigenasa u oxidasas de función mixta, estas son enzimas que hacen uso del oxígeno molecular, del que utilizan uno de los átomos para oxigenar al xenobiótico (oxidación + incorporación de oxígeno a una molécula orgánica), al tiempo que el otro átomo termina reducido a $\mathrm{H}_{2} \mathrm{O}$. Existen dos grandes familias de oxigenasas en el hígado: las dependientes de citocromos P450 (denominadas CYP450) y las monooxigenasas de flavín (denominadas MOF). A diferencia de las segundas, la acción de los CYP requiere de la coparticipación de una enzima auxiliar (CYP reductasa), a través de la cual fluyen los electrones necesarios para la reducción de uno de los átomos de oxígeno hacia la formación de $\mathrm{H}_{2} \mathrm{O}$. También encontramos a diversas oxidasas (alcohol deshidrogenasa, aldehído deshidrogenasa, amino oxidasas, aromatasas), la epóxido hidrolasa o esterasas y amidasas hepáticas y plasmáticas (Calabuig, 2005; Castell, 2010). 
Las enzimas que intervienen en estos mecanismos se encuentran principalmente localizadas en el hígado, aunque pueden estar presentes, en menor concentración, en otros órganos, tales como riñón, pulmón, intestino y cerebro. En términos cuantitativos, la mayoría de las reacciones oxidativas se llevan a cabo por las familias de los citocromos P450 (Calabuig, 2005). La mayor parte de la biotransformación de los xenobióticos, catalizada por los enzimas de la fase I, se verifica por las monooxigenasas microsómicas dependientes de I CYP450, una superfamilia de numerosas hemo-proteínas-tiolato.

\subsection{CITOCROMO P450 COMO MEDIADOR DE LA FASE I DEL METABOLISMO}

Los citocromo P450 (CYP450), son un grupo de hemoproteínas, mediadores primarios de las células del metabolismo oxidativo. Es una gran familia de más de 40 enzimas presentes en la evolución desde hace un billón de años, encontrándose en todo un reino biológico, incluidas las bacterias. Se encuentran presentes en múltiples tejidos (cerebro, riñones, pulmones, intestino) con una alta concentración en hepatocitos. Se localizan en las mitocondrias y en el retículo endoplásmico liso de las células del hígado (hepatocitos) (Chapple, 1998; Guzmán y Carmona, 2006). Estas enzimas participan en la desintoxicación de elementos xenobióticos, como los medicamentos, y en el metabolismo de algunos endobióticos, como los esteroides, eicosanoides y las vitaminas liposolubles (Figura 2.1) (Chapple, 1998).

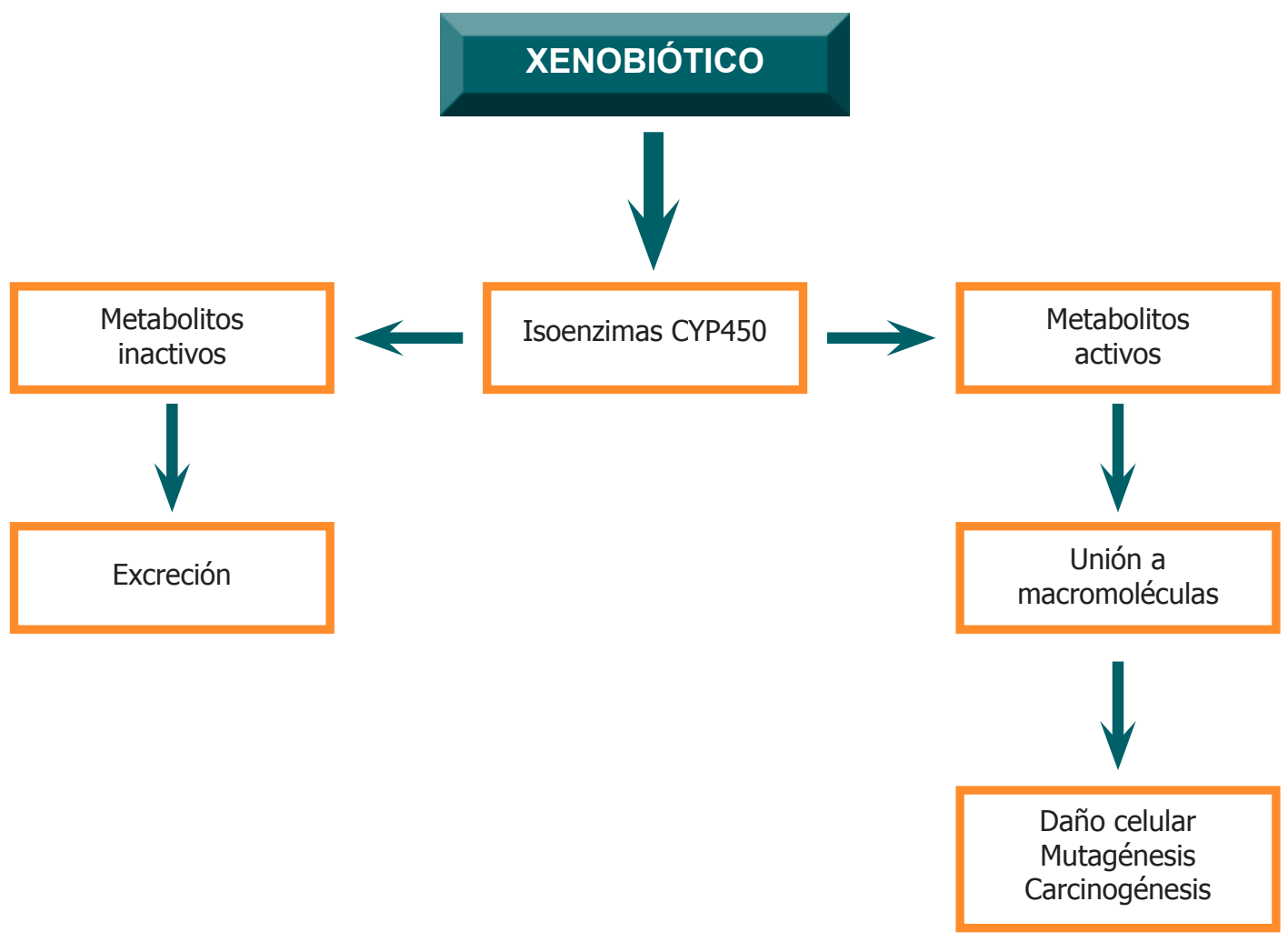

Figura 2.1. Desintoxicación de xenobióticos por CYP450. 


\subsubsection{Estructura y mecanismo enzimático del citocromo p450}

Cada enzima está compuesta por cuatro elementos (Chapple, 1998):

A) Un grupo proteínico hémico del tipo de ferroprotoporfirina IX, en el que el átomo de hierro se encuentra en estado férrico $\left(\mathrm{Fe}^{3+}\right.$.

B) Una cadena polipeptídica codificada por un solo gen, cuyas variaciones originan las diferencias entre una enzima y otra.

C) Una enzima flavoproteínica dependiente de NADPH.

D) El citocromo b5, relacionado con el transporte del segundo electrón en el proceso oxidativo catalizado por este sistema enzimático.

El sistema de monooxigenasas u oxigenasas de función mixta (átomos de oxígeno es incorporado en la molécula del sustrato, mientras el otro es reducido hasta agua) conocido como CYP450, es un grupo de proteínas que presentan un grupo hemo, se caracterizan por utilizar el NADPH o NADP+ para reducir el oxígeno molecular, hasta $\mathrm{H}_{2} \mathrm{O}$ y la incorporación de un átomo de $\mathrm{O}_{2}$ al sustrato (Fig. 2.2) (Galli, 2002).

$$
\mathrm{RH}+\mathrm{NADPH}+\mathrm{O}_{2}+\mathrm{H}^{+} \longrightarrow \mathrm{ROH}+\mathrm{NADP}++\mathrm{H}_{2} \mathrm{O}
$$

Figura 2.2. Reacción enzimática de monooxigenasas.

De forma general, la molécula de la enzima está constituida por una combinación de regiones $\alpha$-hélice fundamentalmente en la región de la proteína que rodea al grupo hemo, mientras que las regiones más variables son las que constituyen los lugares de anclaje a la membrana o de unión y reconocimiento de sustratos.

La enzima permanece anclada a la membrana a través de una hélice hidrofóbica cercana al extremo $\mathrm{N}$-terminal, por lo que la mayor parte de la proteína se sitúa en la cara citosólica de la membrana (Capple, 1998).

En los organismos eucariotas los citocromos P450 de clase I se encuentran asociados a la membrana interna de la mitocondria; en mamíferos estos CYP450 catalizan diversos pasos de la biosíntesis de hormonas esteroideas y vitamina D3. Las enzimas clase Il son las más abundantes en eucariotas, entre sus funciones fisiológicas se incluyen la biosíntesis y el catabolismo de moléculas señalizadoras, hormonas esteroideas y ácido retinoico. Además de sus funciones biosintéticas, los CYP450 de clase I y II participan en procesos de metabolización de xenobióticos tanto en plantas como en animales. Los CYP450 de clase III participan en la síntesis de prostaglandinas en mamíferos, mientras que la clase IV sólo se ha identificado en hongos (Mansuy, 1998; Honkakoski y Negishi, 2000). 


\subsubsection{Nomenclatura}

La denominación CYP450, es debida a que absorben la luz ultravioleta (UV) en presencia de monóxido de carbono en una longitud de onda de $450 \mathrm{~nm}$, tomando en cuenta que la función sigue a la estructura, las enzimas están agrupadas en familias y subfamilias de acuerdo al grado de similitud en la secuencia de aminoácidos. Las enzimas de una misma familia son homologas en $40 \%$ al $55 \%$ de la secuencia y las enzimas de la misma subfamilia más del 55\%. El primer número arábigo designad por una letra del alfabeto y el último número arábigo designa el gen que codifica una enzima especifica (Galli y Feijo, 2002; Orellana y Guajardo, 2003).

La nomenclatura de las enzimas depende de la familia, la subfamilia y el gen que las codifica. La familia es un grupo de enzimas con una homología estructural de 35 a 40\% y se representa por un número arábigo precedido de la sigla CYP (que identifica al CYP450) por ejemplo, CYP1, CYP3, etc. Las subfamilias -formadas por enzimas con homología de 65-70\%- se identifican mediante la adición de una letra mayúscula, por ejemplo, CYP3A, CYP2C. La subfamilia CYP3A es la más abundante en humanos y desempeña un papel importante en el metabolismo de prácticamente la mitad de los medicamentos. El gen que codifica una enzima se identifica añadiendo un número arábigo y empleando letra cursiva, por ejemplo CYP2C8, CYP2D6 y CYP3A4 (Plant, 2003; Orella y Guajardo, 2004; Guzmán y Carmona, 2006; González, 2007).

\subsubsection{Mecanismo de acción}

Las enzimas de este complejo funcionan mediante una serie de reacciones metabólicas en las que se transfieren dos electrones y se incorpora un átomo de oxigeno. Esto lleva a la oxidación del compuesto, la cual aumenta su polaridad, su capacidad de excreción y su solubilidad en agua (Guzmán y Carmona, 2006). El mecanismo de acción es complejo y aún no está bien esclarecido debido a la baja vida media de sus intermediarios. Existen evidencias de que en el proceso se generarían especies reactivas de oxígeno como el anión superóxido $\left(\mathrm{O}_{2}{ }^{\bullet}\right)$ y peróxido de hidrógeno $\left(\mathrm{H}_{2} \mathrm{O}_{2}\right)$ además del radical libre sustrato $\left(\mathrm{R}^{*}\right)$ el que al unirse a un radical hidroxilo, generaría finalmente un producto hidroxilado $(\mathrm{ROH})$ (Orellana y Guajardo, 2004).

La descomposición del CYP oxigenado es descrita como una de las mayores fuentes de radicales superóxido en los sistemas biológicos y su producción depende de la isoforma del CYP, la naturaleza del sustrato unido y de la eficiencia en la entrada del segundo electrón (Orellano y Guajardo, 2004). El centro catalítico de los CYP450 es el átomo de hierro hexacoordinado (con los 4 anillos de la protoporfirina IX, con el grupo tiol (-SH) de un residuo de cisteína de la cadena polipeptídica y como solvente normalmente agua). Proceso catalítico (Figura 2.3) (Ortiz, 2005):

a) Unión del sustrato y el desplazamiento del solvente en la sexta posición de coordinación del átomo de hierro. Como consecuencia de ello se originan cambios en el estado de spin, en el potencial redox y en el máximo de absorbancia de la hemoproteína.

b) Reducción del complejo hemoproteína-substrato al estado ferrosos (el $\mathrm{Fe}^{3+}$ del grupo hemo pasa a $\mathrm{Fe}^{2+}$ ) gracias al aporte de un electrón y al aumento del potencial redox originado en el paso anterior.

c) Unión del oxígeno molecular para formar un complejo superóxido

d) Aporte de un segundo electrón con la formación de una especie activada de oxígeno. 
A partir de este punto el mecanismo no se conoce con certeza. La naturaleza de la especie activada de oxígeno es desconocida. En cualquier caso, se trataría de un oxidante electrofílico de vida muy corta formado por la protonación del dioxígeno $(\mathrm{O}=0)$.

El resultado de la actividad enzimática del CYP450 no siempre es la inserción de oxígeno en la molécula del substrato, pudiendo catalizar también reacciones de deshidratación, deshidrogenación, isomerización, dimerización, e incluso reducción. El desacoplamiento del ciclo catalítico del CYP450 se produce cuando los electrones del cofactor NADPH son consumidos sin formación de metabólicos oxidados (Hodgson y Rose, 2010). Esto ocurre cuando:

1) El intermediario $\mathrm{Fe}^{2+}-\mathrm{O}_{2}$ se auto-oxida liberando anión superóxido y regenerando el enzima en estado férrico

2) El intermediario $\mathrm{Fe}^{3+}$-hidroperóxido se disocia en una molécula de $\mathrm{H}_{2} \mathrm{O}_{2}$ y enzima férrico

3) La especie $\mathrm{Fe}=\mathrm{O}$ en lugar de oxidar el sustrato es reducida a una molécula de agua por transferencia adicional de electrones.

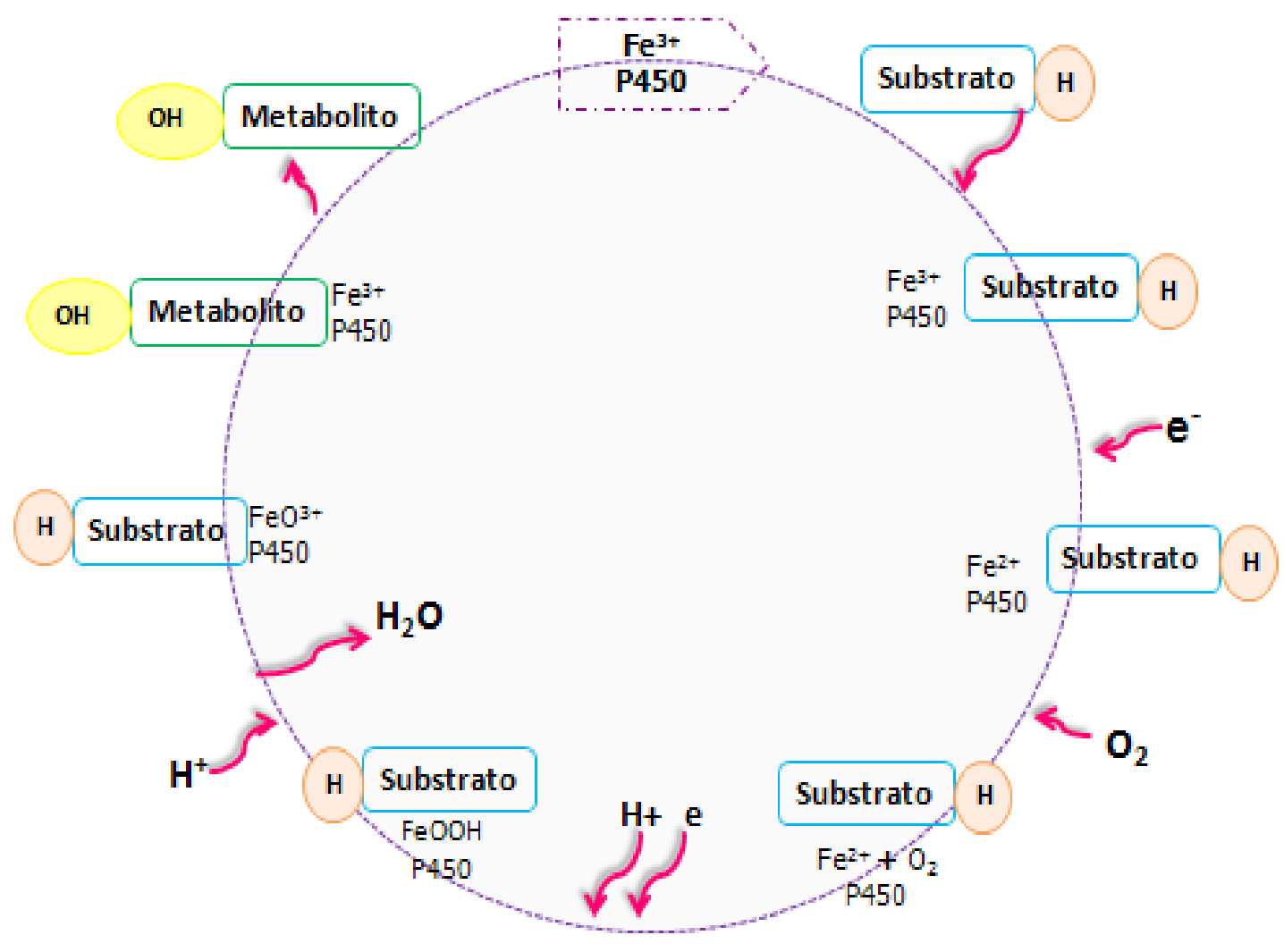

Figura 2.3. Ciclo Catalítico de CYP450 (Modificado de Plant, 2003). 


\subsubsection{Enzimas CYP450 en el humano}

En la Tabla 2.1 se muestran las principales enzimas CYP450 metabolizadoras de drogas presentes en el hígado humano, y los sustratos utilizados como sondas para su estudio. Aproximadamente la mitad de las 53 enzimas CYP450 humanas actualmente conocidas, pertenecen a las familias 1, 2 y 3, estas, son las responsables de la biotransformación de la mayoría de los xenobióticos. Además, como anteriormente se dijo, existen CYP450 que metabolizan sustratos endógenos y que cumplen importantes funciones fisiológicas en el organismo como la subfamilia 4A (CYP4A9 y 4A11 detectadas en el hombre) presentes en gran cantidad en el hígado, se caracterizan por participar en el metabolismo de ácidos grasos como el araquidónico (Orellana y Guardo, 2004).

Las diversas isoenzimas CYP son fácilmente inducibles, lo que posee implicaciones clínicas importantes, puesto que constituye en mecanismo bioquímico de interacción farmacológica. Los inductores más utilizados en los roedores, son el fenobarbital, 3-metilcolantreno y beta-naftoflavona, en cambio en humanos, la rifampicina y el fenobarbital son algunos de los inductores más potentes. En el aumento de la expresión de los diversos tipos de CYP450, está involucrado un incremento de la transcripción génica y/o mecanismos postranscripcionales como la estabilización del RNA (Hodgson y Rose, 2010).

En un caso en particular el CYP2E1, una de las enzimas CYP450 más estudiadas tanto en animales como en humanos, debido a su papel en el metabolismo del etanol y por su participación en la activación metabólica de una serie de procarcinógenos, como $\mathrm{N}$-dimetil-nitrosamina y de solventes orgánicos como el tetracloruro de carbono y el benceno. El contenido hepático de CYP2E1 es alrededor de 7\% de los CYP totales, también se encuentra presente en el cerebro y en el pulmón. La mayoría de sus 70 sustratos demostrados son moléculas pequeñas hidrofóbicas incluyendo sólo algunos pocos productos farmacéuticos como paracetamol, clorzoxazona, enflurano y halotano. El disulfiram es el inhibidor del CYP2E1 usado en clínica y muchos de sus sustratos son además sus inductores, tal como acetona, etanol, piridina, pirazon e isoniacida. EI CYP2E1 además metaboliza acetaminofén o paracetamol, produce N-acetil-p-benzoquinoneimina (NAPQI), metabólito hepatotóxico que en condiciones normales se elimina conjugado con glutatión. En una situación de sobredosis de acetaminofén o frente a una ingesta aumentada de etanol se induce hepatotoxicidad (Sisamón, 2003).

Tabla 2.1. Principales CYP450 que metabolizan drogas en el hígado humano y, algunos sustratos e inhibidores específicos.

\begin{tabular}{lccl}
\hline & Enzima & \multicolumn{1}{c}{ Sustratos in vivo o in vitro } & \multicolumn{1}{c}{ Inhibidores } \\
\hline $\begin{array}{l}\text { Familia CYP1 } \\
\text { Subfamilia IA }\end{array}$ & IA2 & $\begin{array}{l}\text { 7-etoxiresorufina (sustrato de toda la subfamilia 1A), } \\
\text { cafeína, teofilina, fenacetina (o-de-etilación). }\end{array}$ & $\begin{array}{l}\text { Furafillina, 7-8 } \\
\text { benzoflavona, } \\
\text { Metoxsalem }\end{array}$ \\
$\begin{array}{l}\text { Familia CYP2 } \\
\text { Subfamilia 2 }\end{array}$ & 2A6 & Cumarina (7-hidroxilación), Nicotina. & $\begin{array}{l}\text { Dietilditiocarbamato } \\
\text { Metoxsalem }\end{array}$ \\
Subfamilia 2B & 2B6 & $\begin{array}{l}\text { 7-bencil-oxiresorufina, } \\
\text { S-Mefenitoína (N-demetilación). }\end{array}$ & $\begin{array}{l}\text { Fluoxetina } \\
\text { Sertralina }\end{array}$ \\
\hline
\end{tabular}




\begin{tabular}{|c|c|c|c|}
\hline & Enzima & Sustratos in vivo o in vitro & Inhibidores \\
\hline \multirow{3}{*}{ Subfamilia 2C } & $2 \mathrm{C} 8$ & $\begin{array}{l}\text { Paclitaxel, tolbutamida (sustrato de toda la subfamilia } \\
\text { 2C). }\end{array}$ & Sulfafenazol \\
\hline & $2 \mathrm{Cg}$ & Diclofenaco, Warfarina. & $\begin{array}{l}\text { Sulfafenazol, } \\
\text { Fluvoxamina }\end{array}$ \\
\hline & 2C19 & S-Mefenitoína (4-hidroxilación). & Dietilditiocarbamato \\
\hline Subfamilia 2D & 2D6 & $\begin{array}{l}\text { Bufuralol (1-hidroxilación), } \\
\text { Dextrometorfan (O-demetilación) } \\
\text { Debrisoquina. }\end{array}$ & $\begin{array}{l}\text { Quinidina, Parozetina } \\
\text { Fluoxetina. }\end{array}$ \\
\hline Subfamilia 2E & 2E1 & $\begin{array}{l}\text { Clorzoxazona (6-hidroxilación), anilina, acetaminofen, } \\
\text { p-nitrofenol. }\end{array}$ & $\begin{array}{l}\text { Dietilditiocarbanato } \\
\text { Disulfiran, isoniacida. }\end{array}$ \\
\hline $\begin{array}{l}\text { Familia CYP3 } \\
\text { Subfamilia }\end{array}$ & 3A4 & $\begin{array}{l}\text { Diazepan (sustrato de toda la subfamilia } 3 \mathrm{~A}) \text {, } \\
\text { midazolam, flunitrazepam, dextrometorfan } \\
\text { (N-demetilación), testosterona (6-B-hidroxilación), } \\
\text { quinina. }\end{array}$ & $\begin{array}{l}\text { Troleandomicina } \\
\text { Ketoconazol, } \\
\text { Fluvoxamina, } \\
\text { Ciprofloxacina. }\end{array}$ \\
\hline
\end{tabular}

(Orellana y Guajardo, 2004).

Además de activar procarcinógenos, el CYP2E1 es importante en la patología puesto que se ha descrito como una de las enzimas que produce mayor cantidad de especies reactivas de oxígeno (ión superóxido y $\mathrm{H}_{2} \mathrm{O}_{2}$ ), las que son formadas en presencia o en ausencia de sustrato y que serían los que posteriormente causarían daño tisular (Orallena y Guajardo, 2004).

Dentro de las isoformas que constituyen la familia del citocromo P450 encontramos la CYP2D6 que metaboliza cerca del $25 \%$ de todos los medicamentos que se usan en la clínica, actualmente tales como el bloqueador beta, los antiarrítmicos, antidepresivos y derivados de morfina. Otra isoforma, la CYP2C9 metaboliza entre otros a los inhibidores de las bombas de protones. Sin embargo, es bueno aclarar que si bien las CYP participan en el metabolismo de la mayoría de los fármacos, estas no son las únicas enzimas dentro y fuera de la familia que lo hacen, y este metabolismo a su vez es afectado por otros factores genéticos y ambientales (Ramírez, 2007).

Los diversos individuos responden en distinta forma a la acción de ciertos xenobioticos, lo que se debería a un diferente contenido de cada isoforma CYP. Una de las causas de esta variación sería la existencia de polimorfismo genético, lo que produce variantes genéticas que difieren en su actividad para biotransformar xenobióticos. Se conocen alrededor de 50 enzimas de biotransformación polimórficas que varían entre individuos y en diferentes etnias. El polimorfismo más estudiado es el del CYP2D6, el que divide a la población en metabolizadores rápidos y lentos de Debrisoquina. Actualmente se sabe que más de 50 drogas, incluyendo antidepresivos, antipsicóticos y drogas cardiovasculares, son metabolizadas primariamente por el CYP2D6 (Orallena y Guajardo, 2004). 


\subsubsection{Farmacogenética de los CYP450}

El término farmacogenética se aplica al estudio de la contribución de las diferencias genéticas entre individuos, a la variabilidad en la respuesta a fármacos y, su objetivo es identificar la asociación entre la característica genética y una determinada respuesta. La farmacogenética basada en la constitución genética individual puede repercutir de forma importante en la reducción de las reacciones adversas y ofrece una oportunidad evidente, en terapias más eficaces. Esta respuesta variable se refiere habitualmente a la eficacia o a la toxicidad del fármaco y la característica genética suele ser polimórfica para un gen o un determinado locus, de los conocidos como SNP (Single Nucleotide Polymorphism, por sus siglas en ingles), que se distribuyen a lo largo del genoma (Lares y Trujillo, 2000).

Los efectos de estos polimorfismos se dividen en diversos tipos: "Silenciosos" (con efectos no funcionales), "mejorado" (incremento de la cantidad de enzima y/o su actividad) o "decreciente" (con menos cantidad de enzima o actividad). Respecto a estos, el polimorfismo decreciente probablemente produce la mayoría de los efectos clínicos relevantes, con varios alelos de cada uno de los CYP450, que muestra un polimorfismo decreciente. El resultado neto de cada una de las preponderancias de los polimorfismos es que poblaciones específicas, pueden tener frecuencias incrementadas de determinado alelo que puede mostrar diferentes respuestas ante los compuestos químicos, tanto en términos terapéuticos como en efectos tóxicos. Por lo tanto es importante considerar los efectos en la expresión de los alelos de cada uno de los CYP450 que determinan la respuesta total de la población ante la exposición a xenobióticos (Plant, 2003).

Los estudios poblacionales han revelado polimorfismos en los genes CYP, por lo que se ha hecho necesario distinguirlos con sufijos, así el alelo silvestre arbitrariamente escogido, se le nombra como *1 y por lo general representa la forma con la actividad enzimática más alta. Aunque hay que tener en cuenta que una actividad elevada podría reflejar la existencia de múltiples copias para un mismo gen (Ramírez, 2007).

Los estudios de farmacogenética tienen una utilidad clínica cuando se llega a un mejoramiento en la selección de la dosis para una determinad droga, y un resultado claramente ventajoso para el paciente, lo cual está necesariamente ligado a situaciones en las cuales la droga tiene un rango terapéutico muy estrecho (ventana de aplicación terapéutica estrecha), y por lo tanto errores en su aplicación conducen a efectos severos o a reacciones adversas; las fallas en el tratamiento de bloqueadores beta, cuya ventana terapéutica es muy amplia y tiene efectos menores, en contraposición la droga anticoagulante warfarina, algunos neurolépticos y los antidepresivos tricíclicos, tienen una ventana terapéutica estrecha y su sobredosis acarrea severos efectos adversos (Ramírez, 2007). En este caso la tipificación genética de los genes CYP puede acelerar el proceso de selección de las dosis correctas, y minimizar así los efectos adversos.

\subsubsection{Alteraciones de los CYP450 en ciertas patologías}

La actividad y la expresión de las diversas especies de CYP son profundamente alteradas en la enfermedad. Aunque la modulación de las diversas enzimas es especie-selectiva y define entre las diversas patologías, en general, los niveles de CYP hepáticos están deprimidos, causando un potencial deterioro del efecto y, en algunos 
casos, el aumento de la toxicidad de ciertas drogas. Existen en la actualidad evidencias que muestran que los CYP se encuentra alterados en modelo animales de diabetes, hipertensión y obesidad, sin embargo aun es escaso el conocimiento que se tiene al respecto, debido principalmente a que la expresión y actividad de los CYP están determinadas por: la especie, edad, dieta, estado hormonal y tratamiento con drogas; factores que dificultarían su estudio en humanos (Cheng y Morgan, 2001).

\subsubsection{Citocromo P450 y toxicidad}

Como se menciono al inicio, el objetivo de CYP450 y el resto de las enzimas implicadas en el metabolismo de xenobióticos, es transformar el sustrato en metabólitos más fácilmente excretables del organismo, durante estas reacciones de biotransformación el fármaco sufre cambios en la estructura química que no sólo lo convierte en una molécula más polar, sino que además lo inactivan y lo convierten en un metabólito sin actividad farmacológica e inocuo toxicológicamente hablando. Así acelerando su eliminación, sin embargo posteriormente se comprobó que la metabolización no desembocaba en un proceso totalmente inocuo y esta metabolización no es un sinónimo de inactivación, muchos ejemplos avalan que los xenobióticos se convierten en moléculas tóxicas tras su biotransformación. Esta desafortunada circunstancia se produce cuando los metabólitos formados son especies reactivas que interaccionan con elementos o procesos celulares.

Se forman radicales libres y otros metabolitos electrofílicos (epóxidos alifáticos o aromáticos, quinonamidas) capaces de modificar covalentemente macromoléculas o de producir interacciones no covalentes (estrés oxidativo). Los mecanismos de defensa celular tratarán de neutralizar el metabólito lo más rápidamente posible. Si la vida media de la especie reactiva es extremadamente corta sólo afectará a la propia enzima que lo ha generado produciendo la inactivación de la misma (inhibidores llamados sustratos suicidas de los CYP450) (Kentet al., 2001).

Si la vida del metabólito es un poco más larga podrá afectar a otras macromoléculas, pero será neutralizada antes de salir de la célula o del tejido donde se ha formado produciendo únicamente toxicidad local. Los metabólicos más estables pueden llegar a actuar sobre otros tejidos del organismo por lo que sus efectos tóxicos serán generalizados. En última instancia es el balance entre las reacciones de activación metabólica y los procesos de neutralización-eliminación (inactivación) el que determina la severidad y el alcance de la toxicidad. Este balance depende de diversos factores (polimorfismos genéticos, inducción, inhibición, factores dietéticos, interacciones entre fármacos etc.) pudiendo haber notables diferencias a nivel individual (González, 1998).

La bioactivación afecta tanto a fármacos como a otros xenobióticos. El ejemplo mejor conocido es el del paracetamol. Este fármaco puede ser metabolizado por enzimas de fase II con formación de conjugados con glucurónido o con sulfato, los cuales son fácilmente eliminados, o puede ser oxidado por el CYP450 (CYP1A2, CYP2E1, CYP3A4), se produce una quinonamina altamente reactiva capaz de interaccionar con las proteínas celulares. Los procesos de activación también conducen a la conversión de procarcinógenos en carcinógenos. Estas reacciones están catalizadas por diferentes CYP450, si bien los enzimas de la subfamilia CYP1A juegan un papel muy destacado por su capacidad de activar gran número de procarcinógenos procedentes de la combustión de diferentes hidrocarburos que pueden acceder al organismo (principalmente por inhalación) (Sheweita, 2000). 


\subsection{FASE I DEL METABOLISMO MEDIADA POR MONOOXIGENASAS DE FLAVÍN}

La mayor parte de la biotransformación de los xenobióticos, catalizada por los enzimas de la fase I, se verifica por las monooxigenasas microsómicas dependientes del citocromo P450, una gran superfamilia de hemo-proteínastiolato. Sin embargo, existe otra familia de monooxigenasas, las dependientes de Flavín (MOF), las cuales juegan también un importante papel en la salud y la enfermedad humanas (Zhao et al., 2001).

Las MOF fueron identificadas en microsomas de hígado porcino, hace más de treinta años por Daniel Ziegler y Carolyn Mitchell y desde entonces se han caracterizado en humanos, cerdos y conejos y se han descubierto hasta la fecha seis isoenzimas en varios órganos y tejidos (Cascales, 2001). Están asociadas a los microsomas de hepatocitos y estas catalizan la oxigenación de una amplia variedad de nitrógeno, azufre, fósforo, selenio, y otros productos químicos que contienen heteroatomos nucleofílicos, entre ellos muchos medicamentos o drogas; esto en coordinación con los citocromos P450. Las FMO también participan en la regulación de la biosíntesis de auxinas en las plantas (Ballou et al., 2005). Los sustratos que son oxidados por las MOF son compuestos nucleofílicos no cargados que sufren el ataque oxidativo sobre su átomo de Azufre (S) o Nitrógeno (N) (Plant, 2003).

Las MOF, son proteínas monoméricas con un nucleótido de FAD (Flavín Adenin Dinucleotido) y están localizadas en el retículo endoplásmico, por lo que se aíslan en la fracción microsomal (formaciones vesiculares submicroscópicas que se presentan formadas por membranas lipoprotéicas y granulaciones ricas en ácido ribonucleico, además de restos mitocondriales, el complejo de Golgi y otros elementos celulares) (Cascales, 2001; Plant, 2003). Tienen isoformas distintas en los tejidos diferentes (pulmón, riñón e hígado) e incluso dentro de un mismo tejido (Cashman, 1998; Cascales, 2001).

\subsubsection{Nomenclatura y estructura las monooxigenasas de flavín}

A diferencia de los CYP450 hay relativamente pocas enzimas del MOF; los seres humanos expresan solamente cinco enzimas MOF, y solamente tres en el hígado adulto en comparación con las enzimas CYP450. Debido a esto existe una nomenclatura muy simple, con las enzimas llamadas MOFx, donde $\mathrm{X}$ es el número de la enzima (actualmente 1-5) (Plant, 2003).

La nomenclatura se ha desarrollado sobre la base de la identidad de los nucleótidos. Si un gen humano MOF posee una secuencia con una identidad igual o mayor que $80 \%$, se agrupa dentro de una familia 1,2 , 3. Este orden se refiere a la cronología de la publicación de la secuencia para cada miembro de la familia (Cascales, 2001). FMO en cursiva se utiliza para designar el gen o una variante alélica. Las variantes alélicas han sido observadas para un MOF que generalmente posee cambios en una sola base.

Las MOF contienen una similitud menor al $50 \%$ en la secuencia de aminoácido aunados a estos otros genes segregan los complementos que le brindan su particularidad. Las familias ortólogas (con la misma función) requieren la identidad mayor del de $80 \%$ (Cascales, 2001). Usando esta nomenclatura, a las ortólogas se les dará el mismo nombre, que puede llevar a cierta confusión mientras que FMO1 puede referir a la enzima del conejo, del cerdo o del ser humano. 
Las MOF parece que han surgido de una familia ancestral de genes con seis tipos diferentes que comparten al menos un $52 \%$ de identidad en la secuencia de aminoácidos. Las diversas formas de FMO de humanos que se han identificado hasta la fecha, poseen entre 532 y 558 aminoácidos (Cashman, 1998). Una serie de residuos específicos de aminoácidos están conservados en todas las especies, en particular los aminoácidos 4 al 32 y 186 al 213, que contienen dominios muy conservados de unión al FAD- y al NADPH-, respectivamente. En general, la FMO es una enzima asociada a membrana, que se ha detectado en todos los tipos celulares secretores examinados (Cascales, 2001).

A finales del siglo pasado, en los noventa, se caracterizaron por clonaje del cDNA, la MOF2 y la MOF3 de hígado humano adulto $(0.5 \%$ de las proteínas microsomales). Posteriormente, se ha conseguido caracterizar un total de cinco isoenzimas funcionales y cinco isoformas que comprenden cinco familias de genes de un miembro cada una (Cashman, 1998). Algunos autores se refieren a una isoforma más, la MOF6, pero estudios recientes sugieren que el gen MOF6 no codifica una MOF funcional (Cascales, 2001). Estas cinco isoformas de las MOF, están codificadas por un gen distinto localizado en el brazo largo del cromosoma 1. La familia MOF se considera aún más versátil que la familia CYP, característica parcialmente atribuible al mecanismo catalítico único de las MOF.

Los cinco genes MOF de mamíferos poseen diferente expresión tisular y regulación. Las MOF poseen una distinta especificidad por una amplia variedad de sustratos. En humanos la FMO3 es la principal isoforma responsable del aclaramiento hepático de una gran cantidad de fármacos. La variación interindividual que aparece en el metabolismo de fármacos mediada por la MOF se debe probablemente a efectos genéticos y no a efectos ambientales (Cascales, 2001).

La expresión de las diferentes isoformas de MOF es específica de tejido y especie y puede resultar afectada por esteroides e influenciada por variabilidad genética. A pesar del impacto que la expresión diferencial ejerce sobre la eficacia de la terapéutica selectiva y la susceptibilidad toxicológica, es poco lo que se sabe de los mecanismos que regulan la expresión de las MOF (Cashman, 1998).

En humanos los genes FMO1, 2, 3, y 4 se localizan en un solo grupo de $257 \mathrm{Kpb}$ en el cromosoma 1 en los loci 1q23-25. El MOF5 se localiza en la región 1q21. Un sexto miembro putativo de esta familia genética, el MOF6, se ha identificado como parte del proyecto del genoma humano, pero estudios recientes sugieren que este gen no codifica una MOF funcional debido a muchos eventos alternativos en su procesamiento. La proteína codificada por el gen MOF6 ha revelado que esta proteína comparte el 70\% de identidad en la secuencia de aminoácidos con la MOF3. Sin embargo, aún no se ha encontrado una función para esta proteína (Cascales, 2001).

\subsubsection{Regulación de la expresión de las MOFs}

Una serie de investigaciones sobre la familia MOF de mamíferos han estudiado los mecanismos catalíticos y la especificidad del sustrato, la estructura y variabilidad genética y el modelo de expresión. La regulación de la transcripción contribuye significativamente a la capacidad metabólica específica del tejido y de las especies, como también a la diferente susceptibilidad a agentes tóxicos terapéuticos y ambientales (Cascales, 2001; Plant, 2003).

Estas enzimas se expresan en elevadas concentraciones en diversos tejidos y en todas las especies animales examinadas. En humanos se han detectado variaciones de hasta 10 veces en la actividad interindividual de las 
MOF. Sin embargo, al contrario que las monooxigenasas CYP, cuya variación interindividual puede ser debida a diferente exposición ambiental, la expresión de los genes MOF no se encuentra aparentemente afectada por agentes exógenos. La expresión de las diferentes isoformas MOF es selectiva del tejido y de la especie y puede estar influenciada por esteroides endógenos y también por variabilidad genética (Zhao et al., 2001).

Se ha identificado un elemento YY1 Inr en el interior del promotor principal del gen MOF1 de conejo, y se han obtenido evidencias que demuestran que este factor de transcripción no es indispensable para la expresión basal del MOF, el dominio que contiene el factor HNF1 (Factor Nuclear Hepático 1), el factor nuclear HNF4 y la proteína dedo de zinc YY1, tienen papeles importantes en el control de la expresión del MOF1 de conejo (Cascales, 2001).

Correspondiendo a los dominios reguladores previamente descritos, se ha identificado un sitio de enlace YY1 en el promotor principal del MOF1 de conejo (posición -8 a -2), dos sitios HNF1 que se solapan (posición -132 a -105), y dos sitios HNF4 (posición -467 a -454 y -195a-182). Estudios de cotransfección con vectores de expresión HNF1y HNF4, han demostrado que cada uno de estos factores juega un papel importante intensificando la actividad del promotor del MOF (Cascales, 2001). Por el contrario, se ha observado que YY1 no era indispensable para la actividad basal del promotor, sino que suprimía la capacidad de los dominios anteriores a dicho promotor. En contraste con los HNF, YYI se encuentra ubicuamente expresado, Además, este miembro conservado de la familia de dedos de zinc, participa en regulación positiva o negativa de un gran número de genes. La mayoría de los elementos reguladores YY1 están distantes al promotor sirviendo como intensificadores o silenciadores de la actividad basal del promotor.

Estos mismos autores han comparado el MOF1 de conejo y de humano y han demostrado que los elementos reguladores de la transcripción están muy conservados. Con excepción del sitio más lejano del HNF4, cada una de las secuencias ortólogas humanas fue capaz de competir con los elementos cis, de unión específica de las proteínas, en el MOF1 de conejo (Cascales, 2001; Plant, 2003).

Estos resultados no ofrecen demasiadas evidencias de las diferencias interespecies que controla la expresión del MOF1. La expresión del FMO1 es indetectable en hígado humano adulto, es la expresión del FMO3 la predominante, mientras que en hígado fetal humano es la del MOF1 la que predomina. Dado el papel reconocido del HNF1 y el HNF4 en el desarrollo, ambos factores pueden jugar papeles importantes en la expresión del MOF1 en hígado fetal humano. Sin embargo, dado el grado de conservación entre los genes MOF1 humanos y de conejo, no es probable que estos factores reguladores sean críticos para la desviación hacia la expresión del MOF3 observadas en hígado humano adulto (Cascales, 2001).

\subsubsection{Polimorfismos genéticos de las MOFs}

El interés terapéutico de la farmacogenética es cada vez mayor, ya que se ha descubierto una serie de polimorfismos genéticos en los enzimas de la fase I y de la fase II del metabolismo de fármacos. En muchos casos la expresión de alelos variables con capacidad metabólica aumentada o disminuida, se relaciona con factores étnicos. La expresión polimórfica puede ejercer profundos efectos en la eficacia y toxicidad de los medicamentos y en la susceptibilidad a enfermedades inducidas por xenobióticos (Cascales, 2001; Plant, 2003). 
Hasta el momento se han detectado polimorfismos genéticos en dos familias, las MOF2 y MOF3. En el caso de la MOF3 se han observado una serie de alelos mutantes, alguno de los cuales juega un papel importante en la etiología de la trimetilaminuria. Además de actuar como agente causal de esta enfermedad, los pacientes muestran alteraciones en el metabolismo de los medicamentos que utilizan selectivamente a la MOF3 como ruta principal de detoxificación y bioactivación (Reid et al., 2004). Es un hecho conocido que estos pacientes tienen alterado el aclaramiento de la nicotina y de los antidepresivos tricíclicos (Peña et al., 2004).

Ya se ha comentado anteriormente que existen al menos cinco formas de MOF de mamíferos, algunas de ellas pueden estar presentes en muchos tejidos del mismo organismo. En humanos existe considerable variabilidad interindividual e interétnica en los niveles de MOF. Las cinco isoformas de MOF humana están, cada una de ellas, codificada por su propio gen, que exhibe identidad del 48 al 58\% de aminoácidos a través de las especies, que es consistente con la evolución de esta familia génica. Por el contrario la identidad de las formas ortólogas oscila entre el 76 y el 86\%, sugiriéndose un elevado grado de conservación (Cascales, 2001; Plant, 2003). La descripción de las diferentes formas de las MOF se ha conseguido al conocer la secuencia primaria de los aminoácidos que las componen y de los nucleótidos que se presentan en los genes que las codifican.

En cuanto a polimorfismos de la familia MOF, se han identificado variaciones en la secuencia para los genes HNF1y HNF4, alguno de los cuales representan claramente alelos raros, mientras que otros representan polimorfismos (Ballou et al., 2005). El interés en estas variantes es cada vez mayor, al haberse detectado algunas mutaciones en estos genes en casos de diabetes, y que las mutaciones que conllevan a la pérdida de la función del HNF4, que también participa en la expresión de genes implicados en el transporte y metabolismo de la glucosa (Orf y Dolphin, 1974). Las mutaciones identificadas en individuos con fenotipos extremadamente raros no pueden ser típicas de la variación genética de la población. Para determinar si la variación de un gen contribuye a un mayor riesgo de la enfermedad, ha de evaluarse con anterioridad la cantidad y organización de la variación genética en individuos de la población.

Es probable que muchas variaciones genéticas comunes (el alelo frecuentemente mayor al 1\% en la población general, o polimormismo), que tengan efectos menores, se combinen para determinar la fracción principal de variación, en la susceptibilidad a enfermedad humana en la población total. Previos estudios han examinado la prevalencia de los polimorfismos más prominentes del MOF3 humano en poblaciones de canadienses, franceses, australianos caucásicos, europeos y asiáticos. Actualmente existen estudios sobre las frecuencias relativas de sitios sencillos o múltiples en las configuraciones alélicas, haplotipos y genotipos de los tres polimorfismos principales comunes del MOF3 humano en muestras de caucásicos no hispanos, americanos africanos, asiáticos e hispanos (Orf y Dolphin, 1974; Reid et al., 2004).

Existe una considerable variabilidad interindividual en la actividad de la MOF3 microsómica de humano adulto (7 veces variable en la $\mathbf{N}$-oxidación de aminas y, 3 veces variable en la $\mathbf{S}$-oxidación de sulfuros). Como la MOF 3 humana no se induce aparentemente por administración de agentes químicos o fármacos, las diferencias tienen que ser debidas a efectos genéticos y no a efectos ambientales. El gen MOF3 no es el único gen que posee variaciones genéticas significativas. Hasta la fecha se han observado variaciones en el DNA genómico de todos los genes MOF. Por ejemplo los genes MOF1, MOF2, MOF3, MOF4 y MOF5 tienen 34, 57, 40, 30 y 40 variantes en la secuencia del cromosoma 1 humano. No se sabe si esta heterogeneidad genética predispone al metabolismo anormal o adverso de fármacos, predominantemente por el MOF3, pero esta posibilidad existe y se conoce solo la relacionada con la trimetilaminuria (Cascales, 2001; Reid et al., 2004). 
Los individuos con la condición recesiva a trimetilaminuria muestran variación en el metabolismo de desintoxicación de xenobióticos por flavínmonooxigenasa hepática. Las mutaciones en el ser humano del gen de la isoforma 3 (MOF3) de la flavín monooxigenasa, perjudican $\mathrm{N}$-oxidación de xenobióticos y es responsable del fenotipo trimetilaminuria (TMAuria). La TMAuria es un trastorno recesivo autosómico. En el catabolismo de la colina se produce la trimetilamina (TMA) (maloliente y volátil) que deriva de la N-óxido-trimetilamina con la actuación de la MOF3 (Treacy et al., 1998).

Los individuos con TMAuria han disminuido la capacidad para oxidar los productos derivados de aminas TMA a su metabólito inodoro TMA N-óxido (TMANO) y por lo tanto excretan cantidades relativamente grandes de la TMA en la orina, el sudor y la respiración, sufren de el síndrome del olor a pescado (Figura 2.4) (Treacy et al., 1998).

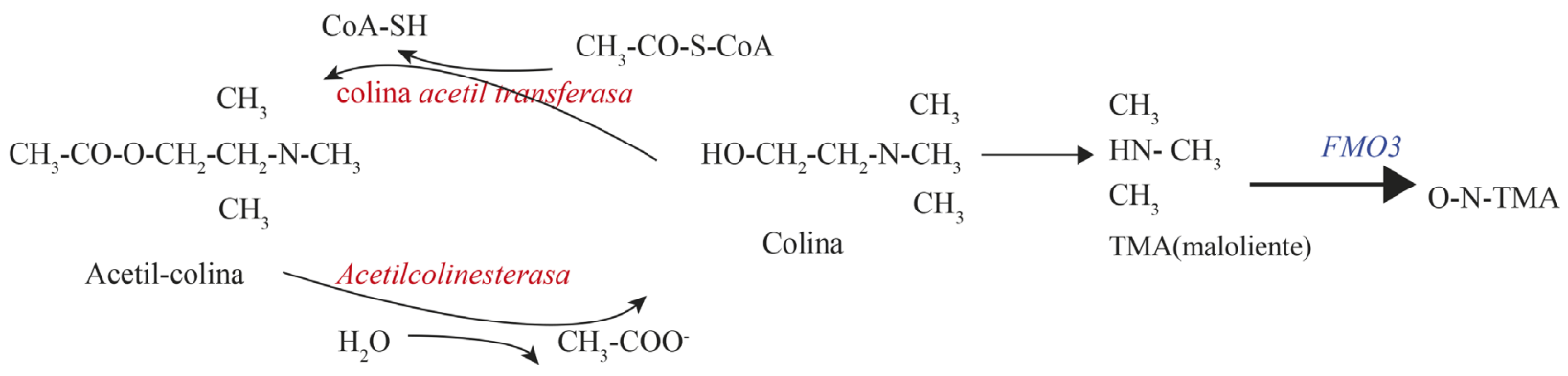

Figura 2.4. Toxicidad mediada por la MOF3 de la TMAuria (Treacy et al., 1998).

\subsubsection{Ciclo catalítico de las monooxigenasas de flavín}

El ciclo catalítico de MOF es similar a la de las enzimas del CYP450:

$$
\mathrm{RH}+\mathrm{NADPH}+\mathrm{H}^{+}+\mathrm{O}_{2} \longrightarrow \mathrm{R}-\mathrm{OH}+\mathrm{NADP}++\mathrm{H}_{2} \mathrm{O}
$$

Donde $\mathrm{R}=$ el resto de la estructura química del sustrato.

Su mecanismo de acción catalítico es singular, son enzimas que poseen como coenzima flavín-adenosin dinucleótido (FAD) y son capaces de utilizar directamente NADPH como cofactor para reducir uno de los dos átomos de oxígeno; a diferencia de los citocromos P450, la interacción del xenobiótico con la enzima es mucho más laxa. La oxidación se produce a través de un intermedio reactivo oxidante generado en el mismo centro catalítico de la enzima (Hidroperoxi-Flavín Monooxigenasa) que oxida al fármaco (Plant, 2003). 
Una diferencia entre las reacciones catalizadas por CYP450 y MOF es que las reacciones catalizadas por MOF tienen especificidad cada vez mayor hacia N- y S- como centro de reacción. Más allá de esto, sin embargo hay dos diferencias mayores entre los dos ciclos catalíticos. Primeramente el núcleo de MOFs es una molécula de Flavín a diferencia del Hemo en los CYP. Sin embargo, ambas mitades actúan como receptores de electrones desde el NADPH así como la interacción con el oxígeno molecular y el substrato. En segundo lugar, mientras que el efecto neto de los dos ciclos catalíticos es el mismo, el orden de las reacciones dentro de los ciclos es diferente (Cashman, 1995; Zhao et al., 2001). La Figura 2.5 muestra el ciclo catalítico completo de la MOF, que puede dividirse en cuatro reacciones separadas para su mejor comprensión:

1.- Inicialmente toda la flavoproteína oxidada es reducida usando NADPH.

2.- La adición de oxigeno molecular produce un intermediario hidroperóxidoflavin lo que forma una especie de oxigenación muy potente, y cualquier nucleofílo que pueda ser oxidado por un peróxido orgánico puede ser un potencial sustrato de este derivado en las MOF.

3.- La adición del sustrato al complejo hidroperóxidoflavin es el último paso antes de su oxigenación. La oxidación del sustrato ocurre más rápido que la regeneración de la enzima activa, siendo en esta última reactivación el paso limitante, la velocidad. Este intermediario hidroperóxido flavin es abierto por los ataques neutrofilicos de substratos en el átomo de oxígeno terminal, y se libera un metabólito oxigenado.

4.- Por último, el agua se libera y la flavoproteína totalmente oxidada puede ser regenerada.

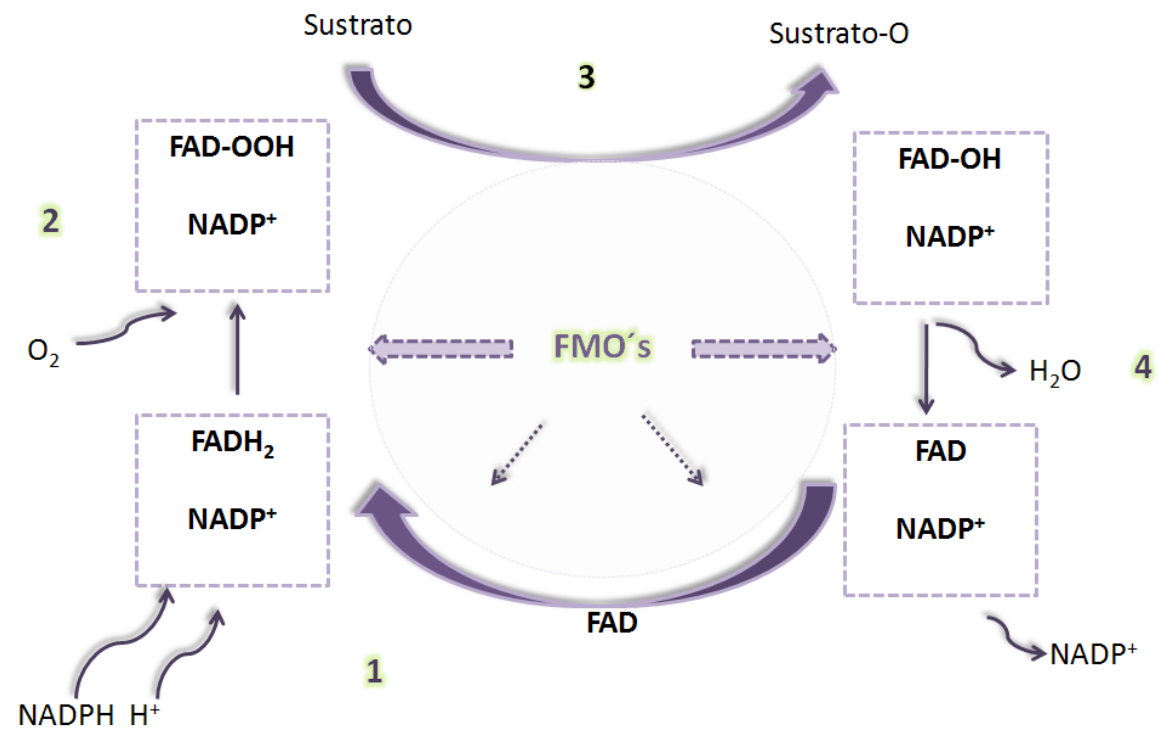

Figura 2.5. Ciclo catalítico de las MOFs (Modificado de Plant, 2003).

Por lo tanto, puede verse que en el ciclo catalítico de las MOF, la reducción inicial de la fracción del flavín se produce antes de la unión del sustrato, mientras que estos pasos se han invertido en el ciclo catalítico de los CYP. 


\subsubsection{Toxicidad mediada por MOFs}

Son enzimas que actúan en la oxidación de xenobióticos orgánicos que contienen heteroatomos ( $\boldsymbol{N}, \boldsymbol{S}$, y $\boldsymbol{P})$. Los sustratos que son oxidados por las MOF son compuestos nucleofílicos (donadores de electrones) suaves y sufren el ataque oxidativo sobre su heteroatomos de $\mathbf{S}$ o de $\mathbf{N}$, nunca son compuestos orgánicos con carga (Smart y Hogson 2008).

La actividad de las MOF no es variable por inhibición o por inducción como ocurre con los CYP450, ambos conjuntos de enzimas están sometidos a controles reguladores diferentes. Los efectos de los xenobióticos sobre la contribución relativa de las dos actividades biotransformadoras: MOF y de los CYP450 aparecen en primer lugar por las variaciones del CYP, ya que las MOF no son inducibles; aunque si son alteradas por factores como la nutrición, embarazo, corticosteroides y varían en relación a diferentes órganos y especies (Ballou et al., 2005).

Las diferencias específicas en la expresión de los conjuntos enzimáticos del CYP450 y de las MOF determinan las diferentes toxicidades de los compuestos para cada una de las especies. Es cierto que existen menos ejemplos de toxicidad mediada por MOF que de los mediados por los CYP y en general el metabolismo mediado por MOF está asociado a procesos de desintoxicación. De hecho, se ha planteado la hipótesis de que la evolución se ha visto obligada a producir las enzimas MOF que metabolizan de forma segura los sustratos que de lo contrario daría lugar a metabolitos tóxicos o auto-inhibidores metabolizados por CYP450 (Treacy et al., 1998).

Sin embargo, algunos ejemplos de sustratos (Tabla 2.2) metabolizados mediante MOF pueden resultar en toxicidad que no existía, incluyendo el metabolismo mediado por MOF de compuestos que contienen tiona (pigmento a base de rutilio, dióxido de titanio, etc.). Los tíocarbamatos se encuentran en muchos medicamentos terapéuticos, agroquímicos y productos químicos industriales. La tíourea es la estructura básica de muchos de estos tíocarbamatos y se ha demostrado, que es causa de tumores en la glándula tiroides y del hígado en ratas. Además, los metabólitos de tíourea han demostrado causar edema pulmonar. Debido al alto potencial de exposición humana a estos compuestos, existe la necesidad de comprender los mecanismos moleculares de estas reacciones tóxicas con el fin de formular correctamente las evaluaciones de riesgo de exposición humana (Plant, 2003).

Se han realizado estudios de la enzima aislada MOF implicada en la S-oxidación inicial del grupo tíocarbonil de tíourea. Para estudiar más a fondo esta reacción Smith y Crespi (2002), evaluaron mediante la ingeniería de células embrionarias de ratón C3H10T1/2, donde se expresaron MOF humanos, la respuesta de la exposición de tíourea. Las células con altos niveles de FMOs humanos mostraron un incremento de susceptibilidad a la toxicidad inducida por la tíourea, lo que sugería que la MOF fue fundamental para la toxicidad mediada por tíourea. Los experimentos con células que expresan niveles más bajos de los MOF produjo una visión más extensa en el mecanismo de la toxicidad, la que se observó solamente cuando se agoto el glutatión (Plant, 2003).

Así, como ya se ha visto con la toxicidad del paracetamol, la producción de un metabólito tóxico no es el único factor para determinar si se ve una reacción tóxica, la velocidad de su eliminación también es importante. En situaciones en que el glutatión se agota, se produce la acumulación de metabólitos tóxicos, dando lugar a una respuesta tóxica. La vía de metabolismo propuesta para la tíourea se muestra en la Figura. 2.6 (Plant, 2003). 
Tabla 2.2. Tipos de sustratos de las MOFs.

\begin{tabular}{|c|c|c|}
\hline Reacción & Tipos de Sustratos & Ejemplos de sustratos \\
\hline $\begin{array}{l}N \text {-oxidación } \\
\text { S-oxidación } \\
P \text {-oxidación } \\
\text { Desulfuración } \\
\text { Oxidación de iones }\end{array}$ & $\begin{array}{l}\text {-Tioles naturales } \\
\text {-Aminas primarias y cíclicas, } \\
\text { Hidracinas } \\
\text {-Tioles y disulfuros } \\
\text {-Fosfinas, Fosfatos } \\
\text {-Ac. Ditio y Ditíocarbamidas } \\
\text {-lones }\end{array}$ & $\begin{array}{l}\text {-Cisteamina } \\
\text {-Nicotina, dimetil-anilina } \\
\text {---'- } \\
\text {-Tíobenzamida, Forato, Tíourea } \\
\text {-Dietil-fenil-fosfina } \\
\text {-Forofos } \\
\text {-HS-, I', Ol-, CNS- }\end{array}$ \\
\hline
\end{tabular}

(Modificada de Plant, 2003).

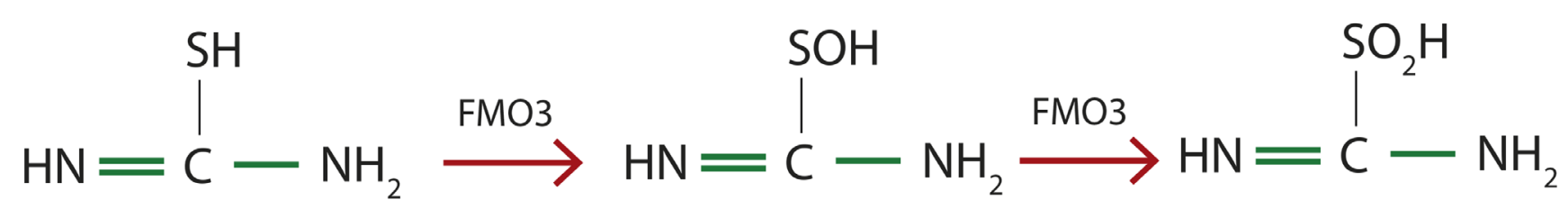

- Tiourea

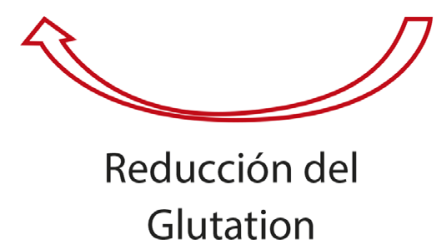

Figura 2.6. Metabolismo de la Tíourea (Modificado de Plant, 2003).

Las MOF juegan un papel importante en la biotransformación de xenobióticos en humanos. La FMO principal en hígado es la MOF3, encargada de convertir la $\mathbf{S}$-nicotina en $\mathbf{N}$-oxido, la $\mathbf{S}$-nicotina produce solo el isómero trans, este producto es el que aparece en la orina de fumadores. En otras especies donde la enzima es MOF1, aparecen en la orina, los dos isómeros (cis y trans) de la S-nicotina; la presencia de estos metabolitos en orina pueden indicar cuál es la isoenzima presente en el tejido u organismo (Furnes y Schlenk, 2004).

Existe una gran variedad de sustratos que catalizan las MOF (Tabla 4); sin embargo uno de los principales sustratos endógenos de estas, es la cisteamina, que se oxida a cistamina por formación de un puente disulfuro. La cisteamina es un intercambiador de puentes disulfuro que participa en la formación de este tipo de enlaces durante la síntesis de péptidos o en la renaturalización de las proteínas. 


\subsection{TOXICIDAD MEDIADA POR OTRAS ENZIMAS FASE I.}

Mientras que la mayor parte de la activación metabólica de compuestos a toxinas en Fase I, son debidos a reacciones de oxidación, mediadas ya sea por los CYP o las FMO, también hay otras enzimas que participan en estas reacciones y son responsables de igual forma de su detoxificación y de reacciones de toxicidad.

\subsubsection{Toxicidad mediada por $\mathbf{P 4 5 0}$ reductasa}

La reductasa P450 fue descubierta antes del mismo CYP450. En 1950 Horecker identificó una enzima microsomal hepática que catalizó la reducción de citocromo P450 $\left(\mathrm{Fe}^{3+}\right.$ a $\left.\mathrm{Fe}^{2+}\right)$ por NADPH. La actividad fue detectada monitoreando el cambio en el espectro de absorbancia del citocromo P450. Horecker nombró a la nueva enzima NADPH citocromo c reductasa, reflejando el método ensayado. En los sesentas, siguiendo el trabajo de Omura y Sato observaron que el substrato fisiológico es el citocromo P450 y la enzima fue renombrada como NADPHcitocromo P450 reductasa (u oxidoreductasa) (Wang et al., 1997; Pearson yWienkers, 2009).

La mayoría de las enzimas que biotransforman los fármacos, están en las membranas del retículo endoplásmico liso y son responsables de la detoxificación. La función microsómica actúa en forma combinada con el sistema de las oxidasas. Para que se lleven a cabo las oxidaciones en los microsomas debe haber un agente reductor (NADPH), citocromo P450, oxidoreductasa ú oxígeno molecular (Miwa et al., 1979; Devlin, 2004;).

\subsubsection{Funciones}

En el retículo endoplásmico el NADPH dona electrones a la flavoproteína denominada NADPH-citocromo P450 reductasa. La enzima tiene una masa molecular de $76558 \mathrm{KDa}$ y contiene como grupos prostéticos tanto la flavín adenina dinucleótico (FAD), como la flavín mononucleótido (FMN). Hasta la reciente caracterización de las óxido nítrico sintasas, era la única flovoproteína de mamífero conocida que contenía a la vez los grupos FAD y FMN. Un número significativo de los residuos situados en el extremo amino de la molécula son hidrofóbicos, y esta parte de la molécula esta incrustada en la membrana del retículo endoplásmico (Figura 2.7). EI FAD sirve como punto de entrada de electrones desde el NADPH, y el FMN le sirve como punto de salida, transfiriendo electrones individualmente al citocromo P450. Ya que la molécula de flavín puede existir en su forma reducida con 1 o 2 electrones, se unen dos moléculas de flavín por molécula de reductasa, la enzima puede recibir electrones de NADPH y almacenarlos entre las dos moléculas de flavín antes de transferirlos individualmente al citocromo P450. La NADPH citocromo P450-reductasa es la única proteína accesoria requerida para el restablecimiento de la actividad de la CYP450 en un sistema puro (Miwa et al., 1979; Wang et al., 1997; Dongtao et al., 1999; Shimada et al., 2000; Orellana y Guajardo, 2004). El cerebro es donde la CYP450-reductasa parece jugar un papel muy importante en la toxicidad. 


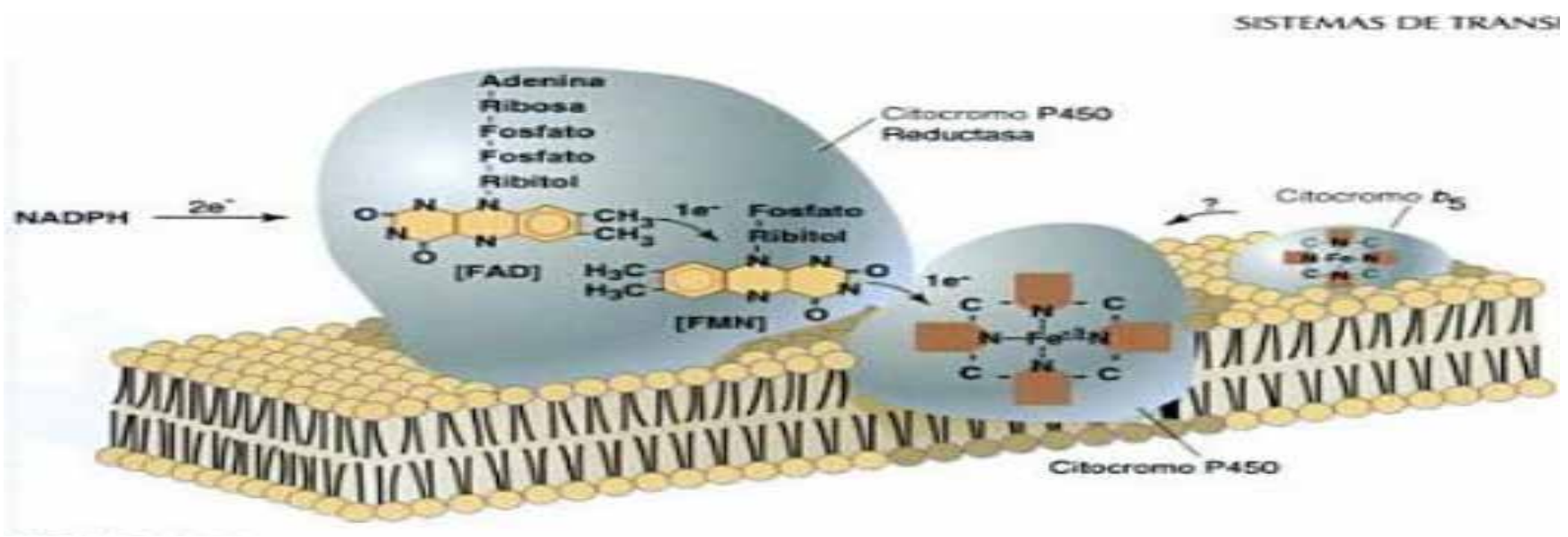

Figura 2.7. Componentes del Citocromo P450 (Miwa et al., 1979; Devlin, 2004).

El cerebro tiene un número importante de neurotransmisores, uno de los cuales es la dopamina. Este químico transmite señales entre neuronas y sus procesos de información en el cerebro. La neurotransmisión mediada por dopamina es de gran interés ya que parece estar relacionado con el desorden mental de esquizofrenia; en el cerebro la dopamina es metabolizada por la prostaglandina $\mathbf{H}$ sintetasa a dopamina quinina, que luego se convierte a aminocromo. El aminocromo es metabolizado por P450-reductasa en una reducción sencilla de electrones produciendo dopamina-o-semiquinona; o por DT-diaforasa en una reducción de dos electrones produciendo dopamina-o-hidroquinona (Figura 2.8). Ambas semiquinona e hidroquinona son inestables y pueden auto-oxidarse para reformar aminocromo, convirtiendo oxígeno molecular a radicales superóxido en el proceso (Plant, 2003).

\subsubsection{Toxicidad mediada por Citocromo b5}

El citocromo b5 (Figura 2.9) fue originalmente descubierto en larvas de gusano de seda, desde entonces ha sido estudiado ampliamente en mamíferos. Como el citocromo P450, el citocromo b5 es una proteína de membrana integral, situada en el lado citosólico del retículo endoplásmico, donde esta principalmente involucrada en la biosíntesis de lípidos. Ésta funciona junto con el citocromo b5 reductasa (Figura 2.10) como el donador de electrones para la fracción microsomal, para sintetizar los ácidos grasos insaturados (Aoyama et al., 1990; Duarte et al., 2005). 


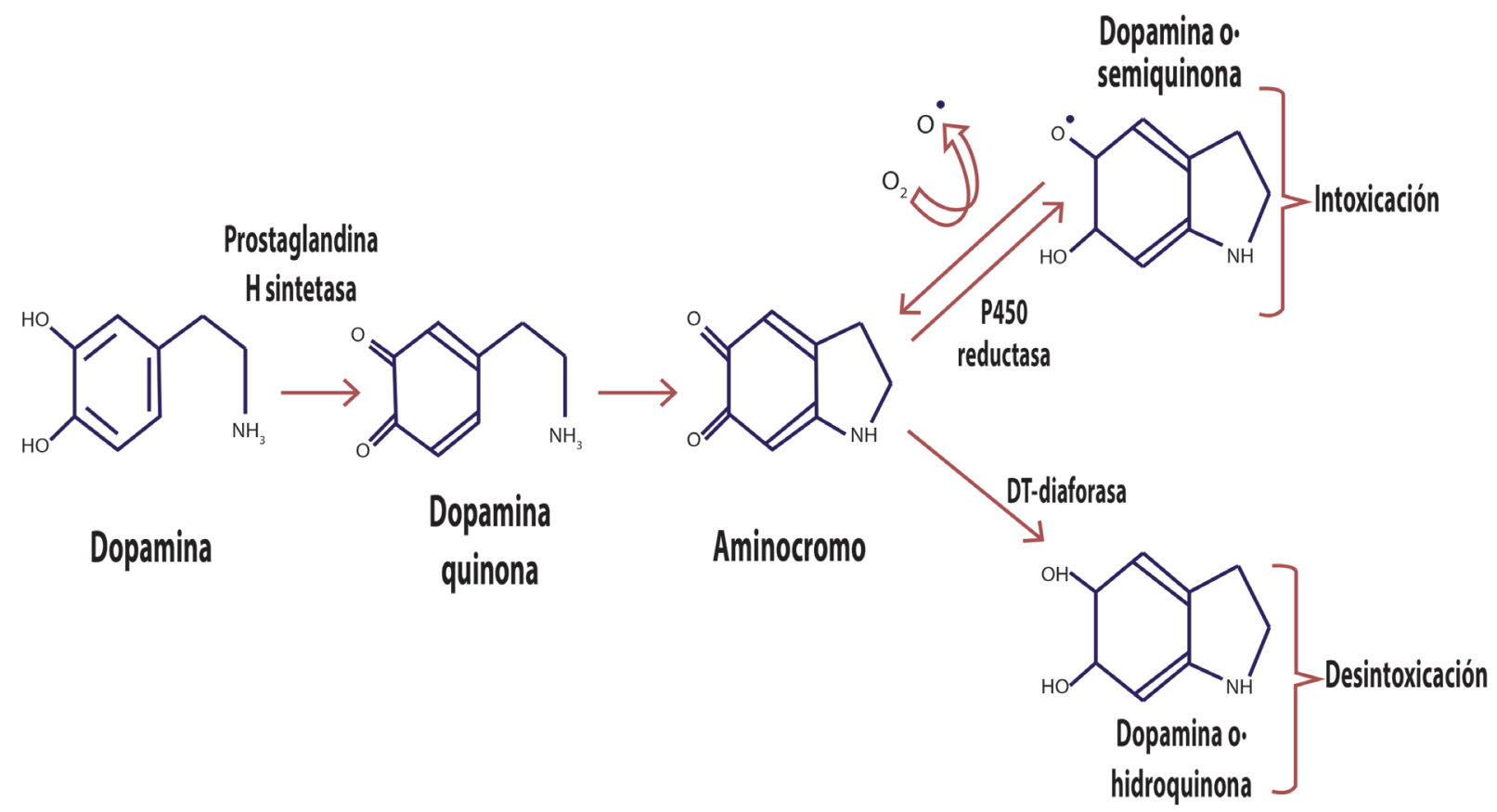

Figura 2.8. Metabolismo de la Dopamina (Modificado de Plant, 2003).

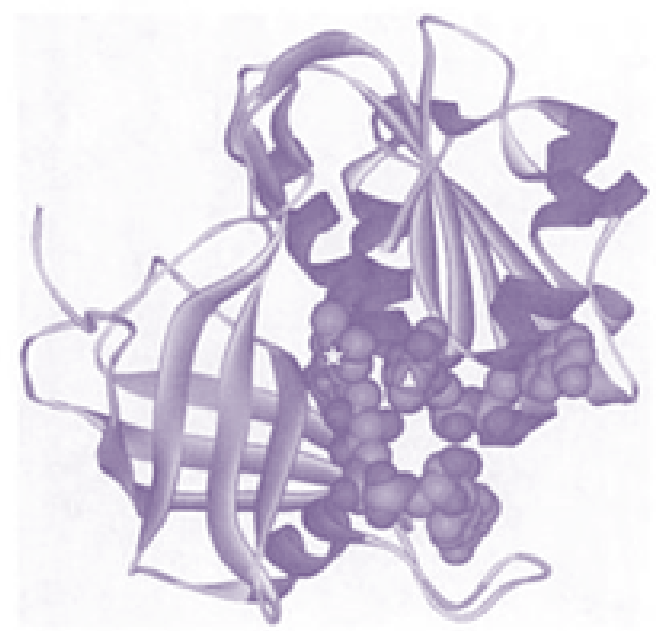

Figura 2.9. Citocromo b5.

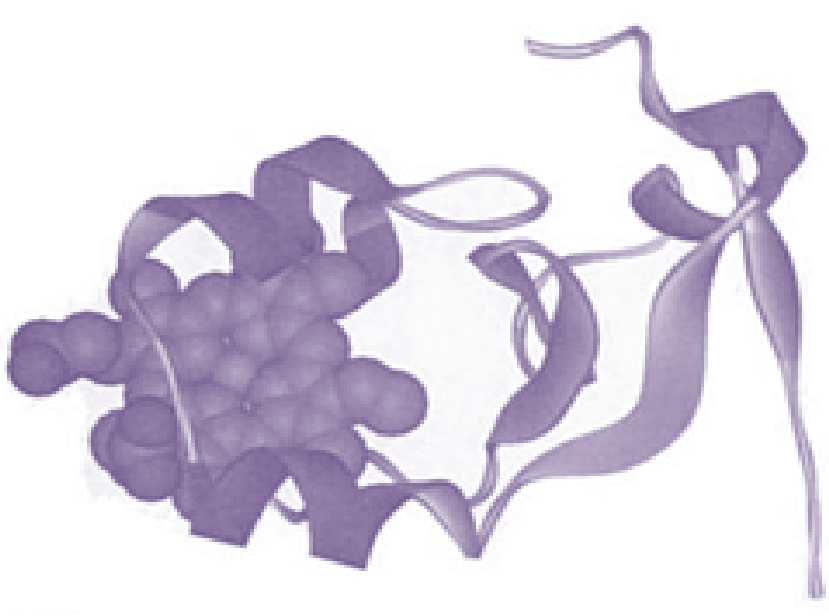

Figura 2.10. Citocromo b5 Reductasa. 
El citocromo b5 es un polipéptido pequeño de 134 residuos de aminoácidos, que se dividen dentro de un dominio hidrofílico hemo-amino-terminal y una región de membrana-vinculante hidrofílica carboxilo-terminal; mientras la forma de membrana-límite del b5 participa en la elongación y desaturación de ácidos grasos, biosíntesis de colesterol y en el metabolismo de fármacos; las otras formas solubles de b5 y b5 reductasa también se encuentran en los eritrocitos donde catalizan la reducción de la metahemoglobina (Duarte et al., 2005).

Las mutaciones en el cromosoma o el gen que codifica al citocromo b5 también pueden causar metahemoglobinemia congénita. Este hallazgo demuestra que el citocromo b5 sí se requiere para una reducción efectiva de metahemoglobina. Las mutaciones en el citocromo b5 son mucho menos frecuentes que las mutaciones en el citocromo b5 reductasa, porque estas tienden a ser letales.

Otra de las funciones del citocromo b5 está involucrado en el 88\% de la reducción del cromo en donde se ha visto que fracciones en hígado humano contienen tanto P450 reductasa como citocromo b5, lo cual sugiere participación de ambas proteínas en la reducción del cromo (Fig. 2.11) (Plant, 2003).

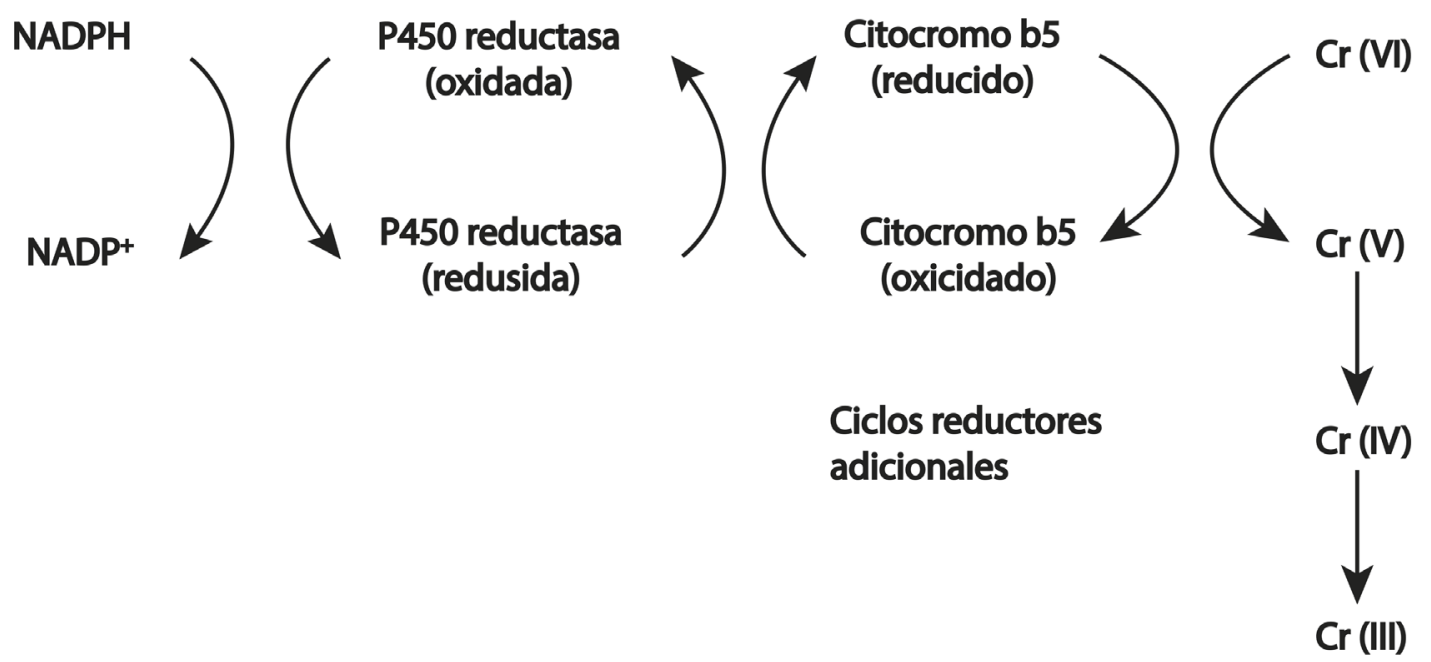

Figura 2.11. Reducción de Cromo por Citocromo b5 (Modificado de Plant, 2003).

\subsubsection{Toxicidad mediada por Prostaglandina Sintetasa}

La prosglandina H sintetasa es, como los CYPs una hemoproteína, enzima clave en la biosíntesis de prostanoides. Los prostanoides (prostaglandinas, prostaciclinas y tromboxanos) son importantes moduladores en muchos procesos fisiológicos a través de su habilidad para modular la actividad de otras hormonas, además de estar involucrada en la contracción de musculo liso uterino durante el parto, activación o inhibición de la respuesta inmune, reacciones de inflamación, la cicatrización de heridas, en la biología reproductiva femenina (luteinización, ovulación y parto son todos modulados por modificaciones en la producción de prostaglandinas), desarrollo óseo, filtración glomerular y el balance de agua y la homeostasis. Las Alteraciones en la producción 
de prostaglandinas ha sido asociada con la artritis, asma, enfermedad cardiovascular, inmunosupresión, ulceras gástricas y cáncer (Herschman, 1994; Plant, 2003).

La prostaglandina $\mathrm{H}$ sintetasa tiene dos distintas actividades químicas, como ciclo-oxígenasa y como función hidroperoxidasa, que neutraliza el ácido araquidónico primero por la prostaglandina $G_{2}$ y después por la prostaglandina $\mathrm{H}_{2}$ (Figura 2.12). Durante este paso ocurre una reacción de co-oxidación y además la activación metabólica de ciertos compuestos, como es el paracetamol, que puede ocurrir por una ruta mediada por radicales (Plant, 2003; Helliwell et al., 2004).

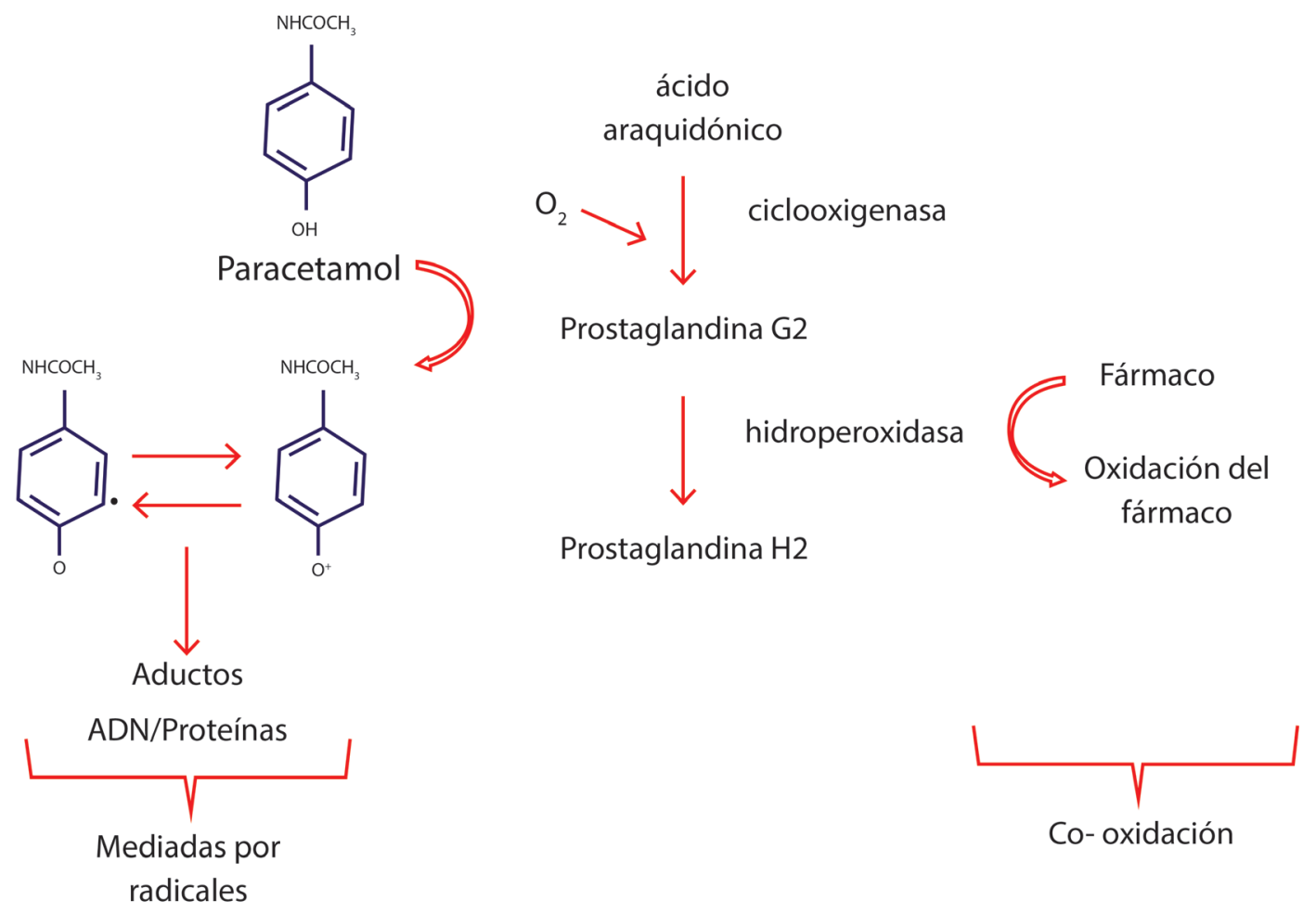

Figura 2.12. Conversión del Ácido Araquidónico por la Prostaglandina H sintetasa (Modificado de Plant, 2003).

Se ha supuesto que el paso limitante en la síntesis inducida por el ligando de las prostaglandinas es la liberación de ácido araquidónico en la membrana de fosfolípidos como consecuencia de la activación de la fosfolipasa. Se daba por supuesto que el ácido araquidónico se convierte en PGH2 por la prostaglandina sintasa constitutiva EC1.14.99.1 ciclooxigenasa (PGS-1) enzima presente en las células. Sin embargo, un segundo gen de la prostaglandina sintetasa, PGS-2 ha sido recientemente descrito. El gen PGS-2 es inducido por una variedad de ligandos, en células tan diversas como los fibroblastos, los monocitos, macrófagos, células musculares lisas, células de la granulosa del ovario, las células epiteliales, células endoteliales y neuronas. Por otra parte, la inducción de PGS- 
2 se inhibe en casi todos los contextos por los glucocorticoides. Parece probable, por tanto, que la regulación en la expresión de PGS-2 juega un papel crítico en la producción de prostanoides, tanto en procesos fisiológicos normales y en los procesos fisiopatológicos que afecten a estos mediadores parácrinos (Herschman, 1994).

\section{REFERENCIAS BIBLIOGRÁFICAS}

Aoyama T., Nagata K., Yamazoe Y., Kato R., Matsunaga E., Gelboin H., Gonzalez F. (1990) Cytochrome b5 potentiation of cytochrome P-450 catalytic activity demostrated by a vaccinia virus-mediated in situ reconstitution system. Proc. Natl. Acad. Sc. USA 87, 5425-5429.

Ballou D., Entsch B., Cole L. (2005) Dynamics involved in catalysis by single-component and two component flavindependent aromatic hydroxilases. Biochemical and Biophysical Research Communications 338, 590-598.

Calabuig G. (2005) Medicina Legal y Toxicología. $5^{\mathrm{a}}$ ed. Editorial MASSON S.A., Barcelona, pp. 718

Cascales M (2001) Monooxigenasas microsómicas de función mixta. En: Mecanismos de hepatotoxicidad Real Academia de Doctores, Marid ISBN 84-92, pp. 73-98.

Cashman J. (1998) Structural and catalytic properties of the mammalian flavina-containing monooxygenases. Chem Res Toxicol 8, 165-181.

Castell J. El Metabolismo De Fármacos, Generación De Metabolitos Reactivos y Su Papel en el Origen De Las Reacciones Inmunológicas a Fármacos. En: línea http://www.uv.es/jcastell/Metabolismo_de_farmacos.pdf. Fecha y hora de consulta: 19/08/2010.

Chapple C. (1998) Molecular-genetic analysis of plant cytochrome P450-dependent monooxigenases. Ann Rev Plant Physiol Plant Mol Biol 49, 311-343.

Devlin T. (2004) Bioquímica libro de texto con aplicaciones clínicas, $4^{a}$ ed. Editorial Reverté S.A., Barcelona pp 1216.

Dongtao M., Pritchard M., Hanlon S., Burchell B., Wolf C., Friedberg T. (1999) Competition between Cytochrome P-450 Isozymes for NADPH-Cytochrome P-450 Oxidoreductase Effects Drug Metabolism. Pharmacology and experimental therapeutics $289,661-667$.

Duarte M., Brito B., Gilep A., Laires A., Olivera J., Usanov S., Rueff J., Kranendonk M. (2005) The stimulatory role of human cytochrome b5 in the bioactivaction activities of human CYP1A2, 2A6 and 2E1: a new cell expression System to study Cytochrome P450 mediated biotransformation. Mutagen 20:2, 93-100.

Furnes B., Schlenk D. (2004) Evaluation of Xenobiotic N- and S-Oxidation by Variant Flavin-Containing Monooxygenase 1 (FMO1) enzymes. Toxicol. Sciences78, 196-203.

Galli E. (2002) Citocromo P450 y su importancia clínica. Revista de Neuro Psiquiatría 65, 18-201.

González M. (2007) Factor principal I Complejo Enzimático Citocromo P450 en las Plantas. Rev. Int. Contam. 23:4,177183.

Gonzalez, F. (1998) The study of xenobiotic-metabolizing enzymes and their role in toxicity in vivo using targeted gene 
disruption. Toxicol Lett 102, 161-166.

Guzmán V. y Carmona F. (2006) El citocromo P-450 y la respuesta terapéutica a los antimaláricos. Rev. Panam. Salud Pública 19:1, 9-22.

Helliwell R., Adams L. y Mitchell M. (2004) Prostaglandin synthases: recent developments and a novel hypothesis. Prostaglandins Leukot Essent Fatty Acids 70,101-113.

Herschman H. (1994) Regulation of prostaglandin synthase-1 and prosglandin synthase-2. Cancer and Metastasis Reviews 13, 241-256.

Honkakoski P. y Negishi M. (2000) Regulation of cytochrome P-450 (CYP) genes by nuclear receptors. Biochem Journal 347, 321-37.

Kent, U., Juschyshyn, M., Hollenberg F. (2001) Mechanism-based inactivators as probes of cytochrome P-450 structure and function. Curr Drug Metab 2, 215-243.

Laress A. y Trujillo J. (2001) La farmacogenética y su importancia en la clínica; Gac- Med. Mex.137:3, 227-236

Mansuy, D. (1998) The great diversity of reactions catalyzed by cytochrome P-450. Comp Biochem Physiol Part C Pharmacol Toxicol Endocrinol 121, 5-14.

Miwa G., West S., Huang M., Lu A. (1979) Studies on the association of Cytochrome P-450 and NADPH-Cytochrome C Reductase during Catalysis in a Resconstituted Hydroxylating System. Biological Chemistry 254:13, 5695- 5700.

Orellana M. y Guajardo V. (2004) Actividad del citocromo P450 y sus alteraciones en diversas patologías. Rev Méd. Chile $132,85-95$.

Orf H. y Dolphin D. (1974) Oxaziridines as Possible Intermediates in Flavin monooxygenases Chemistry: Orf and Dolphin 71:7, 2646-2650.

Ortiz M. (2005) Cytochrome P450: Structure, Mechanism, and Biochemistry, 3ª Edition, New York pp. 689.

Pearson P., Wienkers L. (2009) Handbook of Drug Metabolism, 2ª ed. Editorial Informa Healtheare, New York pp. 694.

Peña C., Canter D., Ayala F. (2004) Toxicología Ambiental: Evaluación de Riesgos y Restauración Ambiental; en línea http://superfund.pharmacy.arizona.edu/toxamb/ consulta: 14/11/ 2010.

Plant N. (2003). Molecular Toxicology. Editorial BIOS Scientific Publisher, USA pp149.

Ramírez J., (2007) Farmacogenómica en enfermedades infecciosas; Salud 11:1, 77-81.

Reid J., Walker D., Miller J., Benson L., Tomlinson A., Naylor S., Blajeski A., LoRusso P. \& Ames M. (2004) The metabolism of Pyrazoloacridine (NSC 366140) by Cytochromes P450 and Flavin Monooxygenase in Human Liver Microsomes. Clinical Cancer Research 10:1, 1471-1480.

Repetto M. y Repetto G. (2009) Toxicología fundamental. 4ª ed. Editorial Díaz de Santos, pp. 587.

Sheweita, S.A. (2000) Drug-metabolizing enzymes: mechanisms and functions. Curr Drug Metab 1, 107-132.

Shimada T., Tsumura F., Gillam E., Guengerich F., Inoue K. (2000) Roles of NADPH-P450 Reductase in the O- 
Deethylation of 7-Ethoxycoumarin by Recombinant Human Cytochrome P450 1B1 Variants in Escherichia coli. Protein Expression and Purification 20, 73-80.

Smart C. y Hodgson E. (2008) Molecular and biochemical toxicology. $4^{\mathrm{a}}$ ed. editorial Wiley, New Jersey pp 901.

Treacy P., Akerman R., Chow L., Youil R. (1998) Mutations of the flavin-containing monooxygenase gene (FMO3) cause trimethylaminuria, a defect in detoxication. Human Mol, Genetics, 7:5, 839- 845.

Wang M., Roberts D., Paschke R., Shea T., Masters B., Kim J. (1997) Three-dimensional structure of NADPH-cytochrome P450 reductase: Prototype for FMN- and FAD-containing enzymes. Proc. Natl. Acad. Sci. 94, 8411.

Zhao Y, Christensen S, Fankhauser C., Cashman J., Cohen J., Weigel D., Chory J. (2001) A role for flavina monooxygenaselike enzymes in auxin biosynthesis, Science 291, 306-309. 



\section{CAPÍTULO}

\section{3}

\section{El papel del metabolismo fase II en toxicología}

\section{METABOLISMO FASE II}

El proceso de biotransformación en la fase I puede reducir la reactividad o toxicidad del xenobiótico a través de procesos como la hidroxilación. Los tóxicos pueden, de igual manera pasar por procesos de conjugación metabólica, ya sea directamente o subsecuente a la Fase I de la biotransformación. El proceso de conjugación o Fase II involucra acoplamientos del tóxico a pequeñas moléculas endógenas que están presentes dentro de la célula. La conjugación típica reduce la actividad tóxica, y así se reduce la toxicidad celular. De igual manera, la conjugación generalmente facilita la eliminación del tóxico por el cuerpo a través de rutas acuosas (principalmente orina) por el incremento de solubilidad de la molécula. La eliminación celular de tóxicos es facilitada por proteínas de membrana que transportan activamente productos de biotransformación fase I y II, fuera de la célula y hacen que estos estén disponibles para eliminarlos del cuerpo (Leblanc, 2008).

Las reacciones de Conjugación pueden ser divididas en dos tipos de mecanismo de reacción. La primera involucra la formación de un conjugado en donde el xenobiótico reacciona con un ligando de alta energía o con ligandos endógenos reactivos.

Tipo I: Xenobiótico + ligando conjugado reactivo = Producto conjugado

El segundo tipo de reacción de conjugación (Tabla. 3.1) involucra el acoplamiento del ligando endógeno conjugado con un xenobiótico de alta energía o xenobiótico reactivo. La reactividad asociada con el xenobiótico es al mismo tiempo consecuencia de la Fase I de biotransformación.

Tipo II: Xenobiótico reactivo + ligando conjugado = Producto conjugado 
El tipo I de reacciones incluye la formación de conjugados glicosilados, sulfatados, metilados y acetilados, mientras que reacciones tipo II incluyen conjugación de péptidos y glutatión. Las reacciones de conjugación comúnmente resultan en la formación de productos hidrofílicos (Leblanc, 2008).

Tabla 3.1. Reacciones de Conjugación.

\begin{tabular}{lll}
\hline \multicolumn{1}{c}{ Reacción } & \multicolumn{1}{c}{ Enzima } & \multicolumn{1}{c}{ Grupo funcional } \\
\hline Glucoronidación & UDP- glicosiltransferasa & $\mathrm{OH}, \mathrm{COOH}, \mathrm{NH}_{2}, \mathrm{SH}, \mathrm{C}-\mathrm{C}$ \\
Glucosidación & UDP- glicosiltransferasa & $\mathrm{OH}, \mathrm{COOH}, \mathrm{SH}, \mathrm{C}-\mathrm{C}$ \\
Sulfatación & Sulfotransferasa & $\mathrm{NH}_{2}, \mathrm{OH}$ \\
Acetilación & Acetiltransferasa & $\mathrm{NH}_{2}, \mathrm{SO}_{2}, \mathrm{NH}_{2}, \mathrm{OH}$ \\
Metilación & Metiltransferasa & $\mathrm{OH}, \mathrm{NH}_{2}, \mathrm{SH}$ \\
Conjugación con aminoácidos & Aciltransferasa & $\mathrm{COOH}$ \\
Conjugación Glutatión & Glutatión S-transferasa & Epóxidos, Halidos orgánicos, \\
& & Compuestos nitro-orgánicos, \\
& & Compuestos insaturados, COOH \\
\hline
\end{tabular}

(Modificado de Plant, 2003; Leblanc, 2008).

\subsection{CONJUGACIÓN GLUCURÓNICA}

La glucuronidación es una de las principales vías del metabolismo fase ll catalizado por glicoproteínas de membrana localizadas en el retículo endoplásmico de los mamíferos llamadas UDP-glucuronosiltransferasas (UGTs), son responsables de la conjugación de una variedad de compuestos endógenos y exógenos con ácido glucurónico (G1cUA). Químicamente, la reacción de glucuronidación resulta en unión covalente de G1cUA con UDP-ácido glucurónico (UDP- G1cUA) a substratos lipofílicos, esto resulta en la conversión de compuestos hidrofóbicos a glucurónidos polares para facilitar su eliminación vía renal y biliar (Figura 3.1) (Guillemette, 2003; Basu et al., 2005; Radominska et al., 2005).

La UGT lleva a cabo la amplia y crítica función de detoxificar fenoles lipofílicos endógenos y exógenos que incluyen metabólicos tóxicos, constituyentes de la dieta, carcinógenos ambientales, y, eventualmente agentes terapéuticos. Las isoenzimas UGT inactivan a un amplio número de estructuras químicas por ataque de ácido glucurónico para generar productos solubles en agua con alta capacidad de excreción (Basu et al., 2008; Ishii et al., 2010).

Los glucurónidos formados en el retículo endoplásmico son trasladados al citosol, sin embargo, las proteínas transportadoras que participan en este paso no han sido identificadas todavía; los glucurónidos son transportados desde el citosol hacia la bilis o la sangre. Dentro de las proteínas trasportadoras de glucurónicos que participan 
en el paso a través de la membrana, se han involucrado a varios miembros de la familia de proteínas asociadas a resistencia multidrogas y aniones orgánicos transportadores (Ishii et al., 2010).

Las UGTs Pueden ser conceptualmente divididas en dos partes: del dominio amino (N-) y Carboxilo (C-) terminal. Las humanas están en el rango de $\mathbf{5 2 9}$ a $\mathbf{5 3 4}$ aminoácidos de largo con regiones altamente conservadas importantes para su orientación en la membrana y actividad, contienen un péptido señal N-terminal que media la integración de la cadena polipeptídica dentro del Retículo Endoplásmico (RE) (Tukey y Strassburg, 2000, Radominska et al., 2006). La expresión y función de la UGT es modulada por regulación génica, fosforilación, glicosilación, homo/hetero oligomerización y asociación proteína-proteína con el citocromo P450 (Shipkova et al., 2005; Ishii et al., 2010).

\section{Substratos Lipofílicos}

\author{
Drogas terapéuticas \\ Carcinogénicos \\ Tóxico ambientales \\ Constituyentes diarios
}

Bilirrubina

Ácidos biliares

Esteroides

Ácidos retinoicos

Ácidos Grasos

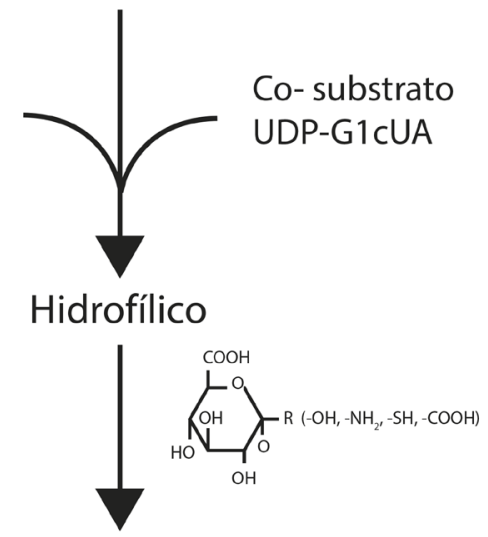

Excreción biliar,

orina

Figura 3.1. Reacción de Glucuronidación (Guillemette, 2003).

La superfamilia de las UGTs es dividida en subfamilias en base a divergencia evolutiva, la UGT1 y UGT2 son las dos principales familias involucradas en glucuronidación. Las UGT humanas pertenecen a 3 subfamilias (UGT1A, 2A, y 2B) sin embargo estudios recientes muestran que UGT3A1 (UDP-N-acetilglucosamiltransferasa) está involucrada de forma mínima, en la glucuronidación. Las enzimas en cada familia son por lo menos $50 \%$ homologas en la secuencia cDNA, mientras que en cada subfamilia son más de 60\% homologas (Bock et al., 2003; Ishii et al., 2010). 
El locus del gen UGT1A está localizado en el cromosoma 2q37 y codifica 9 proteínas funcionales: UGT1A1, $1 \mathrm{~A} 3,1 \mathrm{~A} 4,1 \mathrm{~A} 5,1 \mathrm{~A} 6,1 \mathrm{~A} 7,1 \mathrm{~A} 8,1 \mathrm{~A} 9$, y 1A10. La familia de las UGT2 tiene múltiples locus génicos localizados en el cromosoma 4q13 y consiste en las siguientes proteínas funcionales: UGT2A1, 2B4, 2B7, 2B10, 2B11, 2B15, 2B17, y 2B28. Las UGT están ancladas por su C-terminal a la membrana del retículo endoplásmico (RE) y el cuerpo principal, incluyendo el dominio catalizador, se encuentra dentro del RE (Tukey y Strassburg, 2000; Ishii et al., 2010).

La mayoría de las UGTs se expresan en el hígado pero también se encontran en tejido extrahepático, incluyendo el tracto gastrointestinal, cerebro, riñón, pulmón, tejido adiposo, glándulas suprarrenales, de mama, ovario, útero, placenta, próstata, testículos y piel (Tukey y Strassburg, 2000; Radominska et al., 2005).

La glucuronidación catalizada por UGT lleva a cabo el 35\% de las reacciones fase II. Una variedad de drogas y compuestos endógenos pueden ser directamente glucuronizados independientemente del metabolismo oxidativo catalizado por CYP450. Ha sido ampliamente reconocido que las UGT pueden actuar directamente sobre una variedad de compuestos en donde ya esté presente un grupo funcional nucleofílico, como es el grupo hidroxilo, carboxilo, amino y tiol. Ejemplos de drogas que son detoxificadas por glucuronidación directa incluye al 3' azido-3' deoxitimidina (AZT), ácido valproíco (VA), drogas anti-inflamatorias no esteroidales (NSAID), morfina y oxazepam (Tabla 3.2). Varios de los substratos endógenos incluyen la bilirrubina, esteroides y sus metabólitos, ácidos biliares, ácidos retinoicos hormonas tiroideas, prostaglandinas y otros (Bock, 2003; Radominska et al., 2005, Basu et al., 2008).

Tabla 3.2. Ejemplos de xenobióticos metabolizadas por Glucuronidación en Humanos

\begin{tabular}{cccc}
\hline xenobióticos & $\begin{array}{r}\text { \% de eliminación por } \\
\text { Glucuronidación }\end{array}$ & xenobióticos & $\begin{array}{r}\text { \% de eliminación por } \\
\text { Glucuronidación }\end{array}$ \\
\hline Carprofen & 75 & Morfina & 55 \\
Cloranfenicol & 90 & Acido micofenilico & $>90$ \\
Ácido Clofíbrico & 61 & Oxazepam & 86 \\
Ezetimida & $>80$ & Oxcarbazepina & 49 \\
Isoxepac & 90 & Paracetamil & 63 \\
Ketoprofem & 73 & Salicilamina & 63 \\
Ketorolaco & 73 & Temazepam & 73 \\
Lamotrigina & 89 & Zidovudina & 75 \\
Lorazepam & 92 & Zomepiraco & 90 \\
\hline
\end{tabular}

(Shipkova et al., 2008).

Las UGTs pueden sintetizar glucorónidos con varios grupos funcionales como el - $\mathrm{OH},-\mathrm{COOH},-\mathrm{NH}_{2},-\mathrm{SH}$ y C-C, y glucuronidizar un amplio rango de substratos de origen endógeno y exógeno. La especificidad del sustrato varía entre las isoformas, algunos presentan especificidad relativamente estricta, mientras que otros aceptan una amplia gama de sustratos estructuralmente relacionados (Radominska et al., 2006). 
La glucuronidación de aminas primarias, secundarias y terciarias resultan en la formación de N-glucurónidos. S-glucuronidos surgen en presencia de un grupo funcional sulfhídrilo, mientras que los grupos carbonilo generan C-glucuronidos, los más raros en humanos. Mientras que los O-glucuronidos son los más comunes (Ritter, 2000; Tukey y Strassburg, 2000; Shipkova et al., 2008). La conjugación con ácido glucurónico cambia la estructura del compuesto original y su reactividad química y biológica. Un posible efecto de los metabólicos glucurónicos es en muchos casos asociado con desactivación, rápida excreción del metabólito glucurónico hidrofílico, baja unión a proteínas, y pequeño volumen de distribución (Shipkova et al., 2008).

\subsection{CONJUGACIÓN SULFATO}

Las enzimas sulfotransferasas (SULT) son proteínas $\alpha / \beta$ globulares con la característica de cinco cadenas paralelas en forma de hoja- $\beta$, $\alpha$-hélices a cada lado de los sitios de cada hoja (Negishi et al., 2001). Las enzimas SULT aparecen como un homodimero, mediante una forma monomérica y heterodimérica que han sido detectadas en roedores. La subunidad monomérica de la SULT humana consiste de 284 a 365 residuos de aminoácidos (Glatt y Meinl, 2004).

Las sulfotransferasas pertenecen a una familia de súpergenes de enzimas que catalizan la conjugación de $3^{\prime}$-fosfoadenosina-5' -fosfosulfato (PAPS) con un grupo aceptor O-, N- o S- de una molécula apropiada (Figura 3.2). En general, la O-sulfatación representa la reacción dominante de la sulfatación celular. Sin embargo la $\mathrm{N}$-sulfatación es una reacción crucial en la modificación de cadenas de carbohidratos en macromoléculas como heparina o sulfato de heparan, componentes comunes de proteoglicanos. La N-sulfoconjugación también está involucrada en el metabolismo de xenobióticos de sustancias con quínoles y amino. Las PAPS son un sulfato universal donde la molécula donadora requiere de la sulfonación de la reacción, puede ser sintetizada por todos los tejidos en mamíferos (Glatt, 2000; Negishi et al., 2001; Glatt y Meinl, 2004; Rath et al., 2004; Jancova, 2010). Las SULT transfieren una fracción del grupo sulfonilo al cofactor hidroxilo, amino, sulfhídrilo y grupos N-oxido de sus sustratos (Figura 3.3).

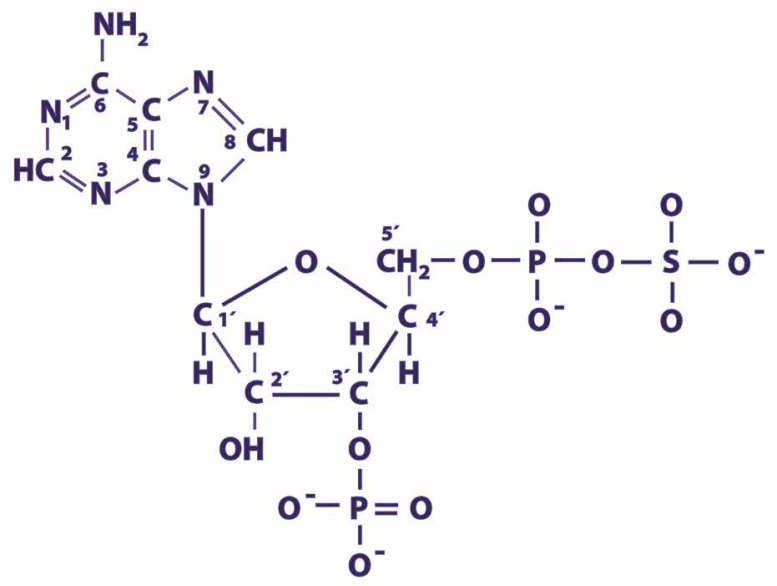

Figura 3.2. Estructura química del sulfato donador 2 'fosfoadenosina 5 '-fosfosulfato PAPS (Jancova, 2010). 
La reacción es llamada sulfonación o sulfatación con referencia a la fracción transferida y al producto más común, donde es un ácido sulfúrico, sulfato o éster en el caso de O-sulfonación. Los sustratos moleculares son metabolizados a través de los sulfotransferasas unidas a la membrana, mientras que los xenobióticos y endobióticos (como hormonas y neurotransmisores) son metabolizadas por enzimas citosólicas (Glatt et al., 2000).

La sulfatación tiene un papel importante en la biotransformación de un gran número de endógenos como compuestos de bajo peso molecular (esteroides, catecolaminas, serotonina, iodotironina, retinol, ascorbato y vitamina D). Cabe agregar que este es una vía importante en la biotransformación de numerosos xenobióticos como drogas y químicos. Por otra parte, numerosos compuestos (procarcinógenos) son convertidos por sulfatación en compuestos intermedios altamente reactivos que pueden actuar como químicos carcinógenos y mutagénicos por unión covalente con el ADN (aductos) (Glatt, 2000; Glatt y Meini, 2005; Jancova et al., 2010).
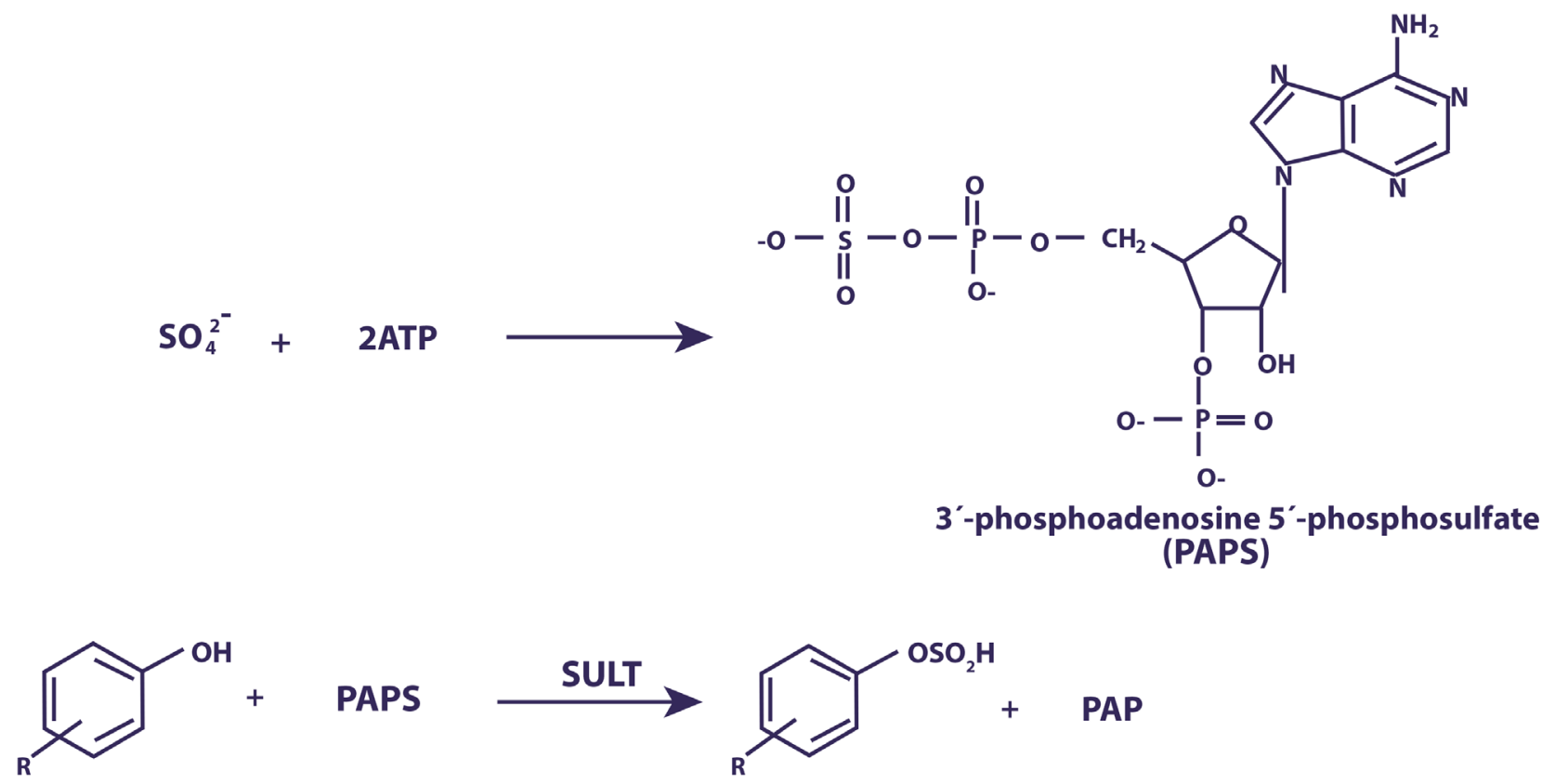

Figura 3.3. Reacción general catalizada por las SULT (Jancova, 2010).

Todas las sulfotransferasas citosólicas estudiadas son miembros de una súper familia determinada SULT, a partir de similitudes en la secuencia de nucleótidos o de sus genes/cDNAs. De acuerdo al grado de similitud entre sus aminoácidos es generalmente aceptada la clasificación en subfamilias 1A, 1B, 1C, 1E, 2A, 2B y 3A. La nomenclatura en base a la estructura de la enzima en particular, ha sido propuesta pero aun no se ha finalizado (Weinshilboum et al., 1997; Glatt et al., 2000; Nagata y Yamazoe, 2000).

La conjugación sulfato fue descrita por primera vez por Baumann en 1876. Las SULT son probablemente el mayor sistema de enzimas encargadas de la desintoxicación en el desarrollo de fetos humanos: donde no se detectaron 
transcritos de UGT en hígado fetal a las 20 semanas de gestación. En la fracción fetal de hígado humano se ha demostrado una actividad significativa de sulfotransferasas para numerosos sustratos (cortisol, dopamina, paracetamol, testosterona, estrógeno, etc.) (Glatt, 2000; Jancova et al., 2010).

\subsubsection{SULTs: Tipos, tejidos y distribución celular}

Existen 4 familias de SULTs humanas, SULT1, SULT2, SULT4 y SULT6, se han identificados 13 miembros distintos. La familia SULT1 que envuelve 9 miembros divididos en 4 subfamilias (1A1, 1A2, 1A3 y 1A4; 1B1; 1C1, 1C2 y 1C3; 1E1) la familia SULT2 que puede ser dividida en dos subfamilias SULT2A y SULT2B; la subfamilia SULT2B esta comprendida por dos isoformas SULT2B1a y SULT2B1b. La SULT4A1 y SULT6B1 son el único miembro de las familias SULT4 y SULT6 respectivamente. Los miembros de la misma familia de genes que codifican para las SULTs muestran una similitud por lo menos del $45 \%$ en su secuencia de aminoácidos mientras que los de las subfamilias muestran una similitud mayor al 60\% (Nagata y Yamazoe, 2000; Gamage et al., 2006; Jancova et al., 2010).

Dos amplias clases de sulfotransferasas han sido identificadas y nombradas como citosólicas y como ancladas a la membrana. Las SULTs ancladas a la membrana están localizadas en el aparato de Golgi y son responsables de la sulfatación de péptidos, proteínas, lípidos y glicosaminoglicanos. Las SULTs citosólicas, por otro lado, catalizan la sulfatación de xenobióticos y pequeñas moléculas endobióticas como esteroides, ácidos biliares y neurotransmisores (Nagata y Yamazoe, 2000; Gamage et al., 2006; Jancova et al., 2010).

Las SULTs tienen una gran distribución en diversos tejidos. Los miembros de la subfamilia SULT1A han sido identificados en el hígado, cerebro, tejido mamario, tejido pulmonar, glándula suprarrenal, endometrio, riñón y plaquetas. De la subfamilia SULT1, las SULT1A1 presentan únicamente una gran expresión en el hígado, en contraste, SULT1A3 es expresada en la mayoría de los tejidos con excepción del hígado de los adultos y SULT1B1 en el hígado, intestino delgado, colon y leucocitos. La expresión de la subfamilia SULT1C se encuentra de forma predominante en fetos humanos. SULT1E1 es expresado en hígado humano y el yeyuno (porción del intestino delgado). SULT2A1 muestra un gran nivel de expresión en el hígado y glándula suprarrenal. La subfamilia SULT2B se localiza en la próstata humana, placenta, glándula renal, ovario, pulmón, riñón y colon. Por otro lado SULT4A1 ha sido identificada en el cerebro y SULT6B1 en testículos y riñón (Glatt, 2000; Nagata y Yamazoe, 2000; Gamage et al., 2006).

La actividad de SULT puede ser un indicador en humanos de exposición a ciertas drogas terapéuticas, la dieta o químicos en el ambiente, por lo tanto, los efectos inhibitorios de varios compuestos han sido examinados a través de miembros de las SULTs.

\subsubsection{Polimorfismos de las SULTs}

Los polimorfismos genéticos son conocidos en mayor forma por SULT1A1 en hígado humano adulto. Un solo polimorfismo es el resultando común de la sustitución de un aminoácido de $\operatorname{Arg}_{213}$ àHis en la posición 213, origina una variación de la actividad y termo-estabilidad. Esta mutación fue encontrada con una frecuencia de 25.4-36.5\% 
en poblaciones caucásicas. Individuos que son homocigotos para His213/His213 tiene reducción significativa en la actividad de la sulfotransferasa (Jancova et al., 2010). Los polimorfismos mejor conocidos son SULT1A2, 1A3, 1C2, 2A1, 2A3, 2B1. Diversos estudios han demostrado que el polimorfismo SULT1A1 puede jugar un papel importante en el desarrollo de cáncer pulmonar, carcinoma urotelial y tumor cerebral meningiomal (Jancova et al., 2010).

\subsection{CONJUGACIÓN GLUTATIÓN}

La Glutatión Transferasa ha sido llamada S-transferasa o GST, y hace referencia a una superfamilia de isoenzimas que catalizan la conjugación del tripéptido glutatión con una gran variedad de xenobióticos así como también sustratos endógenos como la bilirrubina, esteroides, carcinógenos y algunos compuestos orgánicos (Ouaissi et al., 2002). La reacción de las GST se caracteriza por el ataque nucleofílico a través de la reducción de glutatión (GSH) en compuestos no polares que contiene un carbón electrofílico, un átomo de nitrógeno o de azufre. Los sustratos incluyen halogenonitrobencenos, areneóxidos, quinonas, y a, $\beta$-carbonilos insaturados (Hayes et al., 2005).

EI GSTs puede catalizar un gran número de reacciones incluyendo sustitución aromática nucleofílica, isomeración y reducción de hidroperóxidos, conjugación de algunos compuestos hidrofóbicos y electrofílicos que reducen el glutatión. GST tienen un papel muy importante en la detoxificación de epóxidos derivados de Hidrocarburos Aromáticos Policíclicos (PAHs) y alfa-beta quinonas insaturadas. Un gran número de compuestos endógenos como prostaglandinas y esteroides son metabolizados a partir de esta conjugación (Bladeren, 2000; Hayes et al., 2005; Jancova et al., 2010).

Las enzimas Glutatión S-transferasas son una de las familias más grandes que componen la fase II del metabolismo de xenobióticos, y juegan un papel importante en la protección contra el estrés oxidativo (Hayes et al., 2005; Jancova et al., 2010).

Se sabe que algunos conjugados de glutatión están implicados directamente con la carcinogénesis pero también en la detoxificación de estos sustratos. Actualmente ha sido reportada la resistencia a diversos fármacos mediada por GST en plantas o insectos, también en algunos tumores y parásitos (Ouaissi et al., 2002; Hayes et al., 2005).

La principal función biológica del glutatión transferasa es la defensa contra especies tóxicas y ataques electrofílicos provocados por las especies reactivas de oxígenos (radical superóxido y peróxido de hidrógeno) que surgen a través del proceso normal metabólico. Algunos de estos se forman por las reacciones celulares oxidativas catalizadas por el citocromo P450 y otras oxidasas (Jancova et al., 2010).

Las GST se pueden dividir en tres familias, dos de estas, las citosólicas y mitocondriales comprenden enzimas solubles, la tercera familia comprende GST microsomales y se refiere a proteínas asociadas a la membrana en eicosanoides y metabolismo glutatión (MAPEG) (Hayes et al., 2005).

Las GST citosólicas y mitocondriales muestran una similitud en la forma dimensional pero no guarda ninguna semejanza estructural con las enzimas MAPEG. Sin embargo las tres familias que contienen miembros que catalizan la conjugación de GSH con 1-cloro-2,4, dinitrobenceno (CDNB) y exhiben actividad glutatión hacia hidroperóxido de cumeno (CuOOH) (Hayes et al., 2005). 
Las GST son enzimas principalmente citosólicas, constituidas por dos dímeros, a sus ligandos se les asocian las propiedades catalíticas responsables de la detoxificación de agentes quimioterapéuticos. Existe otra clase de GST microsomales con distintas formas, diferente a las citosólicas, son identificadas como proteínas asociadas a la membrana (Sheehan et al., 2001). Las glutatión transferasas son de interés farmacológico y toxicológico porque provee blancos para algunas drogas terapéuticas en el ámbito de antiasmáticos y antitumorales, y su metabolismo para algunos agentes quimioterapéuticos, insecticidas, herbicidas, carcinógenos y para productos que ocasionan estrés oxidativo (Sau et al., 2010; Hayes et al., 2005).

\subsubsection{Tipos de GST, tejidos y distribución celular}

Existen dos distintas superfamilias descritas de GSTs que comprenden enzimas diméricas solubles que están implicadas en la biotransformación de tóxicos xenobióticos y endobióticos. La superfamilia GST soluble es subdividida en ocho clases separadas designadas como Alfa, Kappa, Mu, Pi, Sigma, Teta, Zeta y Omega. Estas enzimas han sido descritas principalmente en el citoplasma pero también se presentan en el núcleo, mitocondrias e inclusive en los peroxisomas. Las enzimas GST humanas pertenecen a clases Alfa (A1-A4), Mu (M1-M5), Pi (P1), Kappa (K1) y Theta (T1, T2) con su subunidad o su tipo de isoenzima designada por números arábigos. Las GST muestran más del $60 \%$ de similitud de los aminoácidos que las compone, las identifica como una clase, sin embargo menos del 30\% habla de clases diferentes (Bladeren, 2000; Sheehan et al., 2001; Jancova et al., 2010).

La otra superfamilia de GST designada como MAPEG, probablemente con la estructura trimérica, está involucrada en el metabolismo del ácido araquidonico (Jancova et al., 2010). La conjugación de la reacción catalítica del glutatión ha sido estudiada ampliamente, este mecanismo establece que la enzima es activada por un grupo sulfídrilo, lo cual facilita la salida del grupo electrofílico (Bladeren, 2000).

La expresión de las GST se encuentra de forma diferente en todos tejidos y tipos celulares. hGSTM3 se localiza exclusivamente en testículos y en el cerebro y la clase Mu GST está también presente en el cristalino. La clase Teta está presente predominantemente en el hígado y pulmón y en niveles relativamente bajos en riñón (Bladeren, 2000).

\subsubsection{Polimorfismo en GST}

Diferentes tipos de variaciones alélicas han sido identificadas en las clases Alfa, Mu, Pi, Teta y los genes de las familias. La alteración de genes como GST-M1, GST-T1 y GST-P1 tiene una gran incidencia en el cáncer de mama, de vejiga, el coló-rectal, y los de cuello y riñón. La perdida de estos genes también se ha correlacionado con el incremento en la susceptibilidad del asma y alergias, aterosclerosis y artritis reumatoide. Aun se conoce poco sobre el polimorfismo de genes MAPEG; lida et al., en el 2001 describe el polimorfismo de un solo nucleótido de MBST1 (un miembro de MAPEG) en voluntarios sanos Japoneses (Bladeren, 2000; Strange et al., 2000; Hayes et al., 2005; Jancova et al., 2010).

Las variaciones alélicas que constituyen los únicos polimorfismos detectados de GST, corresponden a las $\mathrm{Mu}, \mathrm{Pi}$ y Teta que corresponden a GST citosólicas. La clase Alfa, uno de los principales grupos de enzimas transferasas 
del riñón ejercen una influencia importante en procesos de detoxificación. Esto ha sido demostrado mediante polimorfismos detectados en las GSTA1 y GSTA2 que generan una variación ya sea en la proporción de proteínas sintetizadas o directamente en la capacidad alélicas de codificar a determinadas proteínas. Afortunadamente los polimorfismos de GSTM4 y GSTT2 presentan promotores polimórficos en estos genes mostrando así un efecto en la susceptibilidad de diversas enfermedades o, en la diferencia de la eficacia de compuestos terapéuticos, generar reacciones adversas (Strange et al., 2000; Hayes et al., 2005).

\subsection{TOXICIDAD MEDIADA POR EPÓXIDO-HIDROLASA}

Los compuestos que contienen epóxidos son encontrados en el ambiente de manera tanto natural como artificial, y una amplia variedad de compuestos aromáticos y alquenos, son también metabolizados como epóxidos endógenos. Un epóxido (u oxirano) es un éter cíclico de tres miembros que tiene patrones específicos de reactividad debidos a la alta polarización en la interacción oxígeno-carbono, además de un fuerte anillo (Sandberg et al., 2000; Vries y Janssen, 2003; Mossisseau y Hammock, 2005).

Algunos epóxidos reactivos son responsables de reacciones electrofílicas con blancos biológicos como ADN y proteínas, generando efectos tóxicos, mutagénicos y carcinogénicos. Aunque algunos epóxidos son intermediarios reactivos y son relativamente estables en pHs fisiológicos necesitan ser transformados de una manera controlada para no generar daño a las células. La adición catalítica de agua a los epóxidos es por las Epóxido Hidrolasas (EHs); la reacción es energéticamente favorable con el agua como co-substrato (Figura 3.4) (Liang et al., 2005; Mossisseau y Hammock, 2005).

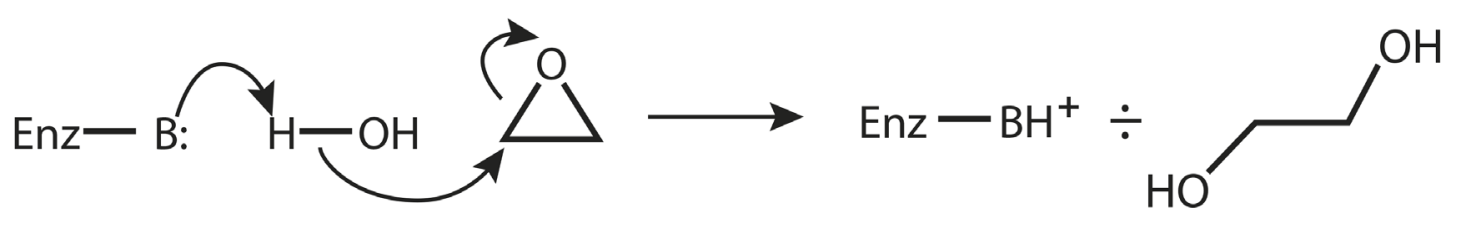

Figura 3.4. Catálisis general por hidratación directa del epóxido (Liang et al., 2005).

Las EHs son encontradas en todos los organismos a lo largo del árbol evolutivo. El papel fisiológico incluye la detoxificación de algunos xenobióticos y compuestos endógenos producidos por estrés oxidativo, o en la bioactivación de hidrocarburos poliaromáticos; además en mamíferos han mostrado estar involucradas en la regulación de la presión sanguínea, y en la respuesta inflamatoria. También cumplen un papel en el metabolismo secundario de varias bacterias, y en las plantas, estás enzimas contribuyen con el sistema de defensa contra patógenos (Mossisseau y Hammock, 2005; Widersten et al., 2010).

Las EHs pueden también jugar un papel importante en las reacciones de toxicidad. Como se observa en la Figura 3.5, las EHs son capaces de convertir el 7,8-epoxido de benzopíreno, un contaminante ambiental, a un diol, que 
por sí solo no es tóxico. Sin embargo, este derivado puede ser blanco del metabolismo por los CYP, formando un potente carcinógeno benzopireno-7,8-diol, 10-epoxido (Plant, 2003).

Hay cinco formas de la enzima EH, pero solamente dos, las EHs microsomales y las EHs solubles son importantes en el metabolismo de xenobióticos. Estas dos formas tienen diferente especificidad de sustratos. La forma microsomal se localiza en el retículo esdoplásmico cercana a los CYP450, es muy abundante en el área centrilobular del hígado (aunque se encuentran en casi todos los tejidos). Las formas solubles, se localiza en la membrana nuclear.

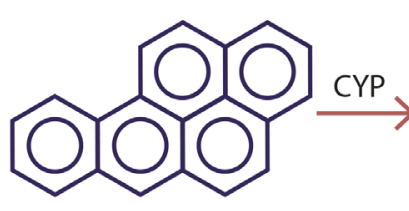

Benzopireno

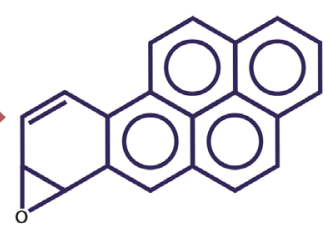

Benzopireno - 7,8 epóxido

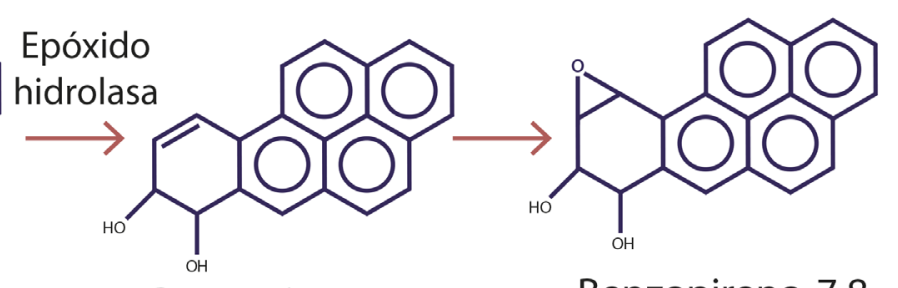

Benzopireno7,8-diol
Benzopireno-7,8diol-9,10-epoxido

Figura 3.5. Activación del Benzopireno mediado por Epóxido Hidrolasa (Modificado de Plan, 2003).

Las $\mathrm{EH}$ solubles (o EH citosólicas) son enzimas metabolizadoras de xenobióticos que también participan en el metabolismo de epóxidos endógenos derivados de ácidos grasos. El gen de estas enzimas en humanos está localizado en el cromosoma 8p21-p12 con aproximadamente 45kb de largo. Las EH microsomales cubren cerca de $20 \mathrm{~kb}$ y catalizan un amplio rango de substratos epóxidos y son de gran interés debido a que están involucradas en la potencial bioactivación de hidrocarburos aromáticos policíclicos que son carcinogénicos (Fretland y Omiecinski, 2000).

\section{REFERENCIAS BIBLIOGRÁFICAS}

Basu N., Kole L., Basu M., Chakraborty K., Mitra P. y Owens I. (2008) The major chemical-detoxifying system of UDPglucuronosyltransferase Requires Regulated Phosphorylation Supported by Protein Kinase C. The Journal of Biological Chemistry 283:349, 23048-23061.

Basu N., Kovarova M., Garza A., Kubota S., Saha T., Mitra P., Banerjee; Rivera J., Owens S. (2005) Phosphorylation of a ADR-glucoronosyltransferase regulates substrate specify. PNAS 102:18, 6285-6290.

Bladeren P. (2000) Glutathione conjugation as a bioactivation reaction. Chemico-Biological Interactions 129, 61-76.

Bock K. (2003) Vertebrate UDP-Glucuronosyltransferases: Functional and evolutionary aspects. Biochemical Pharmacology 66, 691-696 
Fretland A. y Omiecinski (2000) Epoxide hydrolases: biochemistry and molecular biology. Chemico Biological Interactions $129,41-59$

Gamage N., Barnett A., Hempel N., Duggleby RG., Windmill K., Martin J., McManus M., (2006) Human sulfotransferases and their role in chemical metabolism. Toxicol Sci; 90:1, 5-22.

Glatt H., Engelke C., PabelU., Teubner W., Jones A., Cougthrie M., Andrae U., Falany C. y Meinl W., (2000) Sulfotransferases: genetics and role in toxicology. Toxicology Letters 112, 341- 348.

Guillemette C. (2003) Pharmacogenomics of human UDP- glucoronosyltransferase enzymes. The pharmacogenomic journal 3, 136-158.

Hansruedi G. y Walter M., (2005) Sulfotransferases and Acetyltransferases in Mutagenicity Testing: Technical Aspects En: Methods in Enzymology. Vol. 200 Elsevier Inc. pp 230-250.

Hayes J., Flanagan J., Jowsey I. (2005) Glutathione Transferases Annu. Rev. Pharmacol. Toxicol. 45,51-88.

Ishii Y., Nurrochmad A., Yamada H. (2010) Modulation of EDP-Glucoronosyltransferase Activity by Endogenous Compounds. Drug Metab. Pharmacokinet 25:2, 134-148.

Jancova P., Anzenbacher P., Anzenbacherova E. (2010) Phase II Drug Metabolizing Enzymes. Biomed Pap Med Fac Univ Palacky Olomouc Czech Repub. 154:2, 103-116.

Leblanc G. (2008) Phase II-Conjugation of toxicants. En: Molecular and Biochemical Toxicology, $4^{\text {a }}$ Ed. Editorial John Wiley \& Sons. Smart R. y Hogson E. (Eds.) pp. 219-237.

Liang S., Hassett C., Omiecinski C. (2005) Alternative Promoters determine Tissue-Specific Expression Profiles of the Human Microsomal Epoxide Hydrolase gene (EPHX1). Molecular Pharmacology 67, 220-230.

Morisseau C. y Hammock B. (2005) Epoxide Hydrolases: Mechanisms, Inhibitor Designs, and Biological Roles. Annu. Rev. Pharmacol. Toxicol. 45, 311-333.

Nagata K., Yamazoe (2000) Pharmacogenetics of Sulfotransferase. Annu. Rev. Pharmacol. Toxicol. 40, 159-176.

Negishi M., Pedersen L., Petrotchenko E., Shevtsov S., Borokhov Al, Kakuta Y., Pedersen L. (2001) Structure and Function of Sulfotransferases. Archives of Biochemistry and Biophysics. 390:2, 149-157.

Ouaissi A., Ouaissi M., Sereno D. (2002) Glutathione S-transferases and related proteins from pathogenic human parasites behave as immunomodulatory factors. Immunology Letters 81, 159-164.

Plant N. (2003) Molecular Toxicology. Editorial BIOS Scientific Publisher. USA pp. 149.

Radominska A., Bratton S., Little M. (2005) A Historical Overview of the Heterologous Expression of Mammalian UDPGlucuronosyltransferase Isoforms Over the Past Twenty Years. Current Drug Metabolism 6, 141-160.

Radominska A., Ouzzine M., Fournel S. y Magdaluo J. (2006) Structure of UDP-Glucuronosyltransferases in membranes En: Methods in Enzymology vol. 400. Elsevier Page. 116- 147.

Rath V., Verdugo D., Hemmerich (2004) Sulfotransferase structural biology and inhibitor discovery. Research Focus 9:23, 1003-1011. 
Ritter J. (2000) Roles of glucoronidation and UDP-glucoronosyltransferase in xenobiotic bioactivation reaction. ChemicoBiological Interactions 129: 171-193.

Sandberg M., Hassett C., Adman E., Meijer J., Omiecinski C. (2000) Identification and functional characterization of human Soluble Epoxide Hydrolases Genetic Polymorphisms. The Journal of Biological Chemistry 275:37, 28873-28881.

Sau A., Pellizzari F., Valentino F., Federici G., Caccuri A. (2010) Glutathione transferases and development of new principles to overcome drug resistance. Archives of Biochemistry and Biophysics. 200, 116-122.

Sheehan D., Meade G., Foley V. y Dowd C. (2001) Structure, function and evolution of glutathione transferases: implications for classification of non-mammalian members of an ancient enzyme superfamily. Biochemical 360, 1-16.

Shipkova M., Wieland E. (2005) Glucoronidation in therapeutic drug monitoring. Clinical Chemical Acta 358, 2-23

Strange R., Jones P., Fryer A. (2000) Glutathione S-transferase: genetics and role in toxicology. Toxicology Letters. 112, 357-363.

Tukey R y Strassburg C. (2000) Human UDP-glucoronosyltransferases: Metabolism, Expression, and Disease. Annu. Rev. Pharmacil. Toxicol 40, 581-616.

Vries E. y Janssen D. (2003) Biocatalyc Conversion of Epoxides. Current Opinion in Biotechnology 14, 414-420.

Weinshilboum R., Otterness D., Aksoy I., Wood T., Raftodianis R., (1997) Sulfotransferase molecular biology: 1 cDNAs and genes. FASEB J. 11:3, 14

Widersten M., Gurell A., Lindberg D. (2010) Structure-function relationships of epoxide hydrolases and their potential use in biocatalysis. Biochimica et Biophysica Acta 1800, 31-32. 



\section{CAPÍTULO}

4

\section{Respuestas coordinadas \\ a la toxicidad}

\subsection{RESPUESTA INMEDIATA AL DAÑo TóXICO}

La formación de radicales libres se incrementa como consecuencia de la toxicidad de un amplio rango de xenobióticos. Una gran cantidad de compuestos químicos para ejercer su acción tóxica, requieren una activación metabólica a intermediarios reactivos que pueden generar radicales libres (Plant, 2003). Un aspecto sorprendente del metabolismo es que el propio sistema altera los productos químicos para permitir su eliminación eficiente del cuerpo, también puede producir numerosas especies químicas que pudieran ser tóxicas para la célula (bioactivación). Estas especies pueden ser divididas en dos categorías generales, intermediarios reactivos formados a partir del metabolismo de un agente químico (ejem., grandes estructuras químicas con grupos reactivos) y pequeñas especies químicamente reactivas liberadas durante el metabolismo (ejem., pequeñas especies mono o diátomicas) (Smart y Hodgson, 2008).

\subsubsection{Generación de pequeñas especies químicamente reactivas}

Un compuesto puede convertirse en radical libre captando o perdiendo un electrón. Así mismo, los radicales libres también pueden formarse cuando un enlace covalente se rompe y cada electrón de la pareja compartida permanece en un átomo (Martínez, 1998).

Los Radicales Libres $(\mathbf{R L})$ son átomos o grupos de átomos que tienen un electrón desapareado o libre en sus orbitales externos, debido a esta condición, son muy reactivos puesto que tienden a captar un electrón de moléculas estables con el fin de alcanzar su estabilidad electroquímica. Una vez que el RL ha conseguido sustraer el electrón que necesita, la molécula estable que lo cede se convierte a su vez en un radical libre por quedar con un electrón desapareado, iniciándose así una verdadera reacción en cadena que destruye nuestras células. La vida media biológica del radical libre es de microsegundos, pero tiene la capacidad de reaccionar con todo lo que esté a su alrededor provocando un gran daño, tanto a moléculas como a membranas celulares e inclusive a tejidos (Martínez, 1998; Nordberg y Arner, 2001, Plant, 2003).

\subsubsection{Generación de grandes estructuras con grupos reactivos y estrés oxidativo}

La mayoría de los químicos dentro del cuerpo son capaces de intercambiar electrones, ocasionando así alteraciones en su estado de oxidación. Los átomos de oxígeno son particularmente susceptibles a la ganancia de uno a cuatro 
electrones, resultando en la creación de Especies Reactivas de Oxígeno (EROS). Es el término que se aplica colectivamente a las moléculas radicales y no radicales que son agentes oxidantes y/o son fácilmente convertidos a radicales (Plant, 2003).

Los radicales libres y los EROS reaccionan fácilmente con la mayoría de las biomoléculas, a partir de una reacción en cadena de formación de radicales libres. Para poner fin a esta cadena, un radical libre recién formado debe reaccionar con otro radical libre, equilibrando así la carga de los electrones no apareados, o reaccionar con un depósito para radicales libres o antioxidante primario (Nordberg y Arner, 2001).

\subsubsection{Generación de grandes estructuras químicas con grupos reactivos}

Cuando un único electrón reduce la molécula de oxígeno se produce el anión superóxido $\left(\mathbf{O}_{2}\right)$, el cual al aceptar otro electrón, es capaz de producir peróxido de hidrógeno $\left(\mathrm{H}_{2} \mathrm{O}_{2}\right)$ (Figura 4.2). Compuesto peligroso para las células porque es un potente prooxidante que atraviesa fácilmente las membranas biológicas y del que se puede originar el radical hidroxilo $\left(\mathbf{O H}^{*}\right)$. La reducción del oxígeno molecular por tres electrones de lugar al citado radical hidroxilo. Estas especie es una de las más reactivas que se conocen y, por tanto, presenta una vida media y un radio de acción muy cortos (microsegundos y angstroms, respectivamente). Así un radical hidroxilo formado en la mitocondria es imposible que, por sí mismo, tenga un efecto directo en otras partes de la célula. Una fuente importante de radicales hidroxilo esta representada por la reacción de Haber-Weiss que es a su vez, el balance de dos reacciones (Figura 4.1) (Martínez, 1998).

$$
\begin{array}{ll}
\mathrm{O}_{2}^{-}+\mathrm{O}_{2}^{-}+2 \mathrm{H}^{+} & \mathrm{H}_{2} \mathrm{O}_{2}+\mathrm{O}_{2} \\
\mathrm{O}_{2}^{-}+\mathrm{Fe}^{3+} & \mathrm{O}_{2}+\mathrm{Fe}^{2+} \\
\mathrm{Fe}^{2+}+\mathrm{H}_{2} \mathrm{O}_{2} & \mathrm{Fe}^{3+}+\mathrm{OH}^{-}+\mathrm{OH}^{-} \\
\mathrm{O}_{2}^{-}+\mathrm{H}_{2} \mathrm{O}_{2} & \mathrm{O}_{2}^{+}+\mathrm{OH}^{-}+\mathrm{OH}^{-}
\end{array}
$$

Figura 4.1. Reacciones principales que intervienen en la formación de EROS. (1) Formación de Peróxido de Hidrógeno a partir de Oxígeno Molecular, (2) Reacción de Haber-Weiss, (3) Reacción de Fenton, (4) Oxidación del Peróxido de Hidrógeno hasta formar el ión Superóxido (Martínez, 1998).

Las EROS se forman y degradan por organismos anaeróbicos en concentraciones fisiológicas necesarias para la función normal de las células, sin embargo, cuando la cantidad de estos es excesiva, el estado es llamado estrés oxidativo. La liberación de EROS puede resultar en un cambio en el potencial redox (reducción: oxidación) dentro de la célula, y esto resulta en el fenómeno conocido como estrés oxidativo. Durante el estrés oxidativo las moléculas 
de EROS generadas pueden llevar a cabo un ataque nucleofílico a cualquier grupo químico deficiente de un electrón si no son retiradas rápidamente. Algunos blancos potenciales incluyen la mayoría de las macromoléculas, quienes alteran su función celular (Martínez, 1998; Plant, 2003; Smart y Hodgson, 2008).

La Tabla 4.1 muestra algunas formas intracelulares comunes de EROS se enlistan junto a sus principales fuentes celulares de producción y el antioxidante enzimático pertinente para la reducción de EROS (Nordberg y Arner, 2001).

Tabla 4.1. Formas intracelulares más comunes de EROS.

\begin{tabular}{|c|c|c|c|}
\hline Molécula ROS & Principales Fuentes & $\begin{array}{c}\text { Sistema de Defensa } \\
\text { Enzimática }\end{array}$ & Productos \\
\hline $\begin{array}{l}\text { Superóxido } \\
\qquad\left(\mathrm{O}_{2} \cdot-\right)\end{array}$ & $\begin{array}{l}\text { "Fuga" de electrones del } \\
\text { transporte de electrones. } \\
\text { Activación de Fagocitos } \\
\text { Xantina Oxidasa } \\
\text { Flavoenzimas }\end{array}$ & $\begin{array}{l}\text { Superóxido Dismutasa } \\
\text { (SOD). } \\
\text { Superóxido reductasa (en } \\
\text { algunas bacterias) }\end{array}$ & $\begin{array}{l}\mathrm{H}_{2} \mathrm{O}_{2}+\mathrm{O}_{2} \\
\mathrm{H}_{2} \mathrm{O}_{2}\end{array}$ \\
\hline $\begin{array}{l}\text { Peróxido de Hidrógeno } \\
\qquad\left(\mathrm{H}_{2} \mathrm{O}_{2}\right)\end{array}$ & $\begin{array}{l}\text { De la vía } \mathrm{O}_{2} \cdot \text { - superóxido } \\
\text { dismutasa (SOD). } \\
\text { NADP-Oxidasa (neutrofilos). } \\
\text { Glucoxidasa. } \\
\text { Xantinoxidasa. }\end{array}$ & $\begin{array}{l}\text { Glutatión peroxidasa } \\
\text { Catalasas } \\
\text { Peroxiredoxinas (Prx) }\end{array}$ & $\begin{array}{c}\mathrm{H}_{2} \mathrm{O}+\mathrm{GSSG} \\
\mathrm{H}_{2} \mathrm{O}+\mathrm{O}_{2} \\
\mathrm{H}_{2} \mathrm{O}\end{array}$ \\
\hline Óxido Nítrico (NO) & Síntesis de Óxido Nítrico & Glutatión TrxR & GSNO \\
\hline
\end{tabular}

(Klaus y Heribert, 2004).

La reducción gradual del oxígeno molecular mediante la transferencia de un electrón, la producción y la relación de las moléculas de EROS que se encuentran en la tabla 6, se reducen como se muestra en la Figura 4.2.

Los aductos de ADN pueden estar formados como resultado de uniones covalentes altamente electrofílico con el ADN durante la bioactivación. Por ejemplo, los aductos de ADN se han relacionado a la carcinogénesis producida por diversos químicos encontrados en la carne azada (casi carbonizada) o ahumada y, en el humo de cigarro, lo cual puede ser el paso crítico inicial hacia la carcinogénesis (Martínez, 1998; Norberg y Arner, 2001).

Las consecuencias de las modificaciones covalentes en las bases de ADN incluyen las alteraciones en la estructura y subsecuentes procesos de replicación transcripción y reparación. Si la conformación adecuada de ADN no es restituida por los mecanismos de reparación y los aductos persisten, esta alteraciones pueden causar mutaciones y finalmente resultar en el desarrollo del cáncer (Martínez, 1998). 


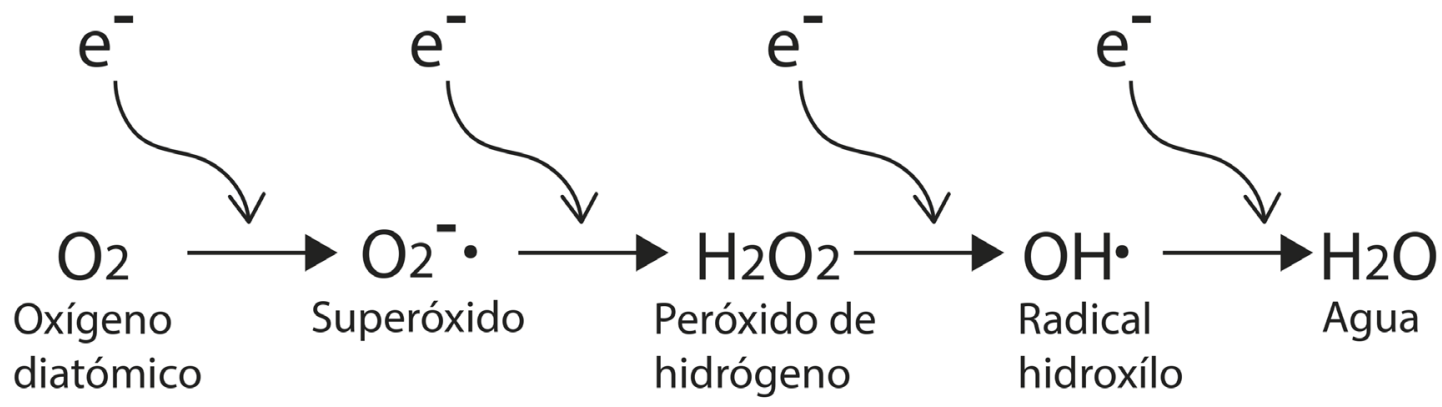

Figura 4.2. Generación de diferentes EROS por la transferencia de energía o reducción univalente secuencial de la formación de especies reactivas no relacionadas en el interior de la célula, formando agua que es fácilmente eliminada (Modificado de Plant, 2003).

Defensa contra infecciones: Cuando los fagocitos son activados, producen EROS en cantidades necesarias para matar bacterias intrusas. Por lo que tienen efectos antimicrobianos (Norberg y Arner, 2001).

Regulación redox de la actividad del factor de transcripción: Las EROs pueden afectar directamente la formación y actividades de todas las moléculas que contienen sulfídrilo, como las proteínas o GSH, por oxidación de su sitio tiol. Este tipo de regulación redox puede tener un efecto sobre proteínas importantes en la transducción de señales y carcinogénesis como la proteína $\mathrm{C}$ cinasa, $\mathrm{Ca}^{2+}$-ATPasa, colagenasa y tirosina-cinasa, receptores de membrana, entre muchas otras enzimas (Martínez, 1998; Norberg y Arner, 2001).

Los EROS implican la producción intracelular de los intermediarios de oxígeno, estos pueden amenazar la integridad de biomoléculas diferentes incluyendo proteínas, lípidos, carbohidratos y sin duda el ADN (Martínez, 1998; Nordberg y Arner, 2001; Plant, 2003).

\subsubsection{Efecto de EROS en proteínas}

Las proteínas son modificadas debido a los EROS, por ejemplo al reaccionar sobre el ligando metálico de muchas metaloproteínas. Debido a la reactividad de los radicales libres con las moléculas insaturadas o que contienen azufre, las proteínas con proporciones elevadas de triptófano, tirosina, fenilalanina, histidina, metionina y cisteína pueden sufrir modificaciones aminoacídicas mediadas por radicales libres. En este sentido se ha observado que enzimas como la papaína, la gliceraldehido-3-fosfato deshidrogenasa e incluso la superóxido dismutasa, que dependen todas ellas de estos aminoácidos para presentar actividad, se inhiben en presencia de radicales libres.

Las reacciones de los radicales libres con estos aminoácidos dan lugar también a alteraciones estructurales en las proteínas provocando entrecruzamientos y fenómenos de agregación, que se ven favorecidos por la formación de puentes disulfuro intra e intermoleculares (Martínez, 1998; Nordberg y Arner, 2001). Los enlaces peptídicos 
también son susceptibles de ser atacados por los radicales libres. Estos enlaces pueden romperse tras la oxidación de residuos de prolina por radicales hidroxilo o superóxido (Martínez, 1998).

\subsubsection{Efecto de EROS en lípidos}

Los radicales libres de hidroxilo e hidropéroxilo y el oxígeno simplemente pueden reaccionar con los ácidos grasos de los fosfolípidos y otros componentes lipídicos de las membranas para formar hidroperóxidos lipídicos. Este proceso de peroxidación lipídica comienza cuando el radical libre quita un átomo de hidrógeno de uno de los carbonos metilenos de la cabeza carbonada para rendir un radical libre lipídico (L). Los ácidos grasos poliinsaturados de la membrana son especialmente susceptibles de ser atacados por radicales libres, puesto que contienen grupos metilenos separados (Nordberg y Arner, 2001).

\subsubsection{Efecto de EROS en carbohidratos}

Los carbohidratos son dañados por los radicales libres en menor proporción que otras moléculas. Azucares como la glucosa, el manitol e inclusive algunos desoxiazucares pueden reaccionar con el radical $\mathbf{O H} \cdot$ para producir sustancias reactivas. Los polisacáridos pueden sufrir un ataque por radicales libres tal, que puede generarse su fragmentación en unidades más sencillas (Nordberg y Arner, 2001).

\subsubsection{Efecto de EROS en ácidos nucleídos}

Los ácidos nucleídos son blanco importante de los EROS. La citotoxicidad producida en gran parte por EROS, es una consecuencia de aberraciones cromosómicas producidas por las modificaciones químicas que sufren las bases y los azucares del ADN al reaccionar con los radicales libres, especialmente con el $\mathbf{O H} \cdot$. Las modificaciones químicas de los nucleótidos provocan, en algunos casos, la ruptura de las hebras del ADN. Por lo que, si el daño que se origina es tan grande que no puede ser reparado, se produce una mutación, o bien, muerte celular (Nordberg y Arner, 2001).

\subsection{COORDINACIÓN A LA RESPUESTA ANTE QUÍMICOS REACTIVOS}

Existen dos mecanismos importantes en el control de respuesta celular ante estrés oxidativo y algunos tóxicos: la activación directa o indirecta de la expresión de genes. Esto es usualmente causado por la expresión alternativa de genes dentro de la célula de modo que los genes cuyos productos son designados de acuerdo con el efecto tóxico de encendido, donde la expresión de los genes se enciende o se apaga.

Las EROS pueden activar a receptores intracelulares que regulan directamente la transcripción de genes dianas, lo que representa la activación directa de la expresión de genes. Estos mecanismos moleculares de interacción con los factores de transcripción de ADN, y cómo esto afecta la expresión de los genes, será revisada más adelante. De 
forma alternativa, las especies químicas o EROS pueden interactuar con otras moléculas dentro de la célula, como ya se menciono antes, y es donde estas moléculas que propagan la señal producen la respuesta celular concreta a la exposición química. Esto es por lo tanto una activación directa de la transcripción génica por estímulos tóxicos (Plant, 2003; Klaus y Heribert, 2004).

En organismos procariotas y hongos, los sistemas de señalización de dos componentes funcionan como sensores redox. En procariontes, los sistemas de señalización de dos componentes usualmente consisten de una histidina cinasa que perciben la señal y una respuesta regulatoria de funciones como un factor de transcripción. Los sensores transmembranales de cinasas con funciones a través de su capacidad de autofosforilar un residuo de histidina en respuesta a la presencia o ausencia de un estimulo externo. El grupo fosfato es subsecuentemente transferido de la histidina a un residuo aspartato como respuesta regulatoria. El cambio conformacional inducido en el regulador de respuesta altera la afinidad de unión al ADN y por lo tanto promueve la expresión de genes de algunos promotores. También en las levaduras de fisión, los sistemas de señalización de dos componentes de histidina cinasa pueden funcionar como sensores ante el estrés oxidativo (Klaus y Heribert, 2004). En contraste con animales y plantas quienes tienen dos componentes de histidinacinasa. Si algunas de las proteínas pueden funcionar como sensores de EROS se encuentra bajo investigación.

La activación de la transcripción de genes es propagada mediante la transducción de señales, esto es parte importante del la coordinación general de la respuesta celular. Estas vías son capaces de responder a un gran rango de estímulos, incluyendo a tóxicos y estrés oxidativo, y provocar un rango de respuestas biológicas incluyendo diferenciación, movimiento, división y muerte celular. Quizá el evento mejor estudiado es la cascadas de transducción de señales de las Proteínas Kinasas Activadas por Mitógenos (Mitogen-activated protein kinase/ MAPK). La importancia de la cascada MAPK para la coordinación de la respuesta celular al estrés fue recientemente demostrada en el nematodo C. elegans, donde se mostró un grado de conservación evolutivo importante en la vía de señalización MAPK (Plant, 2003; Klaus y Heribert, 2004).

El sistema de señalización MAPK (Figura 4.3) existe como una cascada de tres niveles, donde cada cascada responde en coordinación a la repuesta específica de un estímulo. Dentro de cada cascada la respuesta biológica es mediada por una MAPK. La enzima puede llevar a cabo sus funciones una vez que fue activada, vía fosforilación, por una MAPK kinasa (MAPKK). Este a su vez, es activado mediante la fosforilación por una MAPKK kinasa/ (MAPKKK). LA activación de MAPKKK es causada por la presencia de el estímulo (Plant, 2003; Klaus y Heribert, 2004).

Como su nombre sugiere, MAPK actúa mediante la vía de fosforilación con el objetivo de fosforilar proteínas ya sea activar o reprimir su actividad biológica. El objetivo de las proteínas para MAPK es a menudo el factor de transcripción, o coactivador/correpresor y su fosforilación es un paso importante en la formación de la transcripción activa donde el factor de transcripción que se une a el ADN ocasiona la transcripción de los genes. 


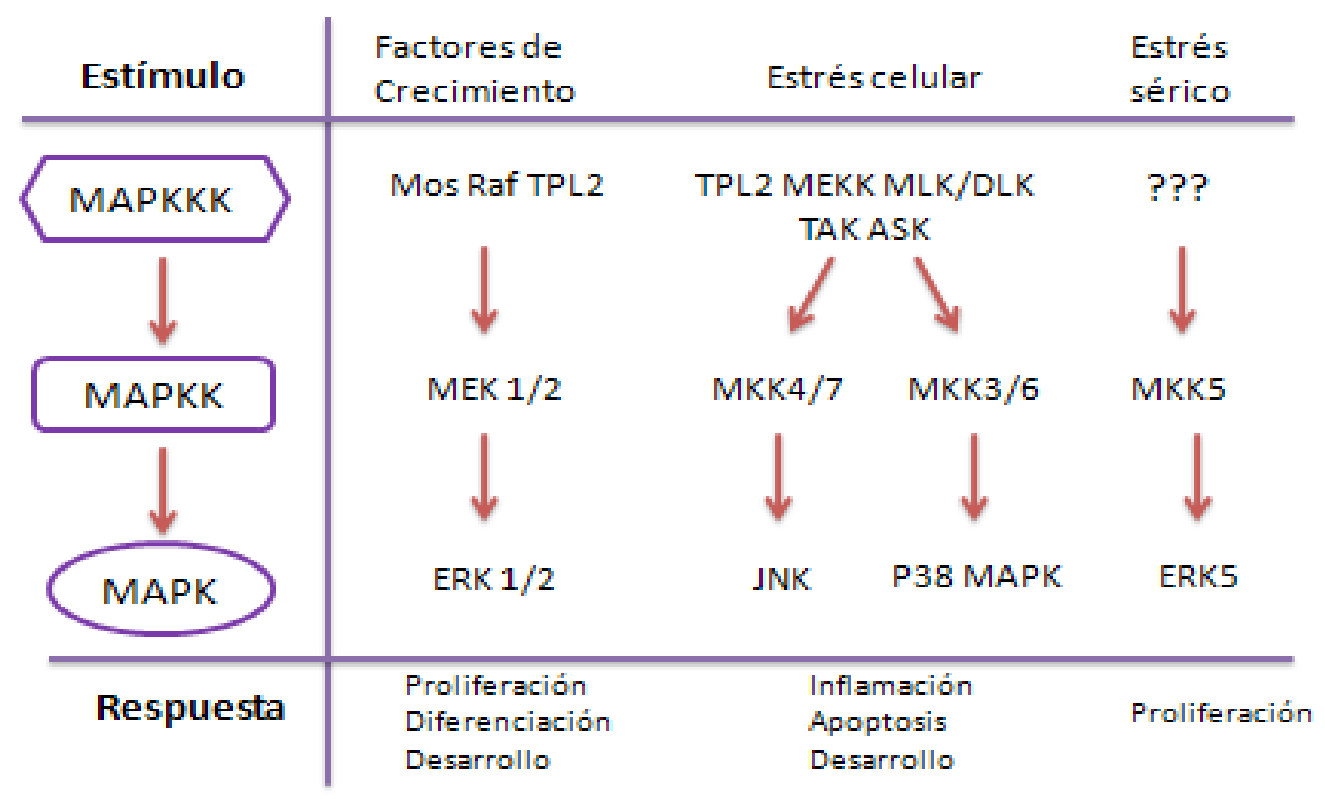

Figura 4.3. Cascada MAPK cinasas en mamíferos (Modificado de Plant, 2003).

\subsubsection{Pequeñas especies químicamente reactivas como señales moleculares}

La consecuencia de la producción de EROS es doble. Primeramente la especie reactiva puede reaccionar con macromoléculas celulares que lo rodean, formando aductos proteicos o de ADN como anteriormente se menciono. Estas reacciones son indeseables, pues ocasiona un enorme daño celular, suficiente como para provocar la destrucción y/o muerte. Sin embargo, los EROS también actúan como señalizadores moleculares intracelulares aunque en proporciones más pequeñas. Las EROS realizan el mayor proceso de señalización molecular, hay varios mecanismos de su producción generalmente controlados y posteriormente se realiza su eliminación de la célula mediante algunos mecanismos o reacciones biológicas (enzimáticas y/o antioxidantes), estas pequeñas moléculas son capaces de trasladarse a pequeñas distancias dentro de la célula.

Los EROS son capaces de ocasionar efectos en numerosos procesos biológicos, desde la proliferación celular a la apoptosis. Estos procesos pueden tomar ambas direcciones, los EROS son capaces de estimular la división celular y también de inhibirla. Para estudiar la medida en que los EROS pueden afectar los niveles de expresión del ADN, puede usarse la tecnología de microarreglos para examinar los cambios en el transcriptoma durante el estrés oxidativo (Plant, 2003).

Chung y colaboradores (2002) estudiaron los cambios en la expresión de células mamarias expuestas a 3 oxidantes, $\mathrm{H}_{2} \mathrm{O}_{2}$, menediona y t-butyl hydroperóxido, usando microarreglos de 17000 genes. Ellos identificaron que 421, fueron alterados por todos los tratamientos, al mostrar que el patrón de expresión total de los genes, fue muy similar, sin tener en cuenta la fuente de los EROS. Con el uso de nuevas tecnologías no solo se identifican genes centrales en la expresión génica mediada por EROS a partir de fuentes oxidantes, sino que también se 
identificaron otros genes que no estaban asociados previamente con la respuesta mediada por EROS. Este trabajo y otros han mostrado un panorama de cambios celulares causados por EROS, formulando hipótesis de donde se muestra como la exposición a EROS resulta en diversos destinos celulares (Figura 4.4).

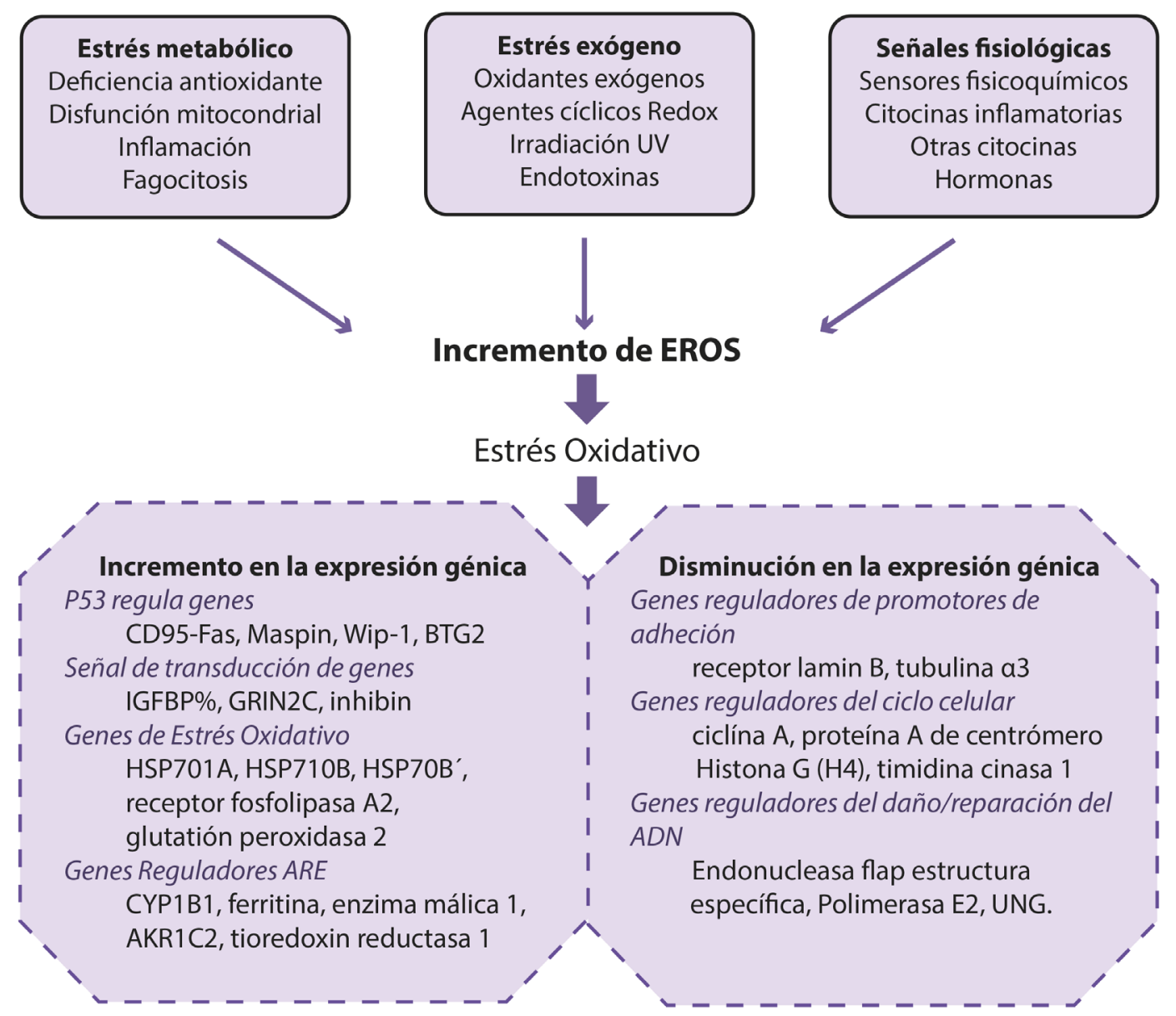

Figura 4.4. Cambios en la expresión génica causados por EROS (Modificado de Plant, 2003).

\subsection{REPARACIÓN DEL DAÑO CELULAR}

\subsubsection{Reparación del daño al ADN}

El daño al ADN no es inevitable por completo, aunque hay numerosas estrategias de defensa que minimizan el riesgo de que estas alteraciones sean permanentes. Estos sofisticados sistemas de protección han sido altamente conservados por el proceso evolutivo. Se han mostrado evidencias, que indican que las células cuentan con múltiples sistemas de reparación del ADN, que operan con distintos mecanismos para enfrentar a la gran variedad de lesiones, que dañan a ésta macromolécula (Gonzales, 2004). 
La reparación pre-replicativa de las lesiones causadas aI ADN por agentes alquilantes, son reparadas básicamente por el sistema de escisión de bases (BER) que elimina las bases alteradas por la acción de las ADN glicosilasas, para varios tipos de daño al ADN, y el sistema de reparación por la proteína alquil-guanina-transferasa (AGT). Se encuentra también el mecanismo de unión de extremos no-homólogos (NHEJ) que ocurre principalmente en las fases G0/G1 y predomina en mamíferos (Gonzales, 2004).

Dentro del sistema de reparación post-replicativa, se encuentra el dado por apareamiento erróneo (MMR) cuya función es mantener la fidelidad del genoma reparando los errores de apareamiento generados durante la replicación y la recombinación. Igualmente existe la recombinación homóloga (HR) que se efectúa sobre la fase $S$ tardía y $\mathbf{G} 2$ y consiste en un proceso de intercambio genético entre secuencias de ADN que son homólogas (Gonzales, 2004). Hay datos que sugieren que las células deficientes en reparación entran en apoptosis y también indican que se puede estimular el arresto de las células en fase $\mathbf{S}$ del ciclo celular por inhibición de la replicación de ADN o indirectamente por la activación de un mecanismo de control de la fase $S$ y posteriormente sufren apoptosis (Gonzales, 2004).

\subsubsection{Reparación del daño a proteínas}

Las enzimas involucradas en la reparación de proteínas dañadas tienen una función fisiológica común; la degradación de proteínas es una parte importante en la regulación de los niveles proteicos dentro de la célula y por tanto en el control de su acción. La mejor vía de degradación proteica es la ubiquitinación, donde las proteínas son marcadas y degradadas en el proteosoma (Plant, 2003). La ubiquitina representa un buen ejemplo de cómo un mismo mecanismo puede regular el control de la transcripción en sus distintas etapas y componentes, el control de la transcripción mediado por ubiquitinación actúa en niveles como: la regulación directa sobre factores de transcripción o su degradación, remodelación de cromatina y modificación de la RNA polimerasa II (Adams, 2003).

En este sistema ubiquitina-proteosoma, las proteínas a degradar son primero ubiquitinizadas es decir conjugadas con varias moléculas de ubiquitina, proteína de 76 aminoácidos y de peso molecular de $8.5 \mathrm{KDa}$. Las enzimas ligasas de ubiquitina, se encargan de reconocer a las proteínas mal conformadas para degradarlas, les adicionan colas de longitud variable de ubiquitina. Gracias a la cola de ubiquitina el proteosoma reconoce al sustrato o molécula a degradar, las linealiza a la vez que libera la ubiquitina. Las proteínas son conducidas al interior del proteosoma 26S, y son escindidas en pequeños péptidos (6-9 aminoácidos) por proteasas, y posteriormente por aminopeptidasas citoplasmáticas, a aminoácidos (Adams, 2003; Plant, 2003).

El proteasoma es un complejo enzimático multicatalítico presente en el citoplasma de las células eucarióticas. Su función es la degradación de proteínas pero cumple un papel muy importante en la vida y destino de la célula, al degradar proteínas implicadas en la transmisión de señales, la regulación del ciclo celular, genes supresores de tumores y señales inductoras de supervivencia celular o de apoptosis. El proteasoma o macromolécula 26S consiste en dos partículas, el núcleo 20S y la partícula reguladora 19S (Fig. 4.5) (Adams, 2003). El núcleo catalítico $20 S$ no puede degradar a las proteínas, necesita tener al menos una subunidad 19S, al unírsele a la partícula $20 S$ la fracción 19S, se forma el proteasoma completo denominado 26S. El núcleo 20S existe como una partícula latente. La partícula 19S es un complejo de 18 subunidades proteicas, de entre 25 y $110 \mathrm{KDa}$, que se unen al núcleo del proteasoma. Las funciones del complejo regulador 195 parecen ser el reconocimiento de la secuencia 
señal de ubiquitina, la desubiquitinación, el desplegamiento de las proteínas y la traslocación de los substratos al interior del complejo 20S (Adams, 2003; Camps, 2004).

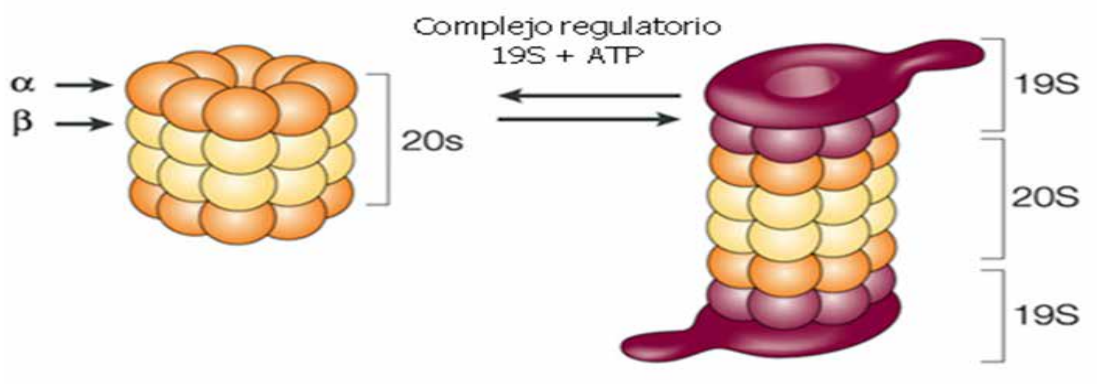

Figura 4.5. Estructura del Proteosoma 26S (Modificado de Adams, 2004).

Cada complejo $19 S$ es capaz de reconocer y unirse a la ubiquitina y escindirla de la proteína diana. Ésta se desnaturaliza perdiendo su estructura terciaria tridimensional y pasa al interior del núcleo catalítico. Además, el complejo 19S tiene actividad ATPasa, la hidrólisis del ATP proporciona la energía para desenrollar a las proteínas desde su conformación tridimensional. La partícula 19S también cumple la función de tapón al impedir que proteínas sin la señal diana de proteólisis penetren en el interior catalítico. La fracción 19S posee actividad isopeptidasa que se encarga de eliminar los residuos de ubiquitina permitiendo su reciclado. Existe otra fracción denominada partícula 11S que se localiza en el citoplasma y su formación se induce cuando se adiciona IFN- gama por lo que se le atribuye un papel importante en la respuesta inmune. El proteasoma se caracteriza por tres actividades frente a péptidos: hidrofóbica (tipo quimotripsina), básica (tipo tripsina) y ácida semejante a las caspasas (hidroliza uniones peptídicas glutamil-peptidil). La actividad tipo quimotripsina representa la función catalítica dominante del proteasoma (Camps, 2004).

La hidrólisis de las proteínas en el proteasoma requiere de dos condiciones imprescindibles, el aporte de energía en forma de ATP y el marcado de las proteínas con una cadena de poliubiquitina. Las principales etapas son: activación de la ubiquitina por un enzima activadora E1, transferencia de la ubiquitina a un enzima de conjugación E2, posteriormente la interacción de los enzimas E2 y una ligasa de ubiquitina E3 llevan a la formación de una proteína poliubiquitinizada que es degradada en el seno del proteasoma 26S (Figura 4.6 ). Este último presenta una estructura cíclica, compuesta de cuatro anillos: dos anillos externos $\alpha$ y dos anillos internos $\beta$. El proteasoma libera, gracias a su subunidad catalítica, el proteasoma 20S, oligopéptidos constituidos por seis a ocho aminoácidos aminoácidos, rápidamente degradados en aminoácidos libres por las peptidasas citosólicas. Esta última fase implica la desubiquitinización de la proteína liberada de las moléculas de ubiquitina, la cual y gracias a su estabilidad puede volver a ser utilizada. Así como el reconocimiento de los substratos proteicos es totalmente específico y dependiente de la señal de ubiquitina, la hidrólisis de las proteínas es completamente inespecífica (Schwarts y Ciechanover 1999; Plant, 2003). 


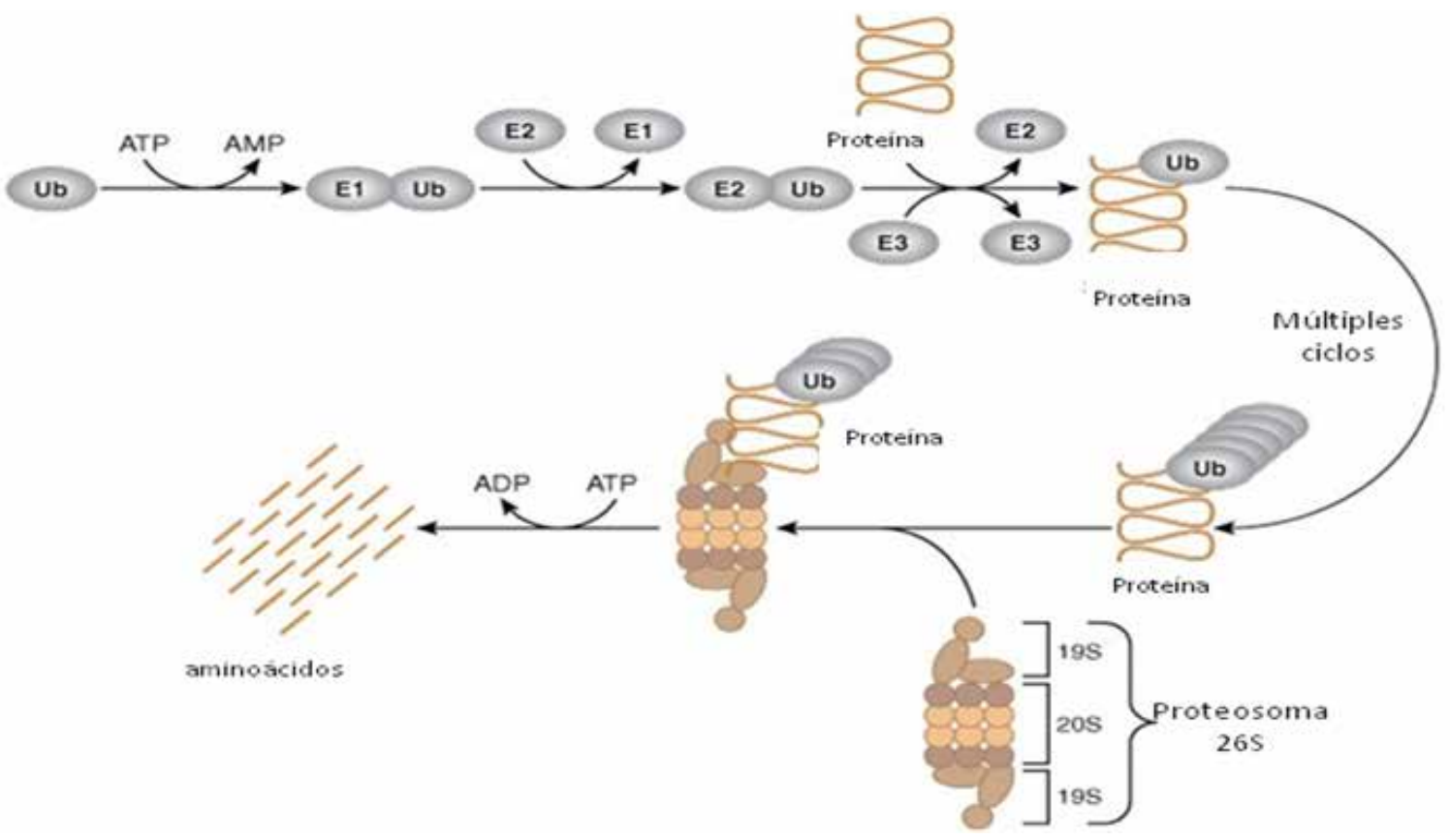

Figura 4.6. Sistema de ubiquitinación para degradación de proteínas (cellsignal.com).

\subsection{REGULACIÓN DE LA APOPTOSIS Y NECROSIS}

Las primeras observaciones de muerte celular fisiológica fueron desarrolladas por Vogt en 1842. El concepto de muerte celular programada fue acuñado por Lockshin y Williams en 1964 y describía la muerte de las células que ocurría en momentos y lugares determinados como eventos programados dentro del plan de desarrollo del organismo (Barcat, 2009; Calderón et al., 2004).

En 1972, John Kerr, Andre Wyllie y Alistar Currie publicaron un articulo pionero describiendo una forma programada de muerte celular a la que denominaron apoptosis, (apoptosis, en griego arcaico, alude a la "caída natural de las hojas en otoño"), hoy en día es uno de los fenómenos más estudiados en biología. Establecieron las diferencias entre los dos tipos de muerte celular: necrosis y apoptosis. Según estos autores, la muerte por apoptosis respondía a un programa de muerte intracelular que podía ser activado o inhibido por una variedad de estímulos tanto fisiológicos como patológicos (Calderón, 2005).

Se pueden distinguir tres tipos morfológicos principales de muerte celular: el tipo I (muerte celular por apoptosis), tipo II (muerte celular autofágica) y tipo III (muerte celular necrótica). Se han descrito detalles de las vías de muerte celular por apoptosis y autofagia y han sido identificados diferentes marcadores bioquímicos. Sin embargo, no se han identificado marcadores de superficie o bioquímicos para la muerte celular necrótica, solo marcadores negativos están disponibles. Estos incluyen la falta de parámetros apoptóticos (activación de caspasas, liberación de citocromo c, etc.) y la cinética diferencial de marcadores de muerte celular. Las células necróticas secundarias se dice que ya han pasado por una fase de apoptosis previa (Edinger, 2004; Krysko et al., 2008) 
La autofagia se caracteriza por la presencia de estructuras autofagicas con una doble membrana; este autofagosoma después se puede fusionar con el lisosoma donde los contenidos son degradados y reciclados (Edinger et al., 2004). Es importante notar que la autofagia es ante todo un mecanismo de supervivencia activa en las células sometidas a diferentes formas de estrés celular. Si el estrés celular continua, la muerte celular por autofagia puede continuar o bien puede desarrollar las características de apoptosis o necrosis (Maiuri et al., 2007; Krysko et al., 2008).

De los tres tipos de muerte, se pueden definir dos de ellos como las clases principales: apoptosis y necrosis, ambas formas de muerte celular son morfológica, bioquímica y fenotípicamente muy distintas (Tabla 2). Apoptosis usualmente se refiere a muerte celular fisiológica o programada; mientras que la necrosis es llamada como muerte celular accidental o patológica (Goottschalk et al., 1995; Edinger et al., 2004).

\subsubsection{Apoptosis}

La apoptosis es un mecanismo de suicidio celular altamente regulado que es importante en procesos biológicos, incluyendo el desarrollo embrionario y la respuesta a la quimioterapia en cáncer; es el principal mecanismo por el cual las células pueden ser fisiológicamente eliminadas en organismos metazoarios (Edinger et al., 2004). Requiere de la activación de un grupo de cisteína-aspartato proteasas llamadas caspasas que son los principales efectores de la apoptosis, capaces de romper proteínas estructurales y funcionales como las del citoesqueleto y proteínas del sistema de reparación del ADN. Las caspasas se expresan y deben ser activadas en el citosol mediante ruptura proteolítica, casi siempre por otra caspasa, formando así una cascada de activación; de acuerdo a su función las caspasas pueden clasificarse como iniciadoras y ejecutoras. La caspasa 3 es una de las más importantes ejecutoras que inicia la vía común final de destrucción celular. La mitocondria es el orgánelo más importante en este mecanismo de muerte, ya que actúa como coordinador central (Wetzel et al., 1999; Calderón et al., 2004). La importancia radica en la liberación de diferentes proteínas desde el espacio intermembranal, tales como el citocromo $c$, quien es requerido como acarreador de electrones en la fosforilación oxídativa, proceso que genera la mayoría del ATP intracelular (Calderón et al., 2004; Carvallo 2007).

Las caspasas han sido divididas de acuerdo a la longitud del predominio y su participación en la cascada proteolítica en dos grupos: Las caspasas iniciadoras 2, 8, 9, 10 que tiene predominios largos que contienen un dominio dominio efector de muerte (DED, por sus siglas en ingles) y un dominio de reclutamiento y activación de caspasas (CAR). Las caspasas efectoras incluyen a las caspasas 3; 6, 7 y tiene un predominio corto. Una de las funciones de las caspasas es inactivar proteínas que protegen a las células de la apoptosis, como es el caso de la fragmentación de una DNAasa activada por caspasas (CAD), la caspasa 3 es un inhibidor de CAD, la que al ser liberada de su inhibidor se activa y produce la fragmentación internucleosomal del ADN. Estas proteasas tienen también como sustratos a proteínas del citoesqueleto como gelsolina y fodrina (básicas para el ensamblaje de filamentos de actina), que al ser fragmentadas contribuyen a la condensación de la cromatina. También degrada a proteínas de la familia de Bcl-2 como Bid y Bax, PKCs, entre otras (Kumar, 2007).

Se han descrito dos vías apoptóticas: la vía intrínseca y la vía extrínseca (Fig. 4.7). La vía intrínseca o mitocondrial es activada por daño al ADN o por estímulos externos, lo cual genera que la activación de p53 promueva la traslocación de Bax a la mitocondria promoviendo la liberación de factores pro-apoptóticos como citocromo-c 
y Smac/DIABLO. El citocromo-c en el citosol promueve el ensamble de Apafl (factor 1 activador de proteasa apoptótica) con la procaspasa 9, formando el apoptosoma, el cual es capaz de activar la caspasa 3 (Wetzel et al., 1999; Plant 2003; Carvallo, 2007).

La vía extrínseca se activa por la familia de receptores de muerte, como CD95 o TNFR, que al ser activados por sus ligandos reclutan proteínas adaptadoras FADD (proteína con dominio de muerte asociado a FAS), que a su vez activa a la caspasa 8 que puede activar directamente a las caspasa 3; La caspasa 8 también puede activar proteolíticamente a Bid, el cual se trasloca a la mitocondria para promover la liberación de citocromo c desencadenando la activación de caspasa 3 (Wetzel et al., 1999, Plant, 2003).

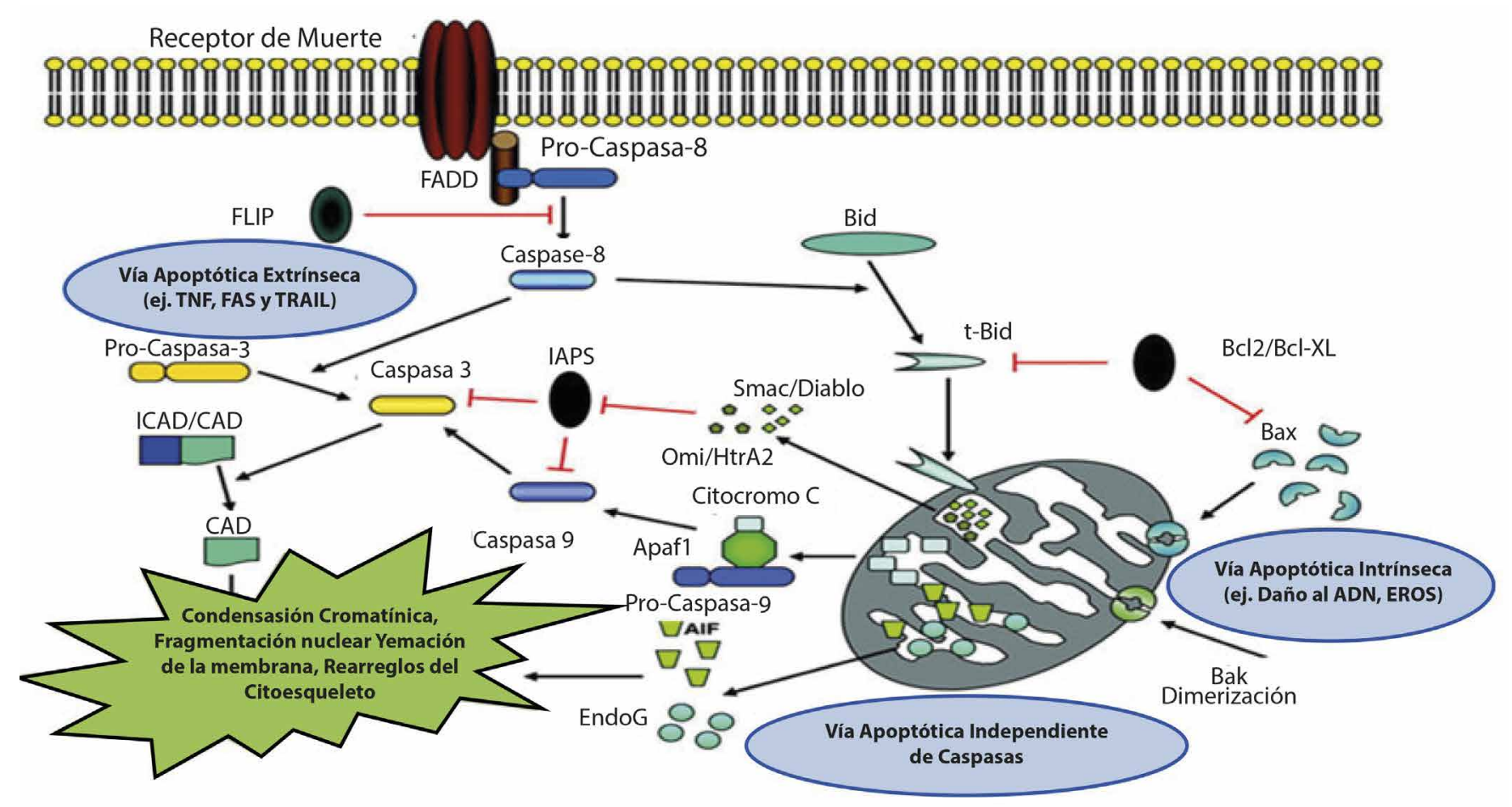

Figura 4.7. Vías de inducción de apoptosis (Modificado de Ghavami et al., 2009).

Quizá la característica más marcada en la apoptosis, es la fragmentación del ADN cada 180 o 200 pares de bases; 146 pares de bases localizadas alrededor de las histonas que componen el nucleosoma y el resto presente en el fragmento de las cadenas de ADN que separa los nucleosomas. Esto ocurre así porque las endonucleasas cortan el ADN donde es accesible, es decir, entre dos nucleosomas (Jordán, 2003).

Las características estructurales de una célula en apoptosis son: el citoplasma comienza a encogerse, hay condensación nuclear que en etapas tempranas de apoptosis puede manifestarse como cromatina marginal y que 
más tarde, conforme avanza el proceso apoptótico, culmina en la fragmentación del material nuclear que puede ser envuelto en cuerpos apoptóticos, y en algunos caso, el núcleo toma la forma de "herradura". Todos estos cambios preparan a la célula para la fagocitosis por los macrófagos (heterofagia). Con el fin de promover este fenómeno las células apoptóticas efectúan cambios en la membrana celular (Leist, 2001; Alberts et al., 2004).

El proceso de apoptosis es conservado en prácticamente todos los organismos. En años recientes, la mayor atención ha sido dirigida al mecanismo molecular de apoptosis y el número de genes que regulan la muerte celular programada en mamíferos, aves, nématodos y otros sistemas. Los genes apoptóticos han sido más estudiados en C. elegans, donde el destino de cada célula ya es conocido (Gottschalk et al., 1995; Zörnig et al., 2001). Cada segundo, varios millones de células del cuerpo humano sufren apoptosis, es decir, en condiciones de homeostasis, cada mitosis es compensada por un caso de apoptosis. Es probable que todas las células del cuerpo humano posean la capacidad intrínseca de apoptosis, incluso en ausencia de la síntesis de nuevas de proteínas (Kroemer et al., 1998).

\subsubsection{Necrosis}

Tradicionalmente se ha pensado que la necrosis es una forma pasiva de muerte celular, la necrosis es el resultado final de una catástrofe bioenergética resultante del agotamiento de ATP a un nivel incompatible con la sobrevivencia celular y se piensa que se inicia principalmente por "accidentes" celulares como es daño tóxico o físico (Edinger, 2004). La necrosis es caracterizada morfológicamente por la vacuolización del citoplasma, muestran citoplasmas pálidos así como daño evidente en la membrana citoplasmica con núcleos intactos en etapas tempranas de necrosis; en cambio las células en estados avanzados del proceso necrótico muestran pérdida del citoplasma y daño irregular en la membrana nuclear con sólo una parte de la estructura nuclear intacta (Alberts et al., 2004). Las células que mueren por necrosis (Tabla 4.2), frecuentemente exhiben cambios en la morfología nuclear pero no en la organización cromatínica, condensación y fragmentación del ADN en 200pb como es común en la apoptosis (Edinger, 2004).

Tabla 4.2. Principales Características de Apoptosis y Necrosis.

\begin{tabular}{ll}
\multicolumn{1}{c}{ Apoptosis } & \multicolumn{1}{c}{ Necrosis } \\
\hline Muerte Fisiológica o Patológica & Muerte accidental, daño tóxico o físico \\
Susceptibilidad estrictamente regulada & No reglamentada o mal regulada \\
Membrana plasmática casi intacta, cambios sutiles en las & Membrana plasmática destruida, lisis de \\
membranas plasmáticas (pérdida de la asimetría de la membrana & orgánulos subcelulares, la célula se hincha \\
antes de la pérdida de la integridad de la membrana), el contenido & \\
celular queda englobado en cuerpos apoptóticos, contracción \\
celular por lo tanto la célula no se hincha.
\end{tabular}


Apoptosis

No existe salida del contenido celular, fagocitosis de los cuerpos apoptóticos.

No inflamación

Participan enzimas celulares causando características bioquímicas y morfológicas incluyendo condensación cromatínica (picnosis), fragmentación nuclear (cariorrexis)

Degradación proteica por proteasas especificas (Caspasas)

Proceso energéticamente activo y requiere de biosíntesis de Proceso energéticamente pasivo proteínas

\section{Necrosis}

Liberación del contenido celular al espacio extracelular, lisis celular y daño en células vecinas

Inflamación

Las características bioquímicas y morfológicas incluyen vacoulización del citoplasma (oncosis)

\section{REFERENCIAS BIBLIOGRÁFICAS}

Adams J. (2003) The proteasome: structure, function, and role in the cell. Cancer Treat Rev. 29:1, 3-9.

Adams J. (2004) The proteosome: a suitable antineoplastic target. Nature Reviews Cancer 4, 349-360.

Alberts B., Bray D., Lewis J., Raff M., Roberts K., Watson J. (2004) Biología Molecular de la Célula.4ª Ed. Ediciones Omega, Barcelona pp. 1362.

Barcat J. (2009) Muerte celular y apoptosis. Medicina (Buenos Aires) 69, 379-381.

Calderón J., Petrone V., Casas F., Gámez C., Gracia I., Ruiz L., (2004) Evaluación inmunohistoquímica y determinación del índice apoptótico en linfomas inducidos por el virus de la enfermedad de Marek, en gallinas reproductoras tratadas con Casiopeína III-ia; $1^{\circ}$ Congreso Química Médica, pág. 22-24.

Camps C. (2004) El complejo ubiquitina proteosoma y la caquexia. Memorias del I simposio SEOM Toledo de ciudadanos continuos en oncología médica.

Carvallo F. (2007) Efectos antiproliferativos y apoptóticos de las Casiopeínas. Tesis de Doctorado. UNAM. Programa de Doctorado en Ciencias de la Producción y Salud Animal UNAM, México D.F.

Edinger L., Thompson B. (2004) Death by design: apoptosis, necrosis and autophagy. Current Opinion in Cell Biology 16, 663-669.

Ghavami S., Hashemi M., Ande S., Yeganeh B., Xiao W., Eshraghi M., Bus C., Kadkhoda K., Wiechec E., Halayko J. (2009) Apoptosis and Cancer: mutations within caspase genes. Med Genet. 46, 497-510.

Gonzales F. (2004) Reparabilidad durante G1 de las lesiones inductoras de Intercambio de Cromátidas Hermanas inducidas por agentes alquilantes en ADN sustituido y no sustituido con BrdU, en células de la glándula salival de ratones in vivo. Tesis de Doctorado en Ciencias. Facultad de Ciencias. UNAM. México. 
Gottschalk A., Quintáns J. (1995) Apoptosis en B-lymphocytes: The WEHI-231 perspective. Immunology and Cell Biology 73, 8-16.

Jordán J. (2003) Apoptosis: muerte celular programada. OFFARM; 22:6, 1-6.

Klaus A. y Heribert H. (2004) Reactive Oxygen Species: Metabolism, Oxidative Stress, and Signal Transduction; Annu. Rev. Plant Biol. 55, 373-399.

Kroemer G., Dallaporta B., Rigon M. (1998) The mitochondrial death/life regulator in apoptosis and necrosis. Rev. Physiol 60, 619-642.

Krysko D., Berghe T., Parthoens E., D’Herde K., Vandenabeele P. (2008) Methods For Distinguishing Apoptotic from necrotic cell and measuring their clearance. Methods in Enzymology 442, 308-337.

Kumar S. (2007) Caspase function in programmed cell death. Cell Death Differ. Jan 14:1, 32-43.

Leist M, Jäättelä M. (2001) Four deaths and a funeral: from caspases to alternative mechanisms. Nat Rev Mol Cell Biol. 2:8, 589-598.

Maiuri, M. C., Zalckvar, E., Kimchi, A., and Kroemer, G. (2007) Self-eating and self-killing: Crosstalk between autophagy and apoptosis. Nat. Rev. Mol. Cell Biol. 8, 741-752.

Martínez C. (1998) Toxicidad de xenobióticos mediada por radicales libres de oxígeno; Ars. Pharmaceutica, 89:1, 5-18.

Medmol. Sistemas de Reparación del ADN (medicina Molecular FIBAO en línea) Disponible en: http://www.medmol.es; $13 / 04 / 2010$.

Nordberg J. y Arner S. (2001) Reactive Oxygen Species, Antioxidants and the mammalian thioredoxin system. Free Radical Biology Medicine 31:11, 1287-1312.

Plant N. (2003) Molecular Toxicology. Editorial BIOS Scientific Publisher. USA pp 149.

Schwartz A., y Ciechanover A. (1999) The ubiquitin-proteasome pathway and pathogenesis of human diseases. Annu Rev. Med. 50, 57-74.

Smart C. y Hodgson E. (2008) Molecular and biochemical toxicology. $4^{\mathrm{a}}$ ed. editorial Wiley, New Jersey pp.901.

Wetzel E. y Green D. (1999) Apoptosis: checkpoint at the mitochondrial frontier. Mutat. Res. 434, 243-251.

Zoning M., Hueber O., Baum W., Evan G. (2001) Apoptosis regulators and their role in tumorgénesis. Biochimica et Biophysica Acta 1551 F1-F37. 


\section{CAPÍTULO}

\section{5 \\ Estudios de caso de toxicidad}

\subsection{GENOTOXICIDAD}

La genotoxicidad puede ser definida como un efecto específico adverso en el genoma de células vivas que durante la duplicación, puede estar expresada como un evento mutagénico o carcinogénico (Carvallo, 2007). Como hemos visto, algunos químicos pueden producir especies reactivas de oxígeno durante su metabolización, o pueden ser reactivas por sí mismas por lo que pueden provocar cambios que encajan en esta categoría (Plant, 2003).

Los agentes genotóxicos son agentes químicos, físicos o biológicos capaces de modificar el material hereditario de las células vivas, como se sabe los cambios genéticos están asociados con efectos adversos a la salud humana, estos incluyen mutaciones genéticas, reordenamientos y aberraciones cromosómicas (AC) (FDA, 2000). Son aquellos que afectan a los ácidos nucleícos y alteran sus funciones. Estas agentes pueden unirse directamente al ADN o pueden llevar a daño indirecto sobre el ADN, afectando a enzimas involucradas en la replicación o, afectar otros participantes involucrados como el huso mitótico, cinetocoros, centrómeros y/o centriolos (University, 2008).

La evaluación del potencial genotóxico de un agente químico o físico es aquella que realiza una valoración de la habilidad de inducir una mutación génica o alguna alteración cromosómica estructural y/o numérica. Las aneuploidías son la mayor causa del fracaso reproductivo humano y un importante contribuyente de los procesos carcinogénicos (Perry et al., 2002).

\subsubsection{Aneugénicos}

Las aneuploidías son anomalías numéricas que afecta a uno o varios cromosomas, pero no a todo el genoma. Una aneuploidía se define como cromosomas de más o de menos al número diploide y/o haploide, de la especie. Esto puede ser inducido por agentes que ejerce su acción sobre diversas estructuras, que se ven involucradas tanto en la división celular, como en los cromosomas mismos (Parry et al., 2002), como consecuencia, se general alteraciones en el reparto equitativo de información genética.

Uno de los proceso que da como resultado la aneuploidía es la no disyunción de cromosomas en anafase, donde las células hijas se convierten en monosómica y disómica (Parry et al., 2002). Este desajuste cromosómico es letal para la célula, por lo tanto, algunos compuestos con actividad aneugénica son altamente citotóxicos, a estos 
agentes que tienen como objetivo el actuar durante la división celular, se les ha encontrado un uso clínico en el tratamiento contra el cáncer (Plant, 2003).

Se ha observado la inducción de aberraciones cromosómicas por varios agentes químicos induciendo aneuploidías: Kirsch-Volders y Parry en 1996, con vincristina; Galloway y colaboradores (1987) con colchicina; Armstrong y colaboradores (1993) con 2,4,5-triclorofenol. La mayor parte de estos compuestos, aun no tienen claro su mecanismo de acción, que da como resultado alteraciones en el número cromosómico, sin embargo, Tinwell y Ashby (1991) concluyen que para el tipo de aberraciones observadas con vincristina y colchicina tiene lugar cuando estructuras como el huso mitótico o los cinetocoros se ven alteradas; y por lo tanto se modifica el reparto equitativo del material genético (Arni y Hertner, 1997).

\section{Alcaloides de la Vinca}

Los alcaloides de la vinca son un conjunto de fármacos derivadas de la planta de bígaro, Catharanthus roseus (Vinca rosea, Lochnera rosea y Ammocallis rosea). Han sido utilizados por sus propiedades anticancerosas, estos son administrados intravenosamente. Después de la inyección, son usualmente metabolizados en el hígado y luego excretados. Sin embargo trabajan de manera dependiente del ciclo celular, parando la mitosis de las células afectadas causándoles la muerte (apoptosis); el mecanismo empieza con la unión a los monómeros de tubulina y no dejando que los microtúbulos (fibras del huso) se formados (Jordán et al., 1991; Harvey et al., 2008). La vinblastina se emplea para el tratamiento de los siguientes tipos de cáncer: de mama, testicular y algunos linfomas (Jordán et al., 1991). La vindestina, es un derivado de la vinblastina, su mecanismo de acción es el mismo, pero se usa preferentemente para padecimientos como leucemia linfocítica aguda, carcinoma del pulmón, leucemia mielógena crónica y cáncer colorrectal (Jordán et al., 1991). La vincristina, es administrada principalmente para padecimientos como leucemia aguda, rabdomiosarcoma, neuroblastoma, enfermedad de Hodgkin (EH) y otros linfomas, y neoplasmas linforreticulares (Jordán et al., 1991). Este compuesto a diferencia de otros alcaloides no causa una severa supresión de la médula ósea (disminución en el conteo sanguíneo).

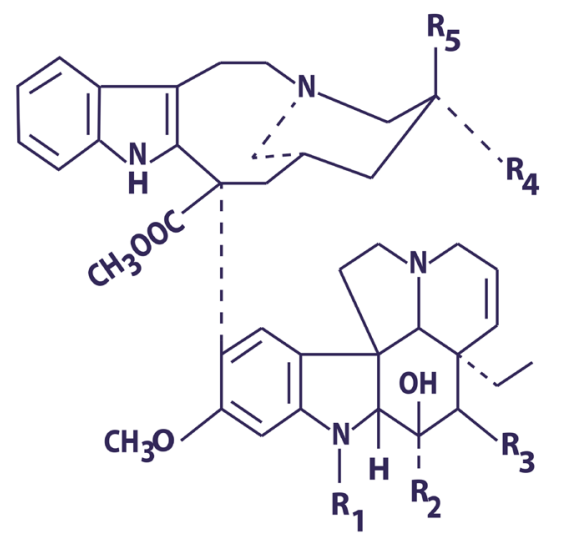

\begin{tabular}{lllllll}
\hline Compuesto & R1 & \multicolumn{1}{c}{ R2 } & \multicolumn{1}{c}{ R3 } & \multicolumn{1}{c}{ R4 } & R5 \\
\hline Vincristina & $\mathrm{CHO}^{2}$ & $\mathrm{COOCH}_{3}$ & $\mathrm{OCOCH}_{3}$ & $\mathrm{CH}_{2} \mathrm{CH}_{3}$ & $\mathrm{OH}$ \\
Vindestina & $\mathrm{CH}_{3}$ & $\mathrm{CONH}_{2}$ & $\mathrm{OH}$ & $\mathrm{CH}_{2} \mathrm{CH}_{3}$ & $\mathrm{OH}$ \\
Vinblastina & $\mathrm{CH}_{3}$ & $\mathrm{COOCH}_{3}$ & $\mathrm{OCOCH}_{3}$ & $\mathrm{CH}_{2} \mathrm{CH}_{3}$ & $\mathrm{OH}$
\end{tabular}

Figura 5.1. Estructura general de Alcaloides de Vinca: Vincrisitina, Vindestina y Vinblastina (Jordán et al., 1991). 


\subsubsection{Clastógenos}

Los compuestos que causan aneuploidías tienen interferencia directa con estructuras involucradas en la división celular, actúan durante la segregación cromosómica en la meiosis y no interaccionan de manera directa con el ADN; por lo tanto, inducen aberraciones cromosómicas numéricas. Sin embargo, la actividad clastogénica causan alteraciones cromosómicas, teniendo una acción directa sobre el ADN, induciendo rompimientos de las cadenas del ADN y se originan desplazamientos (Plant, 2003). Los agentes clastógenos están estrechamente relacionados con la formación de Aberraciones Cromosómicas Estructurales (ACE, cambios en la morfología de los cromosomas), evidencian el reordenamiento del material genético al llevarse a cabo los rompimientos de cadena doble del material genético. Un clastógeno conocido es el cloruro de cadmio.

El cadmio es uno de los metales pesados más tóxicos para los sistemas biológicos, lo podemos encontrar en el agua potable, aire atmosférico o incluso en los alimentos (Al-Hashem et al., 2009). Este metal tiene uso industrial generalizado, en la producción de aleaciones, chapados metálicos y en la manufactura de una variedad de pigmentos, tales usos lo llevan a representar un riesgo potencial en la exposición laboral, en el ingreso al cuerpo mediante la inhalación, durante cualquiera de los procesos antes mencionados. También está presente en la dieta, pero debido a su pobre absorción intestinal, no representa un ruta de exposición importante (Plant, 2003).

La toxicidad del cadmio se manifiesta en el hígado y en el testículo, seguido por diversos efectos agudos, sin embargo la exposición crónica a este metal, pude inducir daño renal. La causa exacta de este daño aún es desconocida; sin embargo recientes investigaciones sugieren la generación de especies reactivas de oxígenos por el cadmio, e inducir así, efecto clastogénico. Se ha investigado por varios grupos, el papel de las metaloproteínas (MT) en la respuesta celular al cadmio. Las MT son el principal grupo de proteínas intracelulares, que se unen al zinc para ejercer propiedades antioxidantes.

\subsubsection{Mutágenos}

La tercera clase de xenobióticos genotóxicos, son los interaccionan con el ADN en una pequeña escala, aunque el resultado final puede ser solo tóxico. Los mutágenos interactúan únicamente con pequeñas regiones del ADN y causan un daño localizado en la doble hélice (Plant, 2003).

El cloruro de vinilo (CV) es un componente monomérico ampliamente usado en los plásticos con cloruro de polivinilo (CPV). Durante la manufactura del CPV, los trabajadores pueden estar expuestos al monómero de cloruro de vinilo, históricamente la exposición aguda ha sido asociada con un sin número de efectos adversos, incluyendo vértigo, letargo, pérdida auditiva o de la visión, e incluso pérdida de conciencia, en exposición a altas dosis. Los resultados de exposiciones crónicas puede ocasionar un tipo de cáncer raro en el hígado, haemangiosarcoma. Algunos trabajos experimentales en animales, demostraron que el metabolismo mediado por el citocromo P450 produce un epóxido reactivo, que a menos que sea desactivado ya sea por la conjugación con glutatión o la acción de la epóxido hidrolasa, puede reaccionar con el ADN y/o proteínas para producir aductos (Villanueva et al., 2001; Plant, 2003). El cloruro de vinilo se absorbe principalmente por la vía respiratoria, pasa al torrente sanguíneo, se absorbe también por el aparato digestivo cuando contamina alimentos y bebidas, y por vía cutánea es poco frecuente. 
Una vez absorbido, sigue el proceso de biotransformación y eliminación (Figura 5.2), sin embargo, existen estudios que indican que la capacidad de metabolización del CV se satura rápidamente (100ppm) (Villanueva et al., 2001). La transformación metabólica se produce principalmente en el hígado, donde el monómero es sometido a oxidación transformándose en óxido de cloroetileno (OCE), compuesto inestable que se transforma en cloroacetaldehído. Existe evidencia de que el OCE puede ser el responsable de los efectos biológicos del CV. Finalmente, el cloroacetaldehído se puede conjugar con glutatión o cisteína o se oxida para dar paso al ácido monocloroacético, que se elimina por orina. Los metabólitos urinarios de CV son la hidroxietil-cisteína, la carboxietil-cisteína (como tal o $\mathrm{N}$-acetilada), y trazas de los ácidos monocloroacéticos y tiodiglicólico. Una pequeña porción de metabólitos se excreta por la bilis (Villanueva et al., 2001).

Existe una gran cantidad de trabajos que reportan sobre sus efectos genotóxicos y mutagénicos, demostrando un incremento en la frecuencia de aberraciones cromosómicas (AC) e intercambio de cromátidas hermanas (ICH), en sujetos expuestos y en su descendencia (aun que esto disminuye con el nivel de exposición), se presenta un aumento en el número de abortos y partos prematuros, además de un incremento en las malformaciones del Sistema Nervioso Central SNC, en la descendencia.

\subsection{HEPATOTOXICIDAD}

El hígado es un tejido blanco de la toxicidad de miembros específicos de todas las clases de tóxicos y toxinas naturales. La reacción adversa a drogas (RAD) es un problema de salud que contribuye a la morbilidad y mortalidad de los individuos, sin embargo, la inducción de daño hepático por drogas, es una de las principales razones, de que nuevas fármacos no cumplan con la aprobación regulatoria o sean removidos del mercado. Por ejemplo, el medicamento Rezulin para diabetes tipo II, fue removido del mercado después de causar daño hepatocelular agudo en individuos susceptibles; mientras que el daño al hígado por repetidas exposiciones a dosis tóxicas de etanol es el principal problema de sanidad en humanos (Park et al., 2005; Wallace y Meyer, 2008).

La biotransformación de compuestos lipofílicos en derivados solubles en agua que son más fácilmente excretados, es el papel fisiológico del hígado, el hígado recibe más del $80 \%$ del flujo sanguíneo del tracto gastrointestinal y tiene una gran capacidad de biotransformación fase I y II. Las enzimas citocromo P450 juegan un papel fundamental en el metabolismo de diversos compuestos (Park et al., 2008). La estructura y función del hígado predispone a la toxicidad de los químicos. Los hepatocitos son expuestos por vía oral a xenobióticos sin modificación sistémica o dilución ya que pueden fluir directamente hacia el hígado por el torrente sanguíneo, que también permite la absorción de nutrientes por el tracto gastrointestinal (Wallace y Meyer, 2008).

La clasificación de los xenobioticos que inducen hepatotoxicidad se basa en un patrón de incidencia y morfología histopatológica. Los xenobióticos hepatotóxicas muestran una amplia incidencia y relación dosis-respuesta y pueden llegar a tener resultados experimentales similares, en animales y en humanos. La incidencia del daño por hepatotóxicos no perceptibles, es limitada a individuos susceptibles y resulta de reacciones de hipersensibilidad o conversiones metabólicas inusuales, que pueden ocurrir debido a polimorfismos en genes del metabolismo de xenobióticos. Morfológicamente el daño hepático varía dependiendo del tiempo de exposición; los principales marcadores de exposición aguda implican función celular y viabilidad que se manifestan histopatologicamente como fibrosis, colestasis, esteatosis y necrosis (Castell et al., 1997; Wallace y Meyer, 2008). 


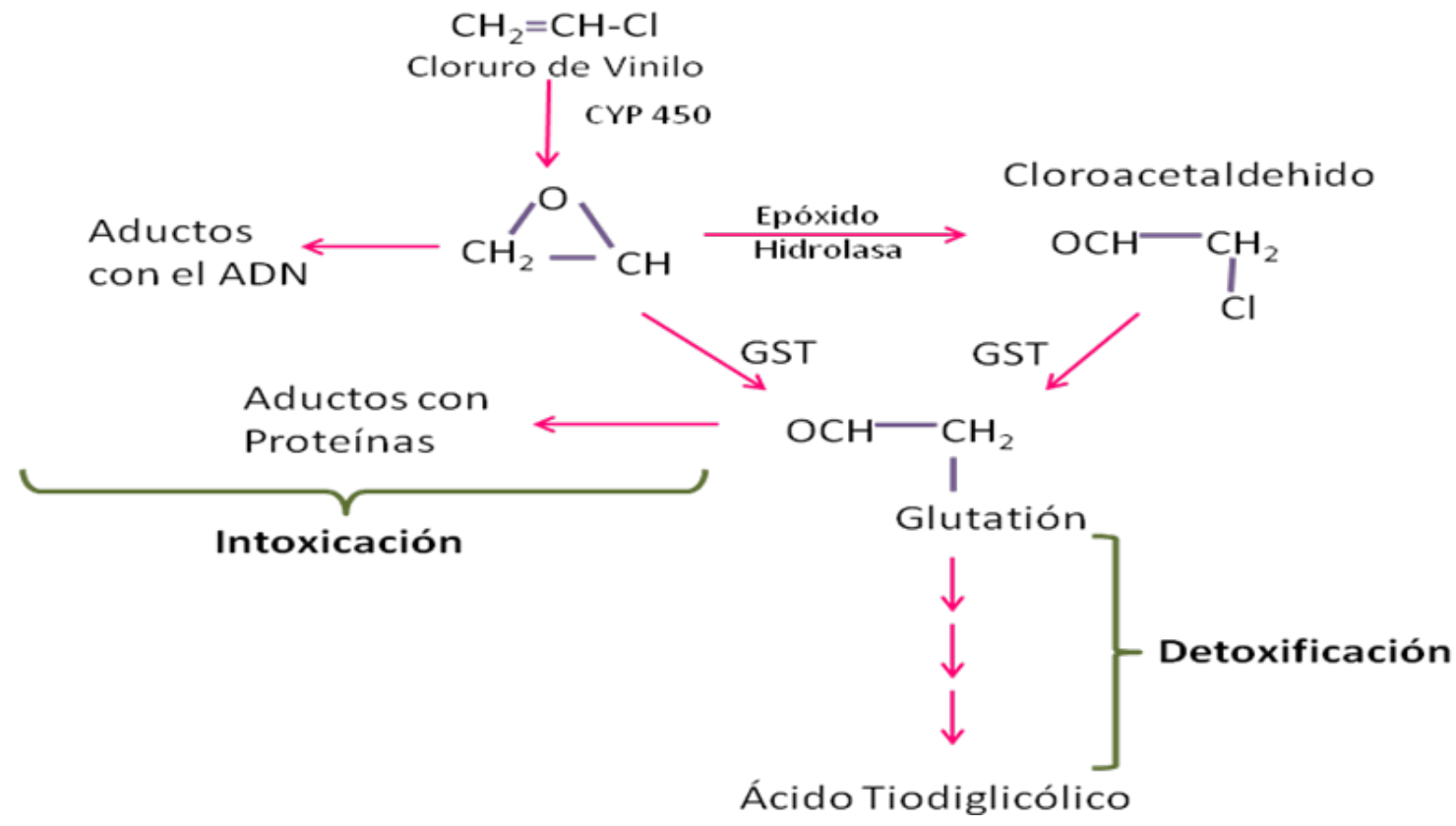

Figura 5.2. Toxicidad del cloruro de vinilo (Modificado de Plant, 2003).

El mecanismo de hepatotoxicidad más directo es a través de interacciones específicas de un químico con los componentes celulares y la consecuente modificación en sus funciones. El mecanismo más común, involucra efectos secundarios por la interacción de agentes tóxicos; eso incluye: agotamiento de moléculas celulares, como es el ATP y GSH; radicales libres y daño oxidante, en lípidos de las membranas particularmente; unión covalente de metabólitos reactivos a moléculas celulares fundamentales; y colapso de los gradientes iónicos (Jaeschke et al., 2002; Wallace y Meyer, 2008).

Existen básicamente seis mecanismos propuestos para las alteraciones hepáticas que pueden ser inducidas por xenobióticos y la forma en que algunos orgánelos intracelulares son afectados, define el patrón de la enfermedad (Bertolami, 2005): 1. Involucra reacciones de alta energía del CYP450 que deterioran la homeostasis del calcio con ruptura de las fibras intracelulares y la lisis del hepatocito. 2. Deterioro de las proteínas transportadoras relacionadas con el flujo de ácidos biliares (mecanismo propuesto para la toxicidad hepática de compuestos del tipo fibrato). 3. Reacción inmune debida a la formación de metabólitos unidos a enzimas del metabolismo hepático de fármacos hipolipemiantes (bajan los niveles de lípidos en sangre). 4. Hepatotoxicidad por las células $\mathbf{T}$ con inflamación adicional mediada por neutrófilos. 5. Apoptosis mediada por TNF y Fas. 6. Estrés oxídativo y daño a orgánelos intracelulares.

Uno de los xenobióticos más conocidos como causantes de hepatotoxicidad es el tetracloruro de carbono $\left(\mathrm{CCL}_{4}\right)$, este ha sido ampliamente reconocido como un modelo tóxico y ha sido el objetivo de muchos estudios toxicológicos in vivo e in vitro. El primer sitio de toxicidad y carcinogénesis es el hígado; al causar daño hepático también provoca degeneración grasa o esteatosis, necrosis celular, fibrosis y cirrosis. Esto ocurre en muchas especies y a través de múltiples vías de exposición. En la mayoría de estudios genotóxicos y mutagénicos el $\mathrm{CCL}_{4}$ ha mostrado 
resultados negativos, cuando se han encontrado efectos positivos, estos han estado estrechamente asociados con citotoxicidad o estrés oxidativo o lipoperoxidación, así que en términos generales no es considerado un agente mutagénico directo. Los efectos mutagénicos, si ocurren, son generados a través de mecanismos indirectos resultando en daño oxidativo y lipoperoxidación y bajo condiciones de citotoxicidad, la bioactivación del $\mathrm{CCL}_{4}$ puede generar efectos genotóxicos.

En la Figura 5.3 se muestra el principal modo de acción propuesto para el $\mathrm{CCL}_{4}$ que requiere de varios eventos para poder desencadenar en carcinogénesis, el incremento en la división celular coincide con el incremento en la frecuencia de daño genético que puede sobrepasar los mecanismos de reparación del ADN, resultando en un incremento en la frecuencia mutagénica y cáncer (Manibusan et al., 2007).

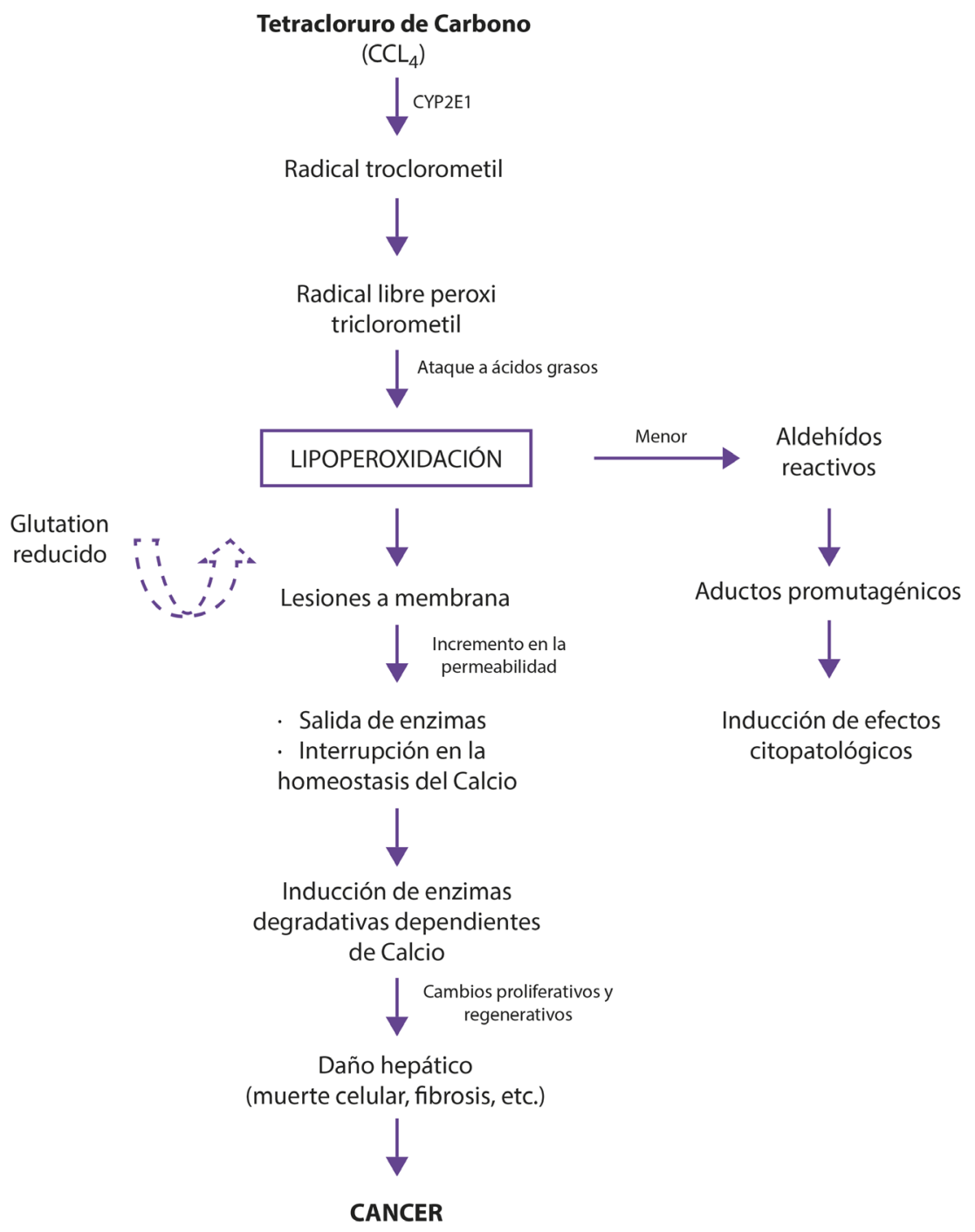

Figura 5.3. Mecanismo de acción propuesto para el Tetracloruro de Carbono (Modificado de Manibusan et al., 2007). 
Los órganos más afectados por la toxicidad del tetracloruro de carbono son el hígado y el riñon. En experimentos con ratones y ratas se ha mostrado que el tetracloruro de carbono puede inducir la formación de hepatomas y carcinomas hepatocelulares. Dado que las dosis que inducían tumores hepáticos eran más altas que las que inducían toxicidad celular, es probable que la capacidad cancerígena del tetracloruro de carbono sea consecuencia de sus efectos hepatotóxicos (ATSDR, 2003).

\subsection{NEFROTOXICIDAD}

La actividad terapéutica o tóxica de un fármaco depende de la dosis, de la pauta de administración y de otros parámetros farmacológicos que determinan la concentración del principio activo en el tejido diana. Otro de los factores que pueden determinar la acción tóxica de un fármaco o xenobiótico es la susceptibilidad relativa de las células, que puede aumentar cuando se encuentran expuestas a determinadas condiciones fisiopatológicas o patológicas.

El riñón es particularmente vulnerable a la acción de fármacos y toxinas, ya que es un órgano que recibe mayor irrigación por gramo de tejido y es la principal vía de eliminación de fármacos y de sus metabólitos. Distintos segmentos de la nefrona pueden estar expuestos a efectos de un fármaco o de sus metabólicos, dependiendo de los diferentes mecanismos que median su eliminación (Rivas et al., 1995).

En una forma similar al hígado, el riñón es un órgano particularmente susceptible a los efectos tóxicos de diversos xenobióticos. Ambos tienen un gran flujo sanguíneo (el riñón recibe alrededor del $25 \%$ de sangre procedente del la actividad cardiaca) lo que significa que la distribución del compuesto en este órgano es alta. Por tanto, estos dos órganos tienen una gran capacidad metabólica y pueden activar xenobióticos (Plant, 2003).

Una razón más para medir la toxicidad observada en el riñón, es el papel esencial que juega este órgano en la excreción. El riñón es uno de los mayores órganos involucrados en la excreción de pequeños metabólitos (PM $<300$ ), y por esta razón los compuestos pueden acumularse en este órgano en niveles potencialmente tóxicos inclusive en cantidades mayores que en otros órganos (Plant, 2003).

En resumen, el que una célula renal sea esencialmente vulnerable a la acción de la nefrotoxina depende de si es blanco para la acción del fármaco, el fármaco se biotransforma en las células renales, el fármaco se concentra en la orina, se capta y se acumula en las células renales, existen procesos concomitantes que aumenten la susceptibilidad de estas células renales (por ejemplo, la isquemia que se pone de manifiesto en tratamientos con aminoglucósidos).

Una sustancia nefrotóxica puede ejercer su efecto sobre la célula renal bien de forma directa (por unión a la membrana plasmática o captación celular), o bien de forma indirecta (por liberación de mediadores vaso activos y producción de isquemia). La citotoxicidad directa es la causa más común de nefrotoxicidad, aunque la isquemia concomitante es capaz de agravar el efecto tóxico renal de un determinado xenobiótico (Rivas et al., 1995).

Existe una gran variedad de xenobióticos o fármacos, que pueden tener un efecto nefrotóxico (Tabla 5.1 ), además de los tóxicos ambientales constantemente usados en procesos industriales, los más relacionados con estos efectos son los metales pesados, hidrocarburos, varios solventes, plaguicidas como el paraquat y mezclas de todos estos como se ilustran en la tabla 5.1 . 
Tabla 5.1. Sustancias químicas de origen industrial relacionadas con lesiones renales.

\begin{tabular}{lll} 
& Plomo & Arsénico (metaloide) \\
Metales & Cadmio & Cobre \\
& Cromo & Mercurio (metal líquido) \\
& Oro & Talio \\
\hline Tetracloruro de carbono & Tetrafluormetileno \\
& Tolueno & Triclorometano \\
& Cloroformo & Disulfuro de Carbono \\
Hidrocarburos & Percloroetileno & Metanol \\
& Dicloroacetileno & Etilenglicol \\
& Bencenos halogenados & \\
\hline Mezclas & Gasolina & Solventes desengrasantes \\
& Inertes de plaguicidas & Solventes de pinturas (tiner) \\
\hline Otros & Sílice & Silicón \\
\hline & Paraquat & Hexaclorobutadieno \\
\hline
\end{tabular}

(Rivas et al., 1995).

\subsubsection{Antibióticos}

Los aminoglicosidos, como la estreptomicina, son un amplio grupo de antibióticos compuestos de un aminoazúcar unidos por un enlace glicosídico a un inositol, los aminoglicósidos son usados en el tratamiento de infecciones causadas por bacterias Gram-positivas y actúan por la inhibición de la traslocación de la cadena proteica naciente de los sitios A a $\mathbf{P}$ en el complejo ribosómico. En condiciones normales el uso de aminoglicósidos está controlado debido a su toxicidad, estas precauciones se deben a los niveles excesivos de consumo por la población pues los niveles de antibiótico requeridos para inhibir la traslocación bacteriana no son suficientemente grandes como para causar efectos adversos sobre la traslocación en las células del individuo infectado, sin embargo, el consumo de grandes cantidades de este fármaco, puede ocasionar nefrotoxicidad (Plant, 2003; De la Cruz et al., 2009).

En los últimos años, el uso de la gentamicina ha sido asociado con un sustancial riesgo de nefrotoxicidad. La excreción renal de la gentamicina, producto de procesos de filtración y transporte tubular expone elevadas concentraciones del antibiótico a una extensa área de superficie del endotelio capilar glomerular y del epitelio tubular, cuya consecuencia es la inducción de la nefrotoxicidad (De la Cruz et al., 2009). Estudios in vitro han demostrado que la Gentamicina se une a los fosfolípidos ácidos de la membrana del ribete en cepillo de la célula tubo renal. Moestrup y colaboradores (2001) han sugerido que la glicoproteína (gp330) de alto peso molecular llamada megalina, sería el receptor de gentamicina en el túbulo proximal. 
Estudios previos han demostrado que el efecto nefrotóxico de la gentamicina puede ser mediado por EROS ya que se ha demostrado un incremento significativo de hidroperóxidos lipídicos y radicales hidroxilo en animales tratados con este agente. Por otro lado, estudios recientes sugieren que los radicales libres como los aniones superóxido e hidroxilo, son mediadores de la falla tisular isquémica y de la fisiopatología de enfermedades renales. En particular se ha demostrado in vitro la generación de peróxido de hidrógeno en dos modelos de fallo renal agudo (De la Cruz et al., 2009).

Existen trabajos que comprueban el daño renal producido por la gentamicina, mostrada en la disminución significativa de la filtración glomerular, con descenso del aclaramiento de creatinina (depuración de creatinina, método para estimar clínicamente el índice de filtración glomerular), coincide con el aumento de malondialdehído (subproducto derivado del metabolismo de los lípidos) y disminución de las enzimas antioxidantes como glutatión peroxidasa y glutatión reductasa. Se ha concluido que la gentamicina induciría un daño mediado por radicales libres, peróxidos lipídicos y otros metabólitos reactivos intermediarios, formados por acción del aminoglucósido sobre los fosfolípidos de la membrana. Esto provocaría cambios estructurales en la célula renal que culminarían con necrosis tubular renal (De la Cruz et al., 2009).

\subsubsection{Arsénico}

El arsénico es un metaloide que en la naturaleza se encuentra en estado sólido, en el agua, en el aire; como un contaminante en los alimentos tanto en forma orgánica como inorgánica. Además es un subproducto de numerosos procesos industriales, que incluyen la producción de cobre, plomo y otros metales; así como en el proceso de combustión del carbón. Estudios epidemiológicos proveen evidencia de que el arsénico es un carcinógeno, que induce cáncer en la piel, pulmón, vejiga, hígado, riñón y posiblemente otros órganos que muestran exposición crónica a agua o aire contaminados por el arsénico, o simplemente por uso industrial (Liu et al., 2000). De tal forma que también esta contemplado en la lista de agentes ambientales que son capaces de inducir neuropatía, en humano (Goodrum et al., 2008).

La exposición humana al metaloide puede llevarse a cabo por dos diferentes rutas: ingestión a través de su exposición en el medioambiente, usualmente a partir de fuentes de agua contaminada, y por la vía de inhalación en la exposición por procesos industriales. La inhalación crónica de arsénico da como resultado un incremento en la incidencia de diversos tipos de neoplasias, asociadas a una segregación desigual de los cromosomas durante la división celular, en este sentido, el arsénico puede ser clasificado como un aneugénico. Además, se ha observado que la exposición al arsénico presenta una amplia variedad de respuestas celulares, incluyendo el arresto del ciclo celular, la disrupción del citoesqueleto, aberraciones cromosómicas e inclusive apoptosis (Plant, 2003). Como se ve con los aminoglicósidos, la toxicidad en el riñón probablemente resulta del papel que juega en la excreción, este órgano. La concentración de arsénico antes de la excreción ocurre en los riñones o el tracto urinario y por lo tanto la toxicidad se sitúa aquí.

El mecanismo exacto que enfatiza a estos cambios es aún desconocido, pero es probable que se deba a la interacción con especies reactivas de oxigeno y/o de nitrógeno liberadas durante la exposición al metaloide. Para investigar los mecanismos moleculares de la toxicidad con arsénico Yih et al. (2002) utilizó la tecnología de los microarreglos para examinar los cambios en la expresión génica, seguida de la exposición de fibroblastos 
humanos a arsénico. Utilizo un microarreglo de 568 genes humanos, e identifico 133 genes con expresión alterada como respuesta a la exposición aguda de los fibroblastos humanos al arsénico. Estos genes pueden ser agrupados en seis tipos distintos dependiendo del patrón temporal y modificación en la dirección causados por la exposición.

Entre los genes cuyo perfil de expresión fue alterado se relacionaron con varios productos proteicos que están asociados con el control de la transcripción, metabolismo de proteínas, regulación del ciclo celular y señalización intracelular. Identificar los cambios en el perfil de la expresión génica seguidos de la exposición al arsénico, provee de información importante para el entendimiento de los mecanismos moleculares que resalten el establecimiento de las respuestas celulares, lo cual tiene como consecuencia la apertura de nuevas líneas de investigación en la comprensión de ésta toxicidad (Plant, 2003).

\subsection{TOXICIDAD DEPENDIENTE DE RECEPTORES}

Anteriormente, se han tratado conceptos y ejemplos sobre el daño de algunos agentes químicos sobre las células a través de su interacción directa con componentes celulares, o la acción de sus metabólicos. Sin embargo, muchos químicos también interactúan con moléculas celulares que transmiten sus efectos a través de las células, alterando procesos en cascada; estos son los receptores.

\subsubsection{Receptor aril hidrocarburo (RAh)}

El Receptor Aril hidrocarburo (RAh) fue identificado por primera vez en 1976 y desde entonces ha sido clasificado como un ligando que activa un factor de transcripción básico (Puga et al., 2002; Ichihara et al., 2007; Jiang et al., 2007; Fritz et al., 2009). El gen codificante para el RAh ha sido identificado en todas las especies de mamíferos estudiadas y en algunos invertebrados como el nematodo $\boldsymbol{C}$. elegans. En común con otros ligandos que activan factores de transcripción este existe en el citosol como un complejo con una molécula chaperona HSP90 cuando se carece del ligando. La unión al ligando causa un cambio conformacional, la disociación de HSP90 y heterodimerización con el traslocador nuclear RAh (TNRA). Entonces, este complejo trasloca al núcleo, donde se puede unir a algunos elementos específicos de respuesta a xenobióticos (REX) y activa la expresión génica (Figura 5.4).

El RAh está involucrado en la inducción de un gran número de genes, que se han dado a conocer como la genes en batería que responden a hidrocarburos aromáticos (HA). Estos genes se involucran tanto en el metabolismo fase I y Fase II, frecuentemente la expresión de enzimas fase I y Fase II se acompaña de la exposición a diversos compuestos como respuesta que ayuda a desechar el compuesto de forma rápida y eficiente del cuerpo. ¿Por qué entonces la inducción vía RAh a menudo resulta en un punto tóxico crítico? Para esto, hay dos respuestas relacionadas; primero los ligandos por sí mismos y, segundo, la relativa inducción de genes en batería (Ah) inducidos por los primeros (Plant, 2003; Ichihara et al., 2007). 


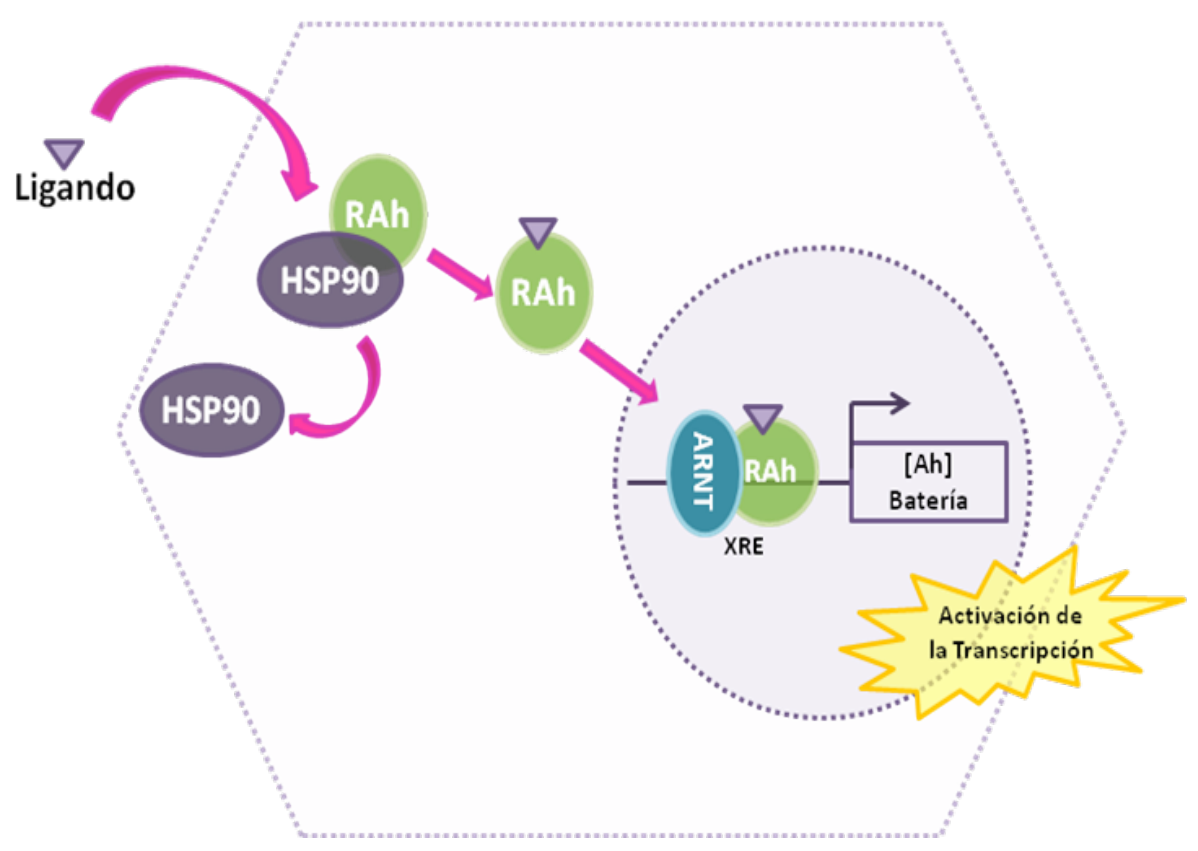

Figura 5.4. Activación de la transcripción de genes en batería (Modificado de Plant, 2003).

Los ligandos de RAh pueden incluir algunos compuestos heterocíclicos que están presentes en el ambiente y que son producidos durante procesos industriales. Esto incluye las aminas aromáticas heterocíclicas formadas durante la cocción de carnes a altas temperaturas, y en el humo de cigarro, los hidrocarburos aromáticos policíclicos y los policlorados bifenilicos (Fritz et al., 2009). La mayoría de estos compuestos forman intermediarios altamente reactivos durante su metabolización, y por lo tanto, incrementan la proporción del metabolismo lo que resulta en un incremento en la frecuencia de formación de aductos (Puga et al., 2002; Plant, 2003; Ichihara et al., 2007).

El segundo factor se asocia al incremento de la incidencia de efectos asociados a la toxicidad con la activación de RAh, aumenta la expresión génica, que es importante aclarar, no es la misma en todos los genes de respuesta al RAh.

Como hemos visto, la toxicidad no solo se debe a la producción o presencia de especies reactivas, sino también a la proporción de su eliminación del cuerpo. Es este el equilibrio general que determina si los metabólicos tóxicos se acumulan o no. En el caso de expresión de los genes en batería (Ah) la de CYP450 Fase I, generalmente se induce a concentraciones bajas del ligando en comparación con otros genes de la misma clase. Por ejemplo, la expresión del gen CYP1A1 es inducida en una concentración 1000 veces menor de TCDD que la expresión del gen UGT1A6 (Puga et al., 2002; Hee et al., 2007; Ichihara et al., 2007; Kawajiri y Fujii, 2007). Estas diferencias llevan a las desigualdades en la proporción de producción y eliminación de intermediarios reactivos y puede aumentar la porcentaje de toxicidad observado (Plant, 2003).

El estudio de ARh de genes baterías puede proveer de más pistas sobre el papel endógeno del ARh. Como los genes batería pueden estar involucrados en el metabolismo de compuestos endógenos así como de xenobióticos, 
coordinar la regulación de la "batería" que puede afectar estos procesos. Mientras que previamente hemos descrito que la producción de intermedios reactivos y especies reactivas de oxígeno se forman durante un metabolismo desigual como una función negativa con riesgo de toxicidad, esto es importante, puesto que las especies reactivas de oxigeno también son moléculas de señalización celular y son de gran importancia en la regulación de procesos celulares como apoptosis y división celular.

Los ARh, en común con muchos ligandos que activan factores de transcripción, pueden usar la alternativa de heterodimerización para regular la expresión génica. Se ha mostrado que ARh interactúa con la proteína de retinoblastoma, y este complejo actúa como un supresor de la expresión génica. El mecanismo exacto de esta supresión es aun desconocido, pero esta inhibe la transcripción dependiente de E2F, que ocasiona el arresto del ciclo celular (Figura 5.5).

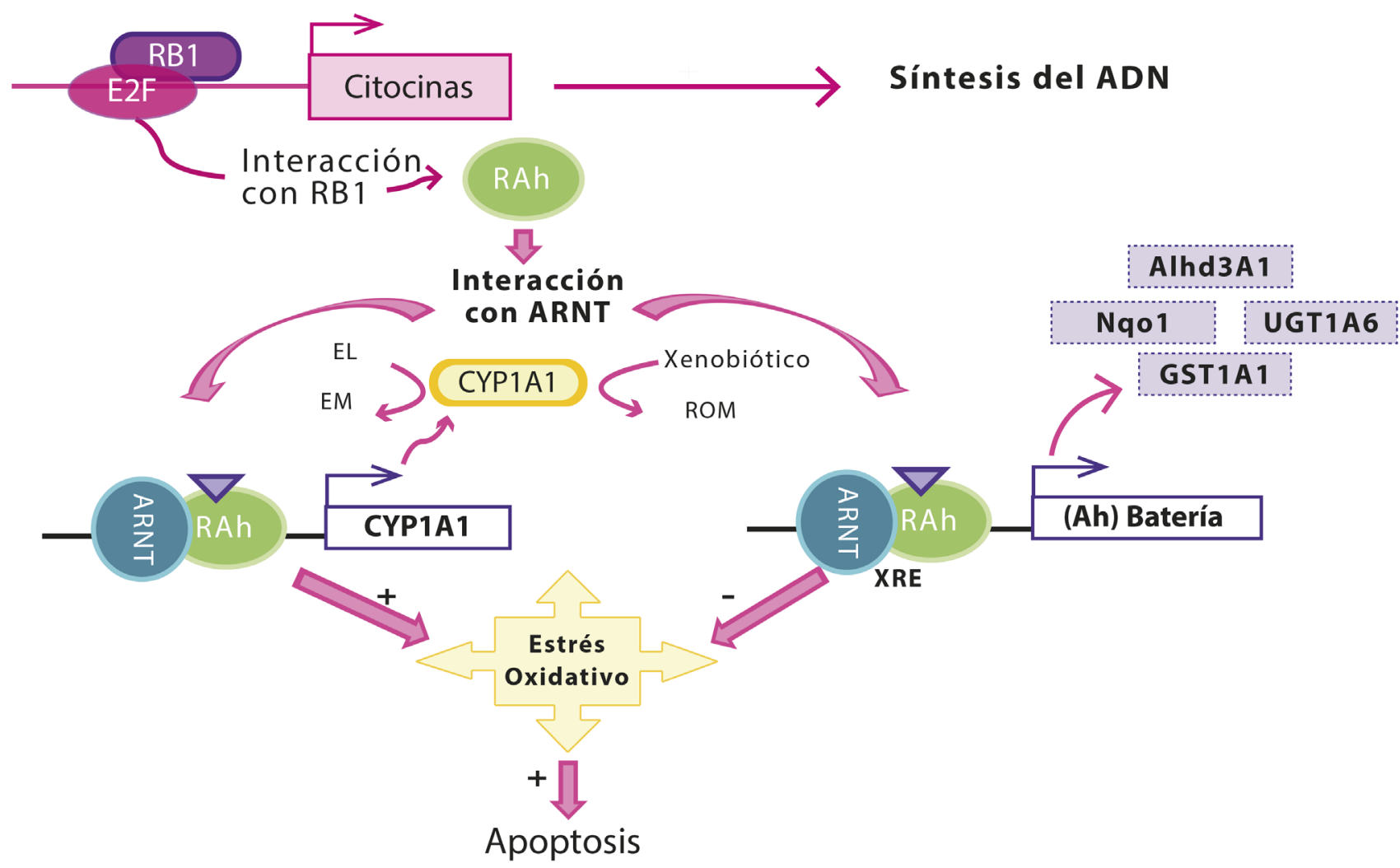

Figura 5.5. Papel del RAh en la señalización celular (Modificado de Plant, 2003).

Es importante mencionar que RAh tiene un acoplamiento con algunas cascadas de señalización celular que transducen las señales en una dirección alternativa de proliferación, arresto del ciclo celular o apoptosis. Por lo tanto, un cambio en la proteína activadora del RAh por variación genética puede generar un proceso de carcinogénesis a 
nivel pulmonar. Con mayor frecuencia se ha estudiado el polimorfismo de RAh con cDNA, donde existe un cambio de un aminoácido: arginina por lisina, en la posición 554. Este cambio resulta en un incremento de la actividad significativa de CYP1A1. Sin embargo, la relación entre el gen polimórfico RAh (que incluye el cambio), y el riesgo de padecer cáncer pulmonar aun no se han establecido (Jin et al., 2007).

\subsubsection{Receptor N-metil-D-aspartato (NMDA)}

Los receptores NMDA son uno de los principales ligandos ionotrópicos del cuerpo, regulan el transporte de $\mathrm{Na}^{+}, \mathrm{K}^{+}$ y $\mathrm{Ca}^{2+}$. Los receptores NMDA son estimulados por glutamato, podría decirse que es el neurotransmisor excitatorio más importante en el cerebro. Mientras que la estimulación es vital para la neuromodulación dentro del cuerpo, el exceso de estimulación resultan en excitotoxicidad y muerte neuronal, la excitotoxicidad mediada por NMDA ha sido ligada con un sin número de desordenes neurológicos (Plant, 2003).

El glutamato es el principal neurotransmisor excitatorio del SNC, puede participar en los procesos de transmisión nociceptiva a nivel espinal, siendo el principal responsable de la rápida transmisión sináptica. La acción del glutamato en las vías del dolor está mediada en su mayor parte a través de receptores ionotrópicos (AMPA y NMDA). La activación de los receptores NMDA juega un papel importante en la neurotransmisión excitatoria y la plasticidad sináptica del SNC (Neira y Ortega, 2004).

Los receptores del L-glutamato son los encargados de mediar la neurotransmisión excitatoria en el cerebro, siendo además importantes en la adquisición de la memoria, el aprendizaje y en algunos desórdenes neurodegenerativos. Los receptores de este neurotransmisor han sido clasificados de acuerdo a sus propiedades farmacológicas y electrofisiológicas en dos grandes grupos: receptores ionotrópicos y metabotrópicos. Los receptores ionotrópicos están subdivididos a su vez en receptores N-Metil-D-aspartato (NMDA) y en receptores no N-Metil-D-aspartato (Ruiz y Quito, 2008).

Los receptores NMDA están asociados con los procesos de aprendizaje y memoria, el desarrollo y la plasticidad neural, así como con los estados de dolor agudo y crónico que intervienen en el inicio y mantenimiento de la sensibilización central asociada a daño o inflamación de tejidos periféricos (Neira y Ortega, 2004).

Los receptores NMDA se localizan en las células del asta posterior de la médula espinal; después de la sinapsis, son los encargados de mediar la reacción generada por la descarga polisináptica de fibras aferentes primarias nociceptivas.

Un ejemplo donde los receptores NMDA median la toxicidad es el caso del Amoniaco. El amoniaco es una sustancia química que se forma dentro del cuerpo durante la degradación de proteínas. Bajo condiciones fisiológicas normales el amoniaco es removido del cuerpo antes de que este pueda llegar a niveles tóxicos atreves de la acción del ciclo de la urea, incorporando amoniaco en urea para la excreción. Sin embargo, en situaciones en las que está comprometida la función del hígado, como la cirrosis donde los niveles de amoniaco en la sangre pueden llegar a niveles tóxicos y dar como resultado encefalopatía hepática (lesión cerebral mediada por el hígado). El amoniaco no parece ser un agonista para los receptores NMDA, entonces ¿Cómo este causa la activación de receptores? Una posible explicación para estos efectos, es el amonio abre indirectamente los canales iónicos NMDA, lo que causa despolimerización de la membrana celular, apertura de los canales NMDA y liberación del $\mathrm{Mg}^{2+}$ (Plant, 2003). 


\subsection{NEUROTOXICIDAD}

La neurotoxicidad es un término que hace referencia a aquellas alteraciones funcionales, estructurales y bioquímicas producidas en el Sistema Nervioso (SN) y que conllevan a la manifestación de diferentes clases de efectos adversos como consecuencia de una exposición a un xenobiótico. Un efecto adverso implica un cambio que produce una desregulación o alteración del SN. La naturaleza de dicho cambio puede ser neuroquímica, morfológica, o relacionada con la conducta y puede manifestarse transitoria o permanentemente. Los xenobióticos o sus metabólitos, responsables de este efecto adverso, se denominan agentes neurotóxicos (Braojos y Lampurlanés, 2010).

Todas las partes del sistema nervioso son susceptibles a daño tóxico. Cuando el daño altera las funciones del Sistema Nervioso Periférico (SNP) el proceso de enfermedad es llamado neuropatía tóxica. El SNP es la parte del sistema nervioso externo, incluye los nervios craneales, la espina dorsal y ventral, nervios espinales y ganglios. El Sistema Nervioso Central (SNC) consiste en el cerebro y el cordón espinal, trabaja a base de mecanismos de excitación balanceada con inhibición; estas funciones son llevadas a cabo por neurotransmisores como el glutamato y GABA, respectivamente. Otros neurotransmisores, como la aceticolina y dopamina, están localizados en diferentes regiones, llevan a cabo diferentes funciones como es el control del movimiento o la respuesta emocional. El tejido neural contiene muchos tipos celulares, debido a que cada uno es especializado en estructura y función, su respuesta a un neurotóxico puede ser muy diferente (Bannon, 2005; Blake, 2008; Goodrum et al., 2008).

La complejidad del funcionamiento y anatomía del SN, su interrelación con otros sistemas y la falta de capacidad regeneradora de las neuronas, dificulta en ocasiones el poder establecer qué tipo de mecanismo de acción emplea un agente neurotóxico. No obstante, las exposiciones a sustancias neurotóxicas pueden producir tres tipos de alteraciones principales:

- Alteraciones sensoriales, en cualquiera de los cinco sentidos. Una gran variedad de sales inorgánicas, compuestos organofosforados, compuestos de plomo, etc., producen pérdida de funciones sensoriales.

- Alteraciones motoras, lo que puede conducir a parálisis de menor o mayor grado (p. ej. Compuestos tipo Hidracida isonicotínica).

- Alteraciones en la capacidad de aprendizaje, pérdida de memoria, cambios emocionales (irritabilidad, aprensión, etc.). El monóxido de carbono estaría en este grupo.

Algunos neurotóxicos directos interfieren la función del sistema nervioso en el proceso de interacción con el neurotransmisor. Por ejemplo, la concentración sináptica del neurotransmisor puede ser alterada por agentes tóxicos que interrumpen la síntesis del neurotransmisor (ej. atrazina y ditiocarbamatos disminuyen la síntesis de norepinefrina), la liberación (ej. heptacloro y deltametrin induce liberación de dopamina), recaptación (ej. metilmercurio bloquea los transportadores de glutamato), y metabolismo (ejem., los orgánofosfatos bloquean la descomposición de acetilcolina a acetilcolinesterasa). Los receptores neurotransmisores, canales iónicos y moléculas de señalización intracelular son blancos frecuentes de toxinas naturales, metales y otros agentes (Bannon, 2005; Blake, 2008). Existen tres mecanismos generales de acción neurotóxica que determinan la interacción directa entre el SN y el xenobiótico o sus metabólitos. 


\subsubsection{Neuropatías}

Este mecanismo hace referencia a aquellas sustancias que actúan directamente sobre las neuronas, provocando su degeneración e incluso su muerte. El proceso de degeneración neuronal, una vez que ha tenido lugar, es irreversible y permanente. En general, el efecto provocado por esta clase de agentes neurotóxicos se caracteriza por la aparición de encefalopatías, produciendo en algunos casos una disfunción global y, en otros, un efecto más concreto, debido a la especificidad del neurotóxico por un grupo de neuronas determinadas dando lugar a pérdida de funcionalidad particular. Por ejemplo, el trimetilestaño produce un daño neuronal difuso con inflamación celular y necrosis, siendo el hipocampo la parte del cerebro más vulnerable; sin embargo, el mecanismo neurotóxico todavía no se conoce con exactitud. Los compuestos orgánomercuriales entran dentro de esta categoría de agentes neurotóxicos; entre ellos, uno de los más estudiados es el metilmercurio, que afecta sobre todo a las neuronas del córtex visual y del córtex del cerebelo, provocando un daño neuronal evidente (Braojos y Lampurlanés, 2010).

\subsubsection{Axonopatías}

En este caso, el agente neurotóxico actúa directamente sobre el axón. El axón degenera y provoca una desnaturalización de la mielina que lo envuelve, lo que puede producir un "gap" o ruptura del axón quedando el cuerpo neuronal intacto. La consecuencia principal de este hecho es la dificultad en la transmisión del impulso nervioso. Si la acción neurotóxica tiene lugar sobre los axones del SNC, el proceso es irreversible; por el contrario, el efecto tóxico sobre los axones del SNP puede ser reversible. En las axonopatías, los axones de mayor longitud son afectados en mayor grado que los de menor longitud debido a su mayor superficie de contacto. Algunos ésteres organofosforados pueden producir graves axonopatías debido a la degeneración de los axones distales, central y periférico, sin llegar a provocar el conocido efecto colinérgico, como en el caso del tri-o-cresil fosfato (TOCP). Los hidrocarburos alifáticos son otro claro ejemplo de sustancias que inducen neuropatías axonales (Braojos y Lampurlanés, 2010).

\subsubsection{Mielinopatías}

El agente neurotóxico interacciona directamente con la mielina o con las células mielinizantes (o productoras de mielina) (oligodendrocitos en el SNC y células de Schwan en el SNP). La mielina se desnaturaliza, produciendo la separación con el axón (edema intramielínico) y la consiguiente pérdida selectiva de la misma (desmielinización). La gravedad de este efecto depende directamente de la extensión de la desmielinización, y sí son, el SNP o el SNC, los sistemas afectados. La principal consecuencia de este hecho es la alteración de la transmisión del impulso nervioso, o en casos graves, cuando la desmielinización es más extensa, puede producirse un bloqueo de la transmisión del mismo. Algunos metales, como el plomo y el telurio, ejercen su acción neurotóxica sobre las células de Schwan en el SNP, mientras que el hexaclorofeno y trietilestaño ejercen su acción directamente sobre la mielina (Garza et al., 2005; Braojos y Lampurlanés, 2010). 


\subsection{TERATOGÉNESIS}

Se define como teratogénesis o dimorfogénesis la alteración morfológica, bioquímica o funcional, en el feto, que es detectada durante su gestación, al nacimiento o con posterioridad. Estas alteraciones pueden clasificarse en mayores (focomelia) o menores (retraso en el desarrollo del comportamiento (Alván et al., 1995).

Los medicamentos pueden dañar al feto en cualquier periodo del embarazo, aunque el periodo de mayor riesgo es el primer trimestre ya que durante la fase embrionaria (18-60 días, post-fertilización), tiene lugar la formación de la mayoría de los órganos (Organogénesis). Los agentes teratógenos causan anormalidades en los siguientes procesos celulares: división, migración, y apoptosis, afectando la histogénesis general o alterando la expresión génica de grupos de células particulares, y cambiar así las características celulares.

No todas las malformaciones pueden ser atribuidas al uso de fármacos. La causa del $40 \%$ de las malformaciones es de origen desconocido. De un 12 a un $25 \%$ de las malformaciones congénitas son defectos genéticos, siendo el síndrome de Down el más frecuente de este grupo. Otro $20 \%$ son debidos a interacciones entre factores hereditarios y factores ambientales. De un 5 a un $9 \%$ de las malformaciones son atribuidas a factores ambientales como agente único. Estos factores ambientales pueden ser enfermedad o infección de la madre, productos químicos o fármacos. Se calcula que del 2 al $5 \%$ de las anomalías congénitas son atribuidas a fármacos, también existen las infecciones como rubeola, citomegalovirus y toxoplasmosis. La rubeola uno de los agentes virales mejor conocidos que pueden causar teratogénesis. Se incluyen, también, enfermedades maternas como diabetes y epilepsia (Azarbayjani, 2001; Ehrenstein et al., 2010). En la tabla 5.2, se enlistan algunos compuestos utilizados en la clínica, con potencial teratogénico.

Hace décadas se creía que la placenta servía de barrera que protegía al feto de los efectos adversos de los fármacos. El "desastre de la talidomida" cambió completamente esta ídea, demostrando que la exposición del feto a fármacos durante los periodos críticos de desarrollo podía producir daños irreversibles. A pesar de las altas tasas de malformaciones (20-30\%) y de sus características especiales la teratogenicidad de la talidomida no fue sospechosa durante años. El daño producido por la talidomida ha sugerido la posibilidad de que cualquier fármaco pueda ser una nueva talidomida (Landeiro et al., 2002).

Inicialmente la talidomida se comercializó como un tratamiento para las convulsiones epilépticas, más tarde se demostró que este tratamiento era inefectivo. Después se utilizó en ensayos clínicos como un nuevo antihistamínico como tratamiento de la alergia. Tras un tiempo, comprobaron que no tenía efecto alguno. Sin embargo, en cada una de estas pruebas que se realizaron se observó que sí era bastante efectivo como sedante. Al final el uso del fármaco fue para tratar nauseas, ansiedad, insomnio y los vómitos matutinos de las embarazadas (Franks et al., 2004).

La talidomida es uno de los teratógenos humanos más potentes. La ingestión de una sola dosis de talidomida durante el comienzo del embarazo puede provocar graves malformaciones en el feto. La malformación más conocida presentada a consecuencia de la administración de talidomida es la focomelia (ausencia de la mayor parte del brazo o de la pierna y la presencia de manos en forma de aleta). En los casos más graves, los bebés carecían por completo de extremidades. Además de que causa malformaciones en: ojos y oídos, corazón, genitales, riñones y el tracto gastrointestinal (TGI), inclusive los labios y la boca (Franks et al., 2004).

\section{4}


Tabla 5.2. Xenobióticos con potencial teratogénico.

\begin{tabular}{|c|c|c|}
\hline Xenobióticos & Blanco terapéutico & Efectos teratogénicos \\
\hline Inhibidores ECA & Hipertensión & $\begin{array}{l}\text { Oligohidramnios; retraso en el crecimiento } \\
\text { intrauterino }\end{array}$ \\
\hline Antiepilépticos & Anticonvulsivos & $\begin{array}{l}\text { Defectos en: SNC, corazón, ojo, TIG, } \\
\text { sistema genitourinario, dimorfismos } \\
\text { faciales, hipoplasia digital,retraso en el } \\
\text { crecimiento }\end{array}$ \\
\hline Ciclofosfamida & Cáncer & $\begin{array}{l}\text { Defectos esqueléticos y oculares; paladar } \\
\text { hendido }\end{array}$ \\
\hline Danazol & Endometriosis & $\begin{array}{l}\text { Masculinización externa de genitales } \\
\text { femeninos }\end{array}$ \\
\hline Dietilestilbestrol & Píldora "de la mañana siguiente" & $\begin{array}{l}\text { Carcinoma genital (mujeres); } \\
\text { anormalidades en el tracto genital (hombres } \\
\text { y mujeres) }\end{array}$ \\
\hline Litio & Enfermedades mentales & Defectos cardiacos \\
\hline Quinina & Malaria & Sordera; abortos \\
\hline Talidomida & Enfermedades inmunopatológicas & $\begin{array}{l}\text { Reducción de extremidades; defectos: } \\
\text { cardiacos, urogenitales, renales, } \\
\text { orofaciales, oculares y TIG, anomalías } \\
\text { nerviocraneales, microtía }\end{array}$ \\
\hline
\end{tabular}

TIG (Tracto Gastrointestinal), ECA (Enzima Convertidora de Angiotensina), adaptado de Polifka y Friedman (2002).

La molécula de la talidomida es un análogo del ácido glutámico, consiste en enantiomeros S (-) y R (+) que se interconvierten bajo condiciones fisiológicas (Figura. 5.6). La forma $S(-)$ inhibe potentemente la liberación del factor de necrosis tumoral (TNFa) de las células mononucleares sanguíneas; mientras que la forma $\mathrm{R}(+)$ parece actuar como sedante, probablemente mediada por los receptores del sueño en el prosencéfalo (Franks et al., 2004).

Hasta ahora se plantean seis principales sitios de acción, que afecta la talidomida: replicación o transcripción del $A D N$, síntesis o función de factores de crecimiento, síntesis o función de integrinas, angiogénesis, condrogénesis y lesión o muerte celular. Se cree que la talidomida compite con el factor de transcripción SP1 en la unión a sitios ricos en GC, al unirse se reduce la expresión génica mediada por SP1 causando los efectos observados. El factor de crecimiento tipo insulinico 1 (IGF1) y el factor de crecimiento fibroblastico 2 (FGF2), estimulan la transcripción de las integrinas av y $\beta 3$; el resultado de la integrina dimérica av $\beta 3$ estimula la angiogénesis en el desarrollo de las extremidades normales (Figura 5.7) (Stephens et al., 2000).

Los mecanismos de tertogénesis mediada por la talidomida han sido un tema importante en el pasado, actualmente el tema de la talidomida ha emergido, considerada principalmente como una droga terapéutica. En 1997, la United States Food and Drug Administration (US-FDA, por sus siglas en inglés), aprobo a la talidomida en el tratamiento de 
eritema nodosum leprosum, una fase aguda y debilitadora de la lepra. A partir de esto se ha propuesto a la talidomida en tratamientos de otros desordenes: baja de peso por tuberculosis, ulceras y baja de peso asociada a VIH (virus de la inmunodeficiencia humana), y cáncer. Sin embargo esto ha incrementado la controversia relacionada con su utilización, ya que a pesar de una regulación estricta sobre su uso, han surgido nuevos casos de teratogénesis, por el uso indebido. Si se conociera la naturaleza exacta del mecanismo de teratogénesis se podría identificar con certeza que parte de la estructura química de la talidomida que es responsable de los tales efectos. Y entonces diseñar una droga relacionada que mantenga su eficacia contra los padecimientos antes señalados, pero sin los efectos adversos conocidos, y por tanto incrementar la su utilidad en esta nueva área terapéutica.

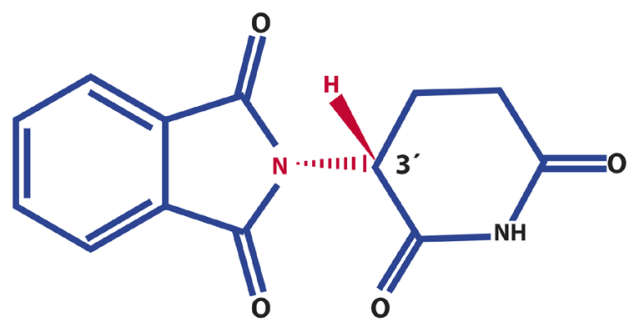

Talidomina $\mathbf{R}(+)$

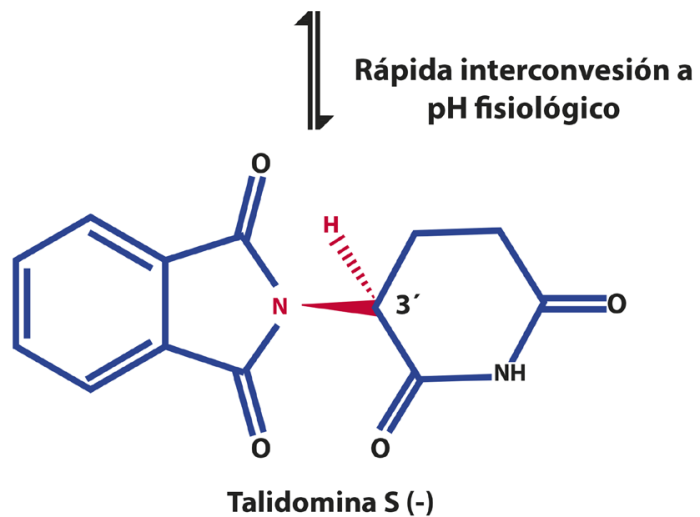

Figura 5.6. Enantiomeros de la molécula de Talidomida (Modificado de Franks et al., 2004). 


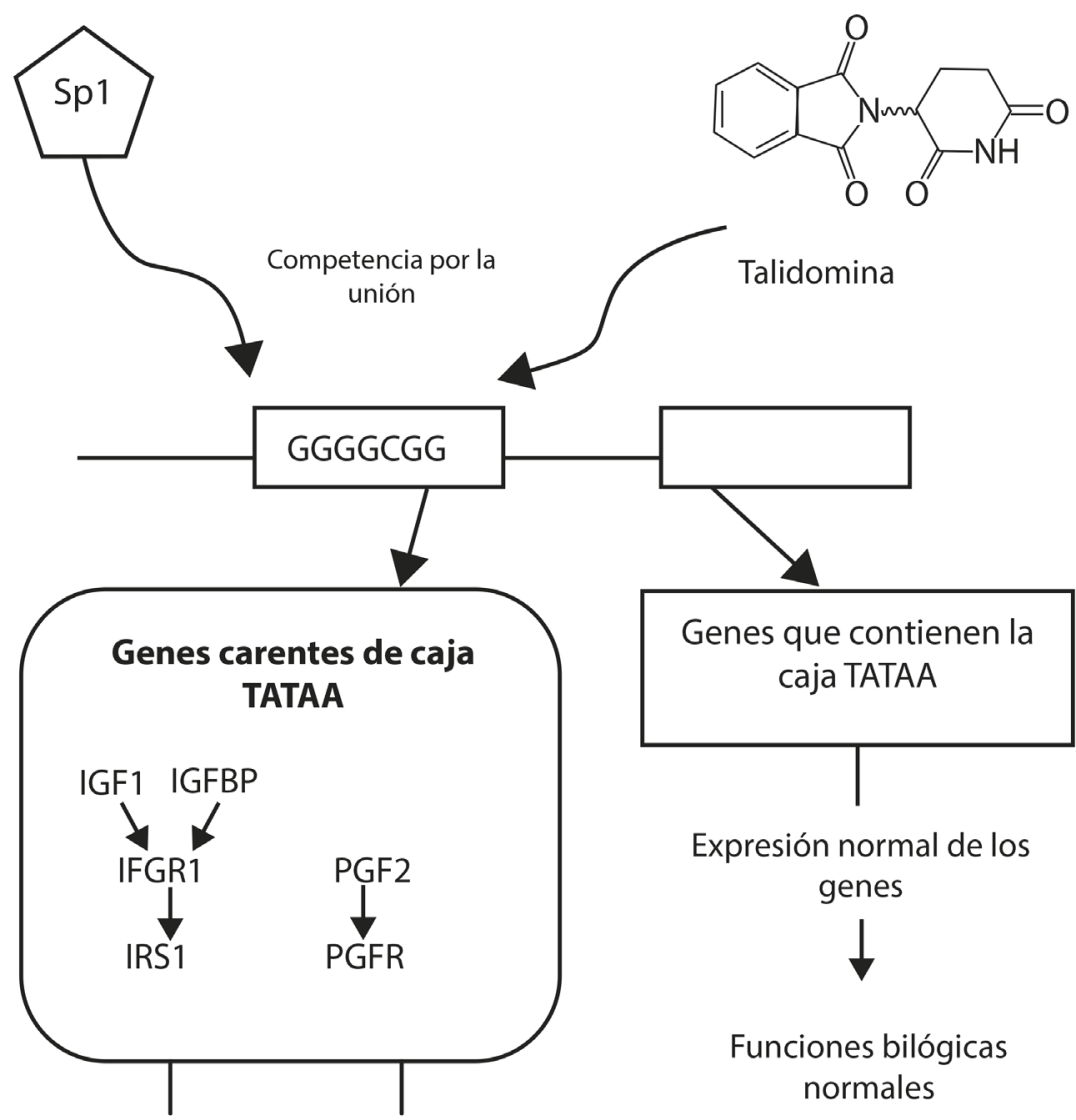

Expresión génica reducida
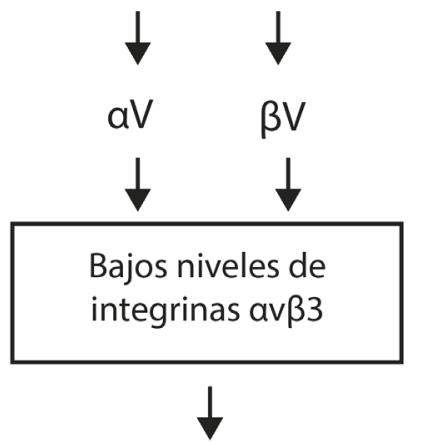

Anormalidades en la cresta neural

Figura 5.7. Mecanismo de acción tóxica de la talidomida (Modificado de Plant, 2003). 


\section{REFERENCIAS BIBLIOGRÁFICAS}

Agency for Toxic Substances and Disease Registry (ATSDR) (2003) Reseña toxicológica del tetracloruro de carbono. Atlanta, GA: Departamento de Salud y Servicios Humanos de los EE.UU., Servicio de Salud Pública.

Al-Hashem, Dallak M., Bashir N., Abbas M., Elessa R., Khalil M. y Al-Khateeb M. (2009) Camel's Milk Protects Against Cadmium Chloride Induced Toxicity in White Albino Rats. American Journal of Pharmacology and Toxicology. 4:3, 107-117.

Alván G., Danielsson R., Kihlström I., Lundborg P., Prame B., Ridley E., Sannerstedt R. (1995) Classification of drugs for teratogenic risk. Eur J Clin Pharmacol 48, 177-178.

Arni P., Hertner T. (1997) Chromosomal aberrations in vitro induced by aneugens. Mutation Research 379, 83-93.

Azarbayjani, F. (2001) Common mechanism for teratogenicity of antiepileptic drugs. Drug induced embryonic arrhythmia and hypoxia-reoxygenation damage. Acta Universities Upsaliensis. Comprehensive Summaries of Uppsala Dissertations from the Faculty of Pharmacy 253. 54 pp. Uppsala. ISBN 91-554-5065-2.

Bannon M. (2005) The dopamine transporter: role in neurotoxicity and human disease. Toxicology and Applied Pharmacology 204, 355-360

Bertolami M. (2005) Mecanismos de hepatotoxicidad. Arquivos Brasileiros de Cardiología 85, suplemento V 24-27.

Blake B. (2008) Biochemical Toxicology of the Central Nervous System. En: Molecular and Biochemical Toxicology 4ta edición editorial Wiley Smart R y Hodgsob E. (Eds.) New Jersey pp. 901.

Braojos L. y Lampurlanés X. (2020) Neurotoxicidad: agentes neurotóxicos. Guía técnica de Prevención. INSHT pág. 1-7

Castell J., Lechon G., Ponsoda X. y Bort R. (1997) The use cultured hepatocytes to investigate the mechanismsof drug hepatotoxicity. Cell Biology and Toxicology 13, 331-338.

De la Cruz R., Rey R., Oldano V., Posleman E. y Araujo R. (2009) Efecto de trimetazidina en la nefrotoxicidad por Gentamicina. Toxicología. 23:4, 601-610.

Ehrenstein V., Sorensen H., Bakketeig L., Pedersen L. (2010) Medical debases in studies of drug teratogenicity: Methodological issues. Clinical epidemiology 2, 37-43.

FDA (Food and Drug Administration) (2000) IV. C.1 Short-Term Test for Genetic Toxicology. Redook 2000.

Franks M., Macpherson G., Figg W. (2004) Thalidomide. The Lancet 363, 1802-1811.

Fritz W., Lin T., Safe S., Moore R. y Peterson R. (2009) The selective aryl hydrocarbon receptor modulator 6-methyl1,3,8-trichlorodibenzofuran inhibits prostate tumor metastasis in TRAMP mice. Biochemical Pharmacology 77 , 1151-1160.

Garza A., Chávez H., Vega R., Soto E. (2004) Mecanismos celulares y moleculares de la neurotoxicidad por plomo. Salud mental 28:2, 1-11.

Goodrum J., Toews A., Bouldin T. (2008) Biochemical Toxicology of the Peripheral Nervous System. En: Molecular and 
Biochemical Toxicology 4aedition editorial Wiley. Smart R y Hodgsob E. (Eds.) New Jersey pp. 901.

Harvey M., Banwell M. y Lupton D. (2008) The synthesis of compounds related to the indole- indoline core of the vinca alkaloids (+)-vinblastine and (+)-vincristine. Tetrahedron Letters. 49, 4780-4783.

Hee J., Kim H., Young K., Kamg J., Lee K., Park S., Yoon H., Whan S., Hong Y. (2007) Aryl hydrocarbon receptor gene polymorphisms affect lung cancer risk. Lung Cancer 56, 9-15.

Hodgson E., Mailman R., and Chambers E. (1998) Dictionary of Toxicology, $2^{\text {nd }}$ Ed. Macmillan Reference Ltd., London.

Ichihara S., Yamada Y., Ichihara G., Nakajima T., Li P., Kondo T., Gonzalez F. y Murohara T. (2007)

A Role for the Aryl Hydrocarbon Receptor in Regulation of Ischemia-Induced Angiogenesis. Journal of the American Heart Association. Online ISSN, 1524-2636.

Jaeschke H., Gores G., Caderbaum A., Hinson J., Pessayre D. y Lemasters J. (2002) Mechanism of Hepatotoxicity. Toxicological Sciences 65, 166-176.

Jiang T., Fan M., Bell R. (2007) Molecular cloning and expression of the aryl hydrocarbon receptor of the Charles River Wistar (Han) rat., Toxicology 204, 164-192.

Joseph P., Lei W., Whong W.Z. y Ong T. (2002) Oncogenic potential of mouse translation elongation factor-1 delta, a novel cadmium-responsive proto-oncogene. J. Biol. Chem 277 (8):6131-6136.

Jordan M., Thrower D. y Wilson L. (1991) Mechanism of Inhibition of Cell Proliferation by Vinca Alkaloids. Cancer Research 51, 2212-2222

Kawajiri K. y Fujii Y. (2007) Cytochrome P450 gene regulation and physiological functions mediated by the aryl hydrocarbon receptor. Archives of Biochemistry and Biophysics 262, 207-212.

Landeiro A., Bandrés A., Fernandez M. y Palomo P. (2002) Teratogénesis: Clasificaciones. Farmacia Hospitalaria 26:3, 171-177.

Liu J., Liu Y., Goyer R., Achanzar W. y Waalkes M. (2000) Metallothionein-I/II Null Mice Are More Sensitive tan WildType to the Hepatotoxic and Nephrotoxic Effects of Chronic Oral or Injected Inorganics Arsenicals. Toxicological Sciences 55, 460-467.

Manibusan M., Odin M., Eastmond D. (2007) Postulated Carbon Tetrachloride Mode of Action: A review. Journal of Environmental Science and Health Part C. 2, 18-209.

Neira F., y Ortega J. (2004) Antagonistas de los receptores glutamatérgicos NMDA en el tratamiento del dolor crónico. Revista de la Sociedad Española del Dolor 11, 210-222.

Olivar T. y Laird (2000) Efectos del bloqueo de los receptores de N-metil-D-aspartato en los reflejos nociceptivos, somáticos y viscerales. Revista de la Sociedad Española del Dolor. 7:291-300.

Parks B., Kitteringham N; Maggs J; Pirmohamed y Williams D. (2005) The Role of Metabolic Activation in Drug- Induced Hepatotoxicity. Annu. Rev. Pharmacol. Toxicol. 45, 177-202.

Parry E., Parry J., Corso C., Doherty A., Haddad F., Hermine T., Johnson G., Kayani M., Quick E., Warr T., Williamson J. 


\section{INTRODUCCIÓN A LA TOXICOLOGÍA}

(2002) Detection and characterization of mechanisms of action of aneugenic chemicals. Mutagenesis 17:6, 509521.

Plant N. (2003) Molecular Toxicology. Editorial Bioscientific Publishers. Nueva York pp. 149.

Puga A., Marlowe J., Barnes S., Chang C., Maier A., Tan Z., Kavin J., Chang X., Strobeck M., Knudsen E. (2002) Role of the Aryl Hydrocarbon receptor in cell cycle regulation. Toxicology 181, 171-177.

Rivas C., Rodríguez B. y López N., (1995) Mecanismos básicos de la nefrotoxicidad. Nefrología 15, 44-48.

Ruiz Z. y Kittok R. (2008) Detección de la subunidad NMDAR-1 del receptor N-metíl-D-aspartato (NMDA) en el hipotálamo del ovino mediante el análisis del Wester Blot. Revista Científica FCV-LUZ. 13:2, 148-153.

Stephens T., Bunde C., Fillmore B. (2000) Mechanisms of action in Thalidomide Teratogénesis.Biochemical Pharmacology $59,1489-1499$.

University, E. Cancer quest. http://www.cancerquest.org/ubdex.cfm?lang=spanishpage=482. Consulta: 20/07/010.

Villanueva V.B., Ballester G., Celma M., Manuel F., Folch G., Gadea M., Llorca R., Vera Q. (2001) Protocolo de vigilancia Sanitaria Específica: Cloruro de Vinilo Monómero. OSALAN. Madrid.

Wallace A. y Meyer S. (2008) Hepatotoxicity. En: Molecular and Biochemical Toxicology $4^{\text {a }}$ Ed. Wiley. Smart R y Hodgsob E. (Eds.) New Jerseypp. 901. 


\section{CAPÍTULO}

\section{6 \\ Tecnologías para la evaluación de la toxicidad}

\subsection{GENÓMICA}

El genoma comprende todo material genético de un organismo y está constituido principalmente por ácido desoxirribonucleico o ADN. El genoma es el manual de instrucciones para la vida donde se encuentran los genes a partir de los cuales se forman las proteínas que a su vez llevan a cabo las funciones de un organismo, su tamaño es variable y generalmente se da en el número total de pares de bases (López et al., 2005).

La genómica es la ciencia que se enfoca al estudio de los genomas así como los genes que contiene, sus funciones, las interacciones entre ellos y con los factores ambientales. El estudio de los genomas incluye los mapas genómicos, las secuencias genómicas y las funciones génicas. La genómica, por lo tanto, puede considerarse como una rama de la genética que estudia los organismos en términos de sus genomas (López et al., 2005; Villegas et al., 2007).

Por lo tanto, podemos decir que la genómica puede explicar el origen del fenotipo, codificado en genes. El reto de la genómica es, entonces, producir modelos utilizando la información proveniente de las secuencias de los genomas, variaciones de las poblaciones, perfiles de expresión génica, proteómica, metabolómica y circuitos genómicos (Villegas y Suárez, 2007). La genómica es parte integral de las ciencias biomédicas y su influencia se ejerce en un amplio campo que incluye desde las pruebas diagnósticas hasta el diagnostico prenatal, pasando por las explicaciones fisiopatológicas del cáncer. Se divide en tres ramas de acuerdo al campo de estudio.

\subsubsection{Genómica estructural}

Se enfoca a la identificación y estudio de las variantes estructurales de secuencia de los genomas. Dichas variantes pueden ser polimorfismos de un solo nucleótido (SNPx), mutaciones, o cambios como repeticiones o inserciones de nucleótidos. La genómica estructural estudia también estructuras tridimensionales hasta ahora conocidas, las proteínas y el papel que éstas realizan en los procesos bioquímicos de un organismo, utilizando técnicas experimentales y con simulaciones por computadora (in silico) (López et al., 2005; Encarnación, 2006).

\subsubsection{Genómica Funcional}

Esta rama de la genómica se encarga de la recolección sistemática de información sobre la función de los genes, mediante la aplicación de aproximaciones experimentales globales que evalúen la función de los genes haciendo 
uso de la información y elementos de la genómica estructural (López et al., 2005; Encarnación, 2006). La genómica estructural se caracteriza por la combinación de metodologías experimentales a gran escala con estudios computacionales de los resultados y también la información obtenida mediante la secuenciación de genomas (genómica comparativa y bioinformática).

El objetivo de la genómica funcional es llenar el hueco existente entre el conocimiento de las secuencias de un gen y su función, para de esta manera revelar el comportamiento de los sistemas biológicos. Se trata de expandir el alcance de la investigación biológica desde el estudio de genes individuales al estudio de todos los genes de una célula al mismo tiempo, en un momento determinado (Encarnación, 2006).

Esta nueva área de la investigación contempla el uso de herramientas de genética de alta capacidad de procesamiento con el análisis de transcripción de ARNm, proteínas y metabólitos, para contestar a la pregunta que se obtiene de todos los proyectos de secuenciación del genoma, que es ¿Cuál es la función biológica de cada gen? la genómica funcional está produciendo un cambio en el paradigma de la investigación más allá del análisis de solo genes, proteínas o metabólitos, hacia el análisis de cada uno de estos parámetros en una escala global. Los métodos de la genómica funcional no son necesariamente hipótesis-dependientes, sin embargo, ofrecen información acerca de expresión de ARNm, regulación génica, función de las proteínas, localización e interacciones protéicas.

\subsubsection{Genómica comparativa}

Se enfoca al estudio comparativo estructural y funcional del genoma de los organismos. El objetivo de esta rama es obtener un mejor entendimiento de cómo han evolucionado las especies y también es útil para determinar la función de los genes y de las regiones no codificantes de los genomas. Los investigadores en genómica comparativa han aprendido sobre la función de los genes en humanos, al examinar y comparar con organismos modelos más simples, como bacterias o el ratón. Al realizar la comparación de los genomas, las investigaciones se enfocan a diferentes aspectos como son: similitud en las secuencias de bases, localización de los genes, tamaño y número de regiones codificantes (exones) en los genes, cantidad de ADN no codificante en el genoma, así como regiones altamente conservadas que se mantienen tanto en organismos como las bacterias hasta el humano (López et al., 2005).

El término sintenia se ha usado para referirse a la conservación del orden de los genes entre segmentos cromosómicos de uno o más organismos. Los mapas físicos proveen la forma más directa para caracterizar la magnitud de la sintenia ya que los loci (regiones de genes ordenados que codifican para una función determinada), altamente conservados que pueden verse como homólogos (es decir, que derivan de un ancestro común) sirven de marcas de anclaje. Sin embargo, se deben usar métodos filogenéticos apropiados para distinguir entre homólogos verdaderos llamados ortólogos y parálogos, que son genes similares que surgieron como resultado de duplicaciones en una o dos líneas subsecuentes a una divergencia evolutiva. En muchos casos, complejos de genes completos han sufrido duplicaciones múltiples, lo que vuelve difícil distinguir entre ortólogos y parálogos. Esto puede ser crucial cuando los mapas físicos comparativos se emplean para sugerir la localización de un locus con efectos médicos o de otro tipo, basados en el ligamiento de una región loci sinténicos. La magnitud de la conservación del orden de los genes es una función inversa del tiempo transcurrido desde su divergencia de un locus ancestral, ya que se requieren rearreglos cromosómicos para romper ligamientos génicos (López et al., 2005). 
La genómica comparativa implica el uso de software que puede alinear genomas múltiples y buscar regiones similares entre ellos. Algunas de estas herramientas de similitud entre secuencias están disponibles al público en portales de internet. Una de las más usadas es BLAST (Basic Local Alignment Search Tool), que es accesible a través del NCBI (Nacional Center for Biotechnology Information), y que comprende una serie de programas diseñados para realizar búsquedas de similitud en todas las bases de datos de las secuencias reportadas disponibles.

\subsubsection{Genes reporteros}

La dilucidación de los mecanismos de muchos procesos celulares se ha facilitado enormemente en las últimas décadas por la llegada de la tecnología de genes reporteros. Los genes reporteros, codifican proteínas con propiedades fenotípicas distintas al sistema estudiado, permitiendo así su monitoreo y supervisión de manera conveniente. Se analiza, la vinculación existente entre la actividad celular y la expresión fenotípica del gen reportado, llevándose a cabo la fusión de secuencias de ADN adecuadas con el gen reportero, estas secuencias son reguladas de forma natural, pueden ser sensibles en diversos eventos celulares, de tal forma que existe una mediación de la codificación protéica, después de la introducción de la proteína en las células, la actividad cualitativa o cuantitativa de los eventos celulares, se extrapola a partir de la expresión del gen reportero de productos vinculados (Naylor, 1999; Alam y Cook, 2003).

El uso de reporteros como la proteína verde fluorescente (GFP/Green Fluorescent Protein) y luciferina, permite la vigilancia altamente sensible y no destructiva de la transferencia y expresión de determinados genes. Algunas modificaciones en GFP incrementan su sensibilidad y estabilidad, a partir de la alteración de algunas de sus cualidades espectrales; de manera que esto facilita el uso de GFP en una variedad de métodos de transferencia génica. Las mejoras en las tecnologías de imagen y el incremento de su aplicación en investigaciones biológicas, ha permitido también que se expanda el uso de reporteros basados en la transformación génica de luciferasa, particularmente en la investigación genómica, así como en el monitoreo de cambios temporales en la expresión génica (Welsh y Kay, 1997).

El uso de Proteínas Reporteras Fluorescentes (PRF), abre un nuevo campo de estudio para la investigación en áreas como la embriología o el estudio de las células madre, estas pueden ser usadas como reporteros para la actividad de promotores génicos o para marcar determinada proteína para estudiar su función y su localización en el espacio intracelular, en células vivas, tejidos y organismos (Habermann et al., 2007).

\subsubsection{Transgénicos}

Los Organismos transgénicos o Genéticamente Modificados (OGM) hacen referencia a aquella planta, animal, hongo o bacteria a la que se le ha agregado por ingeniería genética uno o algunos genes con el fin de producir proteínas de interés industrial, o bien mejorar ciertos rasgos, como la resistencia a plagas, calidad nutricional, tolerancia a heladas, entre otras características (Ablin y Paz, 2001). Los cultivos transgénicos son una de las principales aplicaciones de la ingeniería genética en la actualidad, se trata de incorporar nuevos genes a las plantas con el fin de mejorar los cultivos, con el objetivo de aumentar su productividad, y contribuir a la agricultura sustentable que utiliza los recursos respetando al medio ambiente, pensando en las generaciones futuras (Giddings et al., 2000). 
Animales Transgénicos. Un animal transgénico es un animal genéticamente modificado, que tiene un gen o grupo de genes que no le pertenecen con el fin de producir alguna proteína de interés. El genoma de los animales se puede modificar a partir de la inserción de genes de la misma especie y/o de una especie diferente. Alterando ciertos genes presentes en el animal de manera que esta modificación se transmita a la descendencia.

\subsection{TRANSCRIPTOMA}

La transcripción es el primer proceso de expresión génica, mediante el cual se transfiere la información contenida en una secuencia de ADN hacia la secuencia de proteínas utilizando diversos ARNs como intermediarios. El producto inmediato de la transcripción de un gen es la formación de ácido ribonucleico mensajero (ARNm) que se conoce como transcrito. La síntesis de ARN a partir de un molde de ADN es llevada a cabo por ARN polimerasa dependientes de ADN que utilizan trifosfatos de nucleósido como sustrato y sintetizan las cadenas en sentido 5' à 3'; la secuencia de bases del ARN que se sintetice será idéntica a la cadena codificantes excepto por que contendrá uracilo en lugar de timina (Campbell et al., 2006).

Al parecer, existen alrededor de 23 mil genes con un tamaño promedio de $27 \mathrm{~Kb}$ en el genoma humano. Un paso muy importante ha sido reconocer que la mayoría de los $2.9 \mathrm{~Gb}$ del genoma se transcriben. La actividad de un gen puede ser medida por la cantidad de transcritos que puede producir, aunque estos transcritos no codifiquen proteínas. El conjunto de ARNs de todos los genes es lo que se conoce como transcriptoma (Bastarrachea et al., 2008).

La técnicas transcripcionales a gran escala significa una nueva era en la biología, ya que en lugar de comprender la expresión y acción de los genes individualmente, la transcriptómica permite la evaluación de todos los cambios en el transcriptoma a través de una variedad de condiciones biológicas. Estas técnicas han dado lugar a una acumulación masiva de datos sobre expresión génica y la necesidad de perfeccionar aspectos biológicos al utilizar estos datos (Brady et al., 2006).

Las técnicas a gran escala emplean una de dos estrategias. En primera se generan secuencias Tag (secuencia básica para posicionar un gen) de un ARN sencillo, y la segunda, una población de ARNm de interés, se hibridan con un amplio número de sondas en el sustrato adecuado (ejem. microarreglos). Estas estrategias son complementarias una con otra. La generación de Tags es independiente del conocimiento del gen pero requiere de una amplia secuenciación y una referencia genómica para determinar la identidad del gen; pueden incluir de 200 a 900 nucleótidos, los Tags de 15 nucleótidos son usados para análisis serial de expresión génica (SEGE), y los de 17 a 20 nucleótidos son usados en secuenciación masiva paralela (MPSS).

Métodos alternativos de perfil de expresión génica incluyen microarreglos, un problema principal de los métodos de arreglos es que la medición de perfiles de expresión génica se basa en una relación de hibridación y por lo tanto determina la abundancia de transcripción relativa; experimentos de análisis de transferencia de ARN en gel y ensayos de RT-PCR cuantitativa generalmente pueden confirmar las expresión génica diferencial indicada por análisis de microarreglos (Brady et al., 2006; Peters et al., 2007). 


\subsubsection{Cuantificación RT- PCR en tiempo real}

Por definición la Reacción en cadena de la Polimerasa o PCR permite la amplificación in vitro de una secuencia especifica de ADN y se realiza mediante el uso de un par de oligonucleótidos iniciadores que flanquean la secuencia de ADN por acción de una ADN polimerasa. Básicamente cada ciclo de amplificación se divide en 3 etapas: la desnaturalización, donde se separan las cadenas de ADN por medio de elevación de temperatura; alineamiento, donde los iniciadores se hibridan con las secuencias complementarias; y por último la extensión, donde por acción de la ADN polimerasa se sintetizan nuevas cadenas de ADN complementarias a la cadena molde a partir de los iniciadores (cebadores y/o primers) (Figura 6.1) (Shipley, 2006).

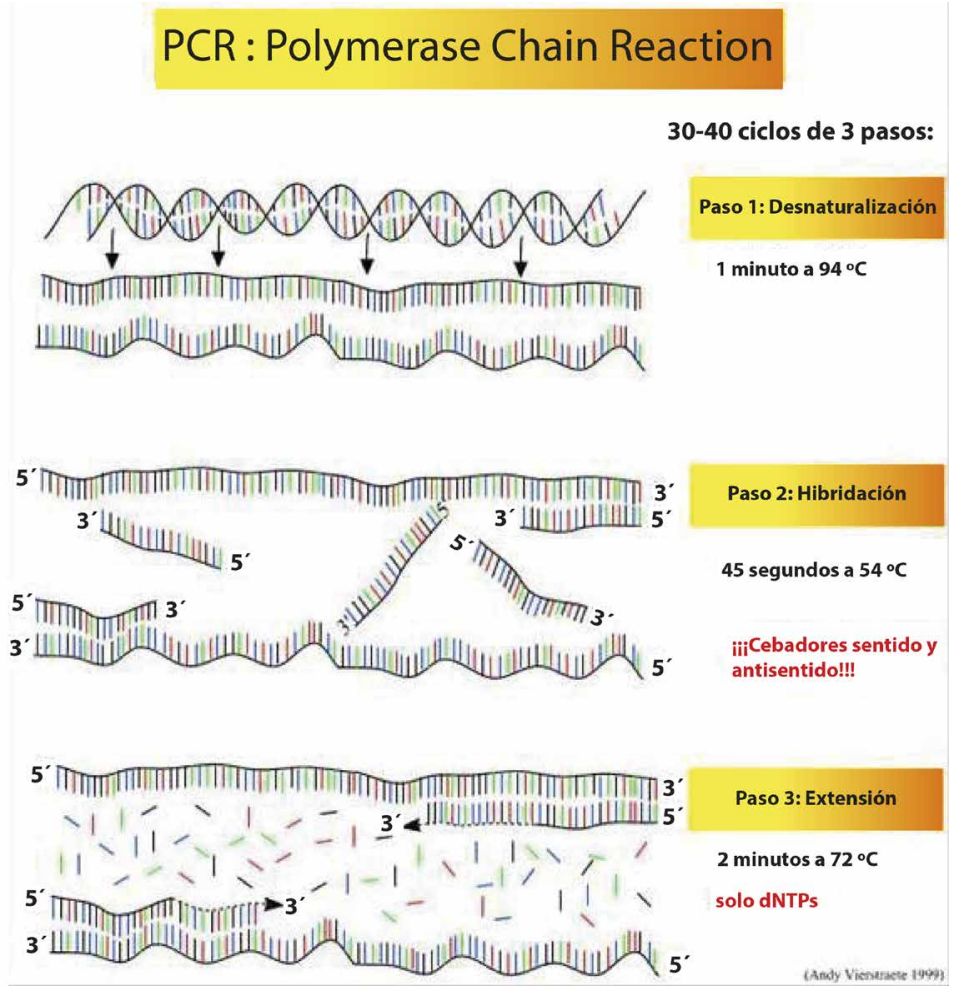

Figura 6.1. Técnica de PCR (Vierstrance, 1999).

La PCR tiempo real (Figura 6.2), es la emisión continua de señales fluorescentes de una o más reacciones en cadena polimerasa sobre una gama de ciclos. La PCR tiempo real cuantitativa es la conversión de la señal fluorescente de cada reacción de las muestras, a un valor numérico (Shipley, 2006).

La clave en la PCR cuantitativa es la posibilidad de detectar en tiempo real la amplificación de nuestro genoma de interés. Para llevar a cabo esta detección existen varios métodos pero casi todos basados en la utilización de 
otro fragmento de ADN (sonda) complementario a una parte intermedia del ADN que queremos amplificar. Esta sonda lleva adherida una molécula fluorescente y otra molécula que inhibe esta fluorescencia ("quencher"), de tal forma que sólo cuando la sonda es desplazada de su sitio por acción de la ADN polimerasa la molécula acciona el "quencher" y emite fluorescencia al ser iluminada con un láser (Figura 6.2). La cuantificación de la fluorescencia emitida durante cada ciclo de la PCR será proporcional a la cantidad de ADN que se está amplificando. En general para que sea válida esta técnica requiere realizar en paralelo una curva patrón en las mismas condiciones para conocer la cantidad total de ADN que se está amplificando (Pfaffi, 2001).

1) Desnaturalización

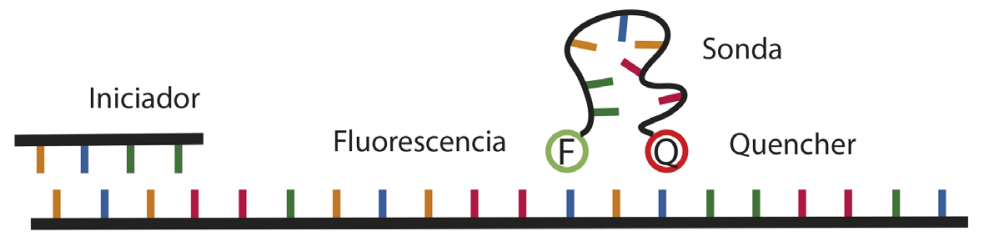

2) Alineación de de iniciadores e hibridación

Polimerasa

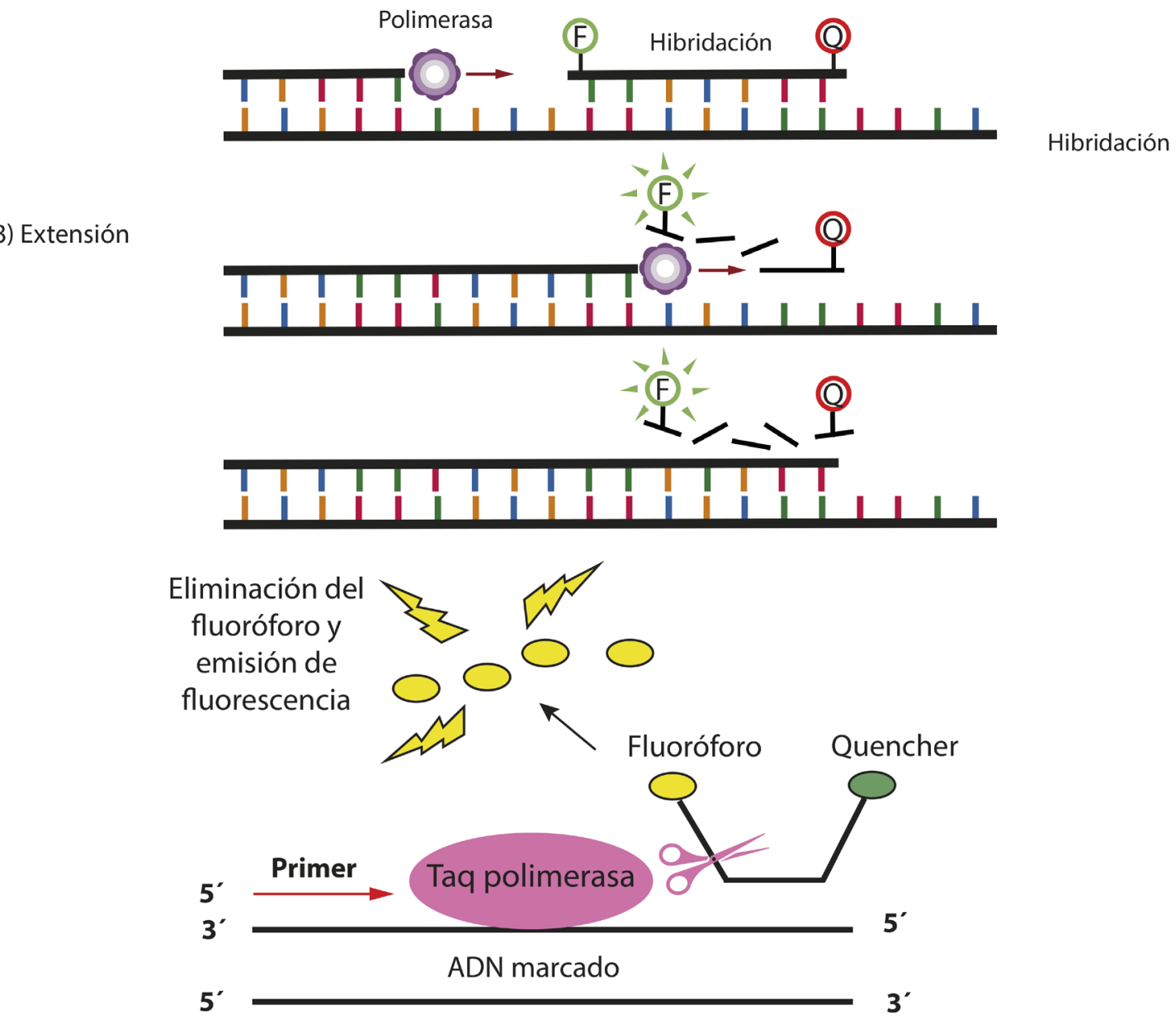

Figura 6.2. PCR tiempo real o cuantitativa (U. de G., 2010). 
La transcripción reversa (TR) seguida de la reacción en cadena polimerasa (PCR) es una técnica elegida para el análisis de expresión de ARNm derivado de varias fuentes. La RT-PCR en tiempo real es altamente sensible y permite la cuantificación de transcritos extraños y de pequeños cambios en la expresión de genes; es fácil de realizar, proporciona alta precisión y productos fiables, así como su rápida cuantificación. El método de evaluación elegido depende de la secuencia marcada, el rango esperado en la cantidad de ARN presente en el tejido; el grado de precisión que se requiere y la cuantificació pueden ser relativa o absoluta (Pfaffi, 2001; VanGuilder et al., 2008).

La RT-PCR tiempo real puede generar amplificaciones de fragmentos pequeños como 60pb. Por lo tanto esta técnica podría ser adecuada para cuantificar los niveles de ARNm en muestras de tejido que contienen ARN parcialmente degradado y podría permitir el análisis de los cambios cuantitativos en los ácidos nucleícos durante el curso de alteraciones patológicas (Bustin, 2002).

\subsubsection{Microarreglos}

Un microarreglo (también denominado ADN array, ADN chip, oligonucleotide array o gene chip) consiste en múltiples fragmentos de ADNc (cada uno de los cuales representa un gen diferente) adheridos a un soporte físico concreto (vidrio, plástico, silicona, etc.) y agrupados de manera ordenada (filas y columnas) según su función (receptores, hormonas, factores de transcripción, citocinas, etc.). Los microarreglos usados hoy en día incluyen entre 9,000 y 40,000 fragmentos de ADNc por $\mathrm{cm}^{2}$. Por tanto, disponen virtualmente de todo el genoma humano; sirve para determinar la expresión genética completa de un tejido en un momento determinado. El transcriptoma, al contrario que el genoma, cambia continuamente, en respuesta a las condiciones microambientales celulares o tisulares (temperatura, $\mathrm{pH}, \mathrm{CO}_{2}$, citosinas, hormonas, etc.). Por tanto, la interpretación del transcriptoma objeto de estudio, requiere necesariamente de su comparación con el de un tejido control. El microarreglo permite esta comparación, que se conoce con el nombre de pantalla diferencial (differential display) (Busquets y Agusti, 2001).

El procedimiento para comparar el transcriptoma del tejido problema con el transcriptoma del tejido control es relativamente simple. En primer lugar, se debe aislar el ARNm de ambos tejidos y, a partir de cada uno de ellos, obtener sus correspondientes ADNc. Estas moléculas de ADNc deben marcarse con un compuesto fluorescente que será diferente en el tejido objeto de estudio y el tejido control (Figura 6.3) (Brady et al., 2006).

El ADNc del tejido problema (patológico) se marca con el compuesto fluorescente Cy3 (que emite fluorescencia a una longitud de onda de $588 \mathrm{~nm}$, lo que en el espectro correspondería a un color cercano al amarillo) y el de tejido sano (control), con el compuesto Cy5 (que emite fluorescencia una longitud de onda de $680 \mathrm{~nm}$, lo que en el espectro correspondería a un color entre naranja y rojo); se mezclan ambos ADNc marcados y se incuban juntos en el arreglo, para que cada especie de ADNc hibride específicamente a su ADNc complementario inmovilizado en el arreglo. Cuanto mayor sea la hibridación de una especie determinada de ADNc marcado con el ADNc del arreglo, mayor será la expresión tisular original del ARNm correspondiente. La cantidad de hibridación existente se calcula determinando la longitud de onda emitida por cada uno de los dos ADNc incubados. Para ello, el sistema lector del microarreglo asigna un código informático de colores a la cantidad de fluorescencia emitida (Albeda et al., 2000). 
Si hay mayor hibridación del ADNc de la condición patológica, el componente amarillo de la emisión predominará, y viceversa, cuando sea mayor la hibridación del ADNc de la condición control, el componente rojo de la emisión será el que predomine. Cuando la hibridación del ADNc de los dos tejidos estudiados sea similar, el programa informático asignará un código de color verde. Hay que tener en cuenta que esta diferencia de emisión debe evaluarse para cada uno de los genes considerados (Lockhart et al., 2000).

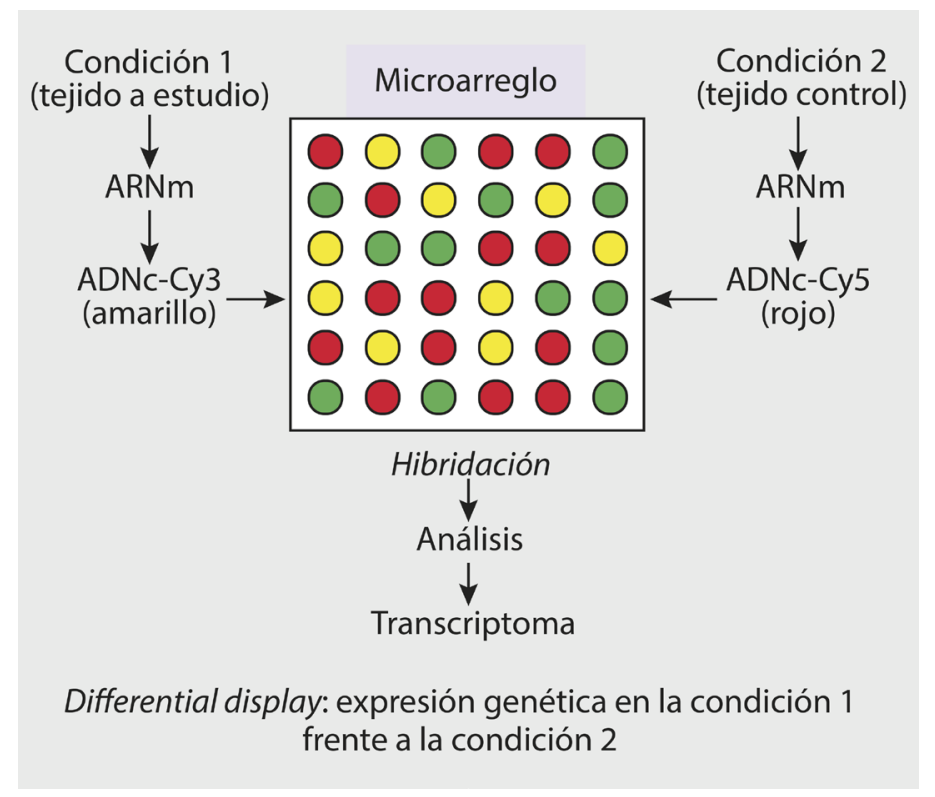

Figura 6.3. Técnica de Microarreglos (Busquets y Agusti, 2001).

Los microarreglos proporcionan información sobre los genes que han variado su expresión (tanto en el sentido de sobreexpresión como de represión) en respuesta a unas condiciones experimentales o fisiopatológicas determinadas; hay que tener en cuenta que la alteración en la expresión de estos genes puede ser causa o consecuencia de la enfermedad estudiada (Busquets y Agusti, 2001).

\subsection{PROTEOMA}

Los proyectos de secuenciación a gran escala están proporcionando una ingente cantidad de secuencias de ADN. Sin embargo, aun se desconoce la función biológica de la mayoría de las proteínas codificadas por los genes detectados. Así que, el siguiente paso en la era post-genómica debe ser el estudio funcional de todos estos genes.

El término proteoma fue usado por primera vez en 1995 para describir el conjunto de proteínas de un genoma, una célula o un tejido. De manera imperceptible, la palabra proteoma dio lugar a una nueva disciplina, la proteómica (Gil, 2003). 
Se puede decir que hubo tres factores decisivos para el desarrollo de la proteómica:

- La secuenciación de genomas a gran escala y el desarrollo de bases de datos de proteínas.

- El desarrollo de técnicas de espectrometría de masas para analizar proteínas y péptidos.

- Los avances realizados en la separación de proteínas mediante 2D-PAGE con la introducción de los gradientes de $\mathrm{pH}$ inmovilizados (IPGs).

Hace algunos años el protocolo básico para la electroforesis en geles de doble dimensión (2-DE) fue descrito por O’Farrel en 1975. Este protocolo aún es válido, por lo tanto la electroforesis 2-DE y la espectrometría de masas (MS) pueden revelar los patrones de síntesis protéica.

La proteómica está configurada como una disciplina fundamental de la era post-genómica que trata de descubrir el grupo de proteínas que dan a las células su estructura y función (Encarnación, 2006). A diferencia del relativamente invariable genoma, el proteoma es dinámico y cambia minuto a minuto en respuesta a miles de señales ambientales intra y extra celulares. La estructura y comportamiento de una proteína están especificados por la secuencia génica, por el número e identidad de otras proteínas producidas en la misma célula al mismo tiempo, y las interacciones con dichas proteínas (López et al., 2005).

La proteómica es el área científica que estudia y analiza la estructura y función de las proteínas de un tipo celular en forma global. La proteómica será la meta de muchas investigaciones futuras que ayuden a elucidar las bases moleculares de la salud y enfermedad a través de métodos bioquímicos (Gil, 2003; López et al., 2005; Bernal y Suárez, 2007).

Distintas tecnologías permiten obtener y comparara "instantáneamente" las proteínas que se están expresando en un momento determinado en una célula (electroforesis 2D, espectrometría de masas, chips, bioinformática). Este análisis puede incluir a todas las proteínas que se expresan en una célula en un determinado momento, ya sean las isoformas como las proteínas modificadas, e incluso las interacciones proteómicas. Sin embargo, la identificación de las proteínas era difícil debido a la falta de métodos analíticos, rápidos y sensibles para la caracterización de las proteínas. En los años noventa, la espectrometría de masas (MS /Mass Spectrometry) surge como un método analítico muy poderoso, ya que elimina la mayoría de las limitaciones del análisis de proteínas. Este desarrollo, junto con la disponibilidad de los genomas secuenciados, marca el comienzo de una nueva era (Gil, 2003; Encarnación, 2006). En la actualidad se puede hablar de dos tipos de proteómica: proteómica de expresión y proteómica del mapa celular.

\subsubsection{Proteómica de expresión}

La proteómica de expresión es el estudio cuantitativo de la expresión de proteínas entre muestras que difieren en alguna variable. En esta estrategia se compara la expresión del proteoma total o de subproteómas entre diferentes muestras. La información obtenida puede permitir la identificación de nuevas proteínas implicadas en transducción de señales, la identificación de proteínas específicas de una enfermedad y proteínas de interés en microbiología médica (Gil, 2003). 


\subsubsection{Proteómica del mapa celular}

La proteómica del mapa celular o estructural es el estudio de la localización subcelular de las proteínas y de las interacciones proteína-proteína, mediante la purificación de orgánulos o complejos y la posterior identificación de sus componentes mediante espectrometría de masas (Gil, 2003). También se utiliza el término de proteómica funcional para referirse a diversas aproximaciones proteómicas que permiten el estudio y caracterización de un grupo de proteínas determinado proporcionando información importante sobre señalización, mecanismos de la enfermedad o interacciones proteína-fármaco.

Para caracterizar el proteoma de una célula es importante tener en cuenta que el proteoma es dinámico y que es reflejo del medio ambiente en el que es estudiado. Como respuesta a estímulos externos e internos, las proteínas pueden ser sintetizadas, modificadas post-traduccionalmente, translocadas, o degradadas.

\subsubsection{Electroforesis}

En los últimos 25 años, y particularmente en la última década han sido testigo de un esfuerzo por incrementar el desarrollo de tecnologías capaz de identificar y cuantificar un gran número de proteínas expresadas en un sistema celular (Proteoma) con la esperanza de encontrar biomarcadores para diversas enfermedades, mapeando circuitos proteicos o identificando nuevos sitios de fosforilación (Haleem y Veenstra, 2008).

La tecnología más utilizada para la separación de proteínas es la electroforesis en geles de poliacrilamida. Fue introducida hace 32 años y hasta el momento es la técnica más eficaz para resolver mezclas complejas de proteínas. Las proteínas son moléculas cuya carga neta depende del contenido de una serie de aminoácidos (principalmente ácido glutámico, ácido aspártico, lisina, arginina e histidina) y del grado de ionización de éstos en función del pH.

Para muchas aplicaciones proteómicas, la electroforesis en una dimensión (1-DE) es el método de elección. Las proteínas se separan de acuerdo a su punto isoeléctrico. Una de las aplicaciones más comunes de la 1-DE, es la caracterización de proteínas después de realizar algún tipo de purificación previa (Kathryn y Dupree, 2001; Gil, 2003; Haleem, 2008).

La Electroforesis bidimensional 2D-PAGE en geles de poliacrilamida (2D-SDS-PAGE,) es una técnica altamente resolutiva para la separación de mezclas de proteína que consiste en el acoplamiento de dos técnicas (Monrroy et al., 2006; Castagnino, 2008):

I) Eje X: El isoelectroenfoque (IEF), que separa proteínas de acuerdo con su punto isoeléctrico (pl) usando un gradiente de $\mathrm{pH}$, denominado primera dimensión (ID).

II) Eje Y: La electroforesis en condiciones desnaturalizantes (SDS-PAGE), conocida como segunda dimensión (2D) y que separa proteínas de acuerdo con su peso molecular.

La electroforesis 2D, permite separar hasta miles de proteínas en un solo experimento, y constituye actualmente el método más eficiente para la separación de mezclas proteicas muy complejas. Está basada en una separación de 
proteínas en función de la carga, seguida de una separación de las proteínas en función de su masa molecular. La separación de la primera dimensión se realiza mediante isoelectroenfoque, durante el cual las proteínas son separadas en un gradiente de $\mathrm{pH}$ hasta alcanzar una posición en la que su carga neta es cero, es decir, su punto isoeléctrico.

En una segunda dimensión, las proteínas son separadas mediante electroforesis en presencia de SDS. La buena resolución de la técnica gira alrededor del supuesto, donde las dos separaciones se encuentran aislando parámetros independientes. La innovación clave para la 2D-PAGE. Fue el desarrollo de geles con un gradiente de pH inmovilizado (IPGs). El gradiente de pH inmovilizado elimina los problemas de inestabilidad de gradiente y baja capacidad de carga que iban asociados a los gradientes de $\mathrm{pH}$ preparados con anfolitos acarreadores. En los geles IPGs, el gradiente es generado por las llamadas "inmovilinas" y está copolimerizado con la matriz de acrilamida del gel. Este sistema ha permitido mejorara la resolución y reproducibilidad de los geles así como aumentar la cantidad de proteína que pueden ser cargada. La reproducibilidad conseguida con los IPGs ha hecho posible la comparación de mapas entre distintos laboratorios, facilitando así el intercambio de información (Gil, 2003).

La aplicación principal de la 2D-PAGE es la proteómica de expresión. En esta aproximación, la expresión de proteínas de dos muestras se puede comparar de forma cuantitativa. La aparición o desaparición de manchas proporciona información sobre la expresión diferencial de proteínas y la intensidad de manchas permite conocer los niveles de expresión. Para realizar estos estudios se puede utilizar organismos completos, líneas celulares o fluidos biológicos (Kathryn y Dupree, 2001).

Otra aplicación importante, es para realizar mapas de proteínas de microorganismos, orgánulos celulares y complejos de proteínas. También se puede usar para caracterizar proteínas en subproteomas que se han obtenido mediante alguna forma de purificación del proteoma.

La técnica 2D-PAGE también presenta muchas limitaciones pues es una técnica laboriosa, de difícil automatización, está limitada por un número y tipo de proteínas a resolver. Las proteínas muy grandes o hidrofóbicas no entran en el gel durante la primera dimensión y las proteínas muy ácidas o muy básicas no se resuelven bien. Otra limitación de esta técnica es la detección de proteínas poco abundantes, algunas de ellas se consideran muy importantes (proteínas regulatorias, proteínas implicadas en la transducción de señales, receptores). En estos estudios es necesario realizar un fraccionamiento de la muestra para reducir la complejidad de los extractos (Gil, 2003).

Las limitaciones de la 2D-PAGE han impulsado el desarrollo de otras metodologías. Una estrategia desarrollada consiste en digerir con tripsina una mezcla de proteínas para después purificar y analizar péptidos mediante espectrometría de masas (MS). Los péptidos se pueden purificar mediante cromatografía líquida, electroforesis capilar o mediante una combinación de técnicas como cromatografía de intercambio iónico y cromatografía de fase reversa. La ventaja de este procedimiento es que se dispone de una gran cantidad de proteínas (Castagnino, 2008).

\subsubsection{Espectrometría de masas (EM).}

Una técnica clave para la identificación y caracterización de las proteínas. En los proyectos proteómicos la identificación de proteínas es esencial. Es el primer paso para otros estudios que suponen en última instancia 
la caracterización funcional. Además, en el caso de los geles bidimensionales, la identificación de las manchas conduce a la creación de "mapas de referencia" que definen las proteínas expresadas por un organismo o tejido en condiciones determinadas (Gil, 2003; Erra, 2004).

Las proteínas pueden ser identificadas por diversos procedimientos, entre los que se incluyen la secuenciación del extremo $\mathrm{N}$-terminal, detección con anticuerpos específicos, composición de aminoácidos, co-migración con proteínas conocidas, y sobre-expresión y delesión de genes. Todos los métodos generales son lentos, laboriosos, o caros por lo tanto, no resultan apropiados para su uso como estrategias a gran escala (Whu et al., 2005).

Por lo tanto, debido a su rapidez y elevada sensibilidad, la espectrometría de masas se ha convertido en el método de elección para la identificación de proteínas a gran escala, el primer paso para el estudio del proteoma de distintos organismos. También permite la caracterización de modificaciones post-traduccionales que presentan relevancia fisiológica, tales como glicosilación y fosforilación.

Los espectrómetros de masa están formados al menos por una fuente de iones, un analizador de masas y un detector, mide la relación masa/carga ( $\boldsymbol{m}$ (carga del ion)/z (masa molar o peso molecular del ion) de los iones en fase gaseosa. Para analizar a las proteínas mediante espectrometría de masas deben ser convertidas en péptidos, mediante proteólisis, generalmente con tripsina, ya que la masa de una proteína no es suficiente para identificarla (Erra, 2004; Whu et al., 2005).

Esta técnica tan robusta implica:

1) La conversión de los péptidos en iones en fase gaseosa mediante técnicas de ionización suave, como desorción con láser asistida con matriz (MALDI) a partir de una muestra en estado sólido, o la ionización mediante electrospray (ESI) de una muestra en resolución.

2) Separación de los iones según su $\mathrm{m} / \mathrm{z}$ en un analizador de masas (por ejemplo un analizador tipo TOF (Time Of Fligh), cuádrupolo, trampa iónica, etc.).

3) Fragmentación opcional de los iones peptídicos seleccionados mediante descomposición metaestable (o técnica de PSD: postsource decay) o mediante disociación inducida por colisión (CID) llevada a cabo en un espectrómetro de masas en tándem combinando dos analizadores diferentes.

4) Medida de las masas en un detector obteniendo un espectro de masas que refleja la abundancia de los iones frente a su valor $(\mathrm{m} / \mathrm{z})$ (Gil, 2003).

Aunque se han desarrollado diversas combinaciones de fuentes de ionización y de analizadores de masas, la fuente de MALDI se suele acoplar a un analizador tipo TOF mientras la ionización mediante ESI normalmente se combina con un triple cuádrupolo, una trampa iónica o con un híbrido cuádrupolo (Q-TOF). Recientemente se han desarrollado también fuentes de MALDI que se acoplan a un analizador Q-TOF o a dos analizadores TOF en tándem (MALDI-TOF-TOF).

Para la identificación de proteínas se han desarrollado dos estrategias: 
a) Identificación mediante huella peptídica (PMF/peptide mass fingerprinting) o mapeo peptídico utilizando un espectrómetro tipo MALDI-TOF.

La huella peptídica (PMF) de una determinada proteína es un conjunto de pétidos generados mediante la digestión de una proteasa específica. Estas masas peptídicas experimentales son comparadas con las masas peptídicas teóricas de proteínas presentes en bases de datos (disponibles ya en internet); para la identificación correcta de la proteína se requiere que las masas de un gran número de péptidos coincidan con las masas teóricas de los péptidos y que cubran parte de la secuencia de la proteína en la base de datos.

La espectrometría de masas tipo MALDI-TOF se considera un pilar de la Proteómica. El instrumento es robusto, relativamente caro y con posibilidades de ser automatizado. Como el tiempo de análisis de una muestra es muy corto se puede utilizar para el análisis a gran escala. Sin embargo, este tipo de espectrometría tiene sus limitaciones:

- La ionización de los péptidos es selectiva y no es cuantitativa. En un conjunto equimolecular de péptidos procedentes de la digestión de una proteína, algunos péptidos pueden no ser detectados y en el resto de ellos puede haber una gran variación en la señal de intensidad.

- Si la cantidad de proteína en el gel es pequeña, el número de péptidos observados puede ser pequeño y por tanto la proteína no se puede identificar con seguridad.

b) Identificación mediante fragmentación de péptidos obteniendo la secuencia total o parcial de los aminoácidos (etiqueta de secuencia) utilizando un espectrómetro de masas en tándem.

Los espectrómetros de masa en tándem MS/MS permiten también la detección de la secuencia de aminoácidos. Se selecciona un ión por la masa en un primer espectrómetro y se fragmenta por colisión con un gas y los fragmentos se analizan en un segundo espectrómetro. Puede utilizarse con una fuente de ionización tipo MALDI o ESI.

El método de secuenciación de novo es la estrategia de elección para aquellos organismos que no han sido secuenciados o su secuencia de ADN no ha sido publicada. El objetivo de esta aproximación es obtener secuencias completas de aminoácidos que se deduzcan de novo de los espectros MS/MS (bien mediante interpretación natural o con ayuda de un programa) y buscar homologías frente a proteínas presentes en bases de datos. Esta estrategia permite encontrar proteínas homólogas en otras especies utilizando algunos programas de búsqueda. Aunque la proteína de interés pueda no ser identificada o sea una proteína desconocida, la información de la secuencia puede ser utilizada para clonar el gen correspondiente (Gil, 2003; Mojica et al., 2003; Erra, 2004).

Los datos que se obtienen de la técnica de espectrometría de masas son huellas digitales de péptidos separados en relación a su masa. La identificación de las proteínas se hace refiriendo los patrones particulares de espectrometría de masas a una base de datos que sirve para entrenamiento (Mojica et al., 2003).

En la actualidad la computación es un componente esencial en la investigación en biología. La masa de los datos producidos es tan grande que no se puede ni siquiera "mirar" sin la ayuda de un programa computarizado. Quizás la bioinformática nunca haya enfrentado un problema de magnitudes tan grandes. Necesitamos bases de datos integrados, eficientes para meter y sacar datos; así mismo, métodos computacionales avanzados para realizar el reconocimiento de patrones y otros enfoques de instrucciones para analizar y entender los datos (Mojica et al., 2003). 


\subsection{METABOLOMA}

La metabolómica puede definirse como la ciencia "omica" más emergente, que permite obtener un perfil metabólico de una muestra biológica compleja, a través de la combinación de técnicas analíticas que generan gran cantidad de datos y del análisis estadístico multivariado de ellos; mediante la metabolómica se exploran a nivel molecular los efectos de múltiples factores sobre un sistema biológico; permite analizar una gran cantidad de metabólitos en matrices complejas como biófluidos y tejidos de manera automatizada y relativamente rápida; el proyecto Metaboloma humano ha fijado en 3000 el número de metabólicos endógenos a analizar (Metabolomics, 2010). Este análisis genera un perfil de identificación y cuantificación de todos los metabólitos en un sistema biológico, cuya comparación, por medio de técnicas estadísticas multivariadas, permite identificar cambios metabólicos específicos para los distintos fenotipos objeto de estudio (Goldsmith et al., 2010).

A la colección completa de todos los metabolitos de bajo peso molecular (< 1,500 Da) encontrados en un sistema (células, tejidos u organismos) bajo un conjunto dado de condiciones, entonces, se le asignaría el término Metaboloma. El metaboloma incluye pequeñas moléculas, como son substratos y productos metabólicos, lípidos, pequeños péptidos, vitaminas y otras cofactores proteicos (Rochfort, 2005; Goldsmith et al., 2010).

Entre otras cosas cabe destacar las aplicaciones clínicas de la metabolómica, como por ejemplo el descubrimiento de biómarcadores y con ello la diagnosis prematura de ciertas enfermedades (ej. la taurina determinada como un metabólito marcador asociado a hígado graso y necrosis); su aplicación al estudio de moléculas candidatas en fase preclínica o el uso de dicha técnica en ensayos sobre eficacia terapéutica (Goldsmith et al., 2010).

En el campo de los trasplantes de órganos, algunos estudios se han intentado enfocar al estudio de la disfunción primaria, retraso en la función del injerto, rechazo agudo, se han encontrado una serie de metabólitos involucrados en estos procesos, como la presencia de glutamina elevada en hígado con disfunción del injerto, así como bajos niveles de urea, disminución de nitratos, nitritos y óxido nítrico, en rechazo agudo, en trasplantes de riñón humano (Wishart, 2005; Goldsmith et al., 2010).

La importancia de los metabólitos en relación con la patogénesis de la enfermedad está comenzando a comprenderse, pero sirve como un buen marcador para el genoma y proteoma. Un simple cambio en una proteína, o una base en el gen, puede llevar a más de 10,000 cambios en la concentración de ciertos metabólitos. Bajo estrés tóxico, las células intentan mantener la homeostasis y el control metabólico variando la composición de los fluidos corporales, esto involucra el desajuste simultáneo en la concentración de cientos o miles de metabólitos, para mantener las características celulares (Ronchfort, 2005).

Básicamente existen dos maneras de abordar un estudio metabolómico usando equipos de Resonancia Magnética Nuclear de alta resolución (HR-NMR, por sus siglas en ingles) que permiten realizar una exploración de todos los metabolitos de bajo peso molecular presentes en distintos tipos de biófluidos o en tejidos tanto de humanos como de modelos animales (Mayr, 2008). El método llamado fingerprinting (huella digital) es el más comúnmente usado en metabolómica; está basado en el análisis conjunto y multivariado de los espectros generados para cada individuo. Cada uno de estos espectros se considera como una huella digital que contiene una serie de señales correspondientes a los metabolitos presentes en la muestra. 
El análisis multivariado del conjunto de espectros permite establecer relaciones de diferencia y similitud entre los individuos que se están analizando. El segundo se conoce como profiling (perfilado), mediante esta técnica, tan solo intervienen en el análisis multivariado aquellos metabolitos que previamente se sabe que intervienen en el fenómeno que se desea estudiar. No permite obtener medidas con la misma frecuencia y de forma automática como en el caso del fingerprinting, puesto que se necesita la intervención del analista, para la cuantificación e identificación de los metabolitos en matrices complejas, como puedan ser el suero o la orina (Wishart, 2007).

Existen también técnicas de espectroscopia de masas (MS), ampliamente usadas y avaladas ya que es una técnica estándar en la industria farmacéutica, para la cuantificación de metabolitos de fármacos. La MS ofrece análisis cuantitativos con alta selectividad, sensibilidad y determinación de fórmula molecular, mediante la medida precisa de la masa. Esto la hace una herramienta muy poderosa para el análisis de un gran número de metabolitos. Las técnicas basadas en MS son más sensitivas que las resonancia magnética nuclear (NRM), pero por lo general requieren preparación de la muestra, a diferencia de la NMR, lo cual puede causar perdida de metabolitos, y con base en el sistema de introducción de la muestra y la técnica de ionización que requiere, algunas clases especificas de metabólitos pueden ser discriminadas (Mayr, 2008; Goldsmith et al., 2010).

\subsection{BIOINFORMÁTICA}

La bioinformática consiste en analizar, comprender y predecir procesos biológicos con la ayuda de herramientas computacionales, estudia el flujo de información a través del dogma central de la biología molecular, como la organización y la regulación de los genes en las secuencias del ADN, la identificación de las zonas de transcripción del ADN, la predicción de la estructura de las proteínas a partir de su secuencia de aminoácidos, y el análisis de la función molecular de las bio-macromoléculas (Voet y Voet, 2007).

Existen dos principales escuelas, tendencias o enfoques que representan hoy en día la bioinformática.

Escuela estructural: es la que define la bioinformática como la aplicación de los sistemas computacionales en la recolección, almacenamiento y análisis de la información biológica. El término información biológica hace referencia a las secuencias de proteínas y ácidos nucleícos. Algunos sustituyen el término bioinformática por genómica, en referencia a que su labor se reduce al análisis de las secuencias de bases o nucleótidos que constituyen el genoma de los seres vivos; de modo análogo, los investigadores dedicados al estudio de proteínas por métodos computacionales introducen el término proteómica (Beltrán, 2004).

Escuela instrumental: mantienen la definición de la bioinformática como la aplicación de los ordenadores a la gestión de información biológica, este término engloba no solo a los ácidos nucleícos y proteínas, sino además toda la terminología científica propia de cualquiera de las especialidades de la biología. Por ejemplo, vocablos como: especie, clon, ecosistema, evolución, etc.

El gran número de estructuras 3D de biomacromoléculas que se han resuelto en las últimas décadas y su deposición en bases de datos (Tabla 6.1) han generado el desarrollo de una subdisciplina dentro de la bioinformática: La bioinformática estructural. La bioinformática estructural es entonces la disciplina de la ciencia que se dedica al 
análisis, caracterización y visualización de estructuras biómacromoleculares, principalmente proteínas, ADN y ARN, y sus interacciones mediante técnicas computacionales. Al igual que otras disciplinas la bioinformática estructural tiene dos objetivos generales: La creación de métodos computacionales para manipular, ordenar y analizar la información generada, y la aplicación de estos métodos para resolver problemas de índole biológico y así generar nuevo conocimiento. Claramente estos objetivos están interrelacionados, dado que la validación de las metodologías involucra su uso exitoso en la resolución de problemas específicos (Martí y Turhanski, 2009).

Tabla 6.1. Bases de datos de Bioinformática Estructural.

\section{BASE DE DATOS ESTRUCTURALES}

Protein Data Bank(PDB)

Nucleic Acid Data Bank

Molecular Modeling Dabase (MMDB)

PQS Protein Quaternary Structure Query Form en el EBI

PROGRAMAS GRÁFICOS MOLECULARES/ PLUG-INS

Chime

Cn3D

Mage

Protein explorer

RasMol

Swiss-PDB Viewer (Deep View)

\section{ALGORITMOS CLASIFICACIÓN ESTRUCTURAL}

CATH (Class, Architecture, Topology, and Homologous Superfamily)

CE (Combinatorial Extension of Optimal Pathaway)

FSSP (Fold Classification Based on Structure-Structure Alignment of Protein)

SCOP (Structural Classification of Protein)

VAST (Vector Alignment Search Tool)

Una base de datos es un archivo computarizado usado para almacenar y organizar datos de tal manera que la información puede ser recuperada fácilmente por medio de una variedad de criterios de búsqueda. Las bases de datos están compuestas por un hardware y software computacional. El objetivo principal del desarrollo de una base de datos, es organizarlos en un conjunto de registros estructurados que permiten la recuperación de información fácilmente; cada registro también llamado entrada, contiene un número de archivos con los datos reales, por ejemplo, archivos de nombres. Para recuperar un registro particular de la base de datos, el usuario puede especificar información llamada valor, que se encuentra en un archivo en particular; este proceso es llamado consulta (Xiong, 2005).

La bioinformática actual es uno de los pilares del estudio de los sistemas vivos desde el punto de vista sistemático y se conoce también como biología de sistemas. Existen en las bases de datos públicas una gran cantidad de secuencias de individuos y patógenos que pueden utilizar los investigadores en su tarea de dilucidar mecanismos 
moleculares de enfermedades. De igual modo, se ha observado un gran avance en la caracterización de la variabilidad genética en seres humanos y en la forma en que esta variabilidad se vincula con determinados riesgos a enfermedades (Barnetche, 2007).

\section{REFERENCIAS BIBLIOGRÁFICAS}

Ablin E., Paz S. (2000) Productos transgénicos y exportaciones agrícolas: Reflexiones en torno de un dilema argentino. Dirección Nacional de Negociaciones Económicas y Cooperación Internacional, Cancillería Argentina.

Avilés C. (2008) Encefalitis por Virus Herpes Simple: Diagnostico y Tratamiento. Medwave 8:7, ISSN 0717-6384.

Alam J. y Cook J. (2003) Reporter genes for monitoring gene expression in mammalian cells. New Comprensive 38, 290-308

Bartnetche J. (2007) La bioinformática como herramienta para la investigación en Salud humana. Salud Pública de México 49, 64-66.

Bastarrachea R., Alvarenga J., Kent J., Molina H., Flores R., Garcidueñas A., Salazar A., Cabrales E., Tejero E., Colew S., Comuzzie A. (2008) Transcriptoma en mexicanos. Metodología para analizar el perfil de expresión genética de gran escala en muestras simultáneas de tejido muscular, adiposo y linfocitos obtenidas en un mismo individuo. Gac Méd Méx 144:6, 473-479

Beltrán R. (2004) Bioinformática: Simulación, vida artificial e inteligencia artificial. Editorial Díaz de Santos. Madrid pp. 574.

Bernal J., Suárez F. (2007) La era genómica y proteómica de la medicina. Universistas médica. 48:2, 105-117.

Brady S., Long T., Benfey P. (2006) Unraveling the Dynamic Transcriptome. The Plant Cell. 18, 2101-2111.

Busquets X. y Agusti A. (2006) Chip genético (ADN array): el futuro ya está aquí. Arch Bronconeumol 37, 394-396.

Bustin S. (2002) Quantification of mRNA using real-time reverse transcription PCR (RT-PCR): trends and problems. Journal of Molecular Endocrinology 29, 23-39.

Campbell P., Smith A., Peters T. (2006) Bioquímica ilustrada: Bioquímica y biología molecular en la era posgenómica. 5a ed. editorial Elservier. Barcelona pp. 242.

Castagnino M. (2008) Proteómica y sus aplicaciones en la medicina humana. Acta Bioquímica de Clínica Latinoamericana 42:2:179-182.

Encarnación S. (2006) Genómica y genómica funcional en microbiología. Revista Latinoamericana de Microbiología. 48:2, 131-145.

Erra B: (2004) Del vuelo de las proteínas y de cómo lograrlo (espectrometría de masas UV-MALDI). Química Viva, 3:2, 56-69.

Giddings G., Allison G., Brooks D. y Carter A. (2000) Transgenic plants as factories for biopharmaceuticals. Nature 
Biotechnology 18, 1151-1155.

Gil G., (2003) La metodología Proteómica, una herramienta para la búsqueda de función. SEM 35, 12-20.

Goldsmith P., Fenton H., Stiff G., Ahmad N., Fisher J., Prasad R. (2010) Metabonomics: a useful Tool Fort he Future Surgeon. Journal of Surgical Research 160, 122-132.

Habermann F., Wuensch A., Sinowatz F. y Wolf E. (2007) Reporter genes for embryogenesis research in livestock species. Theriogenology 68, 116-124.

Haleem J. y Veenstra T. (2008) Two-dimensional polyacrylamide gel electrophoresis (2D-PAGE): advances and perspectives. BioTechniquess 44, 697-700.

Kathryn L. y Dupree P. (2001) Two-dimensional gel electrophoresis: recent advances in simple preparation, detection and quantitation. Chemical Biology, 2, 42-50.

López M., López A., Del Rosario T. y Rosales A. (2005) ¿Qué sabe usted acerca de... Genómica) Revista Mexicana de Ciencias Farmacéuticas 36:1, 42-44.

Martí M. y Turhanski A. (2009) La bioinformática estructural o la realidad virtual de los medicamentos. Química Viva 8:1, 25-34

Mayr M. (2008) Metabolomics: Ready for the Prime Time? Circ Cardiovasc Genet 1: 58-65

Mojica T, Sánchez O y Bobadilla L. (2003) La Proteómica, otra cara de la genómica. Publicación científica1:1, 111-116.

Monroy C. D., Valdéz T., Alarcón A. y Durán R. (2006) Estandarización de la Electroforesis bidimensional para la Determinación de Albúmina S-Nitrosa. Reporte de Servicio Social. División de Servicio Social Unidad Iztapalapa. Instituto Mexicano del Seguro Social.

Naylor L. (1999) Reporter Gene Technology: The Future Looks Bright. Biochemical Pharmacology 58, .749-757.

Peters B., Croix B., Sjöblom T. (2007) Large-scale identification of novel transcripts in the human genome. Genome Res. $17,287-292$.

Pfaffi M. (2001) A new Mathematical Model For Relative Quantification in real- time RT-PCR. Nucleic Acids Research. 29:9, 202-207.

Rochfort S. (2005) Metabolomics Reviewed: A New "Omics" Platform Technology for Systems Biology and Implications for Natural Products Research. J. Nat. Prd. 68, 1818-1820.

Shipley G. (2006) An introduction to real- time PCR. En: Real- Time PCR. Taylor \& Francis Group. Dorak M. (eds) New York pp 333.

The human Metabolome Project http://www.metabolomics.ca/ Consulta: 01/12/210.

Vierstrance A.(1999) Principle of the PCR.http://users.ugent.be/ avierstr/principles/pcr.html Consulta: Diciembre 5, 2010.

VanGuilder H., Vrana K., Freeman M. (2008) Twenty-five years of quantitative PCR for gene expression analysis. BioTechniques 44:5, 619-625. 
Voet D. y Voet J. (2007) Fundamentos de bioquímica: la vida a nivel molecular. $2^{\mathrm{a}}$ ed. editorial Medica Panamericana, Madrid pp. 1260

Welsh S. y Kay S. (1997) Reporter gene expresión for monitoring gene transfer. Biotechnology 8, 617-622.

Whu W., Wang G., Baek J. y Rong-Fong S. (2006) Comparative study of Three Proteomic Quantitative Methods, DIGE, cICAT, and iTRAQ, Using 2D-Gel or LC-MALDI TOF/TOF. Journal of proteome. 5, 651-658.

Wishart D. (2007) Current Progress in computational metabolomics. Briefings in Bioinformatics 8:5, 279-293.

Wishatr D. (2005) Metabolomics: The Principles and Potential Applications to Transplantation. American Journal of Transplantation 5, 2814-2820.

Xiong J. (2005) Essential Bioinformatics. Cambridge University Press, Reino Unido, pp. 336. 



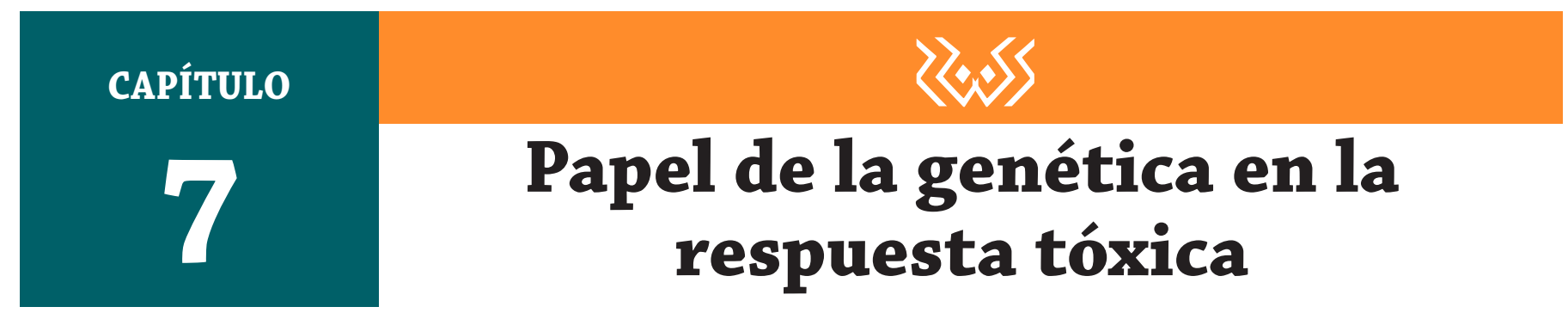

\subsection{INTRODUCCIÓN}

Uno de los retos clave en materia de toxicología molecular es la aplicación de la genómica al entendimiento de la toxicidad y en el descubrimiento de nuevos blancos terapéuticos. Tales aproximaciones nos permitirán entender mejor los procesos biológicos, y como estos cambian en respuesta a una exposición tóxica del organismo. Este conocimiento no solo nos permitirá comprender toxicidad específica, sino el desarrollo de marcadores tempranos para esta, así como contribuir al descubrimiento de nuevos compuestos los cuales no tengan o, minimicen el riesgo de efectos adversos.

Los estudios genómicos se clasifica en tres categorías básicas. Primero, los estudios diseñados para examinar los efectos fundamentales de los tóxicos sobre un organismo, esto provee de un entendimiento mayor de los mecanismos moleculares de la respuesta tóxica. Segundo, los estudios de las diferencias en la respuesta entre modelos de especies animales y humanos, que estén disponibles y sean más seguras en la extrapolación de los datos del modelo animal a la situación en humanos. Finalmente, los estudios de las variaciones interindividuales entre las poblaciones humanas, los cuales están empezando a explicar el espectro de respuestas vistas dentro de la población expuesta, y por tanto establecer con más precisión los límites de exposición segura. Dichas investigaciones permitirán en el futuro la adaptación de drogas y/o régimen de tratamientos diseñados para individuos o subgrupos de poblaciones cuya composición genética podría dar lugar a reacciones adversas a la terapia farmacológica habitual. Estas técnicas están, como veremos más adelante, ya en vigor para algunos tratamientos; pero como se incremente nuestro conocimiento crecerá la capacidad de utilizarlo en una forma productiva para garantizar una mejor respuesta individual al tratamiento farmacológico.

\subsection{MECANISMO DE CONTROL GENÉTICO}

El control de la expresión genética se da en varios niveles, el control preciso de la expresión depende de los requerimientos de una situación particular. El primer nivel de control es el mínimo requerido para producir expresión génica, hay factores que controlan la expresión génica basal. Este mecanismo basal solo origina bajos niveles de expresión, y activa altos niveles, en tejidos específicos de un organismo, o durante estados específicos del desarrollo, se requieren factores para que se de la expresión génica constitutiva. Al final, la expresión de muchos genes es capaz de activar los interruptores de prendido/apagado en respuesta a un estímulo específico (xenobiótico), para responder a los cambios en el ambiente celular. La expresión génica 
reactiva es evidentemente un factor clave en la respuesta a la exposición a agentes químicos, ya sea que se incremente la expresión de genes asociados con el metabolismo de drogas o combatiendo los efectos de una exposición tóxica.

\subsubsection{Expresión génica basal}

Una definición simple de un gen es una región codificante (codifica productos proteicos), y los elementos con los cuales controla su expresión. Esta última región puede ser dividida funcional y espacialmente en dos compartimientos: Las regiones promotoras y potenicadoras ("enhancer"). Los promotores son las regiones inmediatas a la unidad de transcripción (región codificante más la región adicional no traducida), en posición 5', son los únicos requerimientos para la expresión génica basal. En comparación, los potenciadores y las regiones de control- locus, son espacialmente distintas de los promotores, frecuentemente por decenas de miles de bases, $y$, en conjunto con el promotor, son responsables del control de altos niveles de expresión génica asociada con la expresión constitutiva y reactiva.

En todos los eucariontes el ARNm se transcribe a partir de los genes, por la ARN polimerasa II, y he aquí el requerimiento mínimo (expresión génica basal), que es reclutar esta enzima al inicio de la región codificadora y especificar la dirección, en la que transcripción debe ocurrir. En la mayoría de los mamíferos (más del 90\%) se encuentra una secuencia elemental llamada TATA-box, se localiza a 25 pares de bases aproximadamente corriente arriba del sitio donde se inicia la transcripción. Este elemento es reconocido por la proteína de unión a TATA (TBP por sus siglas en inglés), una subunidad del factor de transcripción basal TFIID. Una vez que TFIID está unido a la caja-TATA pueden reclutar numerosos factores, incluyendo a la ARN-polimerasa II, la cual es guiada al sitio de inicio de la transcripción, y entonces se inicia. La figura 7.1 muestra la expresión génica basal del gen de la albúmina, un gen regulado clásicamente por TATA-box (Krebs et al., 2011).

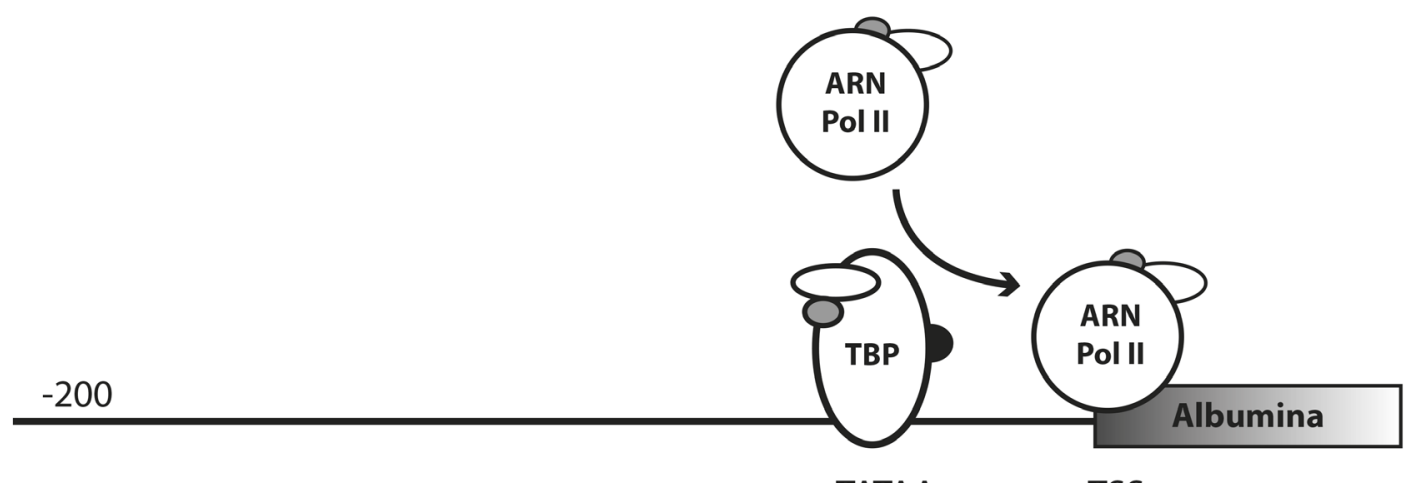

TATAA

TSS

Figura 7.1. Elementos involucrados en la expresión basal del gen de la Albúmina (Modificado de Plant, 2003). 


\subsection{Expresión génica constitutiva}

Se requieren los constituyentes básicos para la transcripción mencionada anteriormente. ¿Cómo se regula la expresión génica en un tejido o estado de desarrollo específicos? La respuesta comprende dos aspectos: Factores específicos pueden ser activados o reprimidos cuando se unen al promotor del complejo de transcripción basal.

Para que el complejo de transcripción se ensamble e inicie la transcripción debe tener libre acceso al ADN en el promotor (el ADN debe estar en una conformación "abierta"). Sin embargo, el ADN no está usualmente en forma desnuda, esta condensado en un orden superior que constituye la estructura de la cromatina. Es decir, en un primer nivel, el ADN está rodeando un octamero de proteínas histonas para formar el núcleosoma. Estos núcleosomas están espaciados a lo largo del ADN, dando la estructura de "cuentas de rosario". Esto a su vez se enrolla aun más, produciendo la cromatina estrechamente empaquetada, en este estado el complejo de transcripción no tiene acceso al promotor (conformación cerrada), así se reprime la expresión génica. Para iniciar la expresión génica, la estructura de la cromatina debe abrirse para que el complejo de transcripción tenga acceso, y este puede ser activado de dos formas. Primero, las histonas deben ser modificadas covalentemente por las enzimas histonaacetil-transferasas (HATs, por su siglas en inglés), adicionando grupos acetilo a cada proteína histona (Krebs et al., 2011).

La acetilación reduce la carga total de las histonas lo que resultará en un interacción débil con el ADN, inicialmente se pensó que esto era suficiente para causar una estructura más abierta. Sin embargo, trabajos posteriores identificaron un segundo grupo de factores modificadores de la cromatina, es probable que este segundo grupo actué donde las HATs ya modificaron la cromatina, tomando esto como una señal para que el segundo grupo de enzimas accione, más que alterar directamente la estructura de la cromatina. Los complejos remodeladores de la cromatina mueven las histonas a lo largo del ADN, sin removerlas por completo, y por lo tanto hay regiones de estructura abierta del ADN. ¿Como entonces estas enzimas actúan sobre regiones específicas del ADN, los promotores de los genes que se prenderán?

La activación de la transcripción en un ambiente de cromatina represivo se activa por los factores de transcripción. Estas proteínas contienen, como mínimo, un dominio de unión al ADN el cual reconoce secuencias específicas del ADN, y una activación del dominio, con el cual puede trabajar en numerosas vías. En algunos casos la activación del dominio tiene ya sea HAT o actividad de remodelación de la cromatina, y esto puede proveer directamente el acceso al ADN para los factores de transcripción.

Alternativamente, los factores de transcripción pueden interactuar con HAT o con los factores de remodelación de la cromatina, reclutándolos para los promotores, y así indirectamente alterar la estructura de la cromatina. Finalmente, la activación de los dominios puede también interactuar con los componentes de los complejos de la transcripción basal y ayudar a reclutar los factores esenciales para el promotor. Tal reclutamiento puede ocurrir ya sea por contacto directo, o pueda requerir proteínas co-activadoras adicionales que actúan como moléculas puente entre los factores de transcripción y la maquinaria de transcripción basal.

La especificidad de esta regulación se activa de dos formas. Primeramente, el ADN se une al dominio de un factor de transcripción que reconoce una secuencia específica del ADN (el elemento de respuesta) y entonces los factores de transcripción únicamente interactúan con los promotores, y tiene efecto sobre la expresión génica de los promotores y los potenciadores que contienen el elemento de respuesta específico. Segundo, el patrón de 
expresión de los factores de transcripción pueden estar restringidos a ciertos tipos celulares, y entonces estos factores serán activados únicamente en esas células. Se sabe, sin embargo, que la expresión génica regulada, es raro que este bajo el control de un solo factor de transcripción y hay interacción frecuente entre diferentes factores de transcripción, que proveen una regulación precisa de la expresión génica.

Un ejemplo de tal expresión tejido-específica se ha visto para el gen de la Albumina. El promotor de la Albumina contiene sitios de unión para varios factores de transcripción que interactúan para producir una regulación tejido específica. Varios elementos de respuesta para los factores de transcripción, del Factor Nuclear Hepático (HNF-1 por sus siglas en inglés), existen en el promotor de la Albumina. El HNF1 está implicado en la remodelación de la cromatina del promotor de la Albumina, y por tanto incrementa el acceso de otros factores de transcripción como $\mathrm{C} / \mathrm{EBPa}$, el cual a su vez recluta la maquinaria de transcripción en el sitio de inicio. Como el HNF1 se expresa en altos niveles en el hígado comparado con otros tejidos, esto significa que el promotor de la Albumina permanece con la formación de cromatina abierta solo en el hígado, y por tanto el gen se expresa únicamente en este órgano.

La figura 7.2 muestra la estructura del promotor de Albumina, identifica los factores responsables de la regulación de este gen, y muestra como la expresión tejido- específica resulta en la expresión hígado- específica de la Albumina (Lichtsteiner et al., 1987).

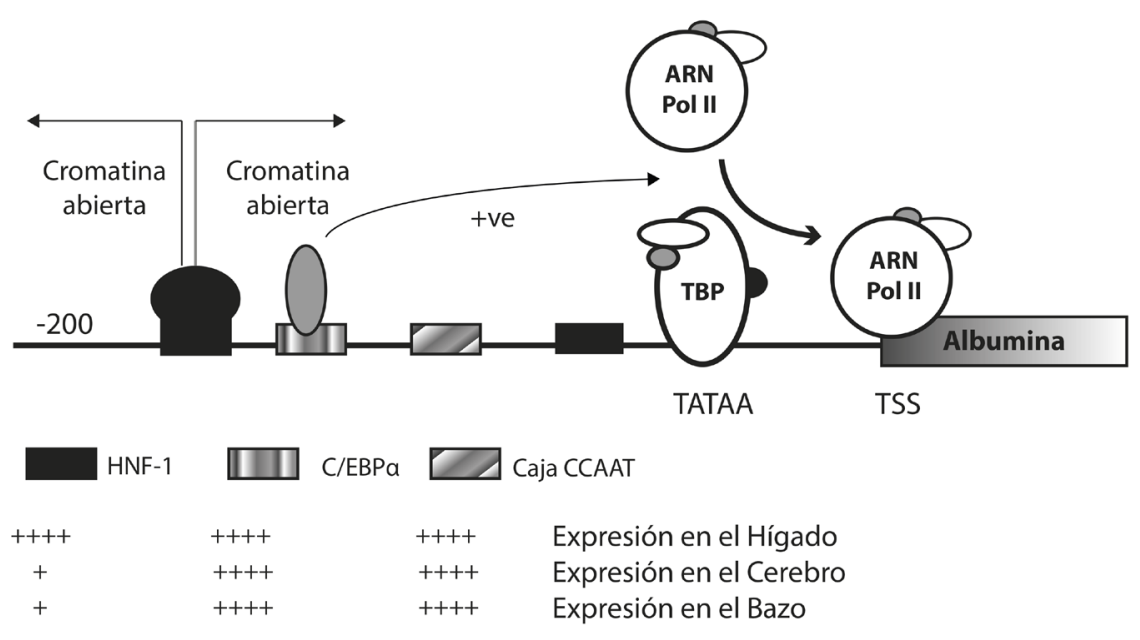

Figura 7.2. Elementos involucrados en la expresión tejido-específica del gen de la Albúmina (adaptado de Lichtsteiner et al., 1987).

Así como la región reguladora del promotor, los genes usualmente poseen una región reguladora adicional, los potenciadores (enhancer). Los potenciadores son físicamente distintos de los genes que regulan, frecuentemente por miles de bases, y pueden estar ya sea corriente arriba o corriente abajo de la región codificadora. Como los promotores, los enhancers contienen elementos de respuesta para factores de transcripción implicados en la expresión génica regulada o reaccionaría y frecuentemente factores de transcripción que se unen al promotor de un gen y también al respectivo enhancer. Entonces los factores de transcripción se unen a los enhancers 
causan eventos moleculares similares a los observados con la unión al promotor (por ejemplo: modificaciones en la cromatina y reclutamiento del complejo de transcripción basal).

La forma exacta por medio de la cual este potenciador espacialmente distinto interactúa con los promotores no se conoce, se piensa que esté es uno de los dos mecanismos. Mientras que los potenciadores son muchos miles de bases más grandes que sus promotores, ellos pueden estar espacialmente muy próximos, debido a la estructura tridimensional del ADN superenrrollado de la estructura cromatínica. Alternativamente, la unión a los factores de transcripción causa transmisión de las señales al ADN promotor, ya sea por medio de las modificaciones de la estructura de la cromatina, o a través de la transmisión de señales vía proteínas facilitadoras "teóricas". El mecanismo exacto de la acción del potenciador, se puede ver en la unión de los factores de transcripción a estas regiones que actúa amplificando los efectos iniciados en el promotor y esto además incrementa la actividad de la transcripción.

Muchos genes se expresan no sólo de forma tejido-específico sino también en un estado de desarrollo específico. Por ejemplo, en el feto humano el CYP3A7 es la principal proteína de CYP3A, mientras que en los adultos se reduce mucho su expresión, en cambio se prende el gen que codifica para la proteína CYP3A4. ¿Como entonces la célula controla esta expresión génica regulada en el desarrollo? Una explicación simple, sería la expresión específica de los factores de transcripción según el estado de desarrollo. Es decir, así como se ha visto en el caso de la expresión tejido-específica, la expresión regulada de un gene únicamente cuando es crucial que los factores de transcripción se expresen.

Quizás los mejores genes estudiados de la regulación génica en el desarrollo, son los de la $\beta$-globina humana, cuyos productos son componentes clave del transporte del oxígeno por parte de la molécula de la hemoglobina. Como se puede ver en la Figura 7.3 el grupo de las $\beta$-globinas se extiende más allá de los $70 \mathrm{kbp}$ y consiste de cinco genes, todos muestran una regulación en función del desarrollo. Cada gen tiene su propio promotor pero comparten una sola región locus-control (LCR, por sus siglas en ingles) un potenciador especializado que coordina la regulación de la expresión génica del grupo completo.

Dentro del grupo de las $\beta$-globinas los genes se expresan en el orden en que se encuentran localizados a lo largo del cromosoma, y este fenómeno provee la primera pista de cómo estos genes pueden ser regulados a través del desarrollo. Ya que cada gen tiene su propio promotor, los cuales compiten por la LCR para mejorar la eficiencia de los promotores e iniciar la transcripción. En experimentos donde se utilizaron ratones transgénicos se ha avanzado sobre este tipo de regulación. Los animales transgénicos que contienen el inicio del grupo humano (LCR más el gen-६) mostraron regulación normal del desarrollo, y expresión en el estado fetal, seguida de una disminución en la expresión, conforme avanza el estado post-natal.

Sin embargo, reemplazar el gen- $\xi$ por el gen- $\beta$ resulto en la expresión de todos los estados de desarrollo, mostrando que no había regulación en función del estado de desarrollo. Adicionando un gen entre la región LCR y el gen- $\beta$ se indujo la expresión para revertir lo usual, en el perfil adulto únicamente. Esto sugiere que la regulación del desarrollo fue llevada por la competencia de LCR, los genes más próximos a LCR (por ejemplo, el gen-६) expresándose por completo, de forma gen-específica, silenciado elementos que lo apagan. Solo entonces los genes, pueden ser activados por la LCR (ej. $\beta$ ) (Enver et al., 1990). Falta investigar, donde un mecanismo similar es responsable de la regulación génica del desarrollo de grupos de genes implicados en la respuesta a químicos tóxicos (ej. el grupo de los CYP3A). 


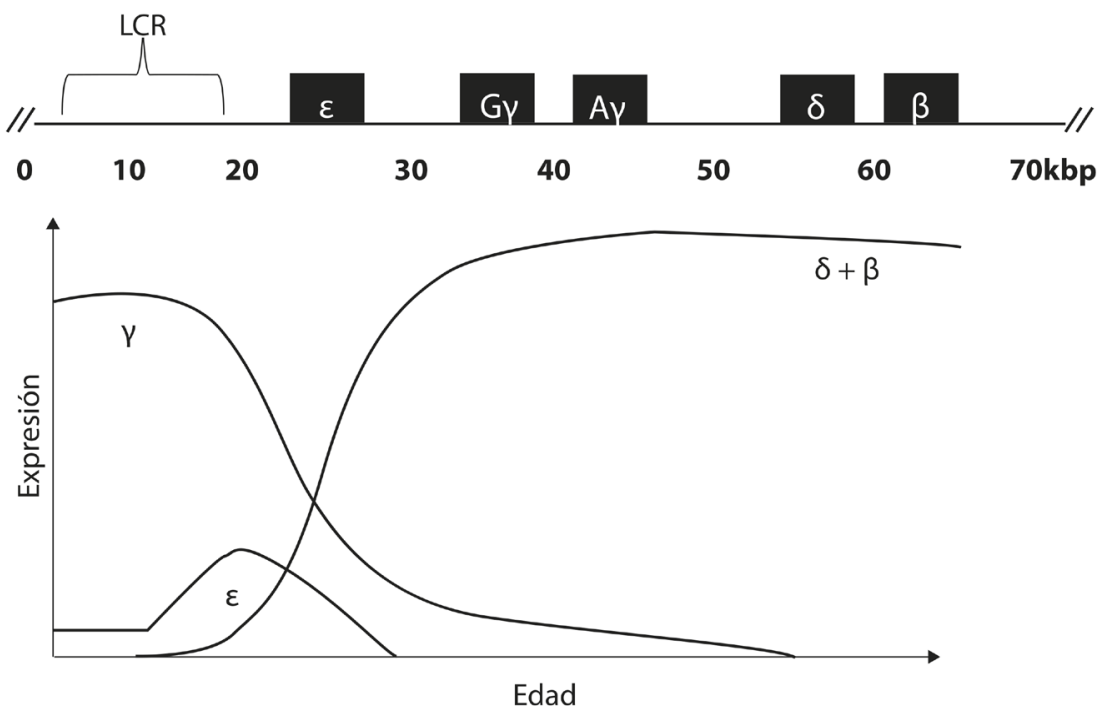

Figura 7.3. El grupo de genes humanos $\beta$-globulina (Modificado de Plant, 2003).

\subsubsection{Expresión génica reactiva}

A través de las acciones de los factores de transcripción específicos tejido-órgano y el estado del desarrollo, podemos ver como la expresión génica está controlada bajo condiciones fisiológicas normales. Sin embargo, ¿Cómo la célula altera la expresión génica en respuesta a cambios en los niveles o concentración de un agente químico? Los factores de transcripción que hemos considerado están lejos de ser constitutivamente activos, así que su única presencia es suficiente para estimular la transcripción. Proporcionan un mecanismo de control inducible, si es necesario tener factores de transcripción que se activen únicamente en la presencia de un agente químico, estos son llamados factores de transcripción-ligando-activos. Los ligandos, pueden ser agentes químicos endógenos o xenobióticos; es solo su acumulación en la célula lo que causa la respuesta. Los receptores-ligando activos están generalmente presentes en el citosol, donde están asociados con moléculas chaperonas como las proteínas de choque térmico (HSPs por sus siglas en inglés).

La unión de los ligandos causa un cambio conformacional en el receptor, resultando en la disociación de las moléculas chaperonas, translocación dentro del núcleo y exposición del dominio de unión al ADN. Estos factores "activados" pueden unirse a los elementos de respuesta en los promotores o los potenciadores de los genes y causar un aumento en la proporción de los factores de trascripción en el promotor. El resultado final es un aumento en la proporción de la transcripción y por lo tanto en los niveles de los productos génicos, designados para lidiar con una exposición química, ya sea a través del metabolismo del agente químico o la reparación de cualquier daño celular producido. 


\subsubsection{CYP3A4: control de la expresión génica de una enzima metabolizadora de drogas}

Como se dijo en el capítulo 3, las enzimas citocromos P450 son responsables de la mayoría del metabolismo Fase I, de la familia de los CYP, los CYP1-3 son los que están implicados en el metabolismo primario de la mayoría de los xenobióticos. No es una sorpresa que cada una de estas familias tenga un mecanismo de control complejo, para asegurar que la expresión génica esté en ambos constitutivamente presente, pero es también capaz de responder a la variación en la concentración del sustrato de la enzima. Actualmente, se sabe como ocurre la regulación del CYP3A4, además se muestran los elementos previamente mencionados, y como se integran para formar una unidad regulatoria de la expresión génica.

La Figura 7.4 presenta la estructura básica del promotor del CYP3A4, y la interacciones que ocurren para que se de la transcripción constitutiva de los genes. La unión de TBP a la caja TATA y el subsecuente reclutamiento de la ARN polimerasa II; como ésta se estimula por dos factores reguladores de la transcripción, SP1 y HNF-3. Estas formas aparecen para ayudar en el reclutamiento de TBP, mientras que el último probablemente usa su actividad HAT para alterar la estructura de la cromatina en una estructura más abierta que conduce a la transcripción. En resumen, la expresión génica tejido-específica de la HNF-3 confirma la expresión del gen CYP3A4, predominantemente en el hígado y el intestino. El resultado total producirá bajos niveles de expresión de CYP3A4 en otras células específicas del cuerpo.

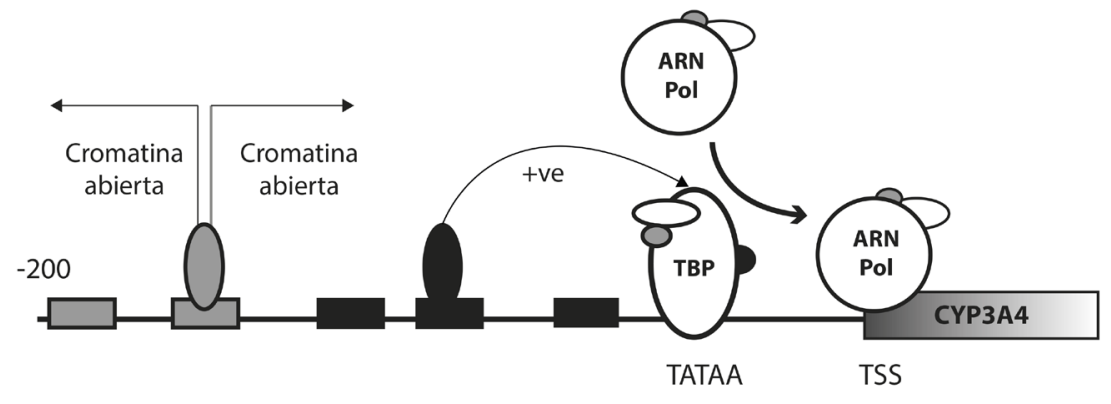

$\square$ SP-1 $\square$ HNF-3

Figura 7.4. Elementos involucrados en la expresión constitutiva del gen CYP3A4 (Modificado de Plant, 2003).

Como se menciono antes, para incrementar los niveles de expresión génica, y para continuar con la expresión génica reactiva, muchos genes tienen elementos de respuesta para receptores ligando-activados asociados a ellos. Para los CYP, estos factores de transcripción están activados por el mismo perfil de químicos que son también su sustrato. La Tabla 7.1 muestra los principales receptores ligando-activados asociados con los familias CYP13 , a lo largo de la secuencia de ADN que ellos reconocen. La presencia de un elemento de respuesta al receptor PXR (Receptor-X-Pregnano, por sus siglas en inglés) se localiza a aproximadamente $-290 \mathrm{pb}$ en el promotor del CYP3A4, proporciona un sitio de unión para PXR, y se caracteriza por ser el principal ejemplo de regulación génica mediada por xenobióticos (Figura 7.5). 
En resumen, para seguir la expresión de los genes reactivos, PXR participa en la expresión génica regulando de dos formas. La primera, los ligandos endógenos para PXR proporcionara un nivel bajo de activación de estos receptores en condiciones fisiológicas normales, y esto incrementará la expresión constitutiva de los genes para CYP3A4. La segunda, la expresión tejido-específica de CYP3A4 de PXR ayuda a mantener la expresión tejidoespecífica de CYP3A4, con mayores niveles de PXR presentes en los tejidos del hígado y el intestino donde CYP3A4 se expresa también en niveles altos. Por lo tanto, las interacciones dentro del promotor, proveen los estímulos necesarios para la expresión génica reactiva tejido-químico específico de CYP3A4.

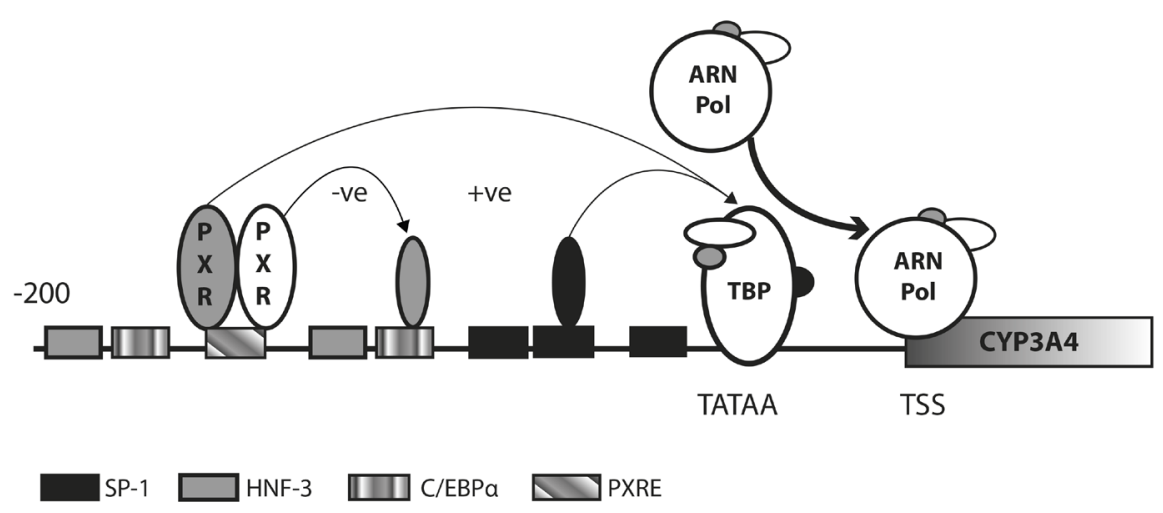

Figura 7.5. Elementos involucrados en la expresión del gen CYP3A4 mediada por xenobióticos (Modificado de Plant, 2003).

Mientras que el control de la expresión génica de CYP3A4 puede deberse a las interacciones en el promotor, las interacciones en el potenciador del CYP3A4 (denominado módulo potenciador de respuesta a xenobióticos o $X R E M$, por sus siglas en inglés) afinan esta regulación y sigue la amplificación de los efectos de la expresión génica reactiva. Goodwin et al. (1999), demostró la importancia de los potenciadores en la propagación de la respuesta a xenobióticos, al examinar el XREM de CYP3A4. Inicialmente Goodwin et al. (1999) clono 13 Kpb río arriba del extremos 5' del ADN de la región codificante en un gen reportero. Entonces, por medio de corte de secuencias pequeñas de esta región clonada, fueron capaces de identificar 230 pb aproximadamente $7.9 \mathrm{Kpb}$ de distancia del gen necesario para activar la inducción máxima en respuesta a xenobióticos. Los análisis bioinformáticos y de huellas dactilares (footprint), de esta región, identificaron los sitios de inicio para el Receptor-X- Pregnano, así como otros factores de transcripción, no identificados actualmente dentro de esta región. PXR puede por lo tanto regular positivamente la expresión del gen del CYP3A4 cuando este se une a XREM, como se ve en la Figura 7.6.

En resumen, se puede ver que cada uno de los niveles de control de la expresión génica (basal, regulada y reactiva) está integrado para producir un poderoso mecanismo de control preciso de la expresión génica. Por medio del uso de factores de transcripción específicos es posible establecer en ambos una expresión finamente regulada (ej. expresión o etapa del desarrollo) pero con la habilidad de aumentar la expresión en respuesta a cambios en las condiciones celulares (ej. expresión génica reactiva). 


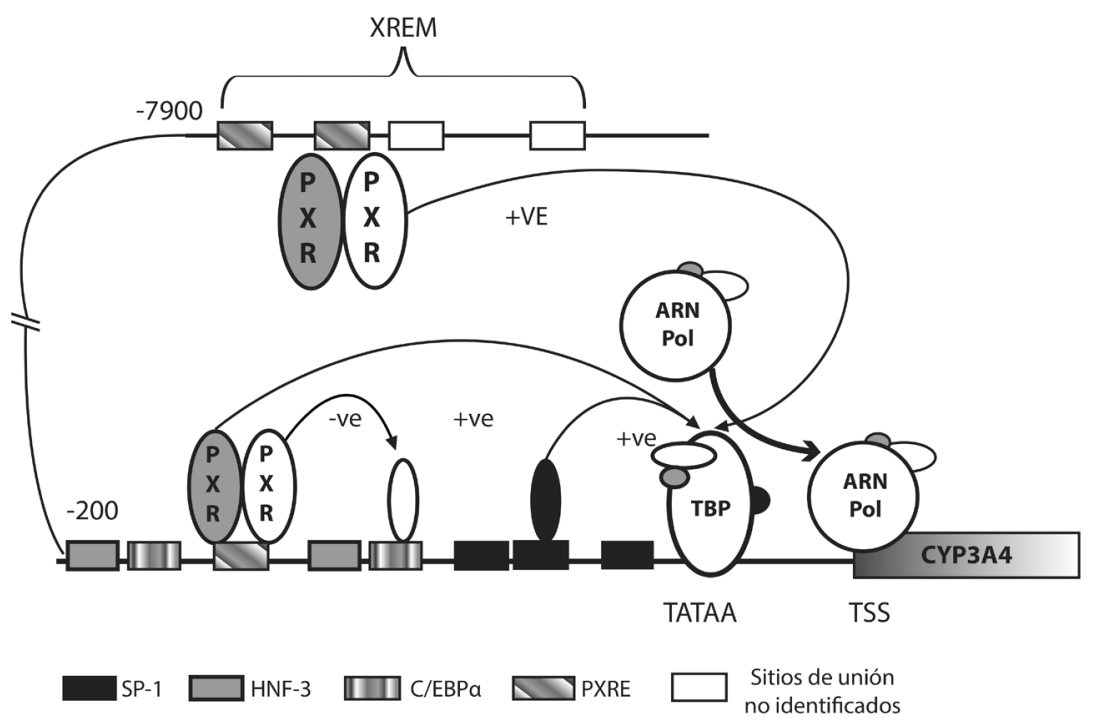

Figura 7.6. Participación del potenciador en el control de la expresión del gen CYP3A4 mediada por xenobióticos (Modificado de Plant, 2003).

\subsubsection{Coordinación de respuesta a la exposición tóxica}

En general, la exposición a xenobióticos resulta en la activación de diferentes genes, no solo uno. ¿Cómo entonces se coordina la respuesta de activación? La vía más común es a través de la presencia de los mismos elementos de respuesta en los promotores de varios genes diferentes. Esto es, la activación de un solo ligando-receptor activado por un ligando que resulte en la activación de numerosos genes diferentes, los cuales incrementaran la expresión resultante, en forma de respuesta celular coordinada, a la exposición química. Sin embargo, otros dos sistemas se sabe que frecuentemente coordinan la expresión génica, perfilando los cambios asociados con la exposición a químicos.

En el primero de estos, son muchos receptores-ligandos activados que exhiben un grado de solapamiento dentro de los ligandos que pueden unirse y activarlos. Por ejemplo, los glucocorticoides como la hidrocortisona, que es el clásico ligando para el receptor a glucocorticoides (GRa). Sin embargo, también son capaces de unirse a ligandos para el receptor PXR, y esto constituye la activación de ambos receptores que producen una inducción óptima de la expresión del gen del CYP3A4 (El-Sankary et al., 2000). Pascussi et al. (2000) demostró que esta respuesta coordinada, no se limita a la unión de los receptores para los promotores y potenciadores del CYP3A4. Ellos demostraron que los glucocorticoides fueron capaces de causar un incremento de la expresión del gen PXR, muy probablemente por medio de la unión a los promotores GRa y PXR. Entonces, los glucocorticoides no solo activan PXR y GRa e inducen que se unan a los promotores/potenciadores del CYP3A4, también incrementan los niveles de expresión de PXRa y la heterodimerización de su homologo RXRa, esto además amplifica la inducción de la respuesta. Tal inducción coordinada de los factores de transcripción se extiende más allá de los factores de transcripción ligando-activados; por ejemplo, se sabe que los glucocorticoides incrementan la expresión de los factores reguladores de la trascripción C/EBPa (Grange et al., 2001). 
La otra vía en la cual la respuesta coordinada puede ser activada a través de compartir los elementos de respuesta más que los ligandos. Dicha coordinación esta ejemplificada por los receptores ligando-activados CAR y PXR. Maglich et al. (2002) examinaron los genes regulados por estos dos factores usando animales transgénicos agonistas y nulo receptores-selectivos. Ellos mostraron que mientras cada receptor estuvo implicado en la regulación de varios genes únicos, un gran subgrupo de genes fue regulado por ambos receptores, incluyendo un gran número de enzimas Fase I y Fase II que metabolizan drogas. ¿Cómo entonces se activó la regulación coordinada? La solución obvia es la presencia de los elementos de respuesta para ambos receptores en los promotores/potenciadores de los genes. Sin embargo, como mostró Xie et al. (2000) este no fue el caso, al exponer que CAR y PXR fueron capaces de activar la expresión de los CYP por medio de los elementos de respuesta: CAR fue por lo tanto, capaz de unirse y activar la transcripción, para la respuesta del elemento nativo en el promotor de CYP2B6 y también del elemento de respuesta del receptor PXR en el promotor del CYP3A4, y viceversa para PXR.

Esta coordinación de la expresión génica para los genes encargados de tratar con la exposición química del cuerpo se denomina frecuentemente "red de seguridad metabólica" y se piensa que actúa como un sistema de sobrevivencia de la célula. Si el sistema primario del metabolismo de drogas está comprometido en cualquier vía entonces la activación coordinada de un sistema alterno, ya sea por medio de la activación de receptores alternativos o un receptor que activa la expresión génica alternativa, ayudará a minimizar la exposición tóxica sufrida por el organismo.

\subsection{HERRAMIENTAS PARA EL ESTUDIO DE LA RESPUESTA GENÉTICA A LA EXPOSICIÓN QUÍMICA}

La ventaja de la biología molecular ha resultado en el desarrollo de una vasta variedad de tecnologías para que los investigadores estudien la respuesta de un organismo a la exposición química tóxica o un agente terapéutico, a nivel genético. Tales tecnologías incluyen los intentos para estudiar la respuesta completa de un organismo (p. e. microarreglos de ADN, tecnología de diferenciación visual) con la cual se estudian pequeños juegos de genes (p. e. QRT-PCR, ensayo de genes reporteros, estudios transgénicos). Los cuales fueron abordados en el Unidad 6.

\subsubsection{El estudio del genoma completo y como responde a la exposición química}

El entendimiento completo de la respuesta de un organismo a un estímulo, sea terapéutico, ambiental o toxicológico, una aproximación ideal será la medida de los niveles de expresión de todos y cada uno de los genes antes y después de la exposición. Esto sería una perspectiva desalentadora considerando que esto corresponde aproximadamente a 31000 genes en la mayoría de los mamíferos. Sin embargo, el advenimiento de la tecnología de los microarreglos de ADN permitirá aproximaciones, cercanas a la realidad. La mancha de varios miles de genes fragmentados sobre una membrana significa que una gran porción del genoma que se puede estudiar. Como no es aún práctico ajustar el genoma entero, de especies superiores sobre un solo chip, o procesar una gran cantidad 
de datos, muchas compañías ahora producen los llamados "chips" que cubren un área particular de interés (ej. la síntesis de ADN, apoptosis o cromosomas individuales). Interrogantes de los microarreglos con ARNm a partir de animales expuestos y silvestres, y entonces la gran cantidad de datos para distinguir genes que se expresan diferencialmente en las dos situaciones, provee de una riqueza de información de ¿cómo los genes representados sobre el microarreglo responde a la exposición?

La información se utiliza, ya sea para el estudio del perfil de la expresión de numerosos genes asociados con procesos celulares particulares, quizás para identificar patrones de expresión similares, causados por numerosos compuestos, o para identificar nuevos genes que están regulados por medio de los mismos compuestos. Esta última provee una extensión importante del conocimiento, seguido de la comprensión de los efectos del compuesto, y de cómo tales efectos pueden impactar los efectos fisiológicos finales.

Ya hemos examinado previamente el papel del citocromo b5 en la reducción del cromo (Unidad 2) y hemos comentado sobre la variedad de la toxicidad mostrada por los compuestos que contienen cromo, incluyendo la citotoxicidad, mutagenicidad y carcinogenicidad. Con este rango tan amplio de efectos, es de esperarse que un gran número de genes estén afectados durante la exposición crónica al cromo, ya sea como resultado directo de toxicidad o debido a los proceso de reparación de la célula con daño sustancial. Se presenta como una respuesta tóxica compleja para el análisis de microarreglos, tal enfoque permite la caracterización de la expresión de numerosos genes al mismo tiempo. El objetivo general de este enfoque sería comprender las respuestas celulares clave, por la intoxicación con cromo, además de identificar los marcadores potenciales para este tipo de toxicidad. Cheng et al. (2002) utilizo el análisis de microarreglos para investigar los efectos del cloruro de cromo (III) en células de Sertoli de testículo humano.

En células de Sertoli expuestas a una dosis no tóxica de cloruro de cromo (III), el ARNm se extrajo y se utilizo para integrar un microarreglo de aproximadamente 10,000 secuencias: fueron identificados 52 genes que mostraron cambios después de la exposición. De estos, varios factores de transcripción y proteínas de defensa de la célula, proveen de información importante sobre la respuesta a la exposición. Hamadeh et al. (2002) utilizaron análisis de microarreglos para identificar los cambios en el perfil de la expresión de genes causados por la exposición de ratas a tres distintos proliferadores de peroxísomas (Wy-14, 643, gemfibrozil y clofibrato), se comparo con los patrones causados por el fenobarbital, el cual no es un proliferador de peroxísomas, pero causa un aumento en el tamaño del hígado, similar al de los proliferadores de peroxísomas. Los cambios fueron observados en aproximadamente $25 \%$ de los genes de este "chip toxicológico" y se pueden hacer dos importantes distinciones.

Primero, fue posible discriminar entre dos tipos de genes: aquellos cuya expresión cambio solo transitoriamente, de aquellos en que los cambios fueron persistentes. Los genes de cambios transitorios tendieron a correlacionar con moléculas de señalización (ej. proteína-G acoplada a receptores quinasa 5), mientras que en los cambios persistentes se observaron en los genes que codifican para proteínas implicadas en el metabolismo (ej. CYPs) o procesos bioquímicos celulares (ej. histidina descarboxilasa). Segundo, fue matemáticamente posible, separar el fenobarbital de los proliferadores de peroxísomas, en base a los cambios en la expresión génica observada. Además las bases de estos datos, revelaran cuales de esté conjunto de cambios, en las dos clases de compuestos, serán utilizados para entender las diferencias en los mecanismos moleculares subyacentes a sus acciones. 


\subsubsection{El estudio de la respuesta génica individual a la exposición tóxica}

A la inversa del estudio de cambios globales asociados con estímulos es el estudio de la regulación de vías únicas o incluso de genes individuales. Se han identificado una de las vías clave o enzimas implicadas en la respuesta tóxica, posiblemente por medio de la tecnología de los microarreglos, es usual concentrar estas reacciones claves para entender los mecanismos moleculares del control genético. Dicha información puede ser usada para producir marcadores tempranos asociados a toxicidad, o para ayudar en el desarrollo de nuevos compuestos que no exhiban efectos adversos. Un método común para estudiar la activación transcripcional, es el ensayo de genes reporteros, el cual relaciona la activación transcripcional de los genes de interés con un parámetro fácilmente medible (ej. secreción de fosfatasa alcalina).

Un ejemplo donde los genes reporteros, han sido empleados exitosamente, es en el monitoreo de compuestos por su habilidad de inducir las enzimas citocromo P450. La especificidad del sustrato normal de los CYP produce el potencial para el estudio de la problemática entre las interacciones droga-droga, con dosis de un compuesto que incrementa los niveles de un CYP y por lo tanto altera la farmacocinética de un segundo compuesto (coadministrado). Esté es particularmente el caso del tratamiento de los desordenes donde, la polifarmacia es prevalente (ej. el tratamiento de desordenes psiquiátricos). Por lo tanto, es importante entender el perfil de inducción de compuestos al inicio de su desarrollo, para poder predecir y por tanto eliminar el problema potencial de las interacciones fármaco-fármaco, de los compuestos que están al alcance del público en general.

Diseñar un gen reportero que este bajo control de un promotor de un CYP, acoplado por transfección a células de hígado humano, seguida de la evaluación confiable de su habilidad para inducir a CYP. Utilizando esta tecnología es posible por lo tanto predecir lo que ocurre de la interacción droga-droga. El-Sankary et al. (2001) utilizó el sistema de gen reportero para comparar el perfil de varios compuestos usados en la clínica, donde fueron capaces de establecer un intervalo, de acuerdo a la habilidad de inducir completamente al CYP3A4 (Tabla 7.2). Tales experimentos proveen una información muy importante sobre las implicaciones posibles de la exposición a compuestos co-administrados y esto ayuda a definir condiciones seguras a usar en la polifarmacia. Las implicaciones de la exposición a la mezcla de fármacos.

Una alternativa es el uso de genes reporteros para el estudio de los factores de transcripción implicados en la regulación de la expresión de genes dentro de un promotor particular. Por medio de la utilización de la mutagénesis sitio-dirigida, es posible separar los elementos de respuesta específica dentro de un promotor y determinar si tienen efectos sobre la expresión de un gen reportero, ya sea en términos de expresión basal o de respuesta a exposición química. Un ejemplo de dicha tecnología fue provista por El-Sankary et al. (2002), qué estudio los efectos de una mutación en el promotor del CYP3A4. Eliminó el sitio la unión a C/EBPa causando una disminución en la respuesta de un gen reportero a los glucocorticoides pero no a la rifampicina, mostró evidencia de que estas dos clases de compuestos actúan, al menos en parte, por mecanismos separados. 
Tabla 7.2. Activadores transcripcionales de CYP3A4.

\begin{tabular}{llc} 
Químico & \multicolumn{1}{c}{ Uso clínico } & $\begin{array}{c}\text { Habilidad de } \\
\text { inducción }\end{array}$ \\
\hline Fenitoína & Anticonvulsivo & Débil \\
Sulfinpirazona & Uricosurico & Débil \\
Fenobarbital & Anticonvulsivo/sedante & Débil \\
Clotrimazol & Antifúngico amplio espectro & Débil \\
Fexofenadina & Tratamiento de hipersensibilidad & Media \\
Rifampicina & Antibiótico macrolido & Media/potente \\
Troglitazona & Antihiperglicemico & Potente \\
Lovastatina & Reductor del colesterol & Potente \\
\hline
\end{tabular}

(Modificado de Plant, 2003).

\subsection{VARIACIÓN ENTRE ESPECIES}

Se han utilizados modelos animales por muchos años para investigar el efecto de compuestos y, son una parte vital de cualquier base de datos donde se registre drogas médicas. Este uso se origina a partir de la suposición de que la respuesta observada en diferentes mamíferos es la misma, o similar a la que se observó en humanos. Dicha suposición, no es sin algunas bases, como muchos tóxicos clásicos (ej., TCDD, $\mathrm{CCl}_{4}$ ), teniendo muchos efectos similares en modelos murinos comparados con humanos, causando toxicidad aguda o una patología similar.

Puede no ser sorprendente cuando consideramos que tan similares somos genéticamente con otros mamíferos, hecho que se ha confirmado con la secuenciación completa de los genomas de varias especies incluyendo ratones y humanos. Por ejemplo, ratones y humanos tienen un número de genes muy similar (aproximadamente $31,000)$ y la mayoría de productos génicos en el hombre tienen contraparte murina. Además, muchos de los genes están acomodados a lo largo del cromosoma en el mismo orden en las dos especies (sintenia). De hecho, el cromosoma $\mathrm{X}$ de humanos y ratones muestra sintenia casi completa, enfatizando como son de similares genéticamente estas dos especies. ¿Tales similitudes lo hacen un modelo perfecto para el estudio de la respuesta a tóxicos y la extrapolación de esta información a la exposición humana? Desafortunadamente, la respuesta puede ser no, mientras hay sorprendentes similitudes entre las especies también hay diferencias importantes (Tabla 7.3). Resaltando las diferencias y similitudes examinaremos dos casos de estudio, donde existen marcadas diferencias de especie; los proliferadores de peroxísomas inducen hepatocarcinogénesis y el paracetamol induce hepatototoxicidad. 
Tabla 7.3. Ejemplos de diferencias entre especies a la respuesta tóxica.

\begin{tabular}{lccl}
\hline Compuesto & Especies sensibles & Respuesta leve y/o nula & Respuesta humana \\
\hline Clofibrato & Rata & Conejo & Ninguna \\
Paracetamol & Ratón & Rata & Media o severa \\
Tricloroetileno & Ratón & Rata & Media, no pulmonar \\
Efavirenz & Rata & Chimpancé & Ninguna \\
Comfrey & Ganado & Borrego & Baja $(¿ ?)$ \\
\hline
\end{tabular}

(Modificado de Plant, 2003).

\subsubsection{Diferencias entre especies en la respuesta a proliferación de peroxísomas}

Los proliferadores de peroxísomas (PPs) son un grupo heterogéneo de compuestos que se utilizan en diversas situaciones: industrial, domestica y médica (Tabla 7.4). Tales usos significan que la exposición humana es alta, y ocurre, después de un periodo de protección, enfatizando la necesidad de asegurar la evaluación del riesgo para esta clase de compuestos. Los PPs son negativos en todos los ensayos estándar de genotoxicidad, inducen cáncer hepático en ratas y ratones estudiados durante dos años, por lo tanto son hepatocarcinogenos no genotóxicos. Con un perfil aparentemente peligroso ¿por qué estos compuestos de uso humano generalizado en situaciones donde la exposición a largo plazo implican una posibilidad real de riesgo? La respuesta es que humanos y ratones/ratas parecen responder de forma diferente a los PPs.

Tabla 7.4. Usos variados de los proliferadores de peroxísomas.

\begin{tabular}{cl}
\hline Compuesto Químico & \multicolumn{1}{c}{ Uso } \\
\hline Gemfibrozil & Agente hipolipidémico fibrato \\
Wy-14,643 & Agente no-hipolipidémico fibrato \\
DEHP & Plastificante \\
Dicamba & Herbicida \\
\hline
\end{tabular}

DEHP = di (2-etil-hexil) talato; Dicamba = 2-metoxy-3-6-ácido diclorobenzoico (Modificado de Plant, 2003).

Ratas y ratones sobreexpuestos a PP sufrieron una respuesta transformante sorprendente; dentro de las primeras 48 horas, el hígado tenía el doble del tamaño normal. Estos es causado por dos procesos: primero, un incremento 
en el número de hepatocitos (hiperplasia) segundo, un aumento en el tamaño de los hepatocitos individuales (hipertrofia). El último fenómeno es causado por un gran incremento en el tamaño y número de orgánelos subcelulares, los peroxísomas, contienen la clase de compuestos con el mismo nombre. Otras especies como el hámster muestran hepatomegalia, mientras que los puercos de guinea parecen ser refractarios a los efectos adversos de los PPs. Para evaluar el riesgo potencial de PPs en humanos es necesario por lo tanto decidir si los humanos responden de forma similar a las sensibles ratas, con semi-sensibilidad como los hámster o los aparentemente refractarios puercos de guinea. Para esto es necesario entender los mecanismos moleculares bajo los que proliferan los peroxísomas.

Como se menciono anteriormente, la expresión génica reactiva es causada por la exposición a agentes químicos que, es frecuentemente mediada por los factores de transcripción ligando-activada, y es lógico suponer que la proliferación de los peroxísomas, no fuera diferente. La identificación de los Receptores Alfa Activadores de la Proliferación de Peroxísomas (PPARa, por sus siglas en inglés), de los que son ligandos los PPs, representan un paso importante en el entendimiento de los mecanismos moleculares de la proliferación de peroxísomas. Sin embargo, porque justo los proliferadores de peroxísomas son ligandos para los PPARa no es necesario seguirlos ya que PPAra es central para la respuesta hepatocarcinogénica. ¿Cómo es entonces que se establece la unión?

Dos líneas de evidencia proveen información del papel central de los PPARa en la proliferación de peroxísomas. Primera, la clonación y secuenciación de los promotores de varios genes cuyos productos estén inducidos durante la proliferación de peroxísomas mostró que ellos contenían los elementos de respuesta para PPARa, llamados PPRES. Utilizando genes reporteros fue posible mostrar que los PPRE fueron responsables de la respuesta observada, una mutación en PPRE previene la unión a PPARa resulta en la pérdida de activación transcripcional del gen reportero en respuesta a la exposición a proliferadores de peroxísomas. Segunda, se diseñaron ratones transgénicos con deficiencia de PPARa, para estudiar la respuesta a proliferadores de peroxísomas. La sobreexposición de ratones null-PPARa a PPs clofibrato y Wy-14,643 donde ninguno de los efecto que se asocial comúnmente con estos compuestos fue observado; no se incremento el tamaño y número de peroxísomas y lo más importante, no hubo cáncer de hígado (Lee et al., 1995).

Ahora que los mecanismos moleculares subrayan que la proliferación de peroxísomas ha sido ligada a un solo receptor es mucho más fácil estudiar con el modelo animal que se aproxime más a los humanos. Los genes ortólogos de PPRa de hámster, puercos de guinea y de humanos fueron clonados y mostraron ser activados por PPs. En resumen, los genes contienen PPREs en ratas y ratones y también en las otras especies anteriormente mencionadas. ¿Cuales son entonces las diferencias entre la respuesta de roedores y la falta de respuesta de los puercos de guinea? Mientras los receptores pueden ser activados en ambos, ratas y puercos de guinea el número de receptores presentes en su hígado es muy diferente.

Los puercos de guinea expresan niveles más bajos de PPRa en el hígado que las ratas y los ratones, esto explica su falta de respuesta. Como los humanos también expresan muy bajos niveles de PPRa hepático esto sugiere que el mejor modelo posible es el puerco de guinea para el estudio de los efectos de PPs en humanos, y evaluar el riesgo puede, por tanto hacerse como una extrapolación a humanos de la respuesta a PPs del puerco de guinea, más que de la rata (Cattey et al., 1998). Entonces, parece que cualquier PPs será seguro para humanos, preverá que este no es significativamente mejor activador de PPRa para humanos que sus precursores. Entonces el uso de un método molecular antecedió a la determinación de un mecanismo molecular, y que tal información se utilice en la evaluación de riesgo en las condiciones bajo las cuales nuevos PPs signifiquen un riego real para la salud humana. 


\subsubsection{Diferencia entre especies en la toxicidad del paracetamol}

Como se ha mencionando (Unidad 2), el paracetamol, es un analgésico normalmente seguro, pero puede causar hepatotoxicidad severa en ciertas circunstancias. La Fase I del metabolismo por CYP2E1 resulta en la producción de un intermediario altamente reactivo $\mathrm{N}$-acetíl-p-benzoquinoneimina (NAPQI por sus siglas en inglés). Bajo condiciones fisiológicas normales NAPQI es rápidamente removido por el metabolismo Fase II, implicando conjugación glucorónica o sulfato. Sin embargo, en situaciones donde CYP2E1 es inducido (ej. ingesta de alcohol) o depleción glucóronica (ej. exposición prolongada a paracetamol) NAPQI se acumula y da como resultado toxicidad. Hoy día los mecanismos son bien entendidos, pero al principio, para delinear los mecanismos moleculares hubo confusión debida a una variación muy marcada entre las especies, en la gravedad de respuesta al paracetamol (Tabla 7.3).

Ratas y conejos son insensibles a la toxicidad del paracetamol, ya que aún poseen todos los ortólogos de los genes responsables del metabolismo y toxicidad del paracetamol en ratón, los que son sensibles a la toxicidad. ¿Por qué entonces no muestran toxicidad? La respuesta no miente en el mecanismo de producción del metabólito tóxico, para en el balance completo de la vía de eliminación. El paracetamol solo causa hepatotoxicidad en ratones cuando la rara formación de NAPQI excede la habilidad del hígado para removerlo: es decir que los niveles relativos y no absolutos de las enzimas son los importantes. La tabla 7.5 muestra la variación en la proporción del metabólicos Fase II excretados en diferentes modelos animales. Esto se puede ver claramente en ratones y hámster, especies particularmente sensibles a la hepatotoxicidad mediada por el paracetamol, excretan una mayor proporción de metabólicos relacionados con la vía de toxicidad (ej. conjugados de glutatión y ácidos mercapturicos) comparados con las especies menos sensibles como lo son ratas y conejos.

Estos datos sugieren fuertemente que los efectos especie específicos están mediados por los niveles de las enzimas responsables de la toxicidad del paracetamol, más específicamente la proporción de enzimas que conducen a la detoxificación como lo opuesto a la toxicidad de los compuestos relacionados.

Figura 7.5. Eliminación especie-específica de metabolitos de paracetamol.

\begin{tabular}{lccc}
\hline \multicolumn{1}{c}{ Especies } & Sensibilidad & $\begin{array}{c}\text { Vías de toxificación } \\
\text { (GLUC y SULF) }\end{array}$ & $\begin{array}{c}\text { Ruta de toxicidad } \\
\text { (Glutatión) }\end{array}$ \\
& Alta & 12 & $27-42$ \\
Hámster & Alta & 41 & $27-42$ \\
Ratas & Media & 62 & $5-7$ \\
Conejos & Media & 27 & $5-7$ \\
Puercos de Guinea & Media & 74 & $5-7$ \\
\hline
\end{tabular}




\subsection{VARIACIÓN DENTRO DE UNA ESPECIE}

En secciones previas las diferencias entre especies destacaron en términos de extrapolación de los datos de toxicidad obtenidos de modelos animales a las situaciones en humanos. Sin embargo, a pesar de los modelos animales disponibles se establece la existencia de una respuesta potencialmente impredecible, en humanos. La desviación a partir de la respuesta esperada puede variar relativamente poco, alterando substancialmente la eficacia general de un compuesto, a grandes cambios comprendidos entre no presentar un efecto deseado o causar una respuesta adversa en el individuo. Las variaciones pueden deberse ya sea a las diferencias entre los sexos o a las diferencias entre la población en general.

\subsubsection{Respuestas sexo-específica a la exposición tóxica}

Si revisamos la definición del metabolismo dada en el Unidad 1, vimos que el metabolismo se describe como "el total de transformaciones químicas de los constituyentes normales del cuerpo". Como "constituyentes normales del cuerpo" se entiende que son las diferencias entre los sexos, particularmente los niveles de hormonas, no es sorpresa que el metabolismo puede ser diferente entre machos y hembras de la misma especie.

En general, los efectos sexo-específicos son más marcados en modelos de roedores que en humanos, probablemente porque las enzimas de los CYPs han mostrado marcada sexo-especificidad (ej. CYP2C11/12) en las ratas y no hay genes ortólogos en humanos. A pesar de esto, hay varios casos en las drogas clínicas que exhiben propiedades farmacocinéticas sexo-específicas, como se detalla en la Tabla 7.6.

Figura 7.6. Metabolismo sexo-específico en humanos.

\begin{tabular}{lll}
\hline Compuesto Químico & \multicolumn{1}{c}{ Uso Clínico } & \multicolumn{1}{c}{ Efecto sexo-específico } \\
\hline $\begin{array}{l}\text { Aspirina } \\
\text { Cloranfenicol }\end{array}$ & Analgésico, anticoagulante & \\
Diazepam & Antibiótico & Bajos niveles en machos \\
Eritromicina & Ansiolítico, anticonvulsivo & Bajo aclaramiento en hembras \\
Lidocaína & Antibiótico & Bajo aclaramiento en machos \\
Oxazepam & Anestésico & Incrementa $\mathrm{T}^{1 / 2} \mathrm{y} \mathrm{V}_{\mathrm{D}}$ en hembras \\
Paracetamol & Ansiolítico, anticonvulsivo & Bajo aclaramiento en hembras \\
Fenitoina & Analgésico, antipirético & Bajos niveles de plasma en hembras \\
Propanolol & Anticonvulsivo & Bajos niveles de plasma en machos \\
Rifampicina & Antihipertensivo & Bajo aclaramiento en machos \\
\hline
\end{tabular}

Modificado de Mugford y Kedderis (1998). 


\subsubsection{Variaciones poblacionales en la respuesta a la exposición tóxica}

Como ya se ah discutido en Unidad 6, la especie humana está expuesta a miles de compuestos químicos todos los días. Cada uno de ellos tiene el potencial de interactuar con otros químicos y alterar los efectos que ejercen en el cuerpo. Dichos efectos se dan primeramente alterando la disposición de las enzimas que se utilizan en el metabolismo de las drogas en el cuerpo y, cambiando la proporción o la ruta del metabolismo de los compuestos co-administrados. ¿Se esperaría que un sujeto fumador, que consume alcohol y que ingiere carne, reaccione de la misma forma que uno que no fuma y no tiene los otros hábitos mencionados? Probablemente no. Por lo tanto debemos tomar en cuenta las diferencias cuando se hace la evaluación de riesgo a compuestos químicos, y el rango de dosis que sería segura.

Sin embargo, aún después de la eliminación de los efectos sexo-específico y ambiental, una población mostrará aún respuesta a los xenobióticos. ¿Por qué? Ya hemos visto que las pequeñas diferencias genéticas entre el hombre y los roedores pueden cambiar dramáticamente su respuesta a xenobióticos. Existen también pequeñas diferencias genéticas dentro de una especie; cualquier cambio en las secuencia de ADN que modifique el normal llamado "silvestre" es denominado mutación, y este cambio dentro del gen puede afectar su producto. Las modificaciones en las regiones codificantes de un gen puede alterar la actividad de una proteína (usualmente disminuye), mientras que una mutación en el promotor o el potenciador puede alterar la cantidad de proteína activa, producida normalmente. Estas mutaciones en los genes de las enzimas del metabolismo de xenobióticos, o proteínas implicadas en la respuesta a la exposición tóxica, puede afectar considerablemente la habilidad de un individuo de responder a dicha exposición química.

Sin embargo, las mutaciones en un solo individuo, no son el principal problema en términos de respuesta a la exposición química, de una población. No obstante, si la mutación ocurre en la línea germinal esta pasará de una generación a otra y entonces se fijará en la población. Cuando una mutación se presenta en un porcentaje mayor al $1 \%$ de la población se le denomina polimorfismo, y esta puede ser la diferencia que produzca la variación significativa en la respuesta completa de una población a un agente químico. El polimorfismo de CYP2D6 se estudiará con más detalle en este capítulo. Las variaciones en la actividad de CYP2D6 se identificaron primeramente a través de una la variedad de la respuesta clínica al agente hipotensivo debrisoquina. Para la mayoría de la población la debrisoquina es la primera alternativa en el tratamiento de hipertensión, sin embargo en una pequeña parte de la población la exposición a este fármaco le lleva a hipotensión excesiva.

Los efectos adversos se debieron a la proporción de la 7-hidroxilación de debrisoquina, la gente con proporciones bajas de 7-hidroxilación acumula el exceso del compuesto original hasta niveles tóxicos (González et al., 1988). Posteriormente se mostró que la oxidación del alcaloide esparteína es polimórfica, y la proporción de los metabólicos ([xenobiótico original]:[metabólito]), estos dos químicos fueron altamente correlacionados en los individuos, sugiriendo una parte de la ruta metabólica. Investigaciones adicionales identificaron a CYP2D6 como la enzima responsable del metabolismo inicial de ambos. Las poblaciones analizadas indican que el CYP2D6 muestra una distribución bimodal con metabolizadores pobres y extensivos, siendo susceptibles de forma adversa a los efectos del fármaco (Figura 7.7).

En las poblaciones Europeas la frecuencia de los metabolizadores pobres es de aproximadamente 7-10\%, esto representa una pequeña pero significativa parte de la población. El análisis de los genes CYP2D6 han identificado alelos múltiples (>70\% comúnmente), lo cual causa incremento, reducción o ausencia de actividad de CYP2D6. 
En la Tabla 7.7 se muestran ejemplos de los principales alelos. Otro factor importante acerca de esto, es que los polimorfismos tienden a agruparse geográficamente, con algunas mutaciones más prevalentes en una localización geográfica que en otra. Esto es cierto, debido a los mecanismos de formación de los polimorfismos; mutaciones de tipo individual seguida de su estabilización en la descendencia de la población. Como la gente tiende a reproducirse con sus vecinos, la expansión del polimorfismo se centra en una sola localización geográfica.

Entonces surge un cuestionamiento importante en el ajuste de los regímenes de tratamiento en diferentes partes del mundo. Por ejemplo, en la Tabla 7.7 se puede ver que el $\mathbf{5 1 \%}$ de la población China tiene el polimorfismo CYP2D6*10, en comparación con otras poblaciones (Zimbauenses), que presentan solo el 6\%. Este polimorfismo resulta en una enzima inestable con actividad reducida, es fácil apreciar como la población china puede tener una incidencia mayor de efectos adversos de los xenobióticos que son metabolizadas por el CYP2D6, que la población Suiza. Estos datos deben ser tomados en cuenta cuando se deciden los regímenes de tratamiento más apropiados para las diferentes poblaciones.

Figura 7.7. Principales polimorfismos de alelos del gen CYP2D6.

\begin{tabular}{llccc} 
& & \multicolumn{3}{c}{ Frecuencia Alélica (\%) } \\
Alelo & $\begin{array}{c}\text { Efectos sobre la } \\
\text { proteína }\end{array}$ & Suizos & Chinos & Zimbabuenses \\
\cline { 3 - 5 } CYP2D6*1/2 & Tipo silvestre & 69 & 43 & 54 \\
CYP2D6*3 & No funcional & 2 & 0 & 0 \\
CYP2D6*4 & No funcional & 22 & $0-1$ & 2 \\
CYP2D6*5 & No proteína & 4 & 6 & 4 \\
CYP2D6*10 & Enzima inestable & n.d. & 51 & 6 \\
CYP2D6*17 & Afinidad reducida & n.d. & n.d. & 34 \\
\hline
\end{tabular}

n.d. = no determinada (Modificado de Bertilsson et al. 2002).

\section{REFERENCIAS BIBLIOGRÁFICAS}

Bertilsson, L., Dahl, M. L., Dalen, P., et al. (2002) Molecular genetics of CYP2D6: clinical relevance with focus on psychotropic drugs. B. J. Clin. Pharmacol. 53(2): 111-122.

Bessems, J. and Vermeulen, N. (2001) Paracetamol (acetaminophen)-induced toxicity: Molecular and biochemical mechanism, analogues and protective approaches. Crit. Rev. Toxic. 31(1): 55-138.

Cattley, R.C., DuLuca, J., Elcombe, C., et al. (1998) Do peroxisome proliferating compounds pose a hepatocarcinogenic hazard to humans? Reg. Toxicol. Pharmacol. 27(1 Pt 1): 47-60. 
Cheng , R.Y.S., Alvord, W.G., Powell, D., et al. (2002) Microarray analysis of altered gene expression in the TM4 sertolilike cell line exposed to chromium (III) chloride. Rep. Toxicol. 16:223-236.

Choudhury, A.I., Chahal, S., Bell, A.R., et al. (2000) Species differences in peroxisome proliferation; mechanisms and relevance. Mut. Res. 448(2): 201-212.

El-Sankary, W., Plant, N. and Gibson, G. (2000) Regulation of the CYP3A4 gene by hydrocortisone and xenobiotcs: role of the glucocorticoid and pregnane X receptors. Drug Metab. Disp. 28(5): 493-496.

El-Sankary, W., Gibson, G.G., Ayrton, A., et al. (2001) Use of a reporter gene assay to predict and rank the potency and efficacy of CYP3A4 inducers. Drug Metav. Disp. 29(11): 1499-1504.

El-Sankary, W., Bombay, V., Gibson, G.G., et al. (2002) Glucocorticoid-mediated induction of CYP3A4 is decreased by disruption of a protein: DNA interaction distinct from the pregnane $\mathrm{X}$ receptor response element. Drug Metab. Disp. 30(9): 1029-1034.

Enver, T., Raich, N., Ebens, A.J. et al. (1990) Developmental regulation of human fetal-to adult globin gene switching in transgenic mice. Nature 344: 309-313.

Gerhold, D., Lu, M.G., Xu, J., et al. (2001) Monitoring expression of genes involved in drug metabolism and toxicology using DNA microarrays. Physiol. Genom. 5(4): 161-170.

González, F., Skoda, R.C., Kimura, S., et al. (1998) Characterization of the common genetic deffects in humans deficient in debrisoquine metabolism. Nature 331: 442-446.

Goodwin, B., Hodgson, E., and Liddle, C. (1999) The orphan human pregnane X receptor mediates the transcriptional activation of CYP3A4 by rifampicin through a distal enhancer module. Mol. Pharmacol. 56(6): 1329-1339.

Grange, T., Cappabianca, L., Flavin, M., et al. (2001) In vivo analysis of the model tyrosine aminotransferase gene reveals sequential steps in glucocorticoid receptor action. Oncogene 20: 3028-3038.

Hamadeh, H.K., Bushel, P.R., Jayadev, S., et al. (2002) Gene expression analysis reveals chemical-specific profiles. Toxicol. Sci. 67(2): 219-231.

Lachtman, D. (2001) Gene Regulation, 4th edn. Nelson Thornes, Cheltenham.

Lee, S.S.T., Pineau, T., Drago, J., et al. (1995) Targeted disruption of the a isoforms of the peroxisome proliferatoractivated receptor gene in mice results en abolishment of the plietrophic effects of peroxisome proliferators. Mol. Cell. Biol. 15(6): 3012-3022.

Lewin's Genes X. (2011) Krebs, J.E., Goldstein E.S., Kilpatrick, S.T., Eds. Jones and Bartlett Publishers, LLC . USA.

Lichtsteiner, S.,Wuarin, J. and Schibler, U. (1987) The interplay of DNA-binding proteins on the promoter of the mouse albumin gene. Cell 51: 963-973.

Maglich, J.M., Stoltz, C.M., Goodwin, B., et al. (2002) Nuclear pregnane X receptor and constitutive androstane receptor regulate overlapping but distinct sets of genes involved in xenobiotic detoxification. Mol. Pharmacol. 62(3) 638-646.

Mugford, C.A. and Kedderis, G.L. (1998) Sex-dependent metabolism of xenobiotics. Drug Metab. Rev. 30(3): 441-498. 


\section{CAPÍtULO}

Pascussi, J.M., Drocourt, L., Fabre, J.M., et al. (2000) Dexamethasone induces pregnane X receptor and retinoid X receptor a expression in human hepatocytes: Synergistic increase of CYP3A4 induction by pregnane $\mathrm{X}$ receptor. Mol. Pharmacol. 58: 361-372.

Xie, W., Barwick, J.L., Simmon, C.M., et al. (2000) Reciprocal activation of xenobiotic responses genes by nuclear receptor SXR/PXR and CAR. Genes Devel. 14: 3014-3023. 


\section{Introduccióna la toxicología Elia Roldán Reyes}
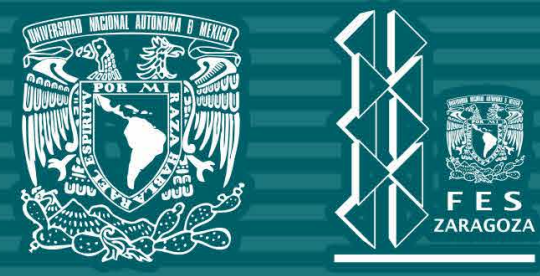

Facultad de Estudios Superiores Zaragoza,

Campus I. Av. Guelatao No. 66 Col. Ejército de Oriente, Campus II. Batalla 5 de Mayo s/n Esq. Fuerte de Loreto.

Col. Ejército de Oriente.

Iztapalapa, C.P. 09230 México D.F. www.zaragoza.unam.mx

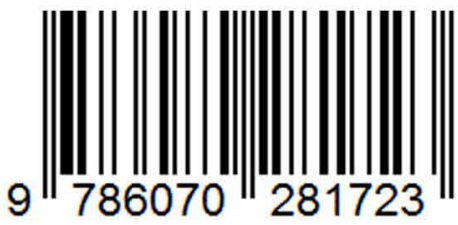

